\title{
Near-Field Explosion Effects on Reinforced Concrete Columns: An Experimental Investigation
}

\author{
by
}

Farouk Siba

A thesis submitted to the Faculty of Graduate and Postdoctoral Affairs in partial fulfillment of the requirements for the degree of

\author{
Master of Applied Science \\ in
}

Civil Engineering

Carleton University

Ottawa, Ontario

(C) 2014, Farouk Siba 


\section{Abstract}

Explosion effects on structures have been an area of research over the last decades. This is mainly due to the fact that structures all over the world are increasingly being exposed to the threat of premeditated explosive attacks, accidental explosions and other forms of explosion related failures. The magnitude of blast loads produced by most explosions are significantly higher than the design loads for conventional structural design. Consequently, this has increased awareness of building owners, government departments as well as design professionals to the vulnerabilities and survivability of structures to blast loading as global terrorist attacks continue at an increasing rate.

Although significant amount of work is continuing on the effects of explosions on infrastructure (systems), especially in the USA, experimental work involving live explosive testing is limited. Moreover experimental testing of reinforced concrete columns to blast loading within the close-in range with scaled distance (z) less than 1.0 $\mathrm{m} / \mathrm{kg}^{1 / 3}$ is scant. This is likely because of the unreliable accuracy and low survivability of most instrumentation in this range.

An experimental program was therefore designed to investigate the effects of near-field explosions on reinforced concrete columns with different transverse reinforcement detailing and at different scaled distances $\left(\mathrm{z}=0.22 \mathrm{~m} / \mathrm{kg}^{1 / 3}, \mathrm{z}=0.54 \mathrm{~m} / \mathrm{kg}^{1 / 3}\right.$, and $\mathrm{z}=0.86$ $\mathrm{m} / \mathrm{kg}^{1 / 3}$ ). The columns were built in the Structures Laboratory at Carleton University, while the live explosive testing was carried out in an open field arena at the Canadian Forces Base (CFB) Petawawa, Ontario.

Analysis of the experimental results showed that, the response of the reinforced concrete columns, irrespective of the column type (Conventional, Seismic or Prestressed) failed at 
the scaled distance of $0.22 \mathrm{~m} / \mathrm{kg}^{1 / 3}$. As the scaled distance increases, the severity of damage is less. At the higher scaled distance of $0.86 \mathrm{~m} / \mathrm{kg}^{1 / 3}$, the response for all columns was relatively the same. The effects of transverse detailing and lap splices was very much pronounced in tests with scaled distance $\mathrm{z}=0.22 \mathrm{~m} / \mathrm{kg}^{1 / 3}$. Conventional columns severed into two pieces, while seismic column did not. Prestressed columns performed better compared to conventional columns, at scaled distance of $\mathrm{z}=0.22 \mathrm{~m} / \mathrm{kg}^{1 / 3}$. However, in tests with scaled distances $\mathrm{z}=0.54 \mathrm{~m} / \mathrm{kg}^{1 / 3}$, the prestressed column suffered severe damage relative to conventional columns. 


\section{Acknowledgements}

First and foremost, I thank almighty God for the unmerited favours bestowed on me. I would like to express my special appreciation and thanks to my supervisor Dr Abass Braimah, who has been a tremendous mentor for me. I would like to thank you for giving me the opportunity to study under your supervision. Your advice, guidance and constant supervision on my research have been priceless.

Thank you to Ben Riley, whose immense work toward this research both in the lab and outside is very much appreciated. I would like to thank Stanley Coley, Pierre Trudel, and Jason Arnott, who have all been helpful in the laboratory. I am very grateful for the time you took to teach me everything I needed to know in the laboratory. A special thank you to George Afriye and Lawrence Abladey for all the time you spent helping in the laboratory and on the field respectively. The support of Conrad Kyei and Aaron Akotuah is also appreciated.

I would also like to thank Rick Guilbeault, Lorne McCauley, Don Wilson, and Bert Von Rosen from the Canadian Explosive Research Laboratory (CERL) for their assistance with the field set up, instrumentation and the high-speed videography during the experimental phase on site.

My thanks and appreciation also goes to my family, especially my mom and my siblings particularly Dr Yahuza Siba, Alhaji Salis Siba, Mr Ibrahim Daaro and Mrs Aicha Bashir. May the good Lord richly bless you all.

This research work was supported by the Defence Research and Development Canada (DRDC), Centre for Security Science Explosives Cluster Non-Competitive (CSSP-2012CD-1067) and Natural Science and Engineering Research Council of Canada grants. 


\section{Table of Content}

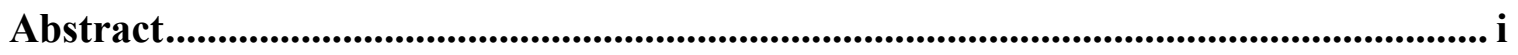

Acknowledgements .................................................................................................................... iii

List of Figures...................................................................................................................................... vi

List of Tables ............................................................................................................................... xiii

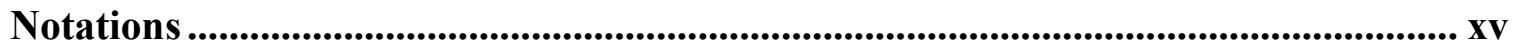

1 Chapter: Introduction........................................................................................... 1

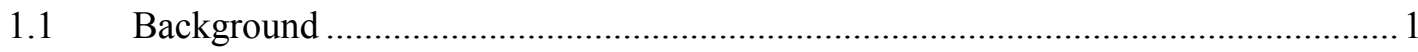

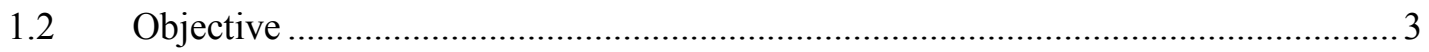

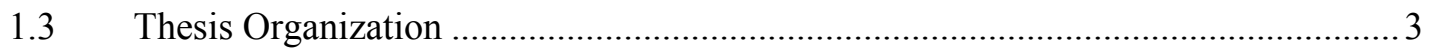

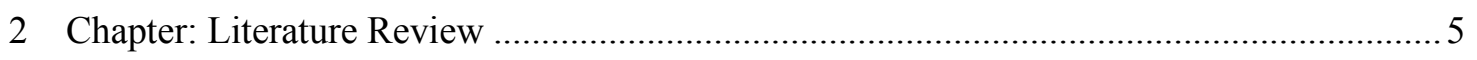

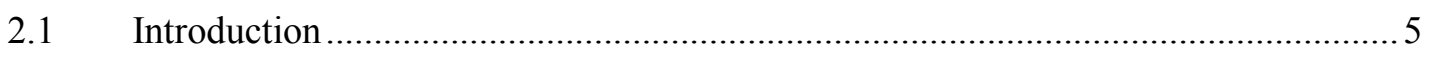

2.2 Recent terrorist attacks and accidental explosions .......................................... 6

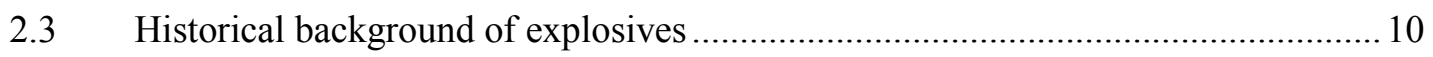

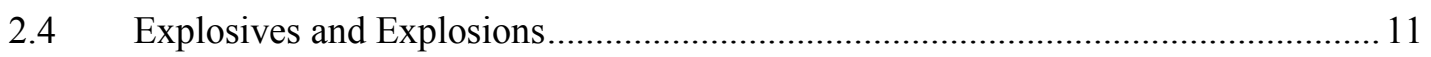

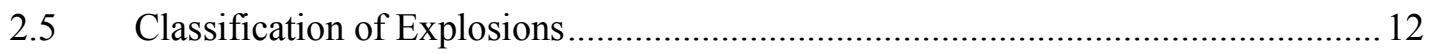

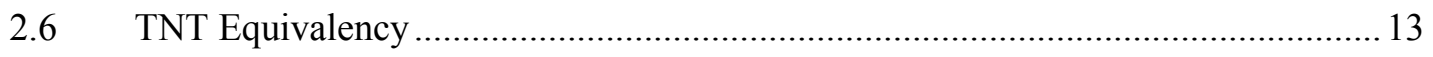

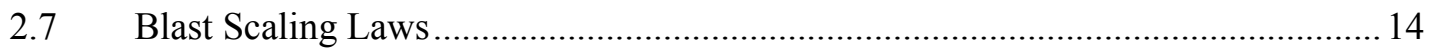

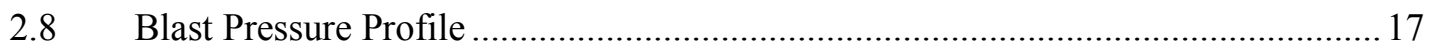

2.9 Blast wave Interactions with reinforced concrete columns ....................................20

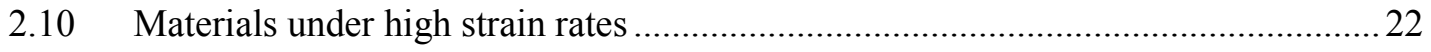

2.11 Review of past studies on behavior of reinforced concrete columns subjected to

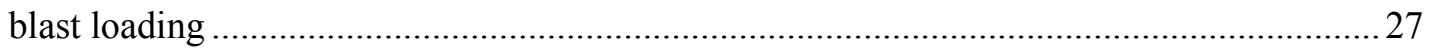

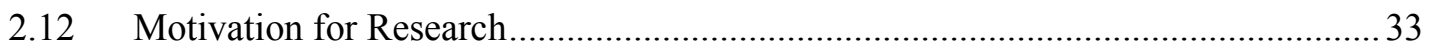

3 Chapter: Experimental Program …...................................................................... 35

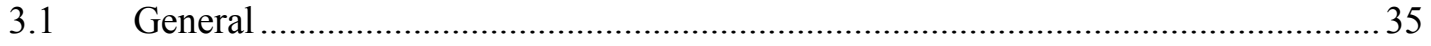




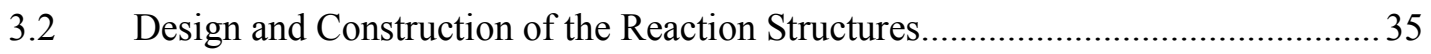

3.3 Design and Description of Test Columns ........................................................ 42

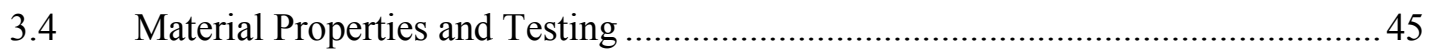

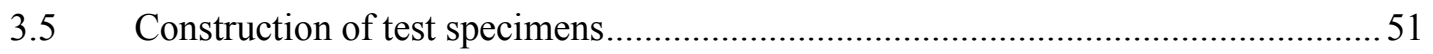

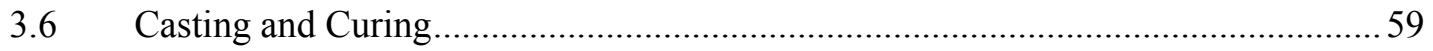

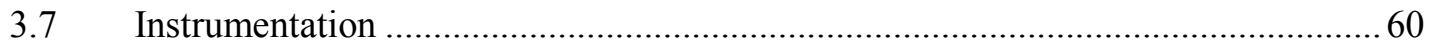

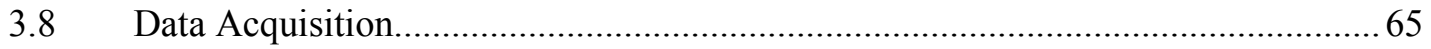

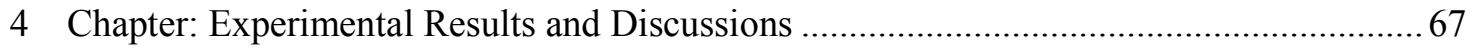

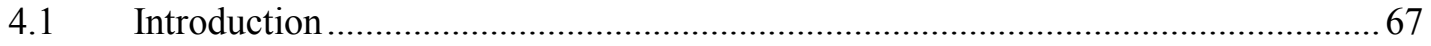

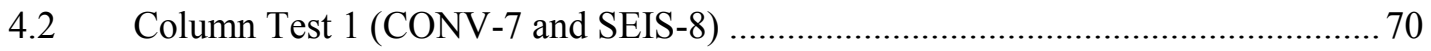

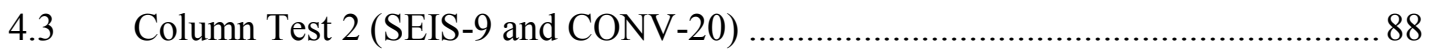

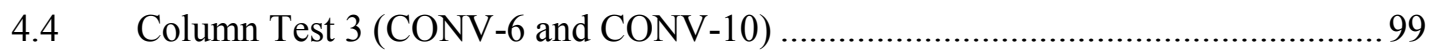

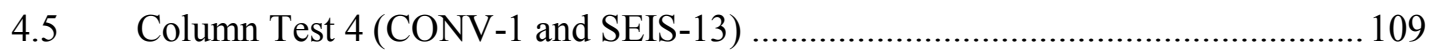

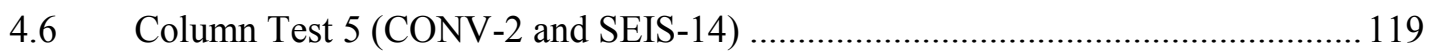

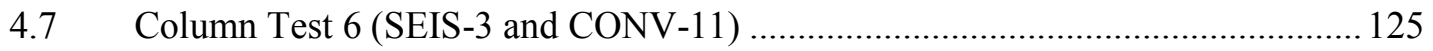

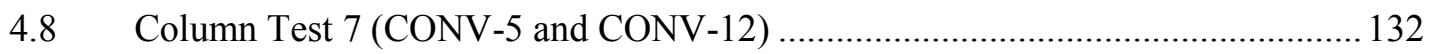

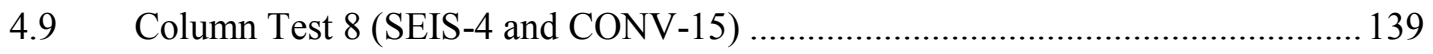

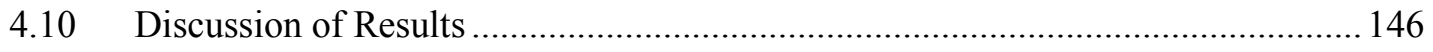

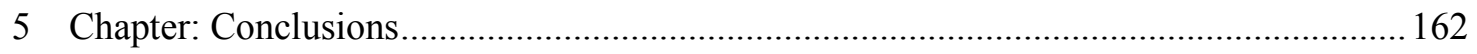

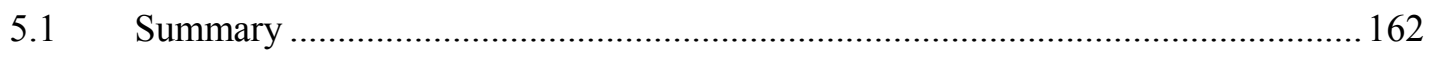

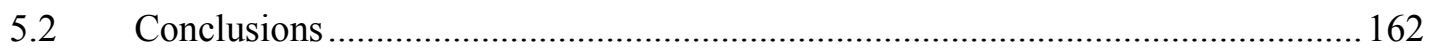

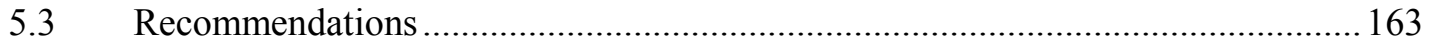

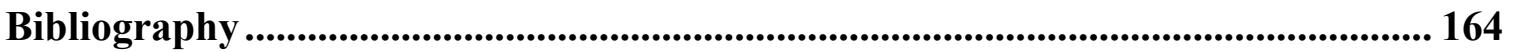

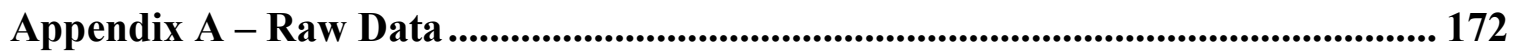




\section{List of Figures}

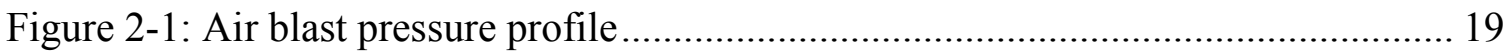

Figure 2-2: A typical case of free standing column subjected to a non-uniform airblast loading

Figure 2-3: Typical stress-strain curve for concrete (TM 5-1300, 1990) ………............. 23

Figure 2-4: Typical stress-strain curve for steel (TM 5-1300, 1990) .............................. 23

Figure 3-1: A modeled support structure with column affixed........................................ 37

Figure 3-2: Elevation of support structure with column affixed..................................... 38

Figure 3-3: Support structure (a) components being assembled (b) assembled with

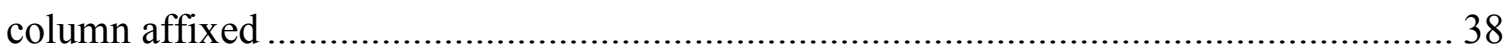

Figure 3-4: Formwork of support structure's cantilevered Y-section .............................. 39

Figure 3-5: Components of support structure's formwork ………………………….... 40

Figure 3-6: vibration of support structure concrete during casting................................... 41

Figure 3-7: Transport of support structure to site …………......................................... 42

Figure 3-8: (a) Conventional column detailing (b) Seismic column detailing ................. 44

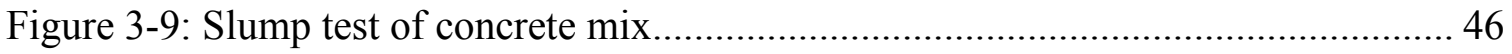

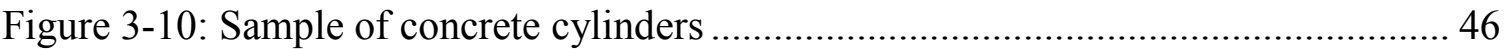

Figure 3-11: a. A typical sample of one of the concrete cylinders and b. Concrete cylinder

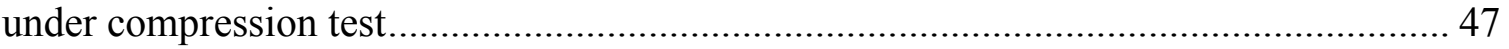

Figure 3-12: Tension test for 25M rebar (a) before necking (b) after necking ................. 49

Figure 3-13: Typical stress-strain curve for 10M rebar ................................................ 50

Figure 3-14: Typical stress-strain curve for 25M rebar ................................................. 51 
Figure 3-15: Strain gauge positions for both (a) frontal face and (b) rear face for a typical

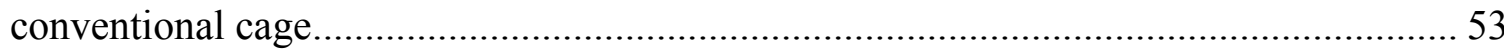

Figure 3-16: Plan of Column footing formwork................................................... 55

Figure 3-17: Column footing formwork with cages placed inside ............................... 56

Figure 3-18: Column formwork placed around reinforcement cage ............................ 58

Figure 3-19: A photograph showing (a. Columns formwork and b. columns braced with

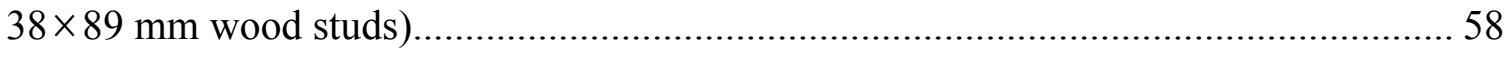

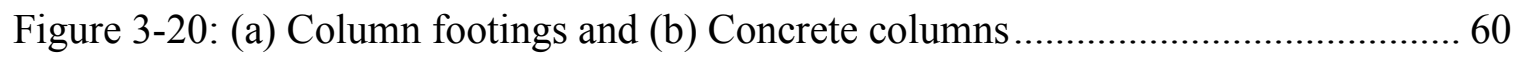

Figure 3-21: A photograph of cages showing strain gauges and leads at mid-height ...... 61

Figure 3-22: Pressure gauge locations for; (a) Front face of column and (b) Rear face of

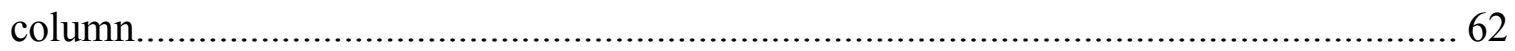

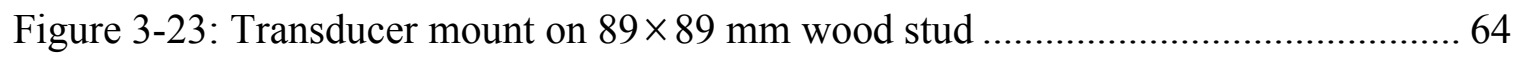

Figure 3-24: A sketch of support structure showing positions of string potentiometers (transducer) 64

Figure 3-25: Photographs of support showing (a) $89 \times 89$ wood studs mount for the transducers and (b) Retractable cable of the string potentiometers .............................. 65

Figure 3-26: Photograph of Yokogawa SL1000 data acquisition system....................... 66

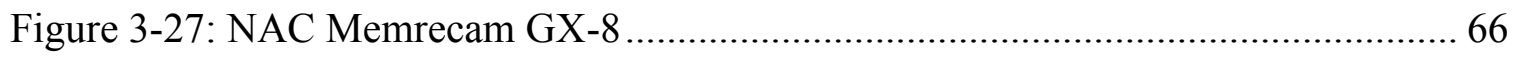

Figure 4-1: Sketch of columns CONV-7 and SEIS-8 experimental setup..................... 71

Figure 4-2: Photographs of columns (CONV-7 and SEIS-8) prior to explosion.............. 72

Figure 4-3: Photograph of columns engulfed in the fireball ...................................... 73

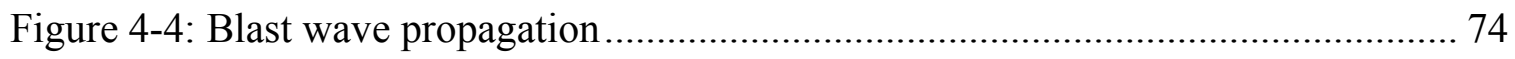

Figure 4-5: Blast pressure profile for Column CONV-7 and SEIS-8 (Bottom front) ...... 77 
Figure 4-6: Blast pressure profile for Columns CONV-7 and SEIS-8 (Top-front gauge) 77 Figure 4-7: Blast pressure profile for Columns CONV-7 and SEIS-8 (Bottom-back

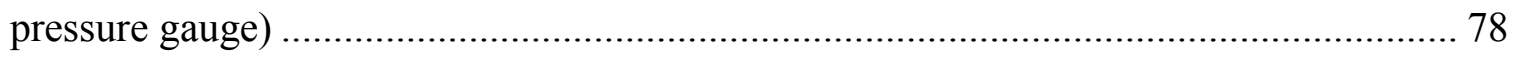

Figure 4-8: Blast pressure profile for Columns CONV-7 and SEIS-8 (Mid-back pressure

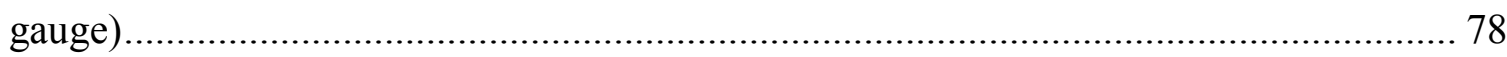

Figure 4-9: Blast pressure profile for Columns CONV-7 and SEIS-8 (Top back pressure

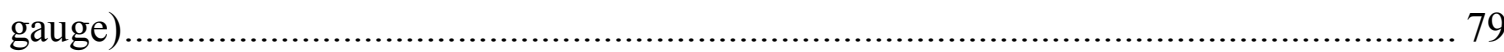

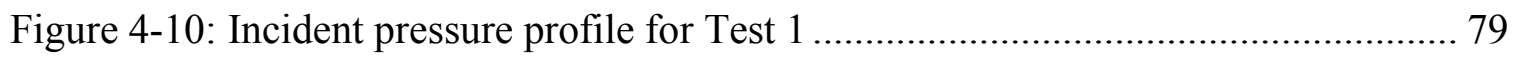

Figure 4-11: Photograph of Column CONV-7 showing; (a) pressure gauge location (b) measuring cable of string potentiometer at $2 \mathrm{~m}$ from the base of the column................. 80 Figure 4-12: Displacement-Time history for Column CONV-7 ................................ 81 Figure 4-13: Post-test photograph of Column CONV-7 faces: (a) Front face, (b) Side face

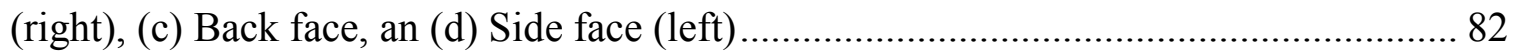
Figure 4-14: Photograph of Column SEIS-8 before test: (a) Front face with pressure gauges (b) Back face with pressure gauges and strain gauge leads ............................. 83 Figure 4-15: Displacement-Time history for Column SEIS-8 ...................................... 83 Figure 4-16: Post-test photograph of Column SEIS-8 faces: (a, b) Front face, (b) Side

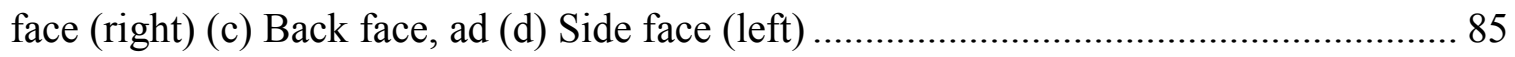

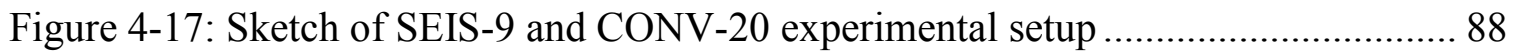

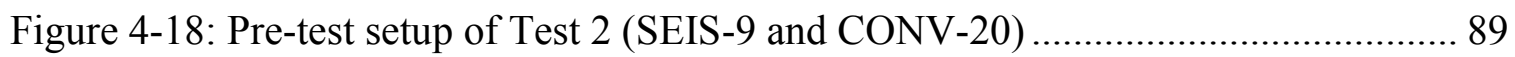
Figure 4-19: Blast pressure profile for Column SEIS-9 and CONV-20 (bottom-front

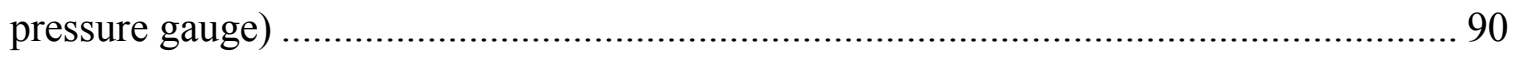


Figure 4-20: Blast pressure profile for Column SEIS-9 and CONV-20 (Mid-front pressure gauge) 91

Figure 4-21: Blast pressure profile for Column SEIS-9 and CONV-20 (Top-front pressure gauge). 91

Figure 4-22: Incident blast pressure profiles for Test 2 92

Figure 4-23: Photograph of Column SEIS-9 before test: (a) Front face (b) Back face with mid-back pressure gauge and a retractable cable of string pot at $1 \mathrm{~m}$ 93

Figure 4-24: Displacement-Time history for Column SEIS-9 .................................... 93

Figure 4-25: Post-test photograph of Column SEIS-9 faces: (a) Front face, (b) Side face (right) (c) Back face, and (d) Side face (left).... 94

Figure 4-26: Photograph of column CONV-20 prior to test. 95 Figure 4-27: Displacement-Time history for Column CONV-20 96

Figure 4-28: Post-test photograph of Column CONV-20 faces: (a) Front face, (b) Side

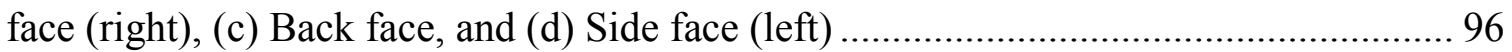

Figure 4-29: A sketch of Test 3 (CONV-6 and CONV-10) experimental setup ............. 99 Figure 4-30: Blast pressure profile for Column CONV-6 and CONV-10 (mid-front pressure gauge) 101

Figure 4-31: Blast pressure profile for Column CONV-6 and CONV-10 (top-front pressure gauge) 101

Figure 4-32: Incident blast pressure profiles for Test 3 102 Figure 4-33: Photograph of Column CONV-6 before test: (a) Front face (b) Back face 103 Figure 4-34: Displacement-Time history for Column CONV-6. 103 
Figure 4-35: Post-test photograph of Column CONV-6 faces: (a) Front face, (b) Side face (right), (c) Back face, and (d) Side face (left) 104

Figure 4-36: Photograph of Column CONV-10 before test: (a) Front face (b) Side face 105

Figure 4-37: Displacement-Time history for Column CONV-10. 106

Figure 4-38: Post-test photograph of Column CONV-10 faces: (a) Front face, (b) Side face (right), (c) Back face, and (d) Side face (left) 107

Figure 4-39: Pre-test setup of columns SEIS-13 and CONV-1 (sketch up drawing) ..... 109 Figure 4-40: Pre-test setup of test 4 (CONV-1 and SEIS-13) 110

Figure 4-41: Photograph of Column CONV-1 before test: (a) Front face (b) Back face of column with mid-back pressure gauge 111 Figure 4-42: Blast pressure profile for Column CONV-1 (mid-front pressure gauge) .. 111 Figure 4-43: Displacement-Time history for Column CONV-1 112 Figure 4-44: Post-test photograph of column CONV-1 113 Figure 4-45: Photograph of Column SEIS-13 before test: (a) Front face of column with pressure gauges (b) back-face column with mid-back pressure gauge and retractable cable of string pot at $1 \mathrm{~m}$ 114

Figure 4-46: Displacement-Time history for column SEIS-13. 115 Figure 4-47: Post-test photograph of Column SEIS-13 faces: (a) Front face, (b) and (d) Side face (right), and (c) Back face 116 Figure 4-48: A sketch of columns SEIS-14 and CONV-2 experimental setup 119 Figure 4-49: Photograph of Column CONV-2 before test: (a) Front face (b) Side face 121 Figure 4-50: Post-test photograph of column CONV-2. 122 
Figure 4-51: Photograph of Column SEIS-14 before test: (a) Front face of column with top-front pressure gauge (b) Back face column with mid-back pressure gauge 124

Figure 4-52: Post-test photograph of column SEIS-14 faces: (a) Front face, (b) Side face

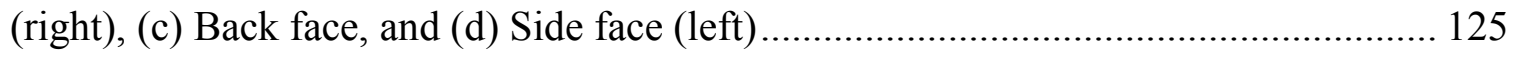

Figure 4-53: Pre-test setup of columns CONV-11 and SEIS-3 ................................ 126

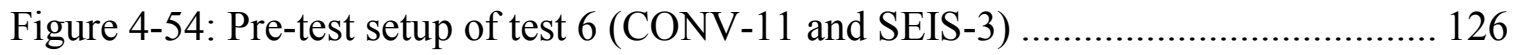

Figure 4-55: Photograph of Column SEIS-3 before test: (a) Front face (b) Side face ... 128

Figure 4-56: Post-test photograph of column SEIS-3 ........................................... 129

Figure 4-57: Photograph of Column CONV-11 before test: (a) Front face of column with mid-front and top-front pressure gauges (b) back-face column with mid-back pressure gauge 131

Figure 4-58: Post-test photograph of Column SEIS-11 face: (a) Side face (right), (b, c) Back face, and (d) Side face (left) 132

Figure 4-59: A sketch columns CONV-12 and CONV-5 experimental setup. 133 Figure 4-60: Photograph of test 7 (CONV-12 and CONV-5) setup prior to detonation 133 Figure 4-61: Photograph of Column CONV-5 prior to test: (a) Front face of column with mid-front pressure gauge (b) Back-face 135 Figure 4-62: Post-test photograph of column CONV-5... 136 Figure 4-63: Photograph of Column CONV-12 prior to test: $(a, b)$ Front face of column with pressure gauges 138 Figure 4-64: Post-test photograph of Column CONV-12 faces: (a) Front face, (b) Side face (right), and (c, d) Back face. 139 Figure 4-65: Pre-test setup of columns CONV-15 and SEIS-4 140 
Figure 4-66: Photograph of Column SEIS-4 prior to test. 142

Figure 4-67: Post-test photograph of Column SEIS-4 faces: (a) Front face, (b) Back face, (c, d) Side face (left) 143

Figure 4-68: Photograph of Column CONV-15 prior to test: (a) Front and Side (right) face, (b) Side (left) and Back face 144

Figure 4-69: Post-test photograph of Column CONV-15 faces: (a) Front face, (b) Side face (left), (c) Back face, and (d) Side face (right) 145

Figure 5-1: Displacement Time History CONV-7 (Raw Data) ................................... 172

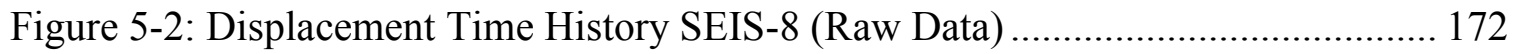

Figure 5-3: Displacement Time History SEIS-9 (Raw Data) ................................... 173

Figure 5-4: Displacement Time History CONV-20 (Raw Data) .................................. 173

Figure 5-5: Displacement Time History CONV-10 (Raw Data) .................................. 174

Figure 5-6: Displacement Time History CONV-6 (Raw Data) .................................. 174

Figure 5-7: Displacement Time History CONV-1 (Raw Data) ................................ 175

Figure 5-8: Displacement Time History SEIS-13 (Raw Data) ................................... 175

Figure 5-9: Blast pressure profile for Test 1 (CONV-7 and SEIS-8) ......................... 176

Figure 5-10: Blast pressure profile for Test 2 (CONV-20 and SEIS-9) ...................... 176

Figure 5-11: Blast pressure profile for Test 3 (CONV-6 and CONV-10) .................... 177

Figure 5-12: Blast pressure profile for Test 4 (CONV-1) ..................................... 177

Figure 5-13: Blast pressure profile for Test 4 (SEIS-13) ........................................ 178 


\section{List of Tables}

Table 2-1: TNT Equivalent masses of some explosives (Braimah, 2012) ....................... 14

Table 2-2: DIF for design of reinforce concrete elements (TM 5-1300, 1990) ................ 26

Table 2-3: Dynamic increase factor for structural steel, cold-formed steel, and aluminum

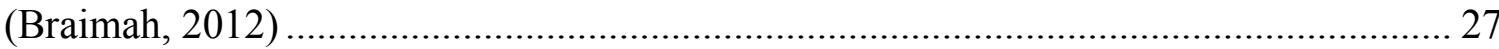

Table 3-1: Columns nomenclature, tie spacing and axial load ratio details ..................... 45

Table 3-2: Compressive test results from column concrete.............................................. 47

Table 3-3: Compressive test results from reaction structure concrete.............................. 48

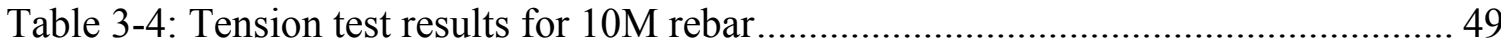

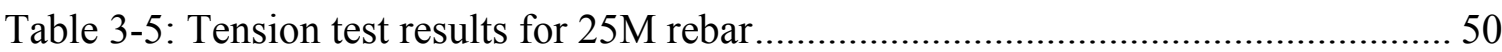

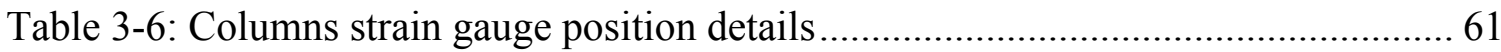

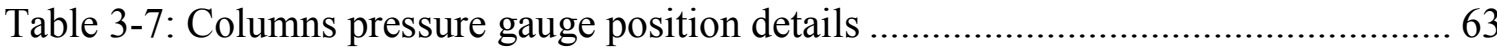

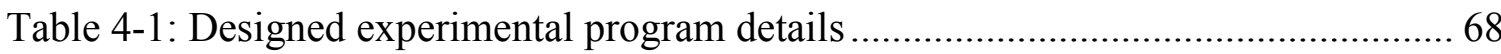

Table 4-2: Measured distance between paired columns for each test................................ 69

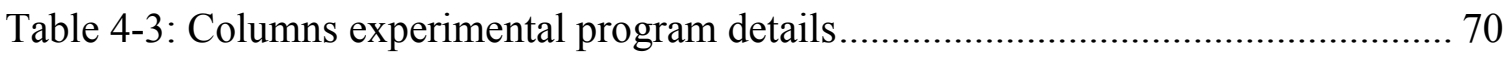

Table 4-4: Summary of test 1 (CONV-7 and SEIS-8) results ........................................ 87

Table 4-5: Summary of test 2 (SEIS-9 and CONV-20) results ......................................... 98

Table 4-6: Summary of test 3 (CONV-6 and CONV-10) results .................................. 108

Table 4-7: Summary of test 4 (CONV-1 and SEIS-13) results .................................... 117

Table 4-8: Reflected pressure results for the front face of CONV-2 using CONWEP .. 120

Table 4-9: Reflected pressure results for the front face of SEIS-14 using CONWEP ... 123

Table 4-10: Reflected pressure results for the front face of SEIS-3 using CONWEP ... 128 
Table 4-11: Reflected pressure results for the front face of CONV-11 using CONWEP

Table 4-12: Reflected pressure results for the front face of CONV-5 using CONWEP 134

Table 4-13: Reflected pressure results for the front face of CONV-12 using CONWEP

Table 4-14: Reflected pressure results for the front face of SEIS-4 using CONWEP ... 141

Table 4-15: Reflected pressure results for the front face of CONV-15 using CONWEP

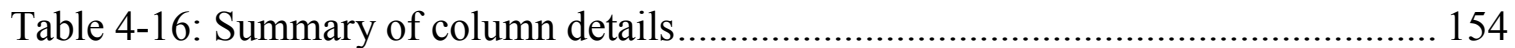




\section{Notations}

$$
\begin{aligned}
& \text { ALR }=\text { Axial load ratio } \\
& b=\text { Friedlander equation decay parameter } \\
& d=\text { diameter of an explosive charge } \\
& D I F=\text { dynamic increase factor } \\
& f_{c}=\text { dynamic strength of concrete } \\
& f_{c}^{\prime}=\text { yield strength of concrete } \\
& f_{c S}=\text { static strength of concrete } \\
& f_{d u}=\text { dynamic ultimate stress of reinforcing steel } \\
& f_{d y}=\text { dynamic yield stress for reinforcing steel } \\
& P_{s}=\text { dynamic tensile strength } \\
& P_{r}=\text { reflected overpressure } \\
& f_{t s}=\text { static tensile strength } \\
& f_{u}=\text { static ultimate stress of reinforcing steel } \\
& f_{y}=\text { static yield stress of reinforcing steel } \\
& H_{T N T}^{+}=\text {positive phase impulse }
\end{aligned}
$$


$R=$ standoff distance from explosive charge

$t_{a}=$ arrival time of shock wave

$t_{d}^{+}=$positive phase duration

$t_{d}^{-}=$negative phase duration

$W=$ explosive charge mass

$W_{E F F}=$ effective charge mass

$W_{T N T}=$ mass of TNT

$z=$ scaled distance

$\tau_{s c}=$ scaled time

$\varepsilon=$ strain rate

$\dot{\mathcal{E}}_{s}=$ static strain rate 


\section{Chapter: Introduction}

\subsection{Background}

Accidental explosions and premeditated attacks on structures over the last decades have served as a call to action for building owners, governments and design professionals alike to pay more attention to the susceptibility and survivability of structures subjected to blast loading. High profile buildings, monuments, buildings in proximity to explosives manufacturing and storage facilities, and other critical structural systems have a high probability of exposure to the threats of terrorist attacks and accidental explosions. The Oklahoma city bombing in 1995 (Wightman et al.,2001), the September 11, 2001 attack in New York (Remennikov, 2003), the Istanbul bombings in 2003 (Rodoplu et al., 2005), the London city bombings in 2005 (Rubin et al., 2005) and the 2013 Boston Marathon Bombings (Kellermann and Peleg, 2013), are few of recent premeditated explosive attacks that resulted in several loss of lives; property damage; injuries to occupants as a result of structural collapse, impact from debris, fire, and smoke. There are also many accidental and other forms of explosion that can result in catastrophic failure of buildings and other structural systems. Some of the most notable accidental explosions are: the Halifax harbor explosion in 1917, from the collision of two ships carrying explosives (Armstrong, 2002), the 2013 Lac-Megantic accident of a freight train carrying crude oil and subsequent explosion (Jebrak, 2014; Campbell, 2013), and the New York City gas explosion in 2014 (Yeres, 2014), where a gas leakage resulted in an explosion that killed eight people, injured dozens and destroyed buildings. Due to the uncertainty and difficulty in predicting terrorists attacks and accidental explosions, little information is available on the design guidelines and performance of reinforced concrete structures 
subjected to blast loading. Most of the research on blast load effects on structures has been carried out by the military and the results are mostly not in the public domain. With this in mind, structural engineers and other professionals are continuously seeking solutions and are developing cost-effective methodologies to protect lives and to prevent total or partial structural collapse. The primary goal of most protective strategies is prevention of fatality and injury to the occupants and increasing the survivability of the structure. Thus, solutions include physical security upgrades to increase and guarantee standoff distance and hardening of the building façade.

Reinforced concrete has been shown to be a desirable material of choice in blast resistant structures due to its availability, relatively low cost, and its inherent ability to absorb energy produced by explosions. Understanding the behaviour of components of a structure in a blast event is therefore critical in increasing the survivability of the structure. The Oklahoma city bombing has drawn the attention of researchers to the importance of understanding blast resistance of reinforced concrete columns. Since it was shown that, in such catastrophic events, first floor columns can fail and lead to progressive collapse of the building.

While significant amount of research has been done to study the behavior of reinforced concrete columns under blast loads, experimental work involving live explosive testing is limited, especially tests that include the effects of axial load on the flexural behavior of columns. This limitation extends to reinforced concrete columns subjected to airblast loading in close-in range of scaled distances, $\mathrm{z} \leq 1.0 \mathrm{~m} / \mathrm{kg}^{1 / 3}$. 


\subsection{Objective}

The goal of the research program reported in this thesis is to bridge these research gaps through live explosive testing of reinforced concrete columns in the close-in range. In order to achieve this, columns with different transverse reinforcement detailing were built in the structures laboratory of Carleton University and tested in an open arena conditions at the Canadian Forces Base (CFB) Petawawa, Ontario. The primary objective was to understand the close-in explosion effects on reinforced concrete columns in general, the effects of different transverse reinforcement detailing and axial loads on the response of reinforced concrete columns.

\subsection{Thesis Organization}

This thesis is organized into the following chapters;

Chapter 2 presents a detailed literature review on the current level of knowledge in the following areas:

- Recent accidental and premeditated explosions

- Historical background of explosives and classification of explosions

- $\quad$ TNT equivalency

- Blast wave interactions with structures

- Materials under high strain rates

- Review of past studies on the behavior of reinforced concrete columns subjected to blast loading

Chapter 3 focuses on the experimental program which includes the following:

- Description and construction of reaction structure

- Description and design of test specimens 
- Material properties and testing

- Construction of test specimens

- Casting and curing of concrete specimen

- Instrumentation

- Data acquisition

Chapter 4 presents the results obtained from the experimental testing. This has been presented and detailed in the sequence of testing:

- Column Test 1 (CONV-7 and SEIS-8)

- Column Test 2 (SEIS-9 and CONV-20)

- Column Test 3 (CONV-6 and CONV-10)

- Column Test 4 (CONV-1 and SEIS-13)

- Column Test 5 (CONV-2 and SEIS-14)

- Column Test 6 (SEIS-3 and CONV-11)

- Column Test 7 (CONV-5 and CONV-12)

- Column Test 8 (SEIS-4 and CONV-15)

- Discussion of results

Chapter 5 highlights the cardinal conclusions and recommendations drawn from the experimental results of this thesis. 


\section{Chapter: Literature Review}

\subsection{Introduction}

Structures around the world are increasingly exposed to the threat of terrorist attacks and other forms of explosions. The US state department in its 2012 annual report on terrorism reported a total of 6,771 terrorist attacks worldwide resulting in as many as 11,000 deaths and more than 21,600 injuries (U.S. Department of State, 2013). In 2013, there was a $43 \%$ rise in global terrorism, as the US state department reported 9,707 terrorists' attacks, with over 17,800 deaths and more than 32,500 injuries (U.S. Department of State, 2014). This alarming trend must be addressed through sophisticated security protocols and blast hardening to protect citizens. The security protocols are designed to detect, delay, deter and defeat terrorists' attacks. When the security protocols fail, the blast hardened structure is expected to resist the abnormal blast loads and protect the building occupants while limiting structural damage to the expected performance level.

The current state of global terrorism has increased the interest of building owners and governments to understand the vulnerabilities of their structures to blast loading and what can be done to increase the survivability of the structures and their occupants. This growing interest by building owners and governments has necessitated the interest of structural engineers, researchers and other design professionals alike to understand the general characteristics of blast loads, the expected behaviour of structures subjected to blast loads and to develop new techniques and design guidelines for the design of buildings to withstand blast loads. 
This chapter reviews available literature on;

- Historical premeditated (terrorists) attacks and accidental explosions and their effect on infrastructure systems to establish possible failure modes of structures subjected to blast loading

- Historical background of explosives, fundamental concepts of blast loads effects, characteristics of blast loads and blast interactions with structures.

- Relevant research carried out on reinforced concrete structures, especially columns, subjected to blast explosion effects and blast loading.

\subsection{Recent terrorist attacks and accidental explosions}

Countries around the world have witnessed an increase in terrorists activities on a grand scale. Unfortunately, human lives and properties have been the primary targets. This section highlights some of the recent premeditated (terrorists) attacks and accidental explosions that have plagued lives and properties around the globe.

\subsubsection{Lac-Megantic explosion - 2013}

On July 6, 2013, a 72 car train carrying large quantity of crude oil run off its tracks and subsequently exploded in the Quebec city of Lac-Megantic, Canada (Jébrak, 2014). The explosion killed about 50 people and destroyed more than 30 buildings including the municipal library, the town's archives, heritage buildings, businesses and residences (E Network, 2013).

\subsubsection{Boston marathon bombing -2013}

On April 15, 2013, two pressure cooker bombs were detonated in short succession near the finish line of the Boston Marathon, in the middle of a densely packed crowd of thousands of runners and spectators. This terrorist act resulted in the death of three people 
and injured an estimated 264 others (Bodden, 2014; Klontz and Jain, 2013). Even though the amount of explosives used in the Boston marathon bombing was limited and caused no damage to buildings and other infrastructures, the level of disruption, social and economic, was substantial. This underscores the importance of the requirements to preventing terrorists' actions.

\subsubsection{Marriott hotel bombing -2008}

On September 20, 2008, the Marriott hotel in Islamabad, Pakistan was subjected to a terrorist attack, when a truck load of explosives was detonated in front of this building. The Marriott hotel is one of the most prestigious hotels in the Pakistani capital (Gunaratna, 2008). Its location near government buildings and diplomatic missions made it an attractive target patronized by foreign nationals. This attack killed at least 54 people and injured 266 others (Wernick and Von Glinow, 2012). The blast caused severe damage to the five-story reinforced concrete building, especially the glazing on the front façade. A natural gas leak accompanying the blast set ablaze the entire hotel building.

\subsubsection{The Shijiazhuang bombings -2001}

On March 16, 2001, the city of Shijiazhuang, China was subjected to a series of bomb attacks. Several quantities of ammonium nitrate fuel oil (ANFO) explosives were detonated near four apartment buildings. A total of 108 people were killed, while 38 others were injured. This terrorist attack is perhaps the worst terrorist act in the history of the People's Republic of China (Li et al., 2012.).

\subsubsection{September 11 attacks -2001}

The twin towers of the World Trade Center in New York City were subjected to terrorist attacks on September 11,2001. The terrorists hijacked four passenger jetliners and flew 
two jetliners into the twin towers causing collapse of the 110-storey towers. The other two jetliners targeted the Pentagon (the headquarters of US state department of defence) and Washington DC. These attacks killed almost 3,000 people and caused at least $\$ 10$ billion in property and infrastructure damage (Seifert, 2002; Charles and Darné, 2006). This act of terrorism remains the most catastrophic terrorist attack in US history. The cost of the World Trade Center bombing in 1993 and the Oklahoma city bombing in 1995 are eclipsed by the terrorist attack on September 11 (Birkland, 2004; Goodrich, 2002).

\subsubsection{AZF chemical factory -2001}

On September 21, 2001, the AZF chemical factory in Toulouse, France exploded due to accidental mixing of incompatible chemicals. This accidental explosion involved three hundred tonnes of ammonium nitrate fertilizer. The blast destroyed the whole factory, killed 29 people and injured as many as 2500 others. The factory was close to the city of Toulouse; as a result, two-thirds of the city's building windows were shattered (Dechy et al., 2004; Lang et al., 2007).

\subsubsection{Khobar towers bombing -1996}

On June 25,1996 , a truck loaded with about $2200 \mathrm{~kg}$ of explosives was detonated a few meters from the eight-storey reinforced concrete Khobar towers in Dhahran, Saudi Arabia. The Khobar Towers housed US Army personnel stationed in Saudi Arabia. Twenty people were killed and as many as 372 others injured. The blast caused severe damage to the front façade and many floor slabs of the Khobar towers (Thompson et al., 2004; Ruby, 2002). 


\subsubsection{Oklahoma city bombing -1995}

On April 19, 1995, a truck loaded with approximately $2200 \mathrm{~kg}$ ANFO was detonated between three to five meters away from the Alfred P. Murrah federal building in Oklahoma city. This terrorist attack killed 168 people, injured more than 680 others, damaged as many as 324 buildings within the neighborhood of Alfred P. Murrah Building. Four main columns of the nine-storey reinforced concrete Alfred P. Murrah building was also destroyed (Corley at al., 1998; Mlakar et al., 1998). The Oklahoma city bombing remains the most devastating act of domestic terrorism in US history (Piotrowski and Vodanovich, 2007).

\subsubsection{Iri station explosion $-\mathbf{1 9 7 7}$}

The Iri station explosion occurred on November 11, 1977 in the Jeollabuk-do province of South Korea (Ha et al., 2008). This was an accidental explosion caused by a guard who was under the influence of alcohol. The intoxicated guard accidentally ignited a train carrying 40 tons of dynamite from Incheon to Gwangju within the Jeollabuk-do province.

The accidental ignition resulted in the explosion of the dynamite. The explosion killed 59 people, injured 1485 others and destroyed about 9500 buildings. The explosion rendered 10,000 people homeless (Han, 1978).

\subsubsection{Texas city explosion -1947}

The Texas city explosion was an industrial accident that occurred on April 16, 1947 in the USA. The explosion was as a result of fire onboard a French vessel, which was carrying approximately 2300 tons of ammonium nitrate fertilizer. The fire ignited the ammonium nitrate fertilizer resulting in a tremendous explosion; killing 581 people, injuring more than 5000 people, destroying over 500 homes, and rendering 2000 
homeless (Blocker and Blocker Jr., 1949; Strehlow and Baker, 1976; Stephens, 1997). This accident is considered as the worst industrial explosion in US history (Meyers and Shanley, 1990). The explosion also made it evident that an inexpensive explosive could be made from ammonium nitrate.

From the reviewed historical terrorists attacks and accidental explosions, it is evident that the importance of safeguarding lives and properties in such catastrophic environments cannot be underestimated.

\subsection{Historical background of explosives}

It is not known who invented the first explosive-black powder, though Roger Bacon, an Englishman, is often given credit for being the first scientist to document the formula of black powder in 1252 (Braimah, 2012). Black powder also known as gunpowder is the earliest form of explosive discovered by man. It is a mixture of saltpeter (potassium nitrate), sulfur, and charcoal (carbon). It originated in China around the tenth century and was used in fireworks displays and signals (Buchanan, 2006). When ignited, it burns rapidly, even in the absence of air. This is because oxygen within the mixture is used for combustion. For this reason, black powder was later used in muzzle-type firearms and boreholes for mining (Buchanan, 2006). Being a mechanical explosive that is smoky and messy, the need for more powerful and smokeless explosives led to increased research into explosives technology. Two major discoveries in 1847 and 1863 paved the way for development of modern day explosives.

In 1847, Ascanio Sobero, an Italian chemist discovered pyroglycerin (nitroglycerin). In his description of the discovery to the Royal Academy of Turin in 1847, he stated that, "It has the property of detonating very violently in certain circumstances. On one occasion a 
small amount of ether solution of pyroglycerin condensed in a glass bowl. When the bowl was heated over a spirit lamp, an extremely violent explosion occurred, which shattered it into small fragments. On another occasion a drop was heated in a test-tube, and exploded with such violence that the glass splinters cut deep into my face and hands, and hurt other people who were standing some distance off in the room.” (Shaplen, 1958).

In 1863 , a German chemist, Joseph Wilbrand, while trying to make a dyestuff, discovered Trinitrotuluene (TNT). It was nearly twenty (20) years before this substance was recognized as an excellent high explosive. The discovery of nitroglycerin and TNT led to intense research and discovery of many more explosives for various applications.

\subsection{Explosives and Explosions}

Meyers and Shanley (1990) define explosive as "a solid, liquid, or gaseous substance or mixture, which is in a metastable state and is capable of undergoing rapid chemical reaction (oxidation) without the presence of external reactants such as atmospheric oxygen". Hinman (2003) on the other hand defined an explosion as "a rapid release of energy taking the form of light, heat, sound and a shockwave". Based on the activation mechanism (energy), explosives can be identified as high (detonating) or low (deflagrating) explosives (Braimah, 2012). Smith et al., (1994) explained that, a detonation is the supersonic combustion of a high explosive that results in a selfpropagating exothermic chemical reaction, and transforms the original energetic material into large quantity of gas. Deflagration on the other hand, is the subsonic combustion of low explosives. The main difference between deflagration and detonation is that the rate of combustion in deflagration is lower than the speed of sound (subsonic) while it is supersonic in detonation. 


\subsection{Classification of Explosions}

Smith et al (1994) classified explosions based on the nature of their energy release mechanism as physical, nuclear and chemical. Example of a physical explosion is the catastrophic failure of a pressure vessel resulting in a shock wave and possible high velocity projectiles. Nuclear explosion is the energy released due to the redistribution of protons and neutrons in the formation of different atomic nuclei, while chemical explosions derive energy from the oxidation of fuel elements such as carbon and hydrogen atoms. The oxidation in chemical explosion leads to the production of relatively large amounts of energy and rapidly expanding gases resulting in a shockwave. Even though the occurrence of either physical or nuclear explosions are catastrophic to their surroundings, they are less frequent compared to chemical explosions. It is for this reason that the effects of chemical explosions is most often considered in designing blast resistant structures.

\subsection{Classification of explosives}

The increase in the number of chemical and petrochemical industries as well as the continuous research into the application and use of explosives have resulted in the discovery as well as the development of new explosives.

Based on their physical state, explosives can be classified as- solid (TNT), liquid (nitroglycerin) or gas (ammonia) (Mahadevan, 2013). Explosives such as pyrotechnics, ammonia and acetylene burn to create heat, smoke, and fire and are termed low explosives. High explosives detonate rapidly releasing relatively large amount of energy in the form of heat and pressure. Solid explosives such as mercury fulminate, lead styphnate, ammonium nitrate, trinitrotoluene (TNT), composition-4 (C4), research 
development explosive (RDX), PETN and ANFO, are primarily classified as high explosives (Mahadevan, 2013; Larson et al., 1999). The high explosives are responsible for the formation of shockwaves that travels at supersonic speeds through the surrounding atmosphere upon detonation. The blast parameters such as pressure and impulse produced is different from one explosive to the other. A common method used to provide comparison between different explosives is their TNT equivalence.

\subsection{TNT Equivalency}

Different kinds of explosives are used in explosions. Therefore, a datum is necessary to be able to quantify and determine the blast wave parameters as well as assess the detonation characteristics of each type of explosive material. The generally accepted standard is Trinitrotoluene (TNT); a relatively pure, safe to handle, and readily available explosive. A lot of research and testing has been done using TNT. With the majority of data on blast effects and blast pressure output from a spherical TNT explosive charge (Beshara, 1994). In quantifying a blast wave from a source other than TNT, the first step is to convert the charge mass into an equivalent mass of TNT (Braimah, 2012). This is done so that the charge mass of the explosive is multiplied by the conversion factor based on the specific heat of detonation of the charge and that of TNT. It should be noted that, the equivalency of materials compared to TNT may be affected by other factors such as material shape (spherical, cylindrical, flat or square), the number of explosive items, explosive confinement, nature of source and the pressure range being considered (Beshara, 1994). The Unified Facilities Criteria Program (UFC 2008) expresses TNT equivalence by equation $2-1$;

$$
W_{E F F}=\frac{H_{E X P}^{d}}{H_{T N T}^{d}} W_{T N T}
$$


Where, $W_{E F F}$ is the effective charge mass (or TNT equivalent mass) in $\mathrm{kg}$ of an explosive, $W_{T N T}$ is the mass of TNT in $\mathrm{kg}, H_{E X P}^{d}$ is the heat of detonation of explosive in $\mathrm{J} / \mathrm{kg}, H_{T N T}^{d}$ is the heat of detonation of TNT in $\mathrm{J} / \mathrm{kg}$.

TNT equivalence can also be calculated for physical and nuclear explosives. For nuclear explosives, the energy released is so great that the TNT equivalence is described in terms of kilotonnes (or megatonnes) of TNT (Braimah, 2012; Beshara, 1994). Table 2-1 presents the TNT equivalence of some common explosives.

Table 2-1: TNT Equivalent masses of some explosives (Braimah, 2012)

\begin{tabular}{|c|c|c|c|}
\hline Explosive & $\begin{array}{c}\text { Density } \\
\left(\mathrm{kg} / \mathrm{m}^{3}\right)\end{array}$ & $\begin{array}{c}\text { TNT Equivalence } \\
\text { Mass for Pressure }\end{array}$ & $\begin{array}{c}\text { TNT Equivalence } \\
\text { Mass for Impulse }\end{array}$ \\
\hline Amatol & 1590 & 0.97 & 0.87 \\
\hline ANFO (94/6 ANFO) & 800 & 0.87 & 0.87 \\
\hline Composition C4 & 1590 & 1.20 & 1.19 \\
\hline HMX & & 1.25 & 1.25 \\
\hline PETN & 1770 & 1.27 & 1.10 \\
\hline RDX & 1820 & 1.10 & 1.00 \\
\hline TNT & 1630 & 1.00 & 0.96 \\
\hline Tritonal & 1720 & 1.07 & \\
\hline
\end{tabular}

\subsection{Blast Scaling Laws}

When an explosion occurs, a blast wave is formed in the surrounding air. The characteristics of the blast wave generated depends on the explosive energy released and on the nature of the medium through which the blast wave propagates (Beshara, 1994). The sudden rise in pressure at the shock front of the blast wave can cause damage to structures within the neighborhood of the detonation centre. The amount of damage is determined by the blast loading and by the structural response due to the load. With the 
large number of explosives available, it is important that experimental testing is done to determine the effects of the different explosives on structures. This requires an enormous amount of resources for experimental testing. Moreover, experimental testing involving explosives is time-consuming and fraught with safety-related constraints. With this in mind, Braimah (2012) explained that researchers usually design tests with small explosive quantities then generate models or scaling laws to extend the range of applicability of the test results and also compare the effects of different explosives, charge weights, and at different standoff distances. Blast scaling law is based on similarity principle, which states that it is sufficient to perform measurements for a single charge, say $1 \mathrm{~kg}$ of TNT, and then the characteristics of blast waves due to a charge with an arbitrary size can be derived from these results by means of scaling factors. The most common form of the blast scaling is the Hopkinson-Cranz scaling law. Hopkinson in 1915 and Cranz in 1926 described a relationship for pressure proportional to the cube root of charge mass and standoff distances for atmospheric explosions. This relationship is what is now termed as the Hopkinson-Cranz scaling law. A comprehensive description of the blast scaling methods can be found in Baker (1973). A simplified mathematical presentation of the Hopkinson-Cranz scaling law is given as follows,

$$
\begin{gathered}
W_{1} \propto d_{1}^{3} \\
\text { and } \\
W_{2} \propto d_{2}^{3}
\end{gathered}
$$

Therefore; $\frac{W_{1}}{W_{2}}=\frac{d_{1}^{3}}{d_{2}^{3}}$ 
Where; $d_{1}$ and $d_{2}$ are the characteristics diameters of the spherically shaped explosive charges. $W_{1}$ and $W_{2}$ are charge masses of the explosive with diameter $d_{1}$ and $d_{2}$ respectively. If $R_{1}$ and $R_{2}$ are standoff distances from $W_{1}$ and $W_{2}$ respectively, then equation (2-4) can be extended to equation (2-5);

$\frac{W_{1}}{W_{2}}=\frac{R_{1}^{3}}{R_{2}^{3}}$

According to the Hopkinson-Cranz scaling law, for the peak overpressure recorded at the stations to be same, the ratio of the charge masses must be the same as the ratio of the cubes of the standoff distances. This ratio is expressed as a constant, $\mathrm{z}$, also known as the scaled distance. Equation (2-6) summarizes the Hopkinson-Cranz scaling law.

$\frac{R_{1}}{R_{2}}=\frac{W_{1}^{1 / 3}}{W_{2}^{1 / 3}} \Rightarrow \frac{R_{1}}{W_{1}^{1 / 3}}=\frac{R_{2}}{W_{2}^{1 / 3}}=$ constant $=z$

The scaled distance $(z)$ or the proximity factor is in units of distance per mass ${ }^{1 / 3}\left(\mathrm{~m} / \mathrm{kg}^{1 / 3}\right)$. Although the use of scaling laws directly relate pressure of different explosions, it must be noted that, other properties (impulse, particle velocity and dynamic pressure) are not linearly proportional to scaled distance. Factors such as temperature, relative humidity and altitude also affect the propagation of explosive shockwaves in air (Kinney and Graham, 1985). Scaling can also be applied to time parameters (Beshara, 1994). The scaled time $\tau_{s c}$ is defined as;

$\tau_{s c}=\frac{t}{W^{1 / 3}}$

Another scaling relationship is the Sachs scaling law, which accounts for the effects of altitude and other ambient conditions on the blast wave properties (Baker 1983). The Sachs law states that dimensionless overpressure and dimensionless impulse can be 
expressed as unique functions of a dimensionless scaled distance, where the dimensionless parameters include quantities, which define the ambient atmospheric conditions prior to the explosion (Dewey and Sperrazza, 1950). Sachs scaled pressure is given as $P / P o$ and scaled impulse is defined as;

$\frac{I_{a_{0}}}{\left(W^{1 / 3} P_{0}^{2 / 3}\right)}$

A dimensionless scaled distance is defined as;

$$
\frac{\left(R P_{0}^{1 / 3}\right)}{W^{1 / 3}}
$$

Where $P$ is the blast pressure, $P_{o}$ is the ambient atmospheric pressure, $R$ is the standoff distance, $I_{a_{0}}$ is the impulse, and $W$ is the charge mass. Sperrazza (1963) has given the careful proof of Sach's law. Though there are other scaling laws in the literature, Sachs scaling law and the Hopkinson-Crannz scaling law have gained widespread use in the field of blast wave theory.

\subsection{Blast Pressure Profile}

When an explosive is detonated, large amount of energy is generated. This energy forces the explosive gas to expand and move outward from the centre of detonation thereby producing a layer of compressed air called the blast (shock) wave. As the shockwave expands, the incident or overpressure decreases. When it encounters a surface that is denser than the medium the shockwave is propagating in, it is reflected resulting in a tremendous amplification of pressure (Hinman, 2003). Hinman (2003) further explained that, unlike acoustical waves which reflect with an amplification factor of two, shockwaves can reflect with an amplification factor of up to twelve, due to the supersonic 
velocity of the shock wave at impact. The magnitude of the amplification factor is a function of the proximity of the explosion and the angle of incidence of the shockwave on the surface. The reflected blast waves are categorized into three types; normal, oblique and Mach reflection (Braimah, 2012). A normal reflection occurs when the blast wave impinges normally on an infinite reflecting (target) surface. When the blast wave impinges on a reflecting surface at an incidence angle less than $90^{\circ}$, an oblique reflection occurs (Braimah, 2012; Hornung, 1986;). Mach stem reflection occurs when the expanding shockwave is reflected off the ground to form a second wave that travels behind the expanding shock wave. This reflected wave travels faster than the expanding shockwave, since it is traveling through a precompressed fluid. The reflected wave merges with the expanding shockwave to form a single wave called the Mach reflection or the Mach stem (Hornung, 1986; Hull, 1997). The peak pressure within the Mach stem regions can be twice as high as that of the original shock front (Hornung, 1986).

The pressure exponentially decays rapidly, measured typically in thousandths of a second. As this pressure decay continues, a partial vacuum is created (underpressure) causing the air to rush back (rarefaction). The partial vacuum leads to the formation of a negative pressure region behind the shock front thus creating a powerful wind or drag pressures (Hinman 2003). The movement of blast wave in air is a nonlinear process involving a nonlinear equation of motion, whereas the wave propagation is a linear problem. Three primary independent parameters characterize the waveform. These parameters are: the overpressure, the duration, and the impulse. For an explosive threat defined by its charge weight and standoff, the peak incident and reflected pressures of the shockwave and other useful parameters such as incident and reflected impulse, shock 
front velocity and time of arrival can be determined. The impulse of the blast wave is determined by calculating the area under a blast pressure-time profile. There are charts available in military handbooks to evaluate these blast parameters. The Friedlander waveform is a graph used to describe the profile of a blast wave. Figure 2-1 presents a typical blast pressure profile of a blast wave.

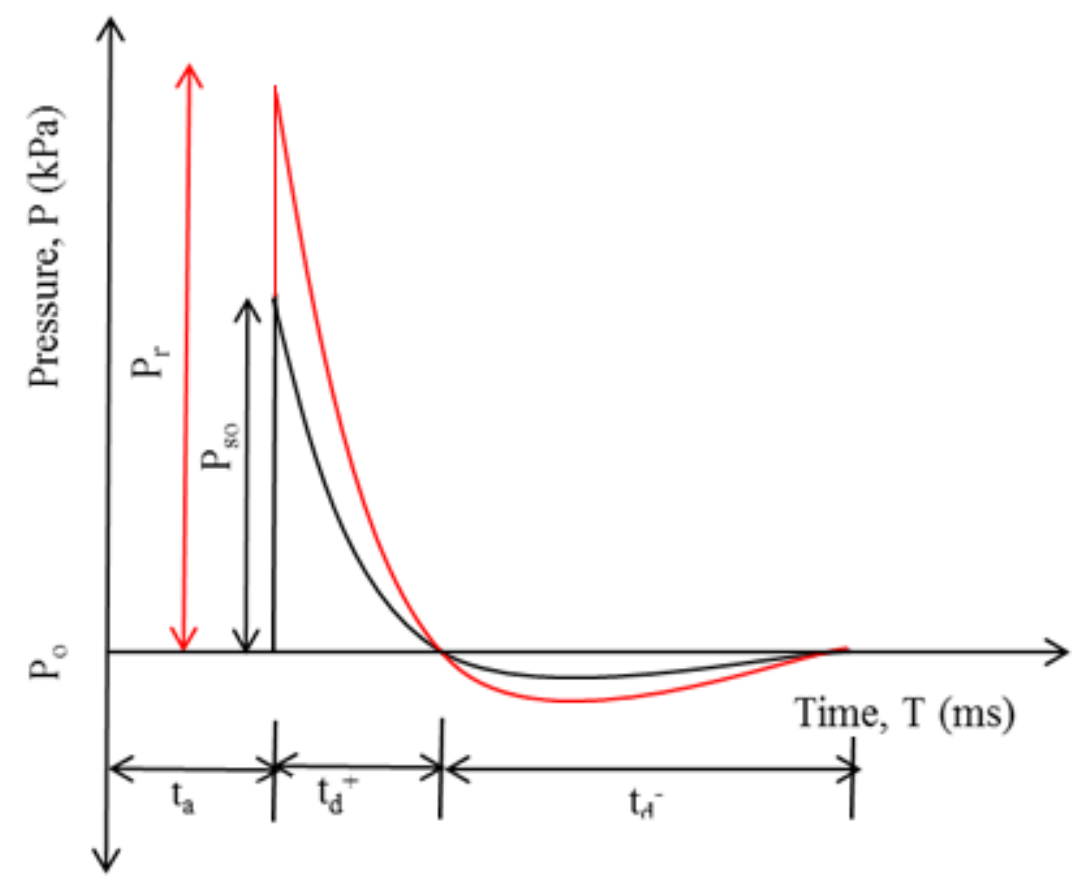

Figure 2-1: Air blast pressure profile

The equation for the Friedlander waveform describes the pressure of blast wave as a function of time. This is presented for the incident blast wave in equation 2-10;

$$
\left\{\begin{array}{l}
P(t)=0, t<t_{a} \\
P(t)=P_{s o}\left(1-\frac{t-t_{a}}{t_{d}^{+}}\right)^{\frac{b\left(t-t_{a}\right)}{t_{d}^{+}}}, t \geq t_{a}
\end{array}\right\}
$$

Where: $P(t)$ is the peak pressure at time $t, P_{s o}$ is the peak incident overpressure, $t_{d}^{+}$is the positive phase duration of blast, $\mathrm{b}$ is the decay parameter. 
Since blast is an impulsive load, the impulse of the blast wave is calculated as the area under the blast pressure profile. This is calculated as;

$I_{s o}^{+}=\int_{t_{a}}^{t_{a}+t_{d}^{+}}\left(P_{s o}(t)\right) d t$

$I_{s o}^{-}=\int_{t_{a}+t_{d}^{+}}^{t_{a}+t_{d}^{+}+t_{d}^{-}}\left(P_{s o}(t)\right) d t$

Where; $I_{s o}^{+}$is positive phase impulse, $I_{s o}^{-}$is negative phase impulse.

\subsection{Blast wave Interactions with reinforced concrete columns}

When a structure is subjected to blast loading, there is the possibility of some damage occurring. In some cases, the structure might not be safe for reuse after an explosion accident. The primary goal of all blast resistant designed structures is to save human lives through prevention of collapse of the structure. For high population buildings exposed to blast, the buildings should be able to withstand the blast pressures so as to enable evacuation and rescue of occupants. For the purpose of preventing collapse of structures in an explosion attack or accident, concrete reinforcement detailing is very critical for ductile response. Ductile detailing of primary members and connections give room for large deformation as well as maintain load carrying capacity (Marjanishvili and Agnew, 2007). Reinforced concrete columns are the most essential structural elements for protecting a reinforced concrete building from collapse. These elements are also the most

vulnerable to airblast loading (Marjanishvili and Gallant, 2005). The entire load of buildings, especially multi storey, and frame structures, is carried by columns. The failure of a single structural column may have a severe effect on the structural integrity of the building. For high rise buildings, the structural columns carry substantial axial load due 
to gravity, as such, it is necessary to include the effect of axial load in blast analysis. Axial load in reinforced concrete columns increases the bending capacity of the columns (Marjanishvili and Gallant, 2005).

Airblast pressure distribution on a column is often approximated as uniform, by assuming planar shock front of the blast wave (Marjanishvili and Agnew, 2007). This is true for columns subjected to far-field blast loading. When the column is loaded in the near-field, the blast pressure along the column varies with the distance from the centre of explosion. Also, when the explosion is hemispherical or with a limited height of burst, the blast wave reflection off the ground amplifies the non-uniformity of the blast load along the height of the column.

The duration and blast pressure on a structure can vary depending on the geometry as well as the presence of non-structural exterior walls (Baylot and Bevins, 2007). When the column is part of the exterior wall system, only the front face of the column is loaded. Depending on the location of the column and the dimensions of the wall, clearing does not affect the blast profile and the whole blast load is reflected. For free-standing columns, the blast wave engulfs the column and causing equal and opposite squashing incident blast load on the sides of the column and a lower magnitude incident blast pressure on the rear face of the column. The free standing column thus experiences some form of drag force. Figure 2-2 presents a typical case of a free standing column subjected to a close-in explosion with limited height of burst. 


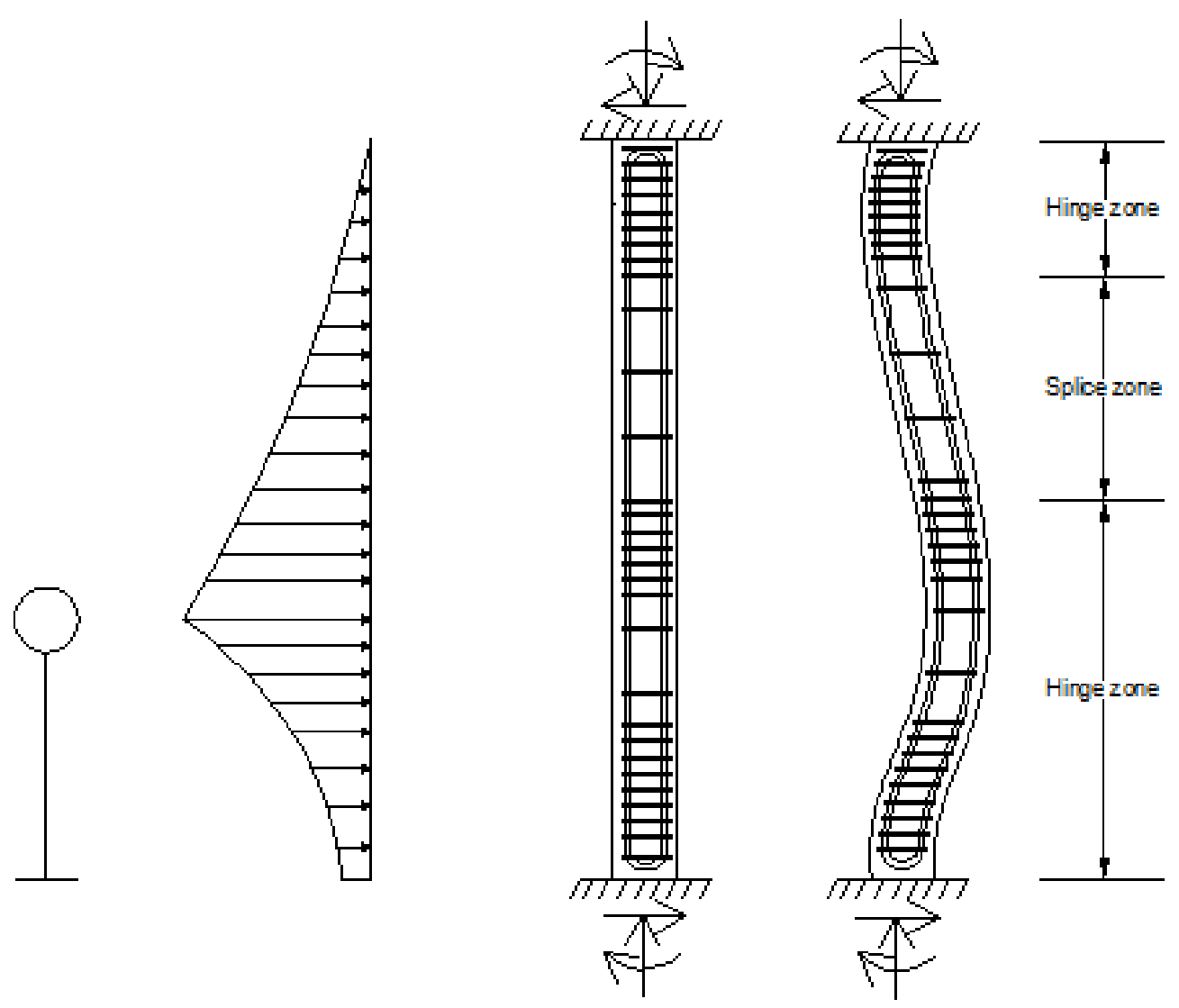

Figure 2-2: A typical case of free standing column subjected to a non-uniform airblast loading

\subsection{Materials under high strain rates}

A structural element subjected to a blast loading exhibits a higher strength than a similar element subjected to a static loading. This increase in strength for both concrete and steel is attributed to the higher rates of strain that occur in dynamically loaded members (TM 5-1300, 1990). For this reason, the increased material strength of steel and concrete must be accounted for in design and analysis of structures involving blast loads. For concrete, the increase in strain rate will lead to an increase in the initial modulus of elasticity and compressive strength, while for steel an increase in the yield stress and ultimate stress results. The general stress-strain relationship for concrete and steel under high strain rates are shown in Figure 2-3 and Figure 2-4 respectively. 


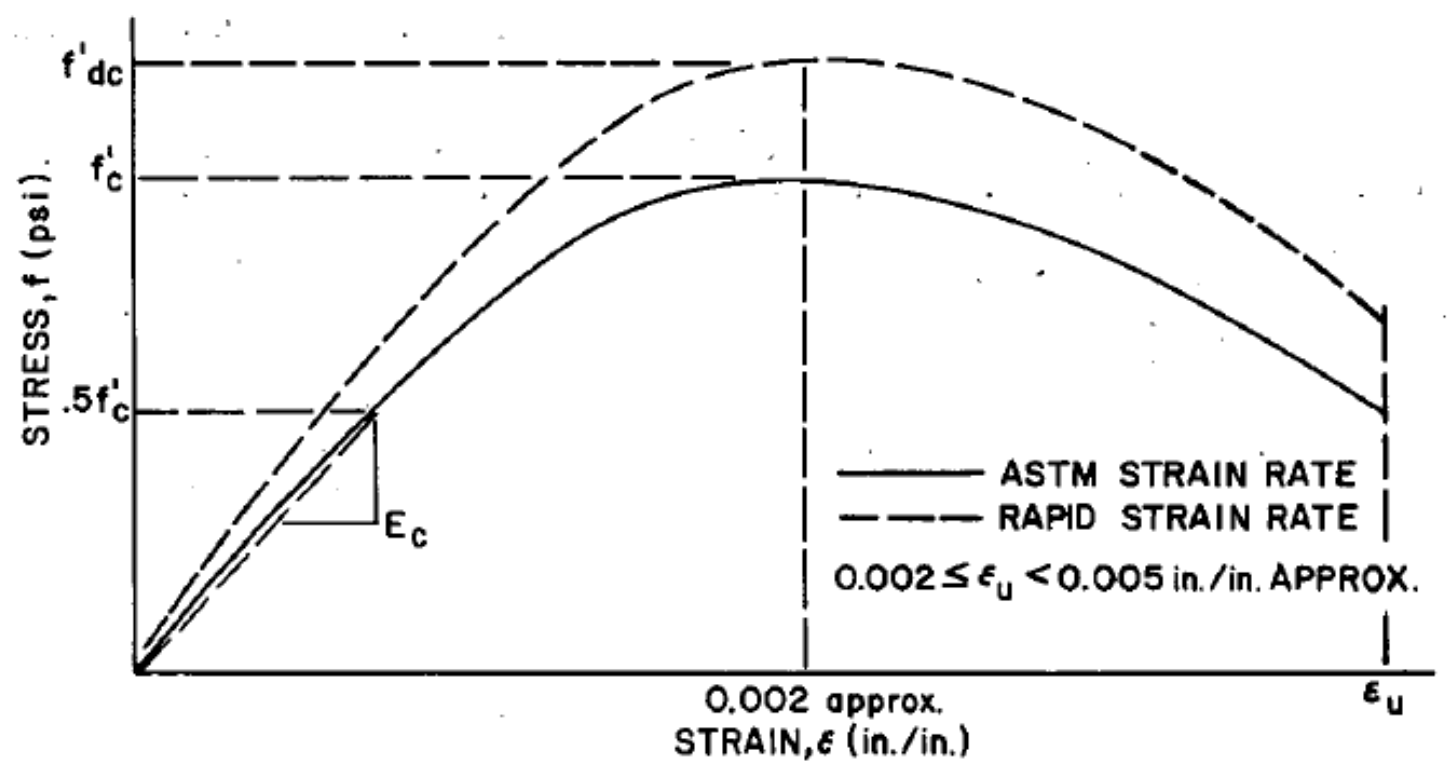

Figure 2-3: Typical stress-strain curve for concrete (TM 5-1300, 1990)

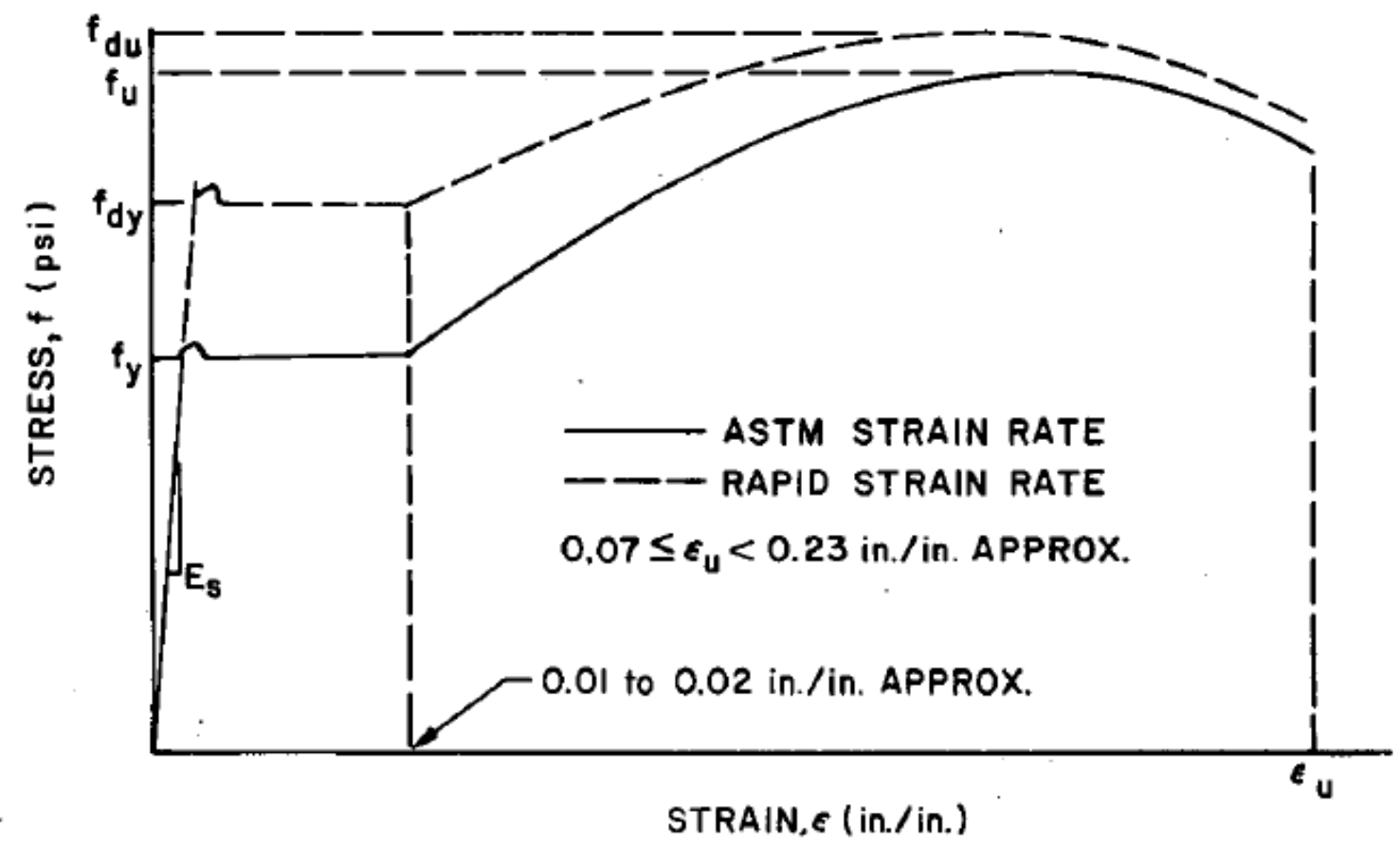

Figure 2-4: Typical stress-strain curve for steel (TM 5-1300, 1990)

The effect of high strain rate on the concrete and steel strength is typically accounted for by dynamic increase factor (DIF). Malvar and Crawford (1998), defined the DIF as ratio of dynamic strength to static strength. Several studies have been undertaken to determine 
the accurate values of the DIF for concrete and steel. Malvar and Crawford (1998) have reviewed results from some of these studies, and a summary of their review is highlighted in the succeeding sections.

\subsubsection{Dynamic Increase Factor (DIF) for Concrete}

Malvar and Crawford (1998), stated that, the Comite European du Beton (CEB) proposals is perhaps the most comprehensive model for the strain rate enhancement for concrete in tension and compression. The Comite European du Beton (CEB) proposed equation for DIF for concrete compressive strength is given in (2-13) and (2-14).

$$
\begin{aligned}
& D I F=\frac{f_{c}}{f_{c s}}=\left(\frac{\dot{\varepsilon}}{\dot{\varepsilon}_{s}}\right)^{1.026 \alpha_{s}}, \quad \text { for } \dot{\varepsilon} \leq 30 s^{-1} \\
& D I F=\frac{f_{c}}{f_{c s}}=\gamma_{s}\left(\frac{\dot{\varepsilon}}{\dot{\varepsilon}_{s}}\right)^{1.026 \alpha_{s}}, \text { for } \dot{\varepsilon}>30 s^{-1}
\end{aligned}
$$

Where; $f_{c}=$ dynamic compressive strength at $\varepsilon$

$$
\begin{aligned}
f_{c s} & =\text { static compressive strength at } \dot{\varepsilon} \\
f_{c} / f_{c s} & =\text { dynamic increase factor (DIF) } \\
\dot{\varepsilon} & =\text { strain rate in the range of } 30 \times 10^{-6} \text { to } 300 \mathrm{~s}^{-1} \\
\varepsilon_{s} & =30 \times 10^{-6} \mathrm{~s}^{-1} \text { (static strain rate) } \\
\log \gamma_{s} & =6.156 \alpha_{s}-2 \\
\alpha_{s} & =\frac{1}{5+\frac{9 f_{c s}}{f_{c o}}}
\end{aligned}
$$




$$
f_{c o}=10 \mathrm{MPa}=1450 \mathrm{psi}
$$

It should be noted that the above formulation captures specific material behaviors, which have been outlined in Malvar and Crawford (1998). Nonetheless, this DIF formulation for concrete in compression has been adopted by most researchers as an accurate representation of actual behavior and is of direct application in numerical analyses (Malvar and Crawford, 1998).

CEB also formulated a model for DIF for concrete in tension. This formulation is bilinear on a log-log plot. CEB formulation explains that, the discontinuity in slope occurs at a strain rate of $30 \mathrm{~s}^{-1}$. It should be noted also that this formulation is valid up to strain rate of $300 \mathrm{~s}^{-1}$. DIF for tensile strength is presented in equation 2-15 and 2-16;

$$
\begin{aligned}
& D I F=\frac{f_{t}}{f_{t s}}=\left(\frac{\dot{\varepsilon}}{\varepsilon_{s}}\right)^{1.016 \delta}, \text { for } \dot{\varepsilon} \leq 30 s^{-1} \\
& D I F=\frac{f_{t}}{f_{t s}}=\beta\left(\frac{\dot{\varepsilon}}{\varepsilon_{s}}\right)^{1 / 3}, \text { for } \dot{\varepsilon}>30 s^{-1}
\end{aligned}
$$

Where; $f_{t}=$ dynamic tensile strength at $\dot{\varepsilon}$

$$
\begin{aligned}
f_{t s} & =\text { static tensile strength } \\
f_{t} / f_{t s} & =\text { for DIF } \\
\dot{\varepsilon} & =\text { strain rate in the range of } 30 \times 10^{-6} \text { to } 300 \mathrm{~s}^{-1} \\
\dot{\varepsilon}_{s} & =3 \times 10^{-6} \mathrm{~s}^{-1} \text { (static strain rate) }
\end{aligned}
$$

$\log \beta=7.11 \delta-2.33$ 


$$
\begin{aligned}
\delta & =\frac{1}{10+\frac{6 f_{c s}}{f_{c o}}} \\
f_{c o} & =10 \mathrm{MPa}=1450 \mathrm{psi}
\end{aligned}
$$

Dynamic increase factors $(D I F)$ used in design have been published by a number of researchers. Table 2-2 provides values used for concrete for close-in and far field designs reproduced from TM 5-1300 (1990).

Table 2-2: DIF for design of reinforce concrete elements (TM 5-1300, 1990)

\begin{tabular}{|l|l|l|l|l|l|l|}
\hline \multirow{3}{*}{ Type of stress } & \multicolumn{3}{|l|}{ Far design range } & \multicolumn{3}{|l|}{ Close-in design range } \\
\cline { 2 - 8 } & \multicolumn{2}{|l|}{ Reinforcing steel } & Concrete & \multicolumn{2}{|l|}{ Reinforcing steel } & Concrete \\
\cline { 2 - 8 } & $\mathrm{f}_{\mathrm{dy}} / \mathrm{f}_{\mathrm{y}}$ & $\mathrm{f}_{\mathrm{du}} / \mathrm{f}_{\mathrm{u}}$ & $\mathrm{f}_{\mathrm{dc}}^{\prime} / \mathrm{f}_{\mathrm{c}}^{\prime}$ & $\mathrm{f}_{\mathrm{dy}} / \mathrm{f}_{\mathrm{y}}$ & $\mathrm{f}_{\mathrm{du}} / \mathrm{f}_{\mathrm{u}}$ & $\mathrm{f}_{\mathrm{dc}}^{\prime} / \mathrm{f}_{\mathrm{c}}$ \\
\hline Bending & 1.17 & 1.05 & 1.19 & 1.23 & 1.05 & 1.25 \\
\hline Diagonal Tension & 1.00 & - & 1.00 & 1.10 & 1.00 & 1.00 \\
\hline Direct Shear & 1.10 & 1.00 & 1.10 & 1.10 & 1.00 & 1.10 \\
\hline Bond & 1.17 & 1.05 & 1.00 & 1.23 & 1.05 & 1.00 \\
\hline Compression & 1.10 & - & 1.12 & 1.13 & - & 1.16 \\
\hline
\end{tabular}

\subsubsection{Dynamic Increase Factor (DIF) for Steel}

Similar to concrete, the strength characteristics of steel under rapid loading varies. Many studies (Furlong, 1967; Slutter and Driscoll, 1963; Sharma, 1986; Norton, 1929; Flathau et al., 1989) have reported increased yield and ultimate strength for steel under high strain rate. Table 2-3 provides the recommended values for $D I F$ for steel and aluminum. 
Table 2-3: Dynamic increase factor for structural steel, cold-formed steel, and aluminum (Braimah, 2012)

\begin{tabular}{|l|c|c|c|}
\hline \multirow{2}{*}{ Materials } & \multicolumn{3}{|c|}{ DIF } \\
\cline { 2 - 3 } & \multicolumn{2}{|c|}{ Yield stress } & \multirow{2}{*}{ Ultimate stress } \\
\cline { 2 - 3 } & Bending shear & Tension,compression & \\
\cline { 2 - 4 } & $\mathrm{F}_{\mathrm{dy}} / \mathrm{F}_{\mathrm{y}}$ & $\mathrm{F}_{\mathrm{dy}} / \mathrm{F}_{\mathrm{y}}$ & $\mathrm{F}_{\mathrm{du}} / \mathrm{F}_{\mathrm{u}}$ \\
\hline A36 & 1.29 & 1.19 & 1.10 \\
\hline A588 & 1.19 & 1.12 & 1.05 \\
\hline A514 & 1.09 & 1.05 & 1.00 \\
\hline A446 & 1.10 & 1.10 & 1.00 \\
\hline $\begin{array}{l}\text { Stainless steel type } \\
\text { 304 }\end{array}$ & 1.18 & 1.15 & 1.00 \\
\hline Aluminum 6061-T6 & 1.02 & 1.00 & \\
\hline
\end{tabular}

\subsection{Review of past studies on behavior of reinforced concrete columns subjected to blast loading}

\subsubsection{Baylot and Bevins (2007)}

Baylot and Bevins (2007) carried out close-range experimental and numerical research to investigate the effect of non-structural exterior walls on the response of reinforced concrete columns subjected to airblast loading. Exterior infill walls in concrete frame structure do not contribute to supporting the gravity loads of a structure. Although these walls are non-structural, they can impact on the loads applied to exterior columns and thus the response of the structure as a whole. To understand the effects of these nonstructural walls on columns subjected to blast loading, the researchers carried out numerical simulations and experimental investigations for a two-story reinforced concrete structure with and without exterior infill Concrete Masonry Unit (CMU) walls. The experimental phase of their research was divided into two; a full-scale and a quarterscale models. A charge mass of $454 \mathrm{~kg}$ of $\mathrm{C} 4$ at a standoff distance of $6.1 \mathrm{~m}$ was preselected for the full scale experimental test. Baylot and Bevins (2007), explained that the 
pre-selection of the $454 \mathrm{~kg}$ of $\mathrm{C} 4$ at a standoff distance of $6.1 \mathrm{~m}$ was purposely to cause failure of the exterior columns so that the potential for progressive collapse of the building could be evaluated. Based on the charge mass of $454 \mathrm{~kg} \mathrm{C} 4$ and standoff of 6.1 $\mathrm{m}$ for the full scale experiment, the charge mass and standoff for the quarter-scale experiment was calculated using the Hopkinson scaling law to be $7.1 \mathrm{~kg}$ of $\mathrm{C} 4$ charge at a standoff distance of $1.52 \mathrm{~m}$.

The objective of the first quarter-scale experiment was to be able to reproduce the full scale experiment. After the first quarter-scale experiment however, Baylot and Bevins (2007) observed minimal damage to the reinforced concrete column in comparison to the full-scale test. In order to determine the requisite standoff distance for the $7.1 \mathrm{~kg} \mathrm{C} 4$ charge to cause a significant damage to the column in the absence of CMU walls, a numerical simulation technique was employed and a standoff of $1.07 \mathrm{~m}$ was obtained.

Baylot and Bevins (2007) concluded that, the interactions of blast load with failing exterior CMU wall has a significant effect on the response of the column. Peak pressure and impulse were slightly higher for columns with CMU walls compared to those without CMU walls. They also concluded that, the duration of the blast was longer due to the presence of CMU walls.

\subsubsection{Elsanadedy et al. (2010)}

Elsanadedy et al. (2010) conducted a numerical study of retrofitted concrete columns under blast loading in the far-range and close-range. The study was aimed at investigating the effects of blast loading on Carbon Fibre Reinforced Polymer (CFRP)-retroffited columns. The researchers used the parameters of an existing reinforced concrete column for their simulation. The RC column selected for the study had a circular cross-section 
with a diameter of $600 \mathrm{~mm}$ and a height of $4 \mathrm{~m}$. The column was reinforced with $16-16-$ $\mathrm{mm}$ diameter longitudinal rebars and $10-\mathrm{mm}$ diameter transverse rebar at $200 \mathrm{~mm}$ centreto-center spacing. A 30-MPa compressive strength concrete was used.

To understand the effects of the CFRP-retrofit, the researchers considered two sets of columns; CFRP-retrofitted columns and un-retrofitted columns. The CFRP-retrofitted columns were wrapped with 1-mm thick CFRP layers to increase concrete confinement and enhance shear and flexural capacity of the columns. Different TNT equivalent charge masses of $100 \mathrm{~kg}, 200 \mathrm{~kg}, 500 \mathrm{~kg}$ and $1000 \mathrm{~kg}$ at standoff distances of $1 \mathrm{~m}, 4 \mathrm{~m}$ and $15 \mathrm{~m}$ were used for the simulations.

Elsanadedy et al. (2010) observed that $500 \mathrm{~kg}$ and $1000 \mathrm{~kg}$ charge masses at a standoff distance of $1 \mathrm{~m}$ completely destroyed both the retrofitted and un-retrofitted columns. For a blast load from $100 \mathrm{~kg}$ charge mass at $15 \mathrm{~m}$ standoff distance, the researchers observed that both sets of columns did not suffer any damage, however, the maximum displacement for the un-retrofitted column was relatively higher compared to the retrofitted column. Similarly, the maximum and permanent displacements observed for different combinations of the charge masses and standoff distances showed that retrofitting of the column reduced the maximum and permanent lateral displacements, considerably. The reduction of lateral displacement varied from $8 \%$ for a charge mass of $100 \mathrm{~kg}$ at a standoff of $4 \mathrm{~m}$ to $79 \%$ for a charge mass of $500 \mathrm{~kg}$ at a standoff of $4 \mathrm{~m}$ (Elsanadedy et al., 2010). The concrete was crushed over the bottom one-third of the unretrofitted column subjected to a blast load from $100 \mathrm{~kg}$ TNT at a standoff of $1 \mathrm{~m}$, while the retrofitted column showed no appreciable damage as the FRP retrofit provided significant confinement to the concrete. Also, for a blast load from $200 \mathrm{~kg}$ TNT charge at 
a standoff of $1 \mathrm{~m}$, the researchers observed that concrete in the bottom half of the unretrofitted was totally destroyed, with longitudinal bars severely deformed and tie bars severely bent. The retrofitted column however, showed minimal damaged to concrete as the concrete was confined by the FRP. Longitudinal bars bent out of shape at the blast height with a few ties fractured at the bottom $1 \mathrm{~m}$ height of the retrofitted column. The FRP material was ruptured at the bottom one-third for this particular simulation.

Elsanadedy et al. (2010) concluded that retrofitting of columns reduces the peak lateral displacement considerably as well as damage to concrete and rebars, thereby providing considerable resistance to blast loads.

\subsubsection{Bao and Li (2010)}

Bao and Li (2010) carried out a close-range numerical simulations to evaluate the dynamic response of columns subjected to blast loadings. The researchers conducted the numerical simulation on a series of twelve (12) reinforced concrete columns, with different transverse and longitudinal reinforcement detailing as well as different axial load ratio.

Bao and Li stated that recent blast incidents showed that, most of the terrorist attacks on public structures were explosions at a short standoff distance (less than $10 \mathrm{~m}$ ), as such, they chose a standoff distance of $5 \mathrm{~m}$ for their simulation. Also, they further stated that considering the limitation of the weight of explosives that can be obtained at a particular location, a maximum TNT equivalent charge mass of $907 \mathrm{~kg}$ (1 ton) was chosen. They then varied the charge mass between 0 and $907 \mathrm{~kg}(0$ and 1 ton) in order to obtain different levels of damage to the columns. Twelve (12) square columns with a crosssection $355 \times 355 \mathrm{~mm}$ and a height ranging from $2130 \mathrm{~mm}$ to $3480 \mathrm{~mm}$ was used in their 
models. Six (6) of these columns were reinforced with $20-\mathrm{mm}$ diameter longitudinal rebars and $10-\mathrm{mm}$ diameter ties, while the six (6) remainder were reinforced with $25-\mathrm{mm}$ diameter longitudinal rebars and 10-mm diameter ties. Bao and Li labelled the columns as series A through $\mathrm{L}$, with series $\mathrm{B}, \mathrm{D}, \mathrm{F}, \mathrm{H} \mathrm{J}$ and $\mathrm{L}$ being seismically detailed columns for which the tie spacing was determined in accordance with the requirement of ACI 318 code. Series A, C, E, G, I and K were detailed as conventional columns in accordance with ACI 318 code.

Based on their numerical study, Bao and Li concluded that seismic detailing significantly reduced the degree of blast induced damage and subsequent collapse of reinforced concrete columns.

\subsubsection{Luccioni et al. (2003)}

Luccioni et al. (2003) carried out a close-in numerical investigation to analyze the structural failure of a reinforced concrete building subjected to blast loading. Luccioni et al. (2003) modeled a reinforced concrete building following the structural and architectural plans of a four-story building at the White Sands range in New Mexico, USA. The four-story building was subjected to a full-scale blast test by the Defense Threat Reduction Agency (DTRA) as part of a research and development program to investigate measures to retrofit US embassies and other critical structures worldwide (Luccioni et al., (2003).

The model of the building was composed of reinforced concrete structure and masonry infill walls. The reinforced concrete structure was a frame structure consisting of columns, beams and slabs. The columns were square of dimension $300 \times 300 \mathrm{~mm}$ and a height of $5 \mathrm{~m}$ and reinforced with a longitudinal reinforcement ratio of 0.04 . A $400 \mathrm{~kg}$ 
TNT charge at a standoff distance of $2.5 \mathrm{~m}$ was chosen in order to reproduce the same level of damage as in the full-scale test conducted by the DTRA.

Luccioni et al. (2003) observed that columns closer to the focus of the explosion failed as a result of direct effect of the reflected pressure of the blast, while, rear columns lost connection with the upper and lower beams due to tension effect imparted by the first floor slabs that were pushed upwards and downwards by the blast pressure. Indeed, Luccioni et al. (2003) stated that the first three lines of ground floor columns and the first two floor levels completely destroyed, thereby resulting in the collapse of the upper floors.

Based on their numerical investigation, Luccioni et al. (2003) concluded that the structural collapse of the reinforced concrete building was due to a gravitational mechanism originated by the destruction of the lower columns.

\subsubsection{Ngo et al. (2007)}

Ngo et al. (2007) carried out a close range numerical study to investigate the effects of blast loading on reinforced concrete columns with different transverse reinforcement detailing and concrete strengths. A $6.4 \mathrm{~m}$ high ground floor column of a typical storey building in Australia was used for their study. Two sets of columns, with $40 \mathrm{MPa}$ concrete strength representative of normal strength concrete (NSC) and $80 \mathrm{MPa}$ concrete strength representative of high strength concrete (HSC) were modeled. A column size of $500 \times 900 \mathrm{~mm}$ was used for the NSC columns, while a $350 \times 750 \mathrm{~mm}$ size was used for the HSC columns. Both sets of columns were detailed as conventional and seismic columns. The tie spacing used for the conventional columns was $400 \mathrm{~mm}$, while that used for the seismic column was $100 \mathrm{~mm}$. 
Ngo et al. (2007) observed that, HSC columns had a better energy absorption capacity relative to the NSC columns. The researchers also observed a significant effect of the shear reinforcement. At failure, the ultimate lateral displacement for HSC column with 400-mm tie spacing was $45 \mathrm{~mm}$ and that for HSC column with 100-mm tie spacing HSC was $63 \mathrm{~mm}$. Similarly, the ultimate peak displacements were $20 \mathrm{~mm}$ and $30 \mathrm{~mm}$ for NSC columns with $400-\mathrm{mm}$ tie spacing and $100-\mathrm{mm}$ tie spacing respectively. This means, there was more room for the 100 -mm tie spacing columns to deflect relative to the 400 mm tie spacing.

Ngo et al. (2007) concluded that ductile reinforcement and strength of concrete significantly improve the performance of structures under severe load conditions.

\subsection{Motivation for Research}

The reviewed literature shows a significant amount of numerical work investigating the effects of blast loading on reinforced concrete structures. However, experimental work involving live explosion testing is limited.

Many researchers (Elsanadedy et al., (2010); Bao and Li (2010); Luccioni et al., (2010); Ngo et al., (2007); Wu et al., (2011)) have investigated the response of reinforced concrete columns to blast loading, in general, using high fidelity physics based computer codes (LS-DYNA, AUTODYN, DYNA3D, CTH). Specifically, the effect of reinforcement detailing was investigated by Bao and Li (2010) and Ngo et al. (2007) while the effect of concrete strength on reinforced concrete column response was investigated by Ngo et al. (2007). Elsanadedy et al. (2010) modelled CFRP retrofitted columns and reported improved blast resistance. 
Only a few researchers (Baylot and Bevins, (2007); Carriere at al., (2009)) have carried out both numerical and experimental investigations. Baylot and Bevins (2007) investigated the effect of masonry infilled walls on columns subjected to blast loadings. Carriere et al. (2009) on the other hand conducted a far-range numerical and experimental work to investigate the effects of steel reinforced polymer (SRP) wrap on beams and beam-columns under blast load.

While the various research works contribute significantly to the understanding of response of reinforced concrete columns to blast loading, they present numerical simulations that have not been thoroughly validated with experimental testing; at least not in close-in range.

An experimental program involving live explosive testing was therefore designed to investigate the explosive effects of reinforced concrete columns within close-range. Particularly, the effects of transverse reinforcement detailing and axial load ratio on the columns to address the gaps in research that currently exist. The succeeding chapters present the experimental program and testing, as well as analysis and discussions of the test results. The cardinal conclusions from the research program are also presented. 


\section{Chapter: Experimental Program}

\subsection{General}

The experimental program was designed to investigate the explosion effects on

reinforced concrete columns in the near field, for scaled distances, $z \leq 1 \mathrm{~m} / \mathrm{kg}^{1 / 3}$. A total of twenty (20) columns were built, of which, sixteen (16) were subjected to close-range explosion testing at the Canadian Forces Base (CFB), Petawawa, while four (4) were designated for static testing in the structures laboratory at Carleton University. Two reaction structures were also built to support the columns during testing. These reaction structures provided the end support conditions for the columns. The end conditions were designed to simulate fixed support conditions. The columns and the support structures were designed in accordance with Canadian standard for design of concrete structures (CSA 2004). The columns were designed with different reinforcement detailing representative of columns designed for predominantly gravity loading and columns forming part of a structures' lateral load resisting system. The primary objective of the test program was the investigation of the response of reinforced concrete columns under close-in blast loading. More specifically the effect of axial loading, transverse reinforcement detailing, and the confining effects of the transverse reinforcement were of interest.

\subsection{Design and Construction of the Reaction Structures}

The reaction (support) structures were designed to support the test specimen during the explosion tests and to be robust enough to survive several exposures to blast loading from close-in standoff distances. The reaction structures provided fixity at the top of the columns while restraining the bottom from translation. The design of the support 
structure presented a number of challenges. Firstly, the structure could not be built on site. Thus, the solution was to build it in the structures laboratory and transport to the site. Secondly, excavation on the test site could be cost prohibitive, thus the support structure could not be founded to prevent sliding during testing. To overcome these challenges, the support structure was designed as a modular structure, each consisting of eight separate sections. The mass of the sections was limited to the capacity of a mobile crane rented to assemble the structures.

The support structure was modelled as a cantilever wall (Figure 3-1) and designed against overturning and sliding while limiting flexural stresses in the support structure. The support structure had a "V" cross-section with an outrigger over the top to support the top end of the column at a distance of $1.50 \mathrm{~m}$ to minimize reflections off the walls loading the rear face of the columns. The fixity at the top support of the column was afforded by two steel brackets bolted to steel plates cast into the face of the concrete outrigger on the support (see Figure 3-3b). The bottom end of the column was cast together with $700 \times$ $700 \mathrm{~mm}$ by $300 \mathrm{~mm}$ deep footings. As the footings could not be founded into the ground, they were braced back to the support structure to prevent sliding under the action of blast loading. (Figure 3-3b).

The sections of one support structure was assembled in the structures laboratory of Carleton University while the sections of the other support structure was assembled on site. Figure 3-3a shows the components of support structure been assembled while Figure 3-3b presents the assembled support structure with column. The assembled support structures were each post-tensioned using $6 \times 35$-mm diameter DYWIDAG Threadbars to give requisite capacity to resist the blast loading (Figure 3-2). Each DYWIDAG 
Threadbar was stressed to $527.5 \mathrm{kN}$ resulting in a precompression of $3.20 \mathrm{MPa}$ in the support structure. Ancillary testing on concrete cylinders cast with the support structures gave a 28-day compressive strength of $80.3 \mathrm{MPa}$.

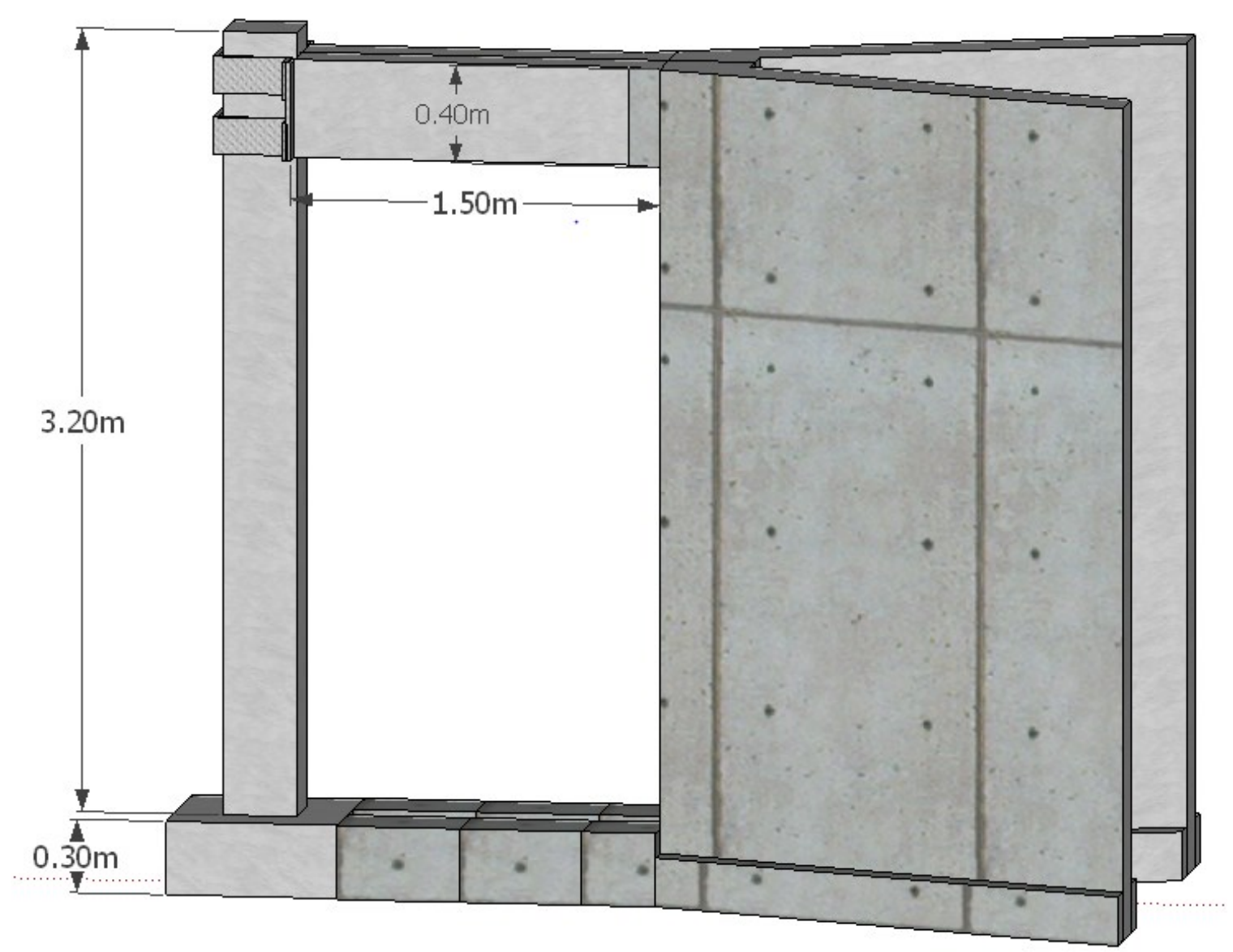

Figure 3-1: A modeled support structure with column affixed 


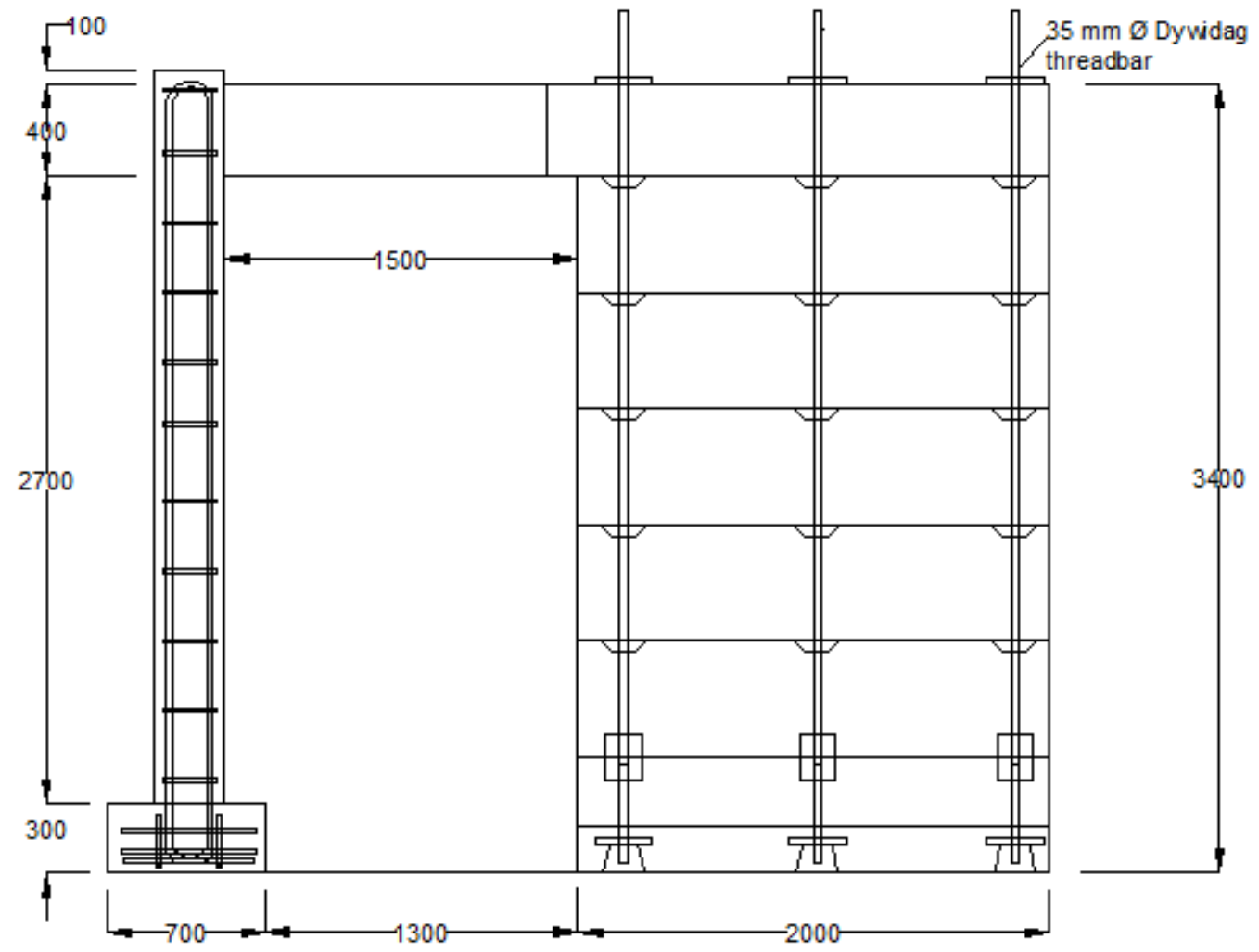

Figure 3-2: Elevation of support structure with column affixed

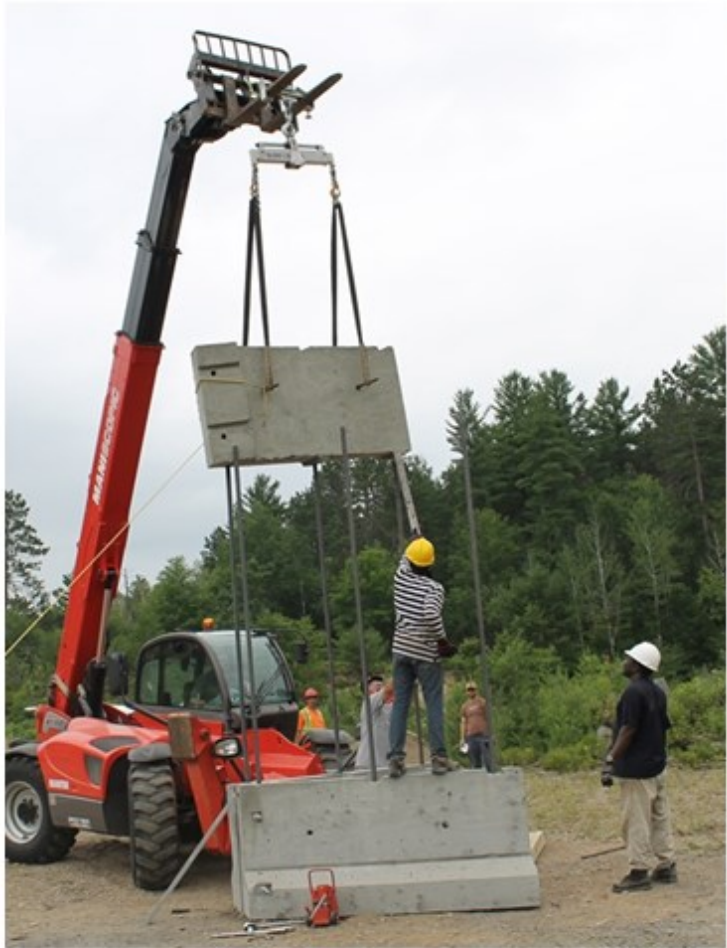

(a)

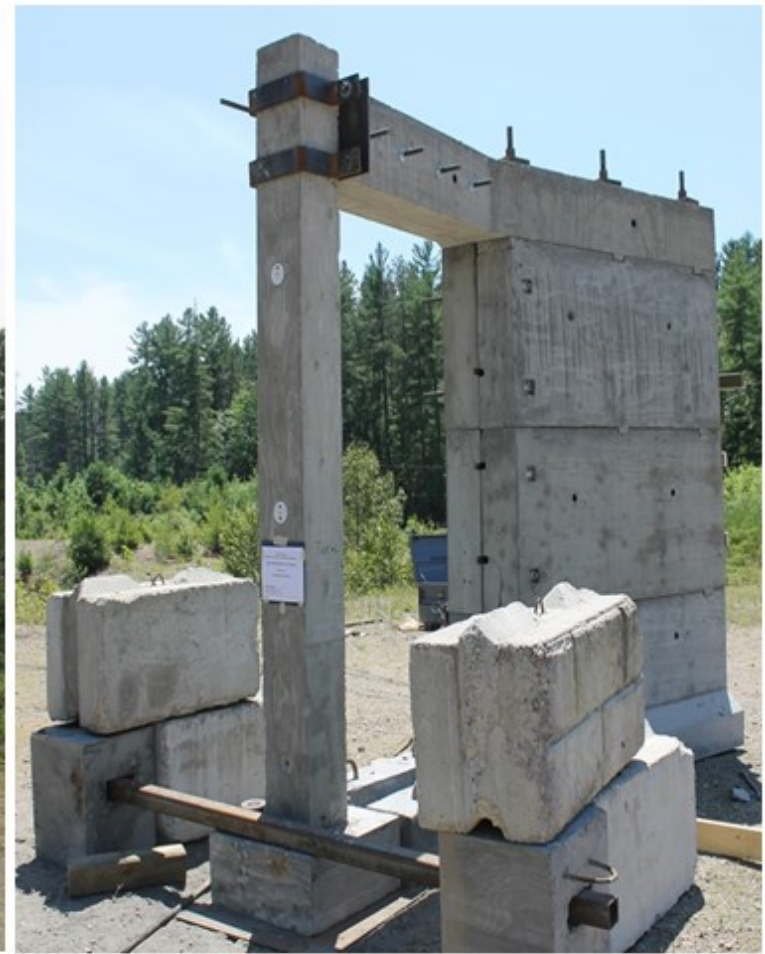

(b)

Figure 3-3: Support structure (a) components being assembled (b) assembled with column affixed 


\subsubsection{Formwork of Reaction Structure}

A reusable formwork was built for the purpose of constructing the support structure. Considering the height of the support structure $(3.4 \mathrm{~m})$, the formwork was divided into a four (4) paired sections, resulting in eight components for each support structure. The paired sections were designed and built to have "V" and "Y" shapes. These shapes, cast in pairs, made it easier to assemble the components. 19-mm thick plywood was cut to appropriate shapes and sizes and assembled using 51-mm screws and a hand drill. $38 \times 89$ mm wood studs were also cut to size with a circular saw and used to brace the 19-mm thick plywood. The prepared formwork was oiled and the reinforcement cages placed in them before the concrete was poured (Figure 3-4 and 3-5).

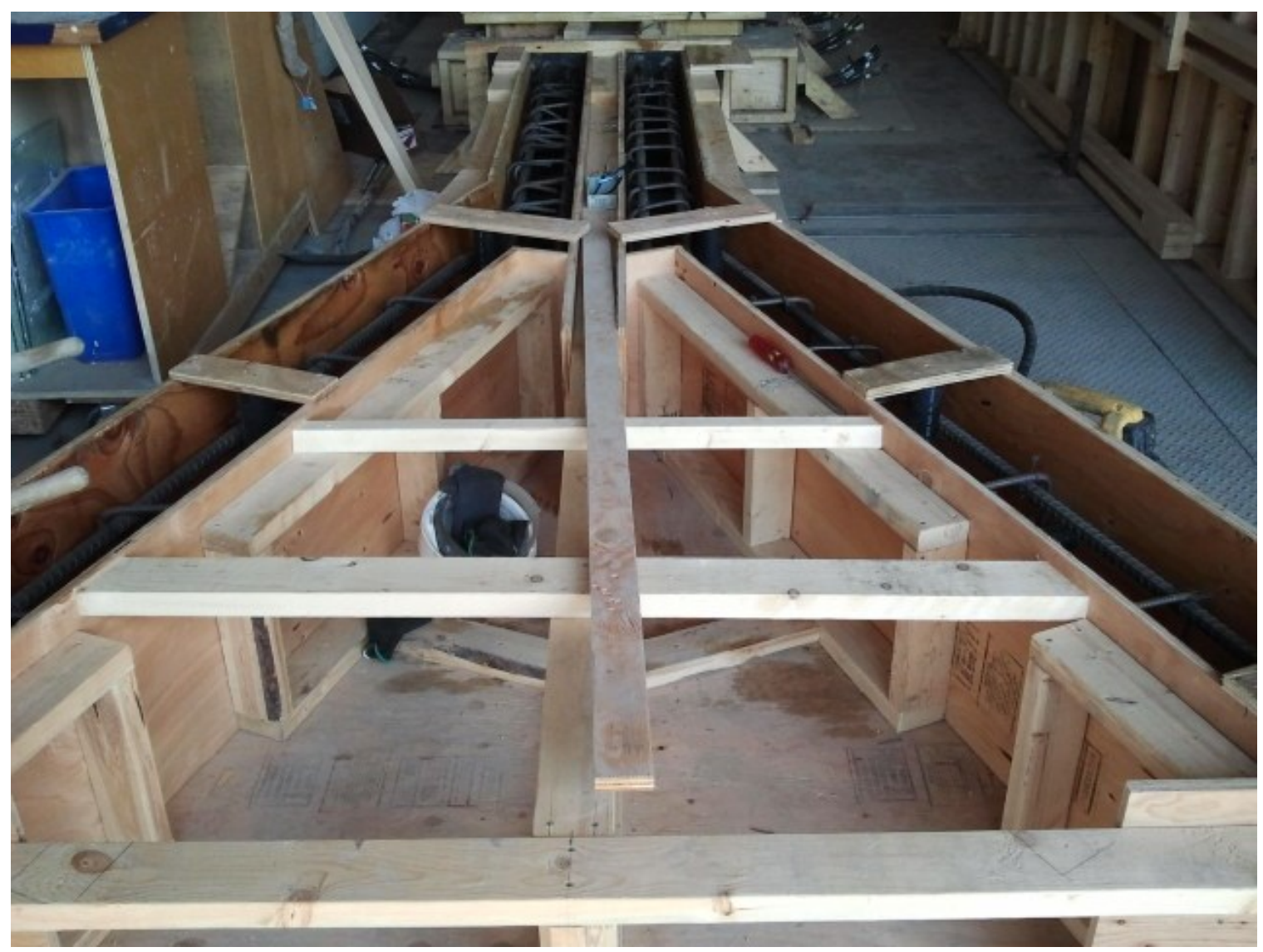

Figure 3-4: Formwork of support structure's cantilevered Y-section 


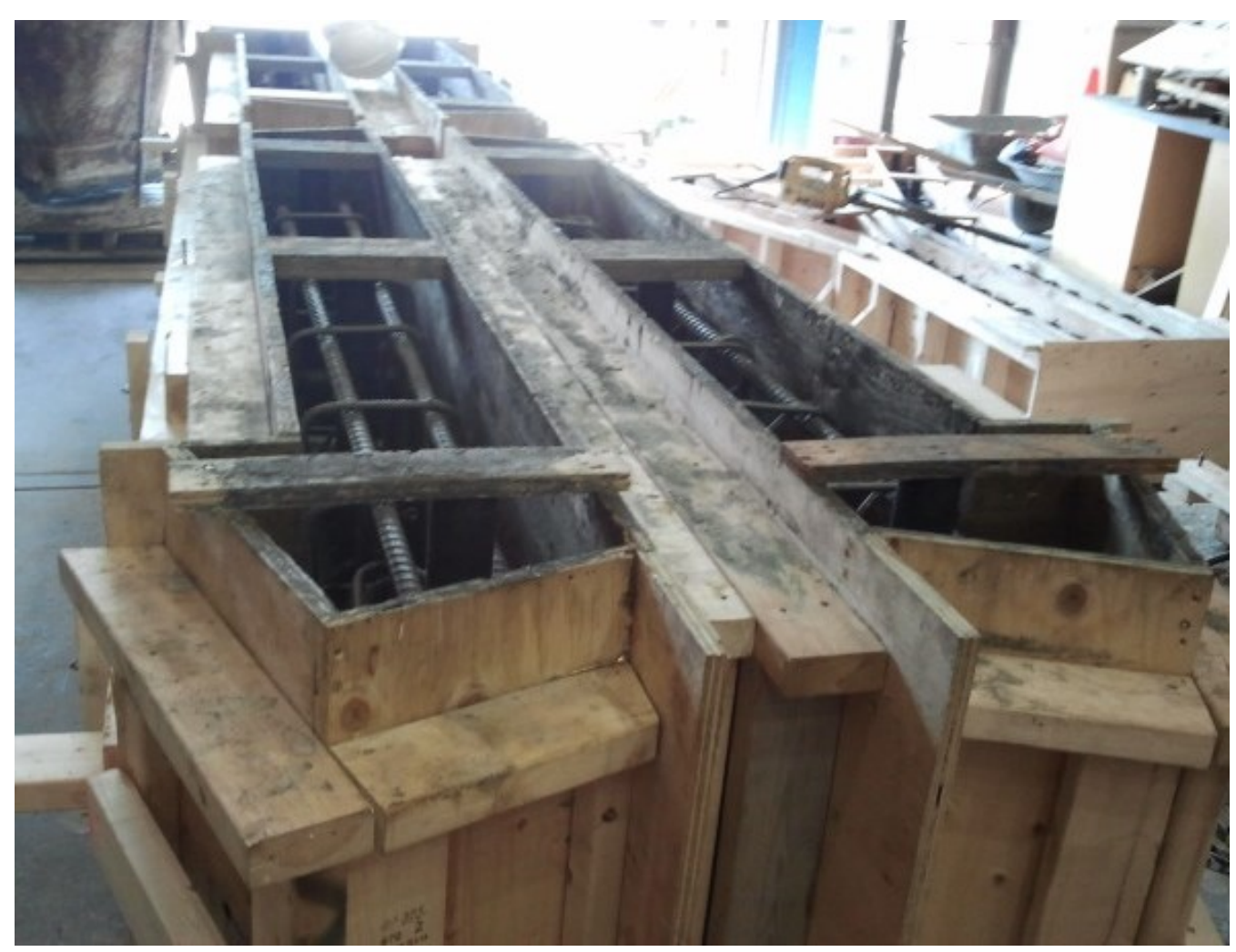

Figure 3-5: Components of support structure's formwork

\subsubsection{Casting and Curing of Reaction Structure}

Casting of the various components for one reaction structure was completed before the second was cast after initial curing and removal of forms from the first. Concrete was poured into form of the various components using the hopper and the extensions on the chute of the concrete truck. A poker vibrator was used to ensure that the concrete pour is even, free from air bubbles as well as distribute aggregate uniformly to all edges and corners of the formwork (Figure 3-6). The concrete was covered with wet burlap and plastic sheating, 8 hours after casting, and wetted daily in accordance with ASTM C192/C192M-07. Forms were subsequently removed after 3 days in accordance with ASTM C192/C192M-07, and reassembled for the second support structure, while the burlap was kept in place and continued to be wetted daily. Five concrete cylinders were prepared in accordance with ASTM C192/C192M-07, to obtain the strength 
characteristics of the concrete. The components of the support structures were assembled using cranes and prestressed using a hydraulic jack. One of the support structures was assembled in the structures laboratory of Carleton University and transported to the site (Canadian Forces Base, Petawawa) while the second was assembled on site. Figure 3-7 shows the assembled support structure and components of other support structure ready to be transported to site.

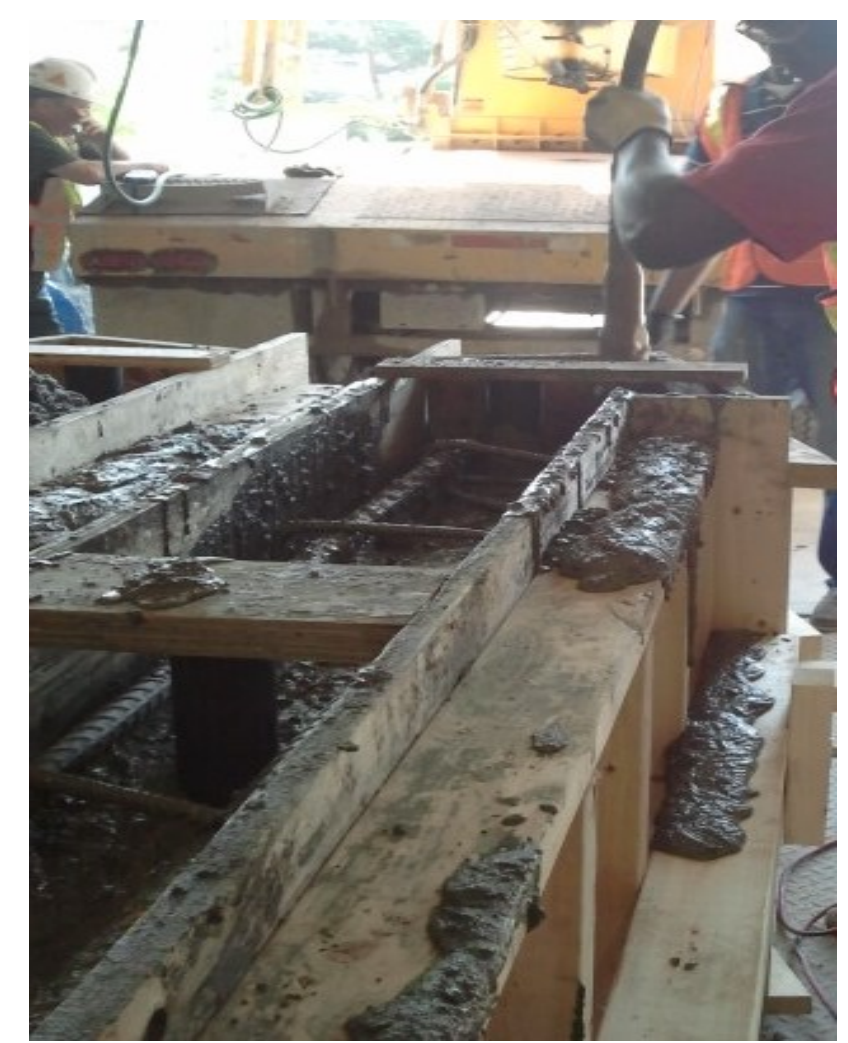

Figure 3-6: vibration of support structure concrete during casting 


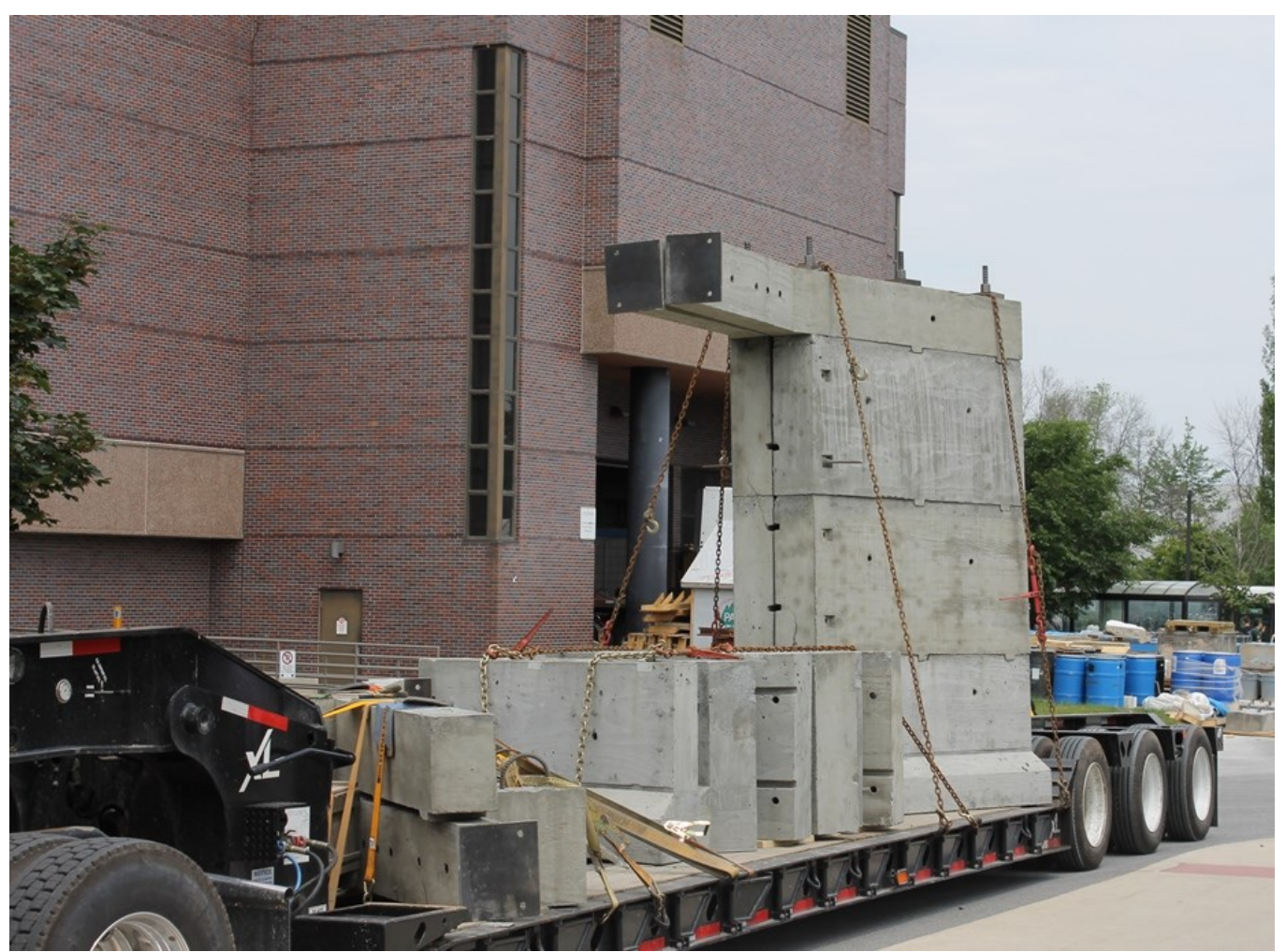

Figure 3-7: Transport of support structure to site

\subsection{Design and Description of Test Columns}

Table 3-1 shows the column designation, tie spacing, column type and axial load ratio (ALR). Twenty (20) reinforced concrete columns, designed in accordance with CAN/CSA-A23.3-04 (CSA 2004), were constructed for the experimental program. Sixteen (16) of the twenty (20) columns were taken to the Canadian Forces Base (CFB) at Petawawa for live explosion testing, while four columns (CONV-16, CONV-17, SEIS18 and SEIS-19) remained in the structures laboratory of Carleton University for static testing. The four columns designated for static testing and the columns from the explosion testing that did not experience significant failure formed part of a residual capacity test program and are not discussed further in this thesis.

The reinforced concrete columns were not specifically designed for axial loading. The $300 \times 300 \mathrm{~mm}$ columns were reinforced with $4-25 \mathrm{M}$ longitudinal reinforcement to give a 
longitudinal reinforcement ratio of 0.02 . Six of the columns were detailed to undergo lateral drifts in addition to resisting gravity loads (SEIS - \#), while ten columns were designed to resist predominantly gravity loads (CONV - \#) in accordance with CSAA23.3-04 (CSA 2004). Columns designation in Table 3-1 (CONV- \# and SEIS- \#) were detailed as per Figure 3-8(a) and Figure 3-8(b) respectively. Three of the Conventional columns (CONV-5, CONV-10, and CONV-15) were post-tensioned to $1027 \mathrm{kN}$ and yielded a compression of 11.4 MPa. The precompression gives an axial load ratio (ratio of applied axial load to axial capacity) of 0.32 on the columns; simulating columns in the lower stories of multi-story buildings.

The two principal ways that the conventional columns vary from the seismic columns is in their tie spacing and the location of the lap splices. The transverse reinforcement of the Conventional Columns was detailed in accordance with CSA A23.3-04 clause 7.6.5.2 (CSA 2004) for columns predominantly resisting gravity loads (Figure 3-8a). The tie spacing was $300 \mathrm{~mm}$ over the entire length (Figure 3-8a).The rebar splicing is located at the base of the columns. This rebar splicing is within the plastic hinge region of the columns. The lap length is $870 \mathrm{~mm}$ (Figure 3-8a).

The Seismic Columns were detailed in accordance with clause 21.7.2.2 (CSA 2004) for columns designed to undergo lateral drifts in addition to gravity loads although they do not form part of structures' lateral load resisting system. The Seismic term used is for designation purpose. The spacing of the ties was taken as $75 \mathrm{~mm}$ over $450 \mathrm{~mm}$ at each end of the column (Figure 3-8b) in accordance with clause 21.7.2.2.3; this clause ensures that the ends of the columns are properly confined. As the support conditions of the columns approximate fixed end conditions the spacing within the plastic hinge region 
also meets clause 21.7 .2 .2 .5 . Over the remainder of the column the tie spacing was taken to be $150 \mathrm{~mm}$ (Figure 3-8b) as per clause 21.7.2.1.3, this clause ensures that diagonal flexural crack must cross at least two ties. The rebar splicing is located at mid span of the column so as to ensure that the splice is well clear of the plastic hinge region of the column, this is in accordance with clause 21.4.3.2. The lap length is $980 \mathrm{~mm}$ (Figure 38). As all the columns were cast in two pours, the footing of each column contained bars with a $90^{\circ}$ hook embedded in the footing. The bar then extends beyond the footing to lap with vertical (longitudinal) bars of the column. However, the location of the lap splice within the column differs between the two column types (Conventional and Seismic Columns). Both the Conventional and Seismic Columns had a $300 \times 300 \mathrm{~mm}$ crosssection and a height of $3200 \mathrm{~mm}$. The concrete columns had a concrete cover of $40 \mathrm{~mm}$ to the ties.

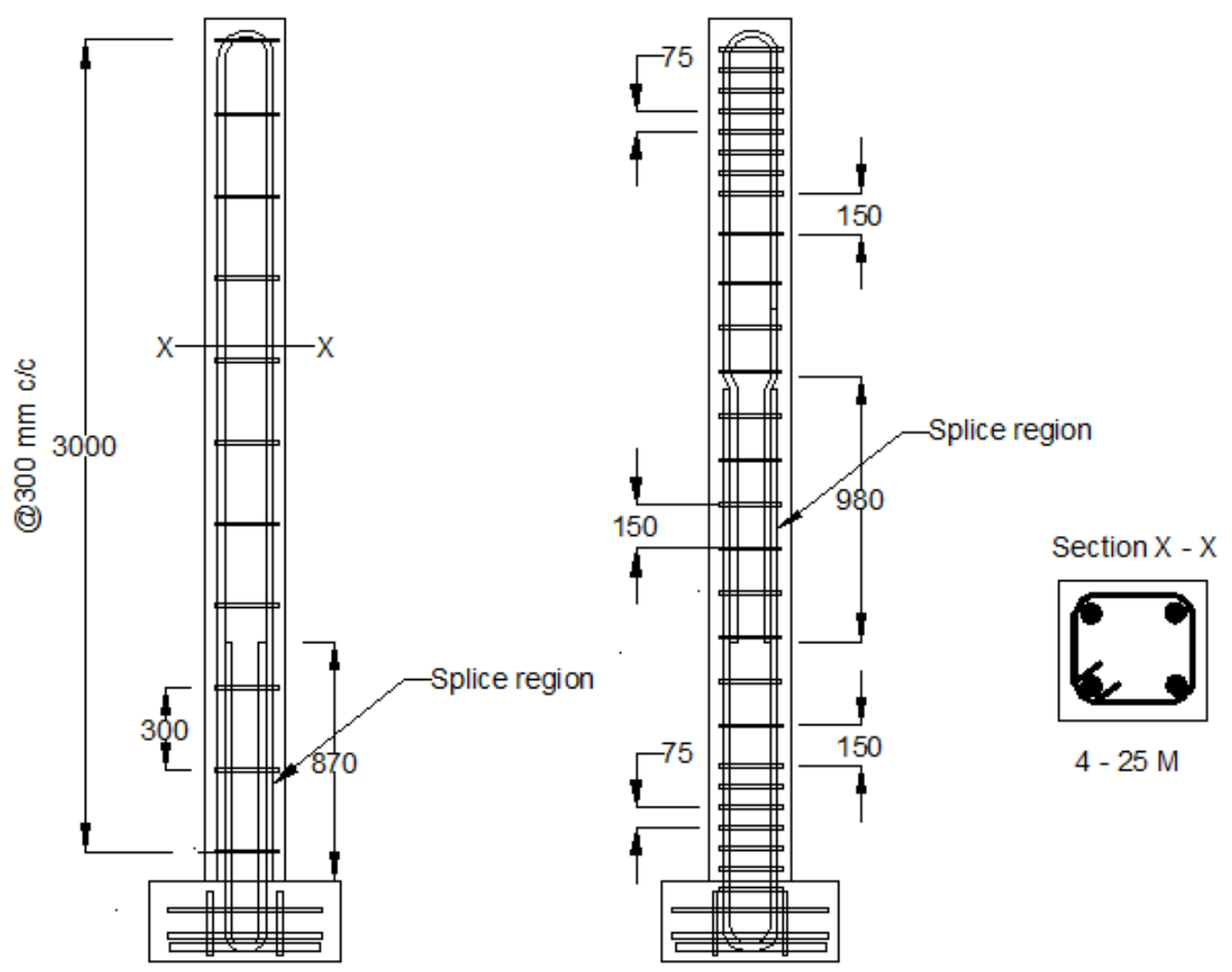

Figure 3-8: (a) Conventional column detailing (b) Seismic column detailing 
Table 3-1: Columns nomenclature, tie spacing and axial load ratio details

\begin{tabular}{|c|c|c|c|c|}
\hline $\begin{array}{c}\text { Column } \\
\text { Designation }\end{array}$ & $\begin{array}{c}\text { Tie } \\
\text { spacing } \\
(\mathrm{mm})\end{array}$ & $\begin{array}{c}\text { Lap } \\
\text { splice } \\
(\mathrm{mm})\end{array}$ & ALR & Column Type \\
\hline CONV-1 & 300 & 870 & 0 & Conventional \\
\hline CONV-2 & 300 & 870 & 0 & Conventional \\
\hline SEIS-3 & 75 & 980 & 0 & Seismic \\
\hline SEIS-4 & 75 & 980 & 0 & Seismic \\
\hline CONV-5 & 300 & 870 & 0.32 & Prestressed \\
\hline CONV-6 & 300 & 870 & 0 & Conventional \\
\hline CONV-7 & 300 & 870 & 0 & Conventional \\
\hline SEIS-8 & 75 & 980 & 0 & Seismic \\
\hline SEIS-9 & 75 & 980 & 0 & Seismic \\
\hline CONV-10 & 300 & 870 & 0.32 & Prestressed \\
\hline CONV-11 & 300 & 870 & 0 & Conventional \\
\hline CONV-12 & 300 & 870 & 0 & Conventional \\
\hline SEIS-13 & 75 & 980 & 0 & Seismic \\
\hline SEIS-14 & 75 & 980 & 0 & Seismic \\
\hline CONV-15 & 300 & 870 & 0.32 & Prestressed \\
\hline CONV-16 & 300 & 870 & 0 & Conventional \\
\hline CONV-17 & 300 & 870 & 0 & Conventional \\
\hline SEIS-18 & 75 & 980 & 0 & Seismic \\
\hline SEIS-19 & 75 & 980 & 0 & Seismic \\
\hline CONV-20 & 300 & 870 & 0 & Conventional \\
\hline
\end{tabular}

\subsection{Material Properties and Testing}

\subsubsection{Concrete}

All the reinforced concrete columns were cast from the same concrete mix. A 28-day concrete compressive strength of $35 \mathrm{MPa}$ was specified and a local concrete supplier designed the mix and supplied the concrete. The concrete mix had a limestone aggregate size of $10 \mathrm{~mm}$. A slump test was performed in accordance with ASTM C143/C143M and was found to be $110 \mathrm{~mm}$ (Figure 3-9). Twelve (12) $100 \times 200 \mathrm{~mm}$ concrete cylinders were prepared in accordance with ASTM C39/C39M-12a, and five (5) of these cylinders were tested on the twenty-eighth (28) day (Figure 3-10 and 3-11) to determine the compressive strength. The average compressive strength obtained for the column concrete mix was 41.3 MPa. Table 3-2 shows the results of the concrete compressive 
tests for the reinforced concrete columns. Similarly, two $100 \times 200 \mathrm{~mm}$ concrete cylinders from the concrete mix of the support structure were prepared and tested in accordance with ASTM C39/C39M-12a. The average twenty-eight (28) day strength obtained was 80.3 MPa. Table 3-3 presents the results of the concrete compressive strength test for the support structure.

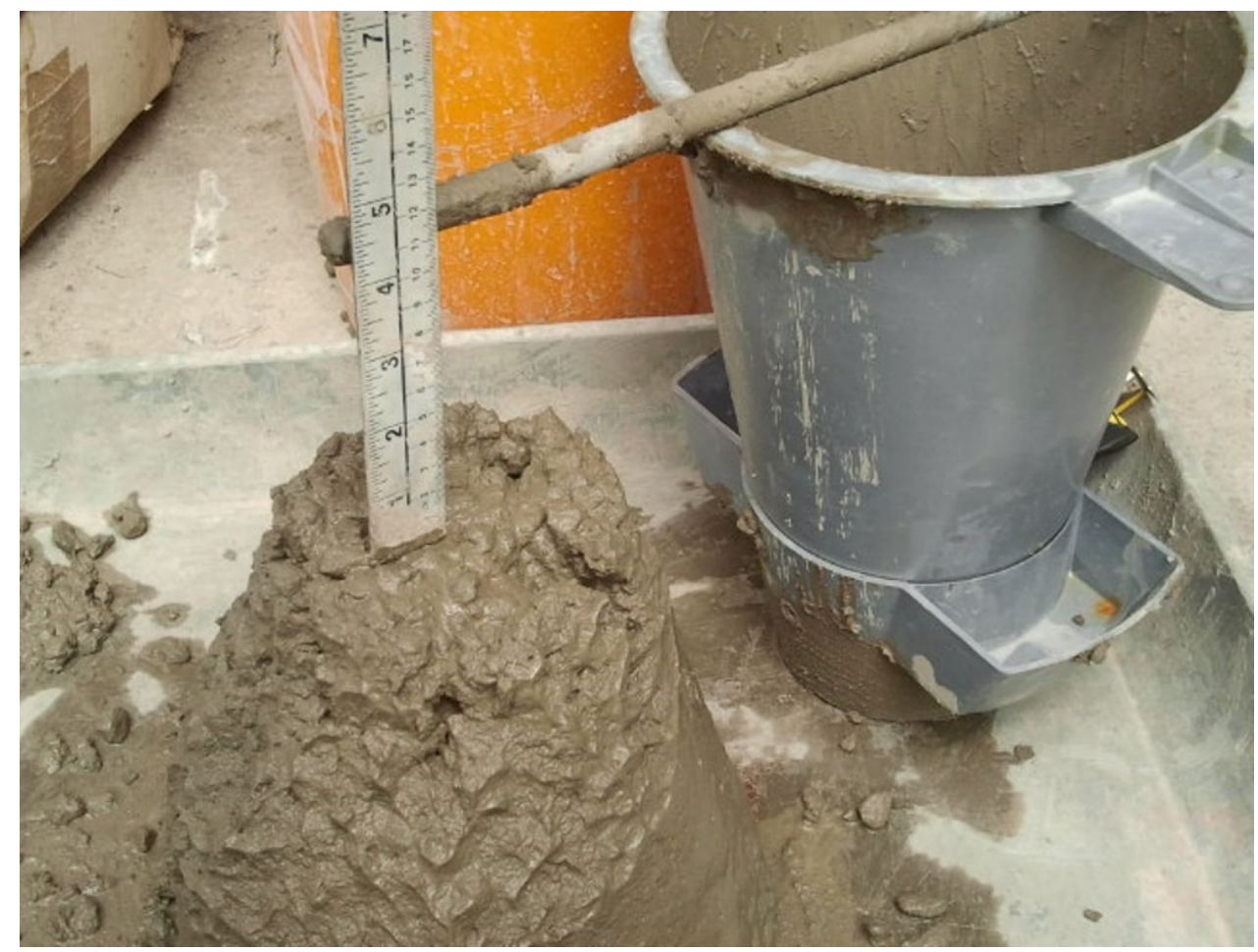

Figure 3-9: Slump test of concrete mix

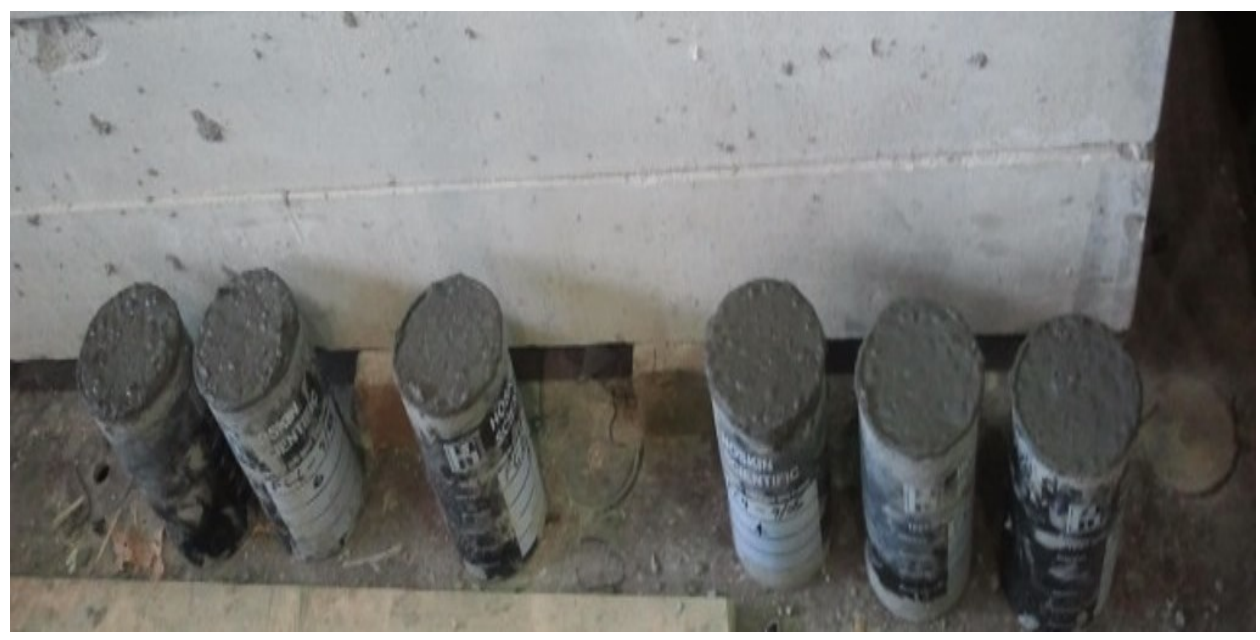

Figure 3-10: Sample of concrete cylinders 


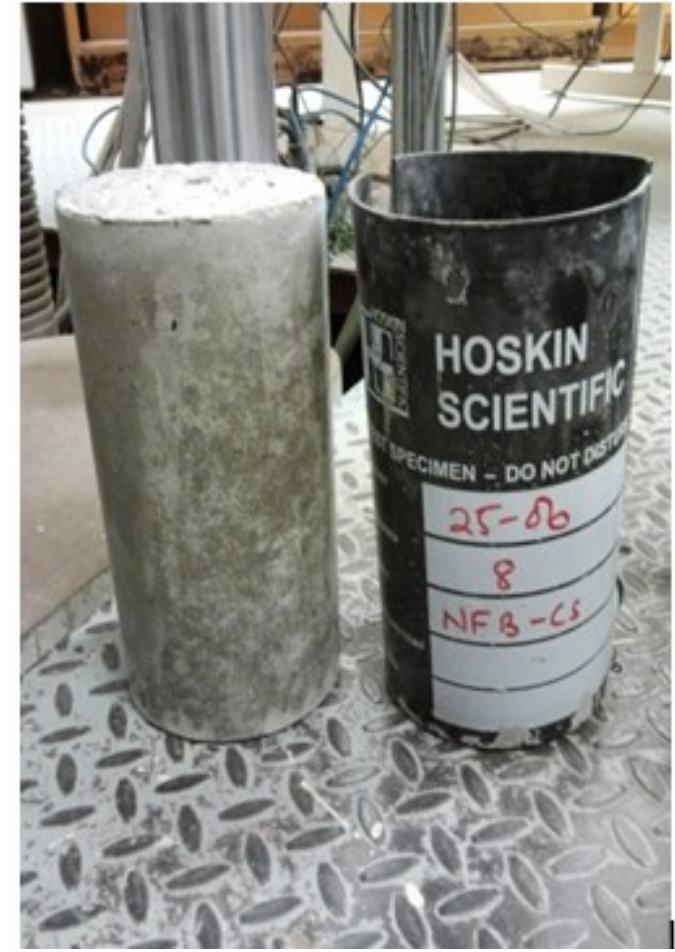

(a)

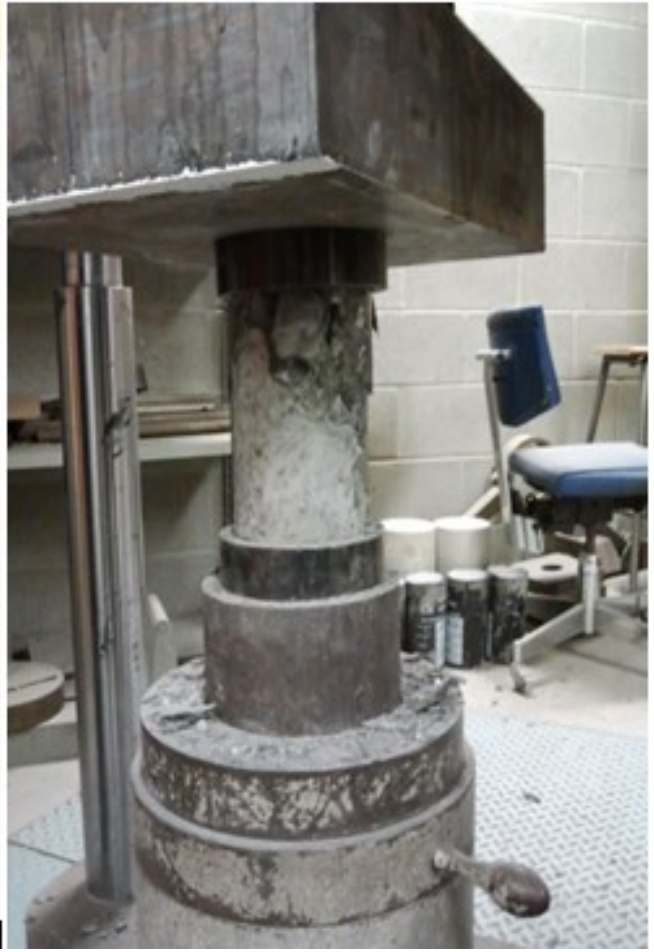

(b)

Figure 3-11: a. A typical sample of one of the concrete cylinders and b. Concrete cylinder under compression test

Table 3-2: Compressive test results from column concrete

\begin{tabular}{|c|c|c|c|}
\hline Test No. & $\begin{array}{c}\text { Failure Load } \\
\left(\times 10^{3} \mathrm{~N}\right)\end{array}$ & Area $\left(\mathrm{mm}^{2}\right)$ & Strength $(\mathrm{MPa})$ \\
\hline 1 & 307.9 & 7855 & 39.20 \\
\hline 2 & 337.9 & 7855 & 43.02 \\
\hline 3 & 321.7 & 7855 & 40.96 \\
\hline 4 & 329.5 & 7855 & 41.94 \\
\hline 5 & 324.9 & 7855 & 41.36 \\
\hline Average & $\mathbf{3 2 4 . 4}$ & $\mathbf{7 8 5 5}$ & $\mathbf{4 1 . 3}$ \\
\hline
\end{tabular}


Table 3-3: Compressive test results from reaction structure concrete

\begin{tabular}{|c|c|c|c|}
\hline Test No. & $\begin{array}{c}\text { Failure Load } \\
\left(\times 10^{3} \mathrm{~N}\right)\end{array}$ & Area $\left(\mathrm{mm}^{2}\right)$ & Strength (MPa) \\
\hline 1 & 643.5 & 7855 & 81.92 \\
\hline 2 & 618.3 & 7855 & 78.72 \\
\hline Average & $\mathbf{6 3 0 . 9}$ & $\mathbf{7 8 5 5}$ & $\mathbf{8 0 . 3}$ \\
\hline
\end{tabular}

\subsubsection{Steel Reinforcement}

Tension test specimens were sampled from the longitudinal and transverse steel reinforcement $(25 \mathrm{M}$ and $10 \mathrm{M})$, used in constructing the reinforced concrete columns and support structures, and tested in accordance with ASTM E8/E8M-09 in an Instron testing machine (Figure 3-12). The yield strength obtained from the 10M (11.3 mm diameter) transverse reinforcement test was $465.2 \mathrm{MPa}$ at a yield strain of 0.0022 . The yield strength obtained from the $25 \mathrm{M}$ (19.5 mm diameter) longitudinal steel reinforcement test was 474.4 MPa at a yield strain of 0.0024. Table 3-4 and Table 3-5 show the strengths (yield and ultimate) and the strain values of the transverse and longitudinal steel reinforcements, respectively. Figure 3-13 presents a typical stress-strain curve for 10M rebar, and Figure 3-14 presents a typical stress-strain curve for test 25M rebar. 


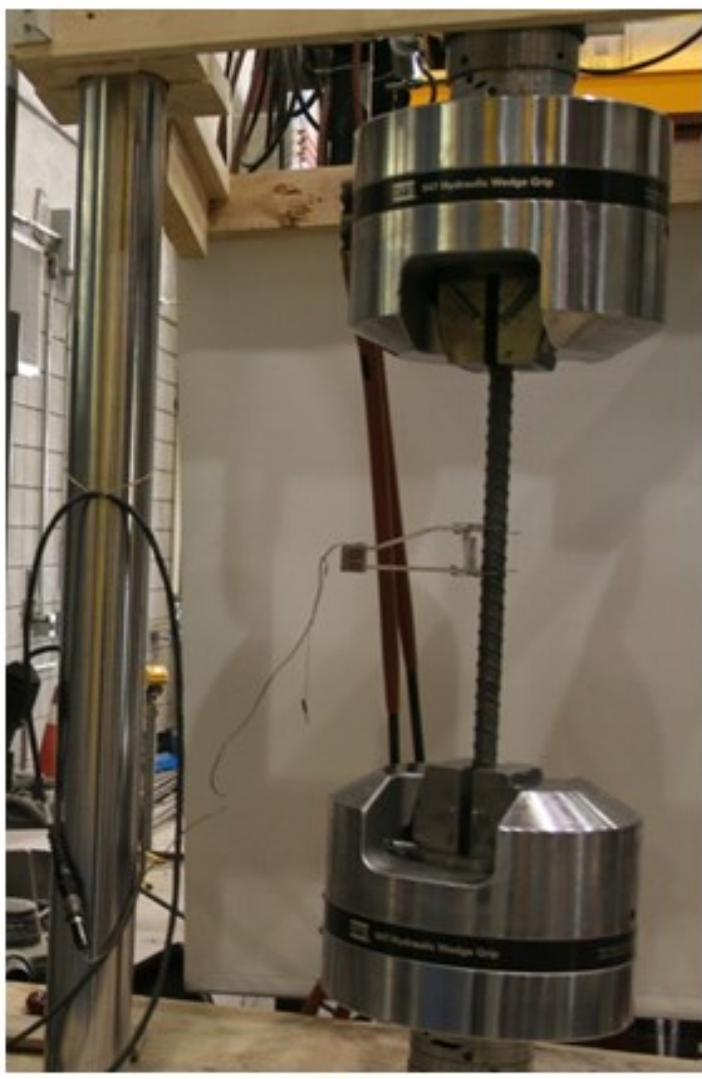

(a)

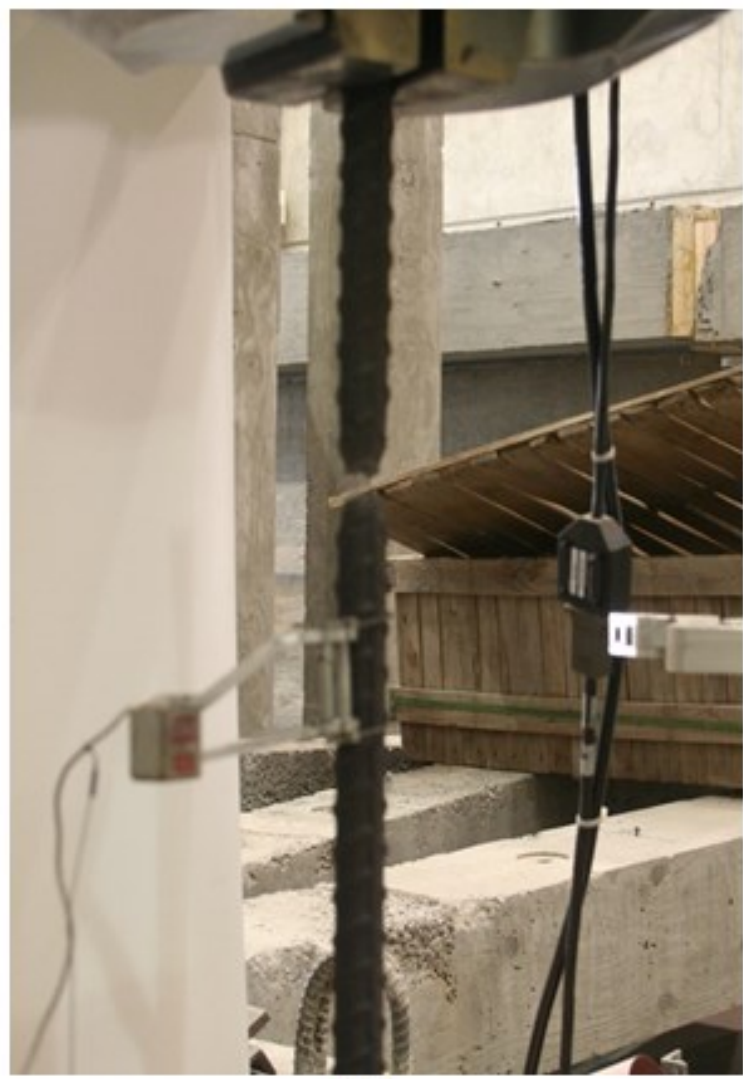

(b)

Figure 3-12: Tension test for $25 \mathrm{M}$ rebar (a) before necking (b) after necking

Table 3-4: Tension test results for 10M rebar

\begin{tabular}{|c|c|c|c|c|c|}
\hline Test No. & Rebar size & $\begin{array}{c}\text { Yield } \\
\text { strength } \\
(\mathrm{MPa})\end{array}$ & $\begin{array}{c}\text { Yield strain } \\
(\mathrm{mm} / \mathrm{mm})\end{array}$ & $\begin{array}{c}\text { Ultimate } \\
\text { strength } \\
(\mathrm{MPa})\end{array}$ & $\begin{array}{c}\text { Ultimate } \\
\text { strain } \\
(\mathrm{mm} / \mathrm{mm})\end{array}$ \\
\hline 1 & $10 \mathrm{M}$ & 465.3 & 0.0024 & 731.3 & 0.11 \\
\hline 2 & $10 \mathrm{M}$ & 465.1 & 0.002 & 731.0 & 0.11 \\
\hline Average & & $\mathbf{4 6 5 . 2}$ & $\mathbf{0 . 0 0 2 2}$ & $\mathbf{7 3 1 . 1}$ & $\mathbf{0 . 1 1}$ \\
\hline
\end{tabular}




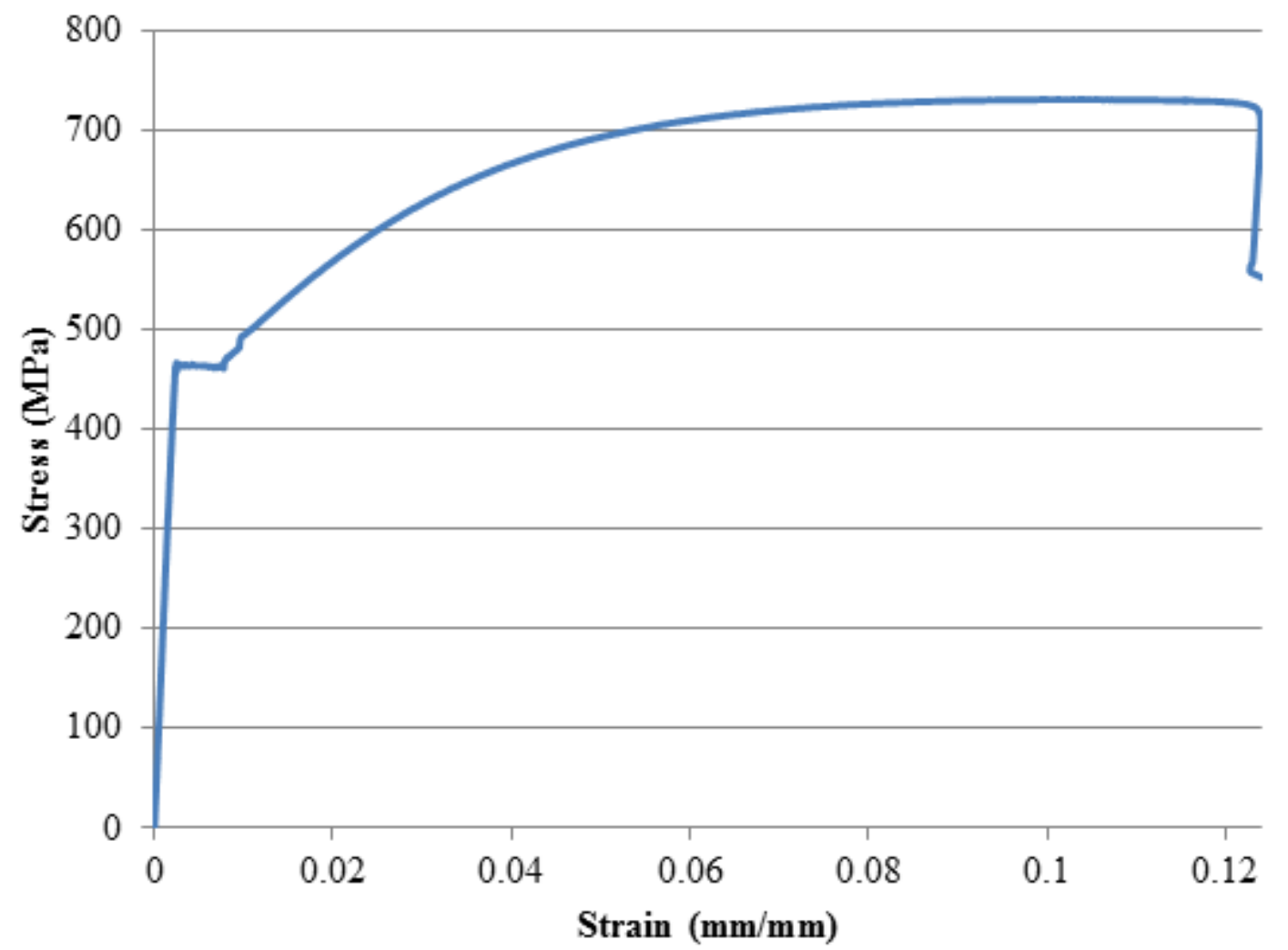

Figure 3-13: Typical stress-strain curve for $10 \mathrm{M}$ rebar

Table 3-5: Tension test results for 25M rebar

\begin{tabular}{|c|c|c|c|c|c|}
\hline Test No. & Rebar size & $\begin{array}{c}\text { Yield } \\
\text { strength } \\
(\mathrm{MPa})\end{array}$ & $\begin{array}{c}\text { Yield strain } \\
(\mathrm{mm} / \mathrm{mm})\end{array}$ & $\begin{array}{c}\text { Ultimate } \\
\text { strength } \\
(\mathrm{MPa})\end{array}$ & $\begin{array}{c}\text { Ultimate } \\
\text { strain } \\
(\mathrm{mm} / \mathrm{mm})\end{array}$ \\
\hline 1 & $25 \mathrm{M}$ & 474.7 & 0.0026 & 672.1 & 0.12 \\
\hline 2 & $25 \mathrm{M}$ & 465.2 & 0.0024 & 675.3 & 0.11 \\
\hline 3 & $25 \mathrm{M}$ & 484.1 & 0.0023 & 672.3 & 0.11 \\
\hline Average & & $\mathbf{4 7 4 . 7}$ & $\mathbf{0 . 0 0 2 4}$ & $\mathbf{6 7 3 . 2}$ & $\mathbf{0 . 1 1}$ \\
\hline
\end{tabular}




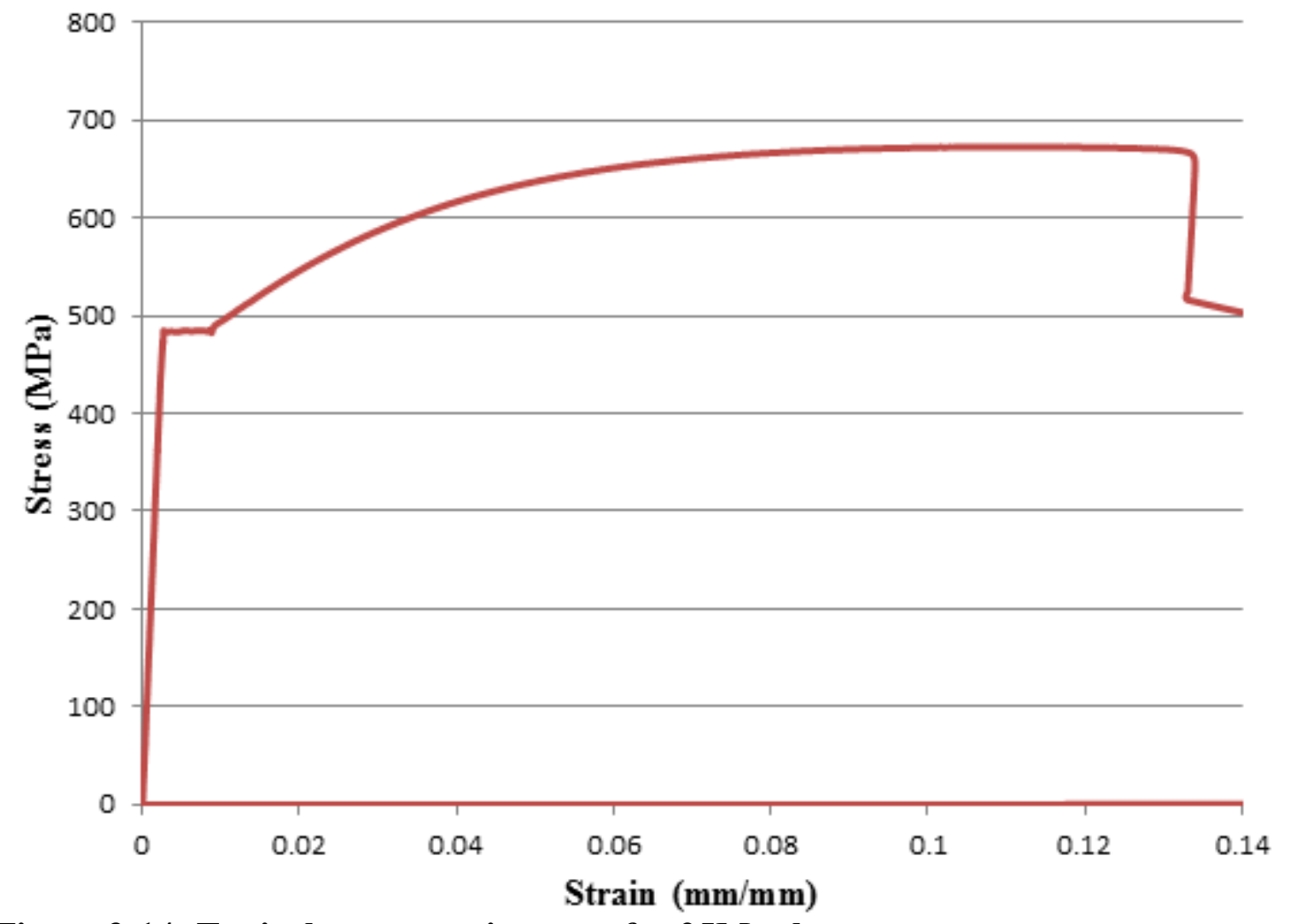

Figure 3-14: Typical stress-strain curve for 25M rebar

\subsection{Construction of test specimens}

The test specimens were constructed in stages at the structures laboratory at Carleton University. These stages included assembly of reinforcement cages, strain gauge placement, construction of formwork and pouring of concrete. This section presents the construction of the specimens.

\subsubsection{Strain gauge placement}

The longitudinal reinforcement of each concrete column was strain gauged with 350-ohm resistance strain gauge (FLA-6-350-11) manufactured by Tokyo Sokki Kenkyujo Co. Ltd. Each column had eight strain gauges; six were placed on reinforcements in the front face (facing the centre of explosion) of the cage and two on the reinforcements at the back of the cage. The strain gauges on the front face were at bottom, mid-height, and top of the $25 \mathrm{M}$ reinforcement while on the rear face, they were placed at mid-height only. 
The dimensions to the locations of the strain gauges from the top of the footing are presented in Figure 3-15. The locations for strain gauge placement were ground with an electric grinder with a $115-\mathrm{mm}$ diameter disc to remove the deformations on the reinforcement and then ground smooth with a pneumatic grinder with a 50-mm diameter disc.

Once all strain gauge locations were ground smooth, a water-based acidic cleaner (MPrep Conditioner A) was used to thoroughly clean any dirt on the surface. This was followed by the use of an alkaline-based surface cleaner (M-Prep Neutralizer A) to further clean and neutralize the surface. After the surfaces were cleaned and dried, a bonding agent Z70, was applied to the surface. Cyanoacrylate adhesive was then applied to the back of the strain gauge and the gauge was placed on the cleaned surface of the steel rebar. Pressure was applied by using the thumb for about a minute to ensure that the strain gauge was well bonded to the rebar surface. The gauge leads were slightly lifted from the surface to ensure no contact between the lead and the surface. An electrical tape was wound around the rebar, under the leads, to electrically insulate the leads from the steel reinforcement. Prior to casting the concrete, the strain gauge were tested to ensure they were functioning properly.

The strain gauges were tested using a multimeter to check that the resistance readings from the gauges was $350 \Omega$. The leads from the strain gauges were lengthened to about $100 \mathrm{~m}$ to enable connection to the data acquisition system. 


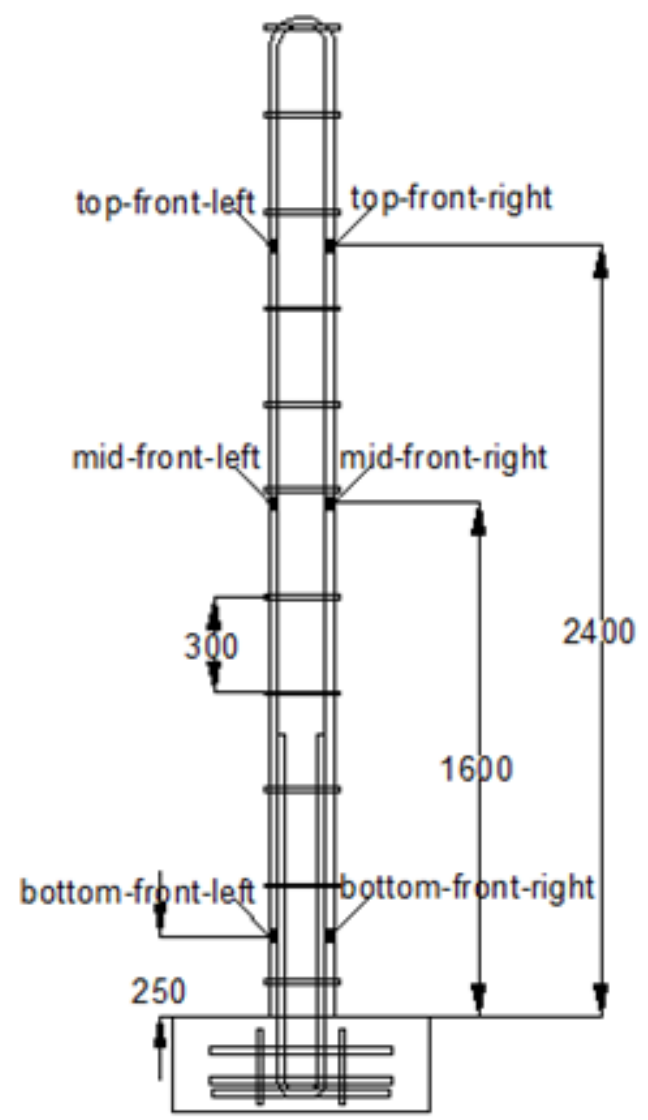

(a)

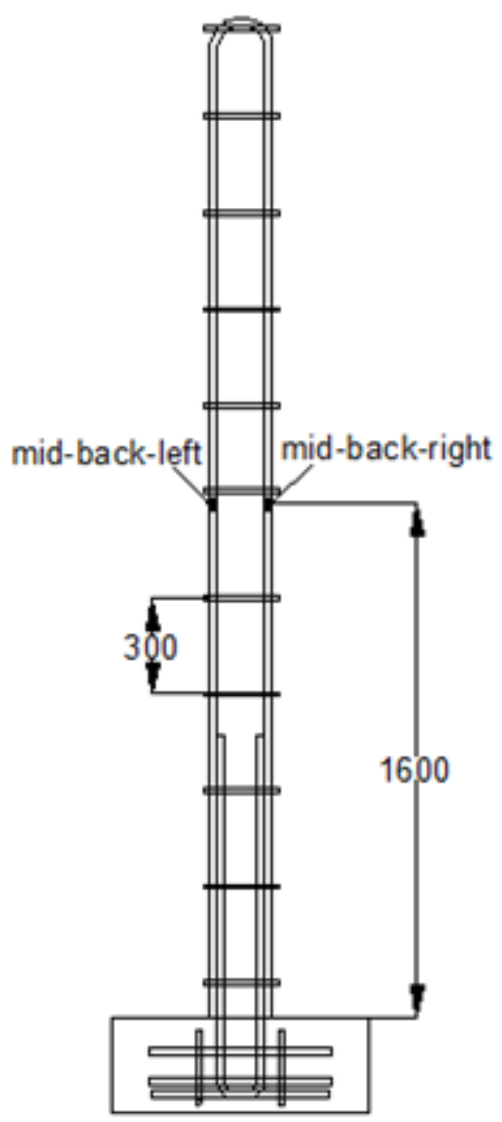

(b)

Figure 3-15: Strain gauge positions for both (a) frontal face and (b) rear face for a typical conventional cage

\subsubsection{Longitudinal and Transverse Reinforcement}

Longitudinal reinforcement for all columns consisted of four 25M (19.5 mm diameter) deformed rebars with a yield strength of $474.4 \mathrm{MPa}$ and a yield strain of $0.24 \%$. The longitudinal rebars were lapped either at the bottom or mid-height of the cage in accordance with Conventional and Seismic Column detailing requirements respectively. The longitudinal reinforcement in the conventionally detailed columns had a lap length of $870 \mathrm{~mm}$ from the top of the concrete footing (base of column) while the seismically detailed columns had a lap length $980 \mathrm{~mm}$ at the mid-height of the column. Each longitudinal rebar developed in the reinforced concrete footing ended in a $90^{\circ}$ hook with 
a development length of $400 \mathrm{~mm}$, while the longitudinal bars developed at the top of the column had a $180^{\circ}$ hook and development length of $180 \mathrm{~mm}$. 25M U-shaped rebars were also pre-formed and used for the reinforcement in the footings. Loop tie wires and a hand tying tool with a hook were used to fastened the longitudinal and transverse rebars together.

Transverse reinforcement used for all the columns consisted of 10M (11.3 mm diameter) deformed bars with a yield strength of $465.2 \mathrm{MPa}$ and a yield strain of $0.22 \%$. The transverse reinforcements were pre-fabricated and supplied by a local supplier. They had three 90-degree angles formed in three corners and a two 135-degree angles formed at the ends to get a either a square or a rectangular stirrups. These stirrups were placed around the longitudinal rebars at specified spacing and were fastened to the longitudinal rebars using loop tie wires and a tying tool.

\subsubsection{Formwork}

The formwork for the columns were constructed in the structures laboratory of Carleton University. This section highlights how the formworks for the column specimens were constructed.

\subsubsection{Columns}

A total of twenty (20) rectangular column forms $(300 \times 300 \mathrm{~mm}$ by $3.2 \mathrm{~m}$ high) and column-footing forms $(700 \times 700 \mathrm{~mm}$ by $300 \mathrm{~mm}$ deep) were built. The footings were constructed first, by cutting 19-mm thick plywood into rectangular shapes. The rectangular shapes were in dimensions of $1460 \times 300 \mathrm{~mm}, 2180 \times 300 \mathrm{~mm}$, and $700 \times 300$ mm. 51-mm screws were used with the aid of an electrical hand drill to assemble the rectangular plywood to form $700 \times 700 \mathrm{~mm}$ by $300 \mathrm{~mm}$ deep forms. $38 \times 89 \mathrm{~mm}$ wood 
studs were cut into appropriate lengths and used to brace the forms and help increase the stiffness of the footing formwork. The formwork was oiled and reinforcement cages placed in them before the concrete was poured. The form oil was to ensure that the formwork is easily removed after the concrete had cured. Figure 3-16 shows the plan of the footing formwork, while Figure 3-17 shows a photograph of the footing formwork with cages placed in them.

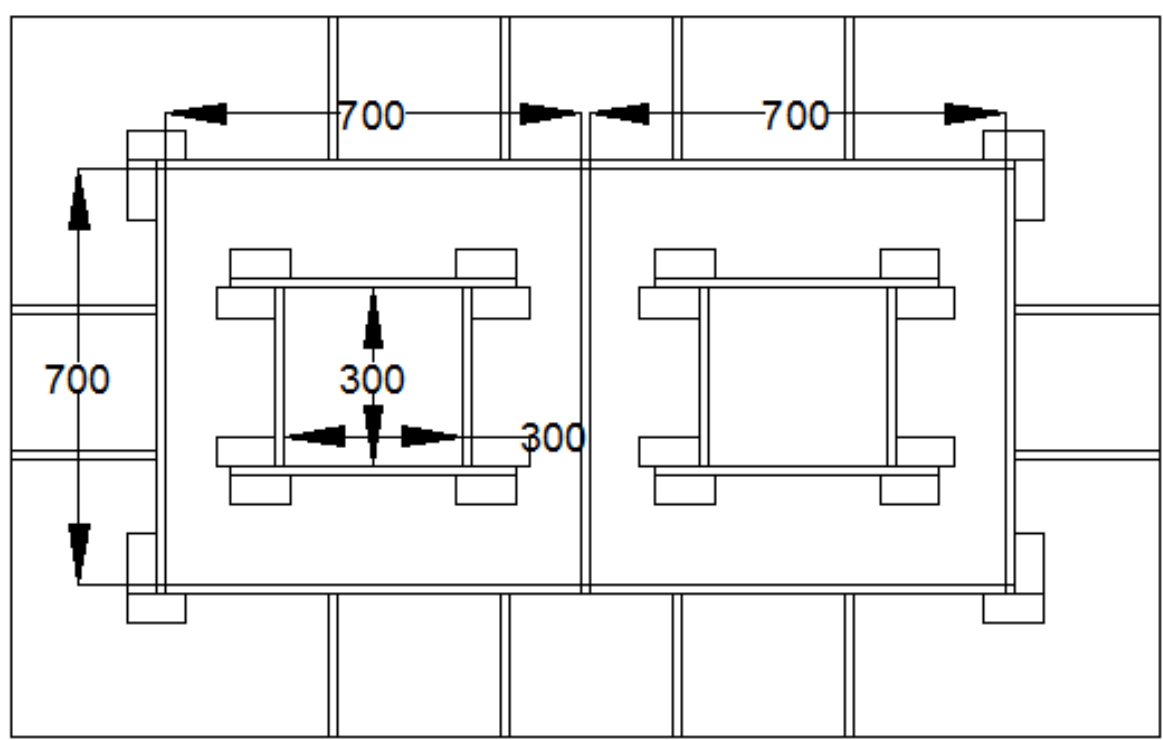

Figure 3-16: Plan of Column footing formwork 


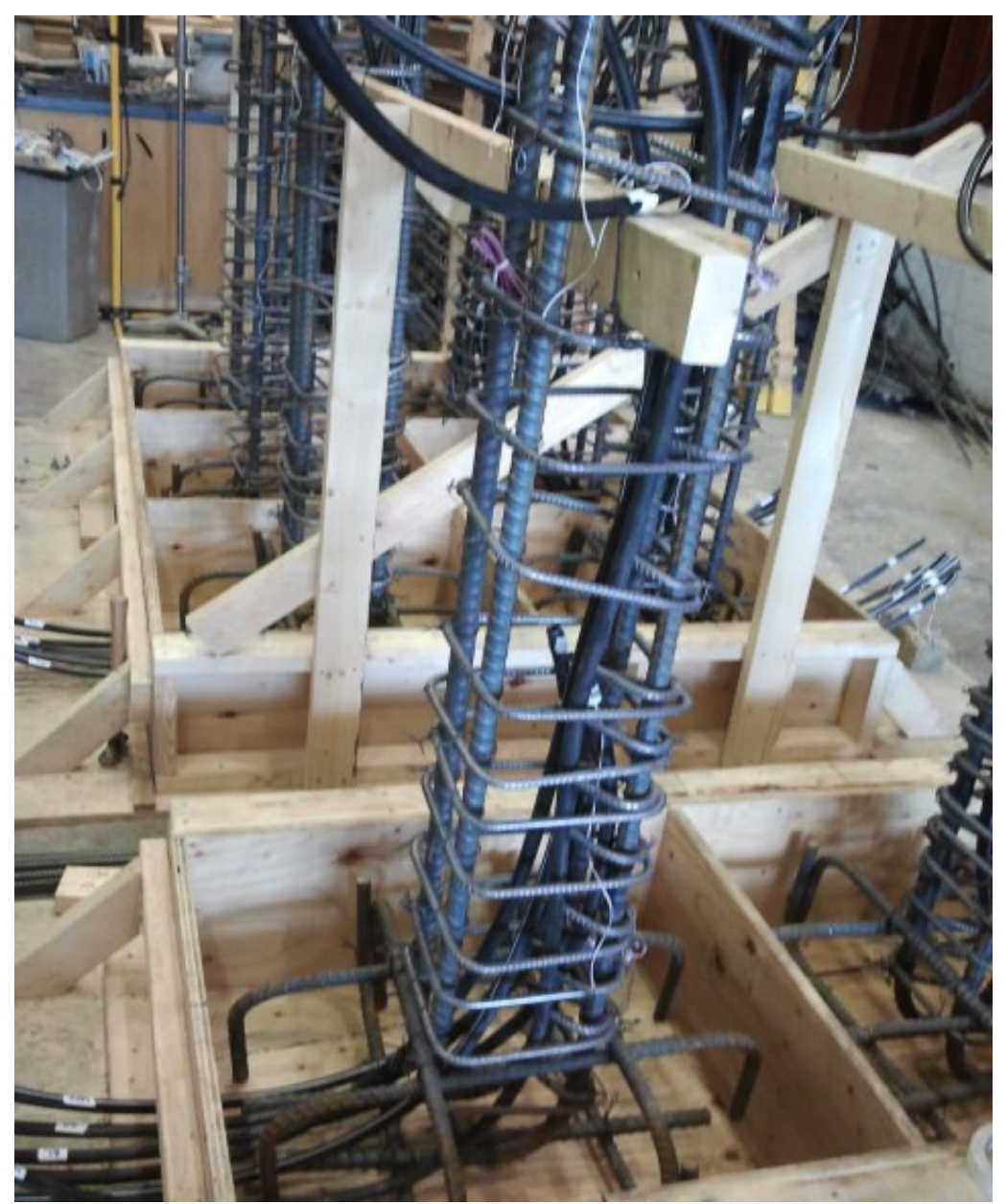

Figure 3-17: Column footing formwork with cages placed inside

The formworks for the columns were constructed similar to that of the footing. 19-mm thick plywood and $38 \times 89 \mathrm{~mm}$ wood studs were used. The $19-\mathrm{mm}$ thick plywood was cut into rectangular shapes of $3.2 \times 0.34 \mathrm{~m}$ and $3.2 \times 0.3 \mathrm{~m}$ with the aid of a circular saw. Three holes (19 mm diameter) were formed along the longitudinal line of symmetry of the $3.2 \times 0.34 \mathrm{~m}$ and $3.2 \times 0.3 \mathrm{~m}$ rectangular plywood. These holes were positioned at the bottom, mid-height and top of the column to accommodate the pressure gauge on each column. A disc of 90-mm diameter was nailed to the plywood at the location of the holes. This was to provide the inserts for the pressure gauges, while the gauge cables run through a flexible tube within the centre core of the column (Figure 3-18a). The 3.2 $\times$ 
$0.34 \mathrm{~m}$ and the $3.2 \times 0.3 \mathrm{~m}$ plywood were assembled to form a channel shaped formwork. The formwork was then oiled and placed around the reinforcement cages (Figure 3-18b). The channel shape was then closed by a $3.2 \times 0.3 \mathrm{~m}$ rectangular plywood to complete the $300 \times 300 \mathrm{~mm}$ by $3.2 \mathrm{~m}$ high column formwork (Figure $3-19 \mathrm{a}$ ). $38 \times 89 \mathrm{~mm}$ wood studs were cut to lengths of $340 \mathrm{~mm}$ and $300 \mathrm{~mm}$. 102-mm screws were used with the aid of a hand drill to form L-shaped $38 \times 89 \mathrm{~mm}$ wood elements, which were screwed to the formwork in order to increase their stiffness. A spirit level was used to ensure that the columns were vertical and plumb. This verticality was maintained by bracing the columns with $38 \times 89 \mathrm{~mm}$ wood ties (Figure $3-19 \mathrm{~b}$ ) before the concrete pour took place. 


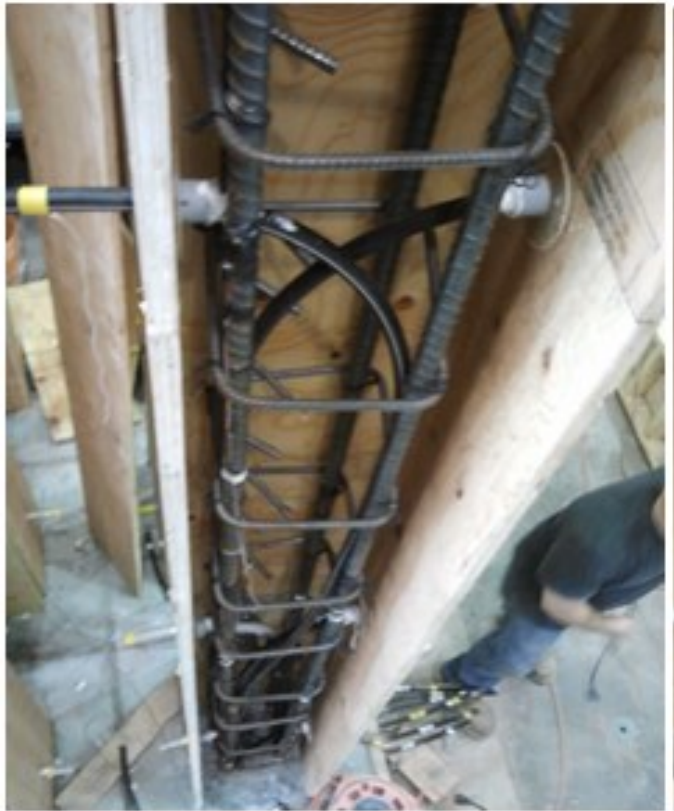

(a)

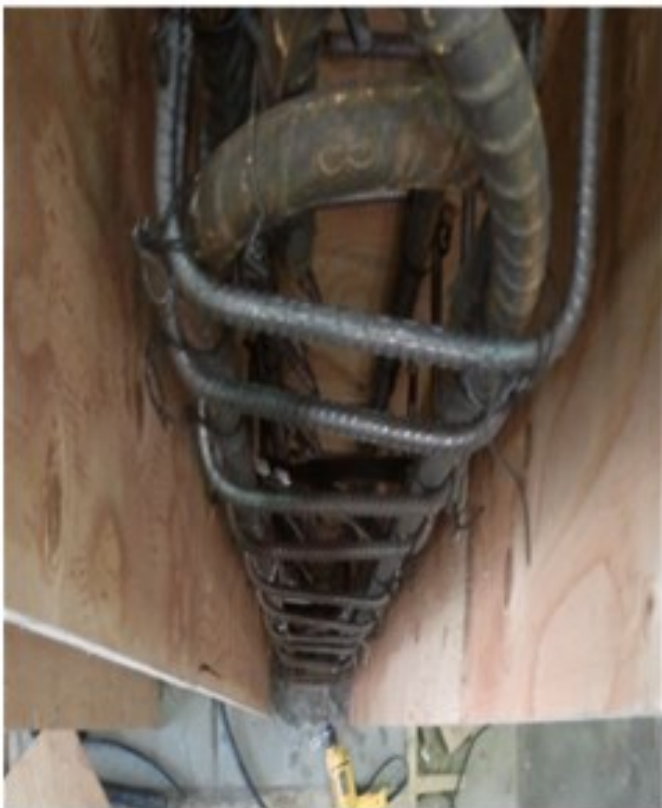

(b)

Figure 3-18: Column formwork placed around reinforcement cage

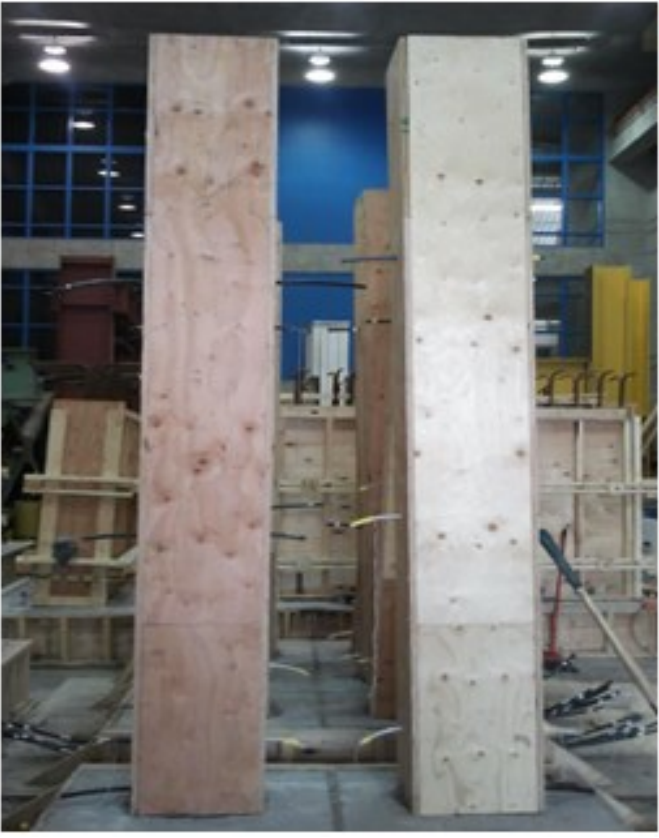

(a)

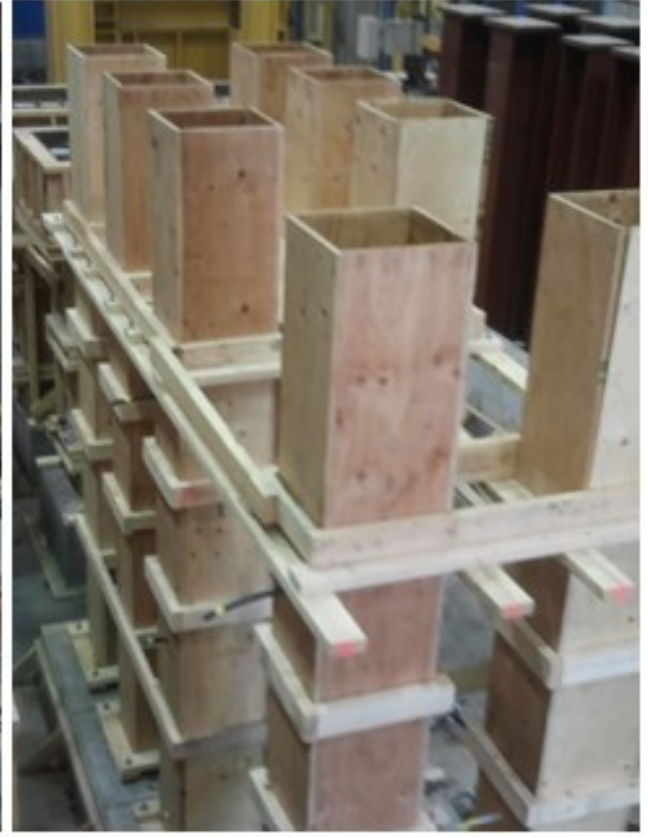

(b)

Figure 3-19: A photograph showing (a. Columns formwork and b. columns braced with $38 \times 89 \mathrm{~mm}$ wood studs) 


\subsection{Casting and Curing}

The casting of concrete was done in two (2) stages at Carleton University structures laboratory. These stages were: casting of the footings and then columns. This section describes how the footings and the columns were cast and cured.

\subsubsection{Casting and Curing of Footings and Columns}

Column footings were the first to be cast (Figure 3-20a). The concrete was poured into the forms of the footings using the hopper and extensions on the chute of the concrete mixing truck. A concrete poker vibrator was used to ensure that the concrete pour was even and free from air bubbles as well as distribute aggregate uniformly to all edges and corners of the formwork. The concrete surface was covered with wet burlap and plastic sheets, 8 hours after casting, and wetted daily in accordance with ASTM C192/C192M07. After the footings were cured for fourteen (14) days, the column reinforcement cages were lapped to the kicker (starter) bars from the footings and the column forms placed around them. Concrete was then poured into the column forms using the hopper and extensions on the chute at the back of the concrete mixing truck. A concrete poker vibrator was used to vibrate the freshly poured concrete in order to ensure that no honey combs developed within the column. The concrete surface was covered with wet burlap and plastic sheets, 8 hours after casting, and wetted daily in accordance with ASTM C192/C192M-07. Twelve (12) $100 \times 200 \mathrm{~mm}$ cylinders were also cast from the concrete used for the columns in order to obtain the strength characteristics of the concrete. These concrete cylinders were prepared in accordance with ASTM C192/192M-07. The column forms were removed $24 \mathrm{hrs}$ after casting, while curing of the concrete continued for fourteen (14) days (Figure 3-20(b)). 


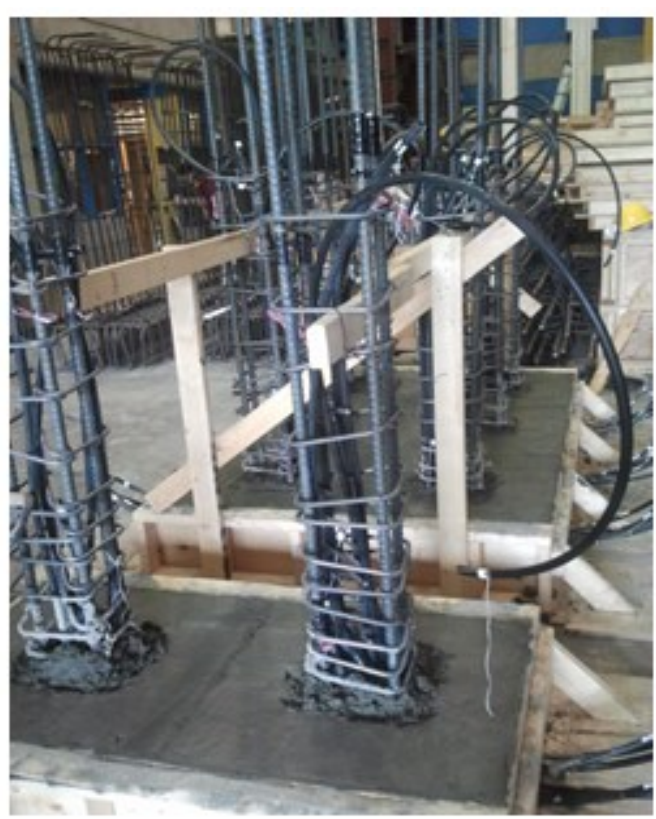

(a)

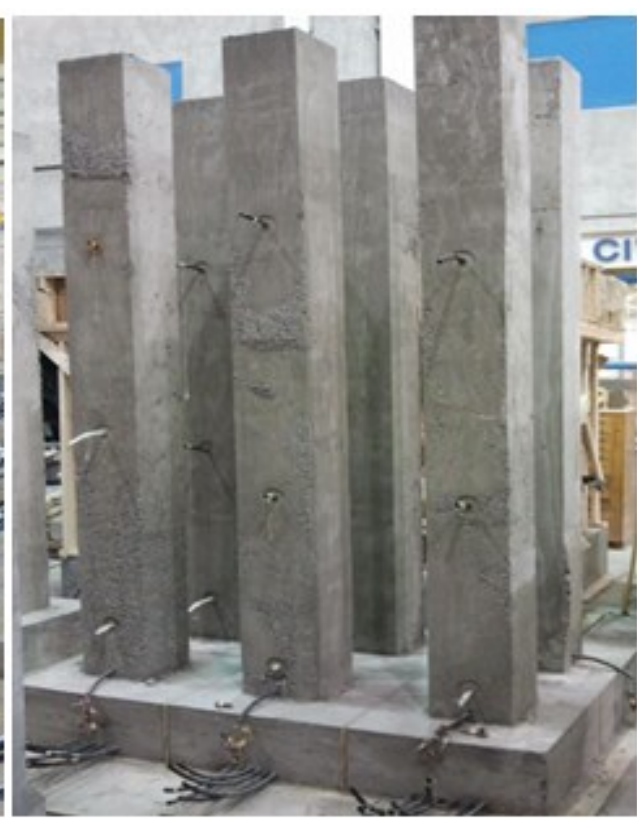

(b)

Figure 3-20: (a) Column footings and (b) Concrete columns

\subsection{Instrumentation}

The columns designated for field testing, were instrumented with strain gauges, pressure gauges and string potentiometers. This section describes how the instrumentation was done as well as the locations of the gauges on the columns.

\subsubsection{Strain gauge}

Strain gauges, type FLA-6-350-11, were attached to the longitudinal reinforcing bar of each column. The positions of the eight strain gauges on the reinforcement in each column are designated; bottom-front-left, bottom-front-right, mid-front-right, mid-frontleft, top-front-left, top-front-right, mid-back-left and mid-back-right. The locations of the strain gauges is presented in Figure 3-15. Figure 3-21 is a photograph showing some of the gauge positions while Table 3-6 presents the detailed location of the strain gauges on each column as constructed. 


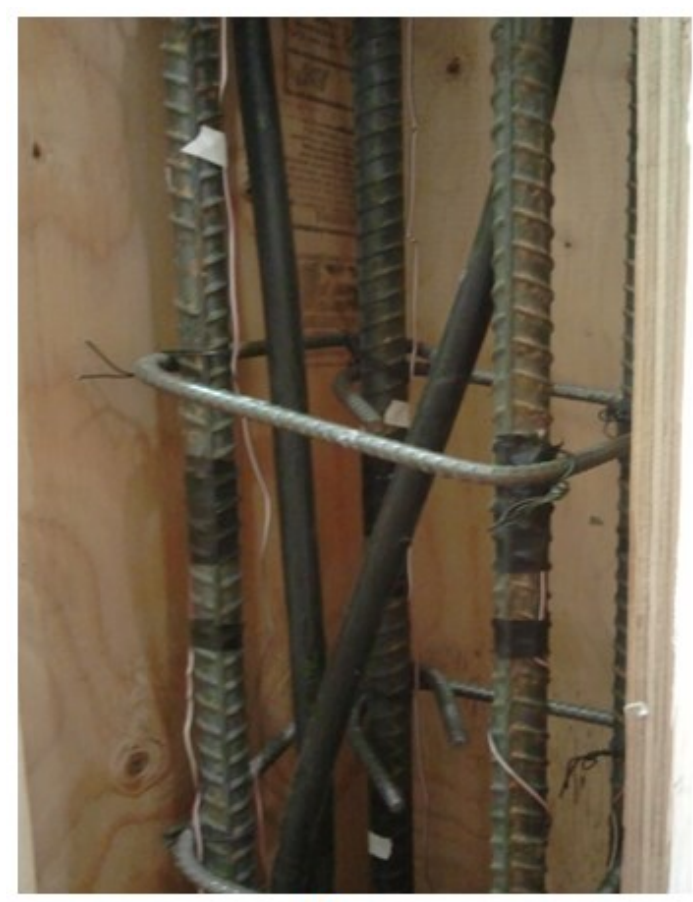

(a)

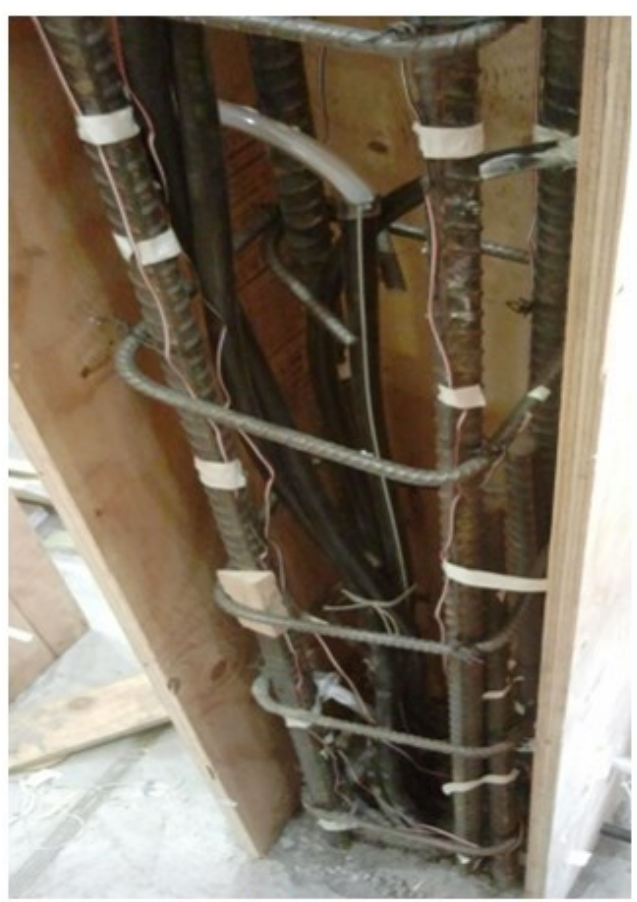

(b)

Figure 3-21: A photograph of cages showing strain gauges and leads at mid-height

Table 3-6: Columns strain gauge position details

\begin{tabular}{|c|c|c|c|c|c|}
\hline \multirow{2}{*}{$\begin{array}{c}\text { Test } \\
\text { No. }\end{array}$} & Column & \multicolumn{3}{|c|}{ Strain Gauge Locations (mm)* } \\
\cline { 3 - 6 } & Designation & $\begin{array}{c}\text { Bottom- } \\
\text { Front }\end{array}$ & Mid-Front & Mid-Back & Top-Front \\
\hline \multirow{2}{*}{$\mathbf{1}$} & SEIS-8 & 250 & 1150 & 1150 & 2350 \\
\cline { 2 - 6 } & CONV-7 & 250 & 1600 & 1600 & 2400 \\
\hline \multirow{2}{*}{$\mathbf{2}$} & CONV-20 & 250 & 1600 & 1600 & 2400 \\
\cline { 2 - 6 } & SEIS-9 & 250 & 1000 & 1200 & 2350 \\
\hline \multirow{2}{*}{$\mathbf{3}$} & CONV-10 & 250 & 1600 & 1600 & 2400 \\
\cline { 2 - 6 } & CONV-6 & 250 & 1600 & 1600 & 2400 \\
\hline \multirow{2}{*}{4} & CONV-1 & 250 & 1600 & 1600 & 2400 \\
\cline { 2 - 6 } & SEIS-13 & 200 & 1050 & 1300 & 2350 \\
\hline \multirow{2}{*}{5} & CONV-2 & 250 & 1600 & 1600 & 2400 \\
\cline { 2 - 6 } & SEIS-14 & 250 & 1250 & 1100 & 2400 \\
\hline \multirow{2}{*}{6} & SEIS-3 & 200 & 1100 & 1300 & 2350 \\
\cline { 2 - 6 } & CONV-11 & 250 & 1600 & 1600 & 2400 \\
\hline \multirow{2}{*}{7} & CONV-5 & 250 & 1600 & 1600 & 2400 \\
\cline { 2 - 6 } & CONV-12 & 250 & 1600 & 1600 & 2400 \\
\hline \multirow{2}{*}{$\mathbf{8}$} & SEIS-4 & 200 & 1100 & 1250 & 2300 \\
\cline { 2 - 6 } & CONV-15 & 250 & 1600 & 1600 & 2400 \\
\hline
\end{tabular}

*dimensions measured from top of concrete footing 


\subsubsection{Pressure gauges}

Each column was instrumented with PicoCoulomB (PCB) piezotronics model 481 pressure gauges to record the blast pressure time history along the height of the column during field testing. Six (6) pressure gauge inserts were provided for each column. The pressure gauge locations varied slightly from column to column, but were generally located at the bottom, mid-height and top of the front and rear faces of the columns. Figure 3-22 shows the locations of the blast pressure gauges and the nomenclature adopted for their identification. Table 3-7 shows the positions of pressure gauges for each column.

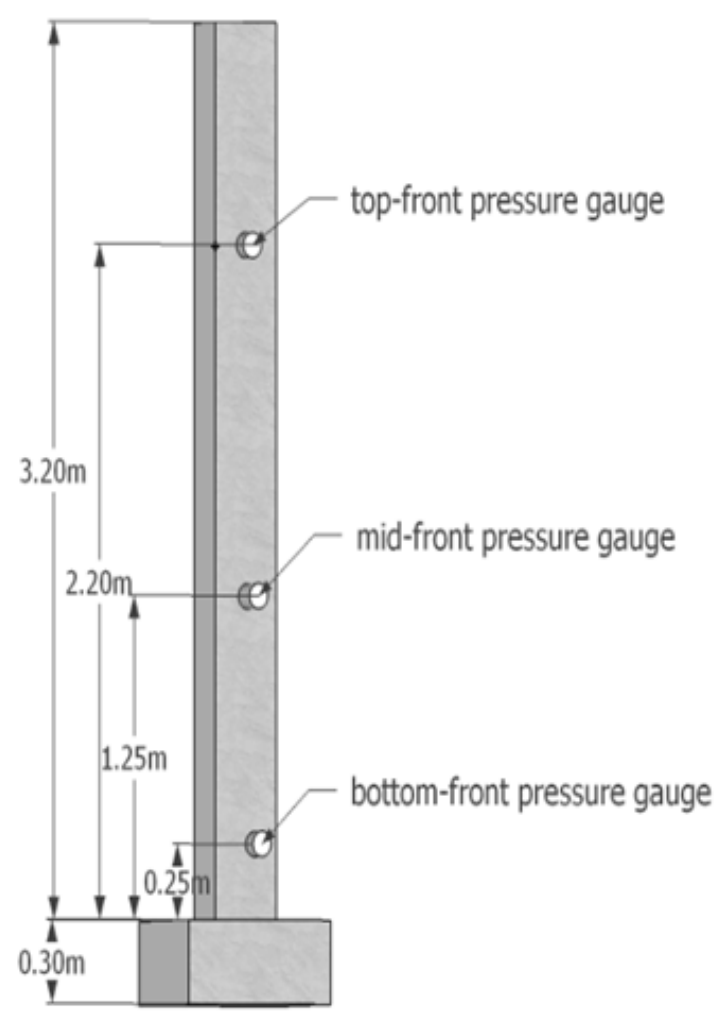

(a)

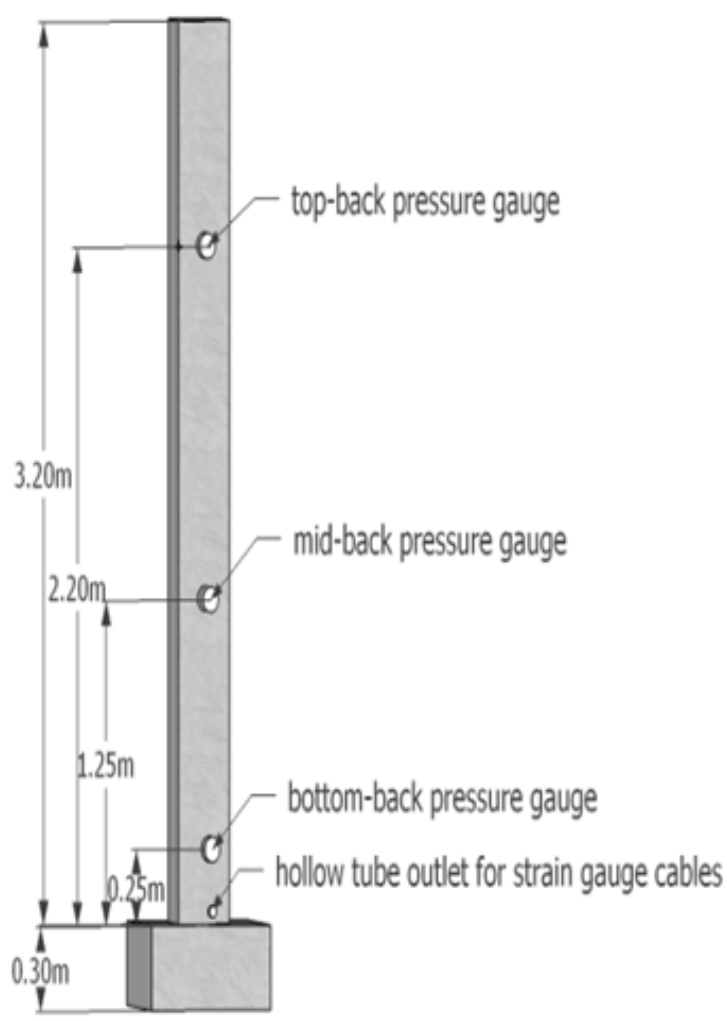

(b)

Figure 3-22: Pressure gauge locations for; (a) Front face of column and (b) Rear face of column 
Table 3-7: Columns pressure gauge position details

\begin{tabular}{|c|c|c|c|c|}
\hline \multirow[b]{2}{*}{$\begin{array}{l}\text { Test } \\
\text { No. }\end{array}$} & \multirow[b]{2}{*}{$\begin{array}{c}\text { Column } \\
\text { Designation }\end{array}$} & \multicolumn{3}{|c|}{ Pressure Gauge Locations (mm)* } \\
\hline & & $\begin{array}{c}\text { Bottom } \\
\text { (Front and } \\
\text { rear face) }\end{array}$ & $\begin{array}{l}\text { Mid-height } \\
\text { (Front and } \\
\text { rear face) }\end{array}$ & $\begin{array}{c}\text { Top (Front } \\
\text { and rear } \\
\text { face) }\end{array}$ \\
\hline \multirow{2}{*}{1} & SEIS-8 & 280 & 1300 & 2250 \\
\hline & CONV-7 & 255 & 1100 & 2180 \\
\hline \multirow{2}{*}{2} & CONV-20 & 210 & 1250 & 2200 \\
\hline & SEIS-9 & 160 & 1000 & 2300 \\
\hline \multirow{2}{*}{3} & CONV-10 & 250 & 1250 & 2200 \\
\hline & CONV-6 & 310 & 1200 & 2400 \\
\hline \multirow{2}{*}{4} & CONV-1 & 160 & 1100 & 2100 \\
\hline & SEIS-13 & 150 & 1010 & 2100 \\
\hline \multirow{2}{*}{5} & CONV-2 & 300 & 1200 & 2400 \\
\hline & SEIS-14 & 250 & 1150 & 2200 \\
\hline \multirow{2}{*}{6} & SEIS-3 & 300 & 1190 & 2300 \\
\hline & CONV-11 & 280 & 1300 & 2400 \\
\hline \multirow{2}{*}{7} & CONV-5 & 250 & 1210 & 2210 \\
\hline & CONV-12 & 310 & 1200 & 2300 \\
\hline \multirow{2}{*}{8} & SEIS-4 & 250 & 1120 & 2200 \\
\hline & CONV-15 & 250 & 1250 & 2200 \\
\hline
\end{tabular}

*dimensions measured from top of concrete footing

\subsubsection{String potentiometer}

String potentiometers (SP3 model) with output signal 4-20 mA were used to measure column displacements in each test. Each column was instrumented with three (3) string potentiometers. The locations for the string potentiometers were the same for all columns. They were connected directly to the rear face of the column at $1.0 \mathrm{~m}, 1.5 \mathrm{~m}$ and $2.0 \mathrm{~m}$ from the footing along the height of each column (Figure 3-24). String potentiometers are mainly composed of four main parts: retractable cable, spool, spring, and rotational sensor. The transducer (Figure 3-23) was mounted onto $89 \times 89 \mathrm{~mm}$ wood studs attached to the back of the reaction structure, while the retractable cable was attached to the back of the column with the aid of self-drilling concrete screws. Inside the transducer's 
housing, a stainless steel cable is wound on a precisely machined constant diameter cylindrical spool that turns as the stainless steel cable reels and unreels. Figure 3-23 is a photograph of a transducer mounted on an $89 \times 89 \mathrm{~mm}$ wood stud attached to the support structure.

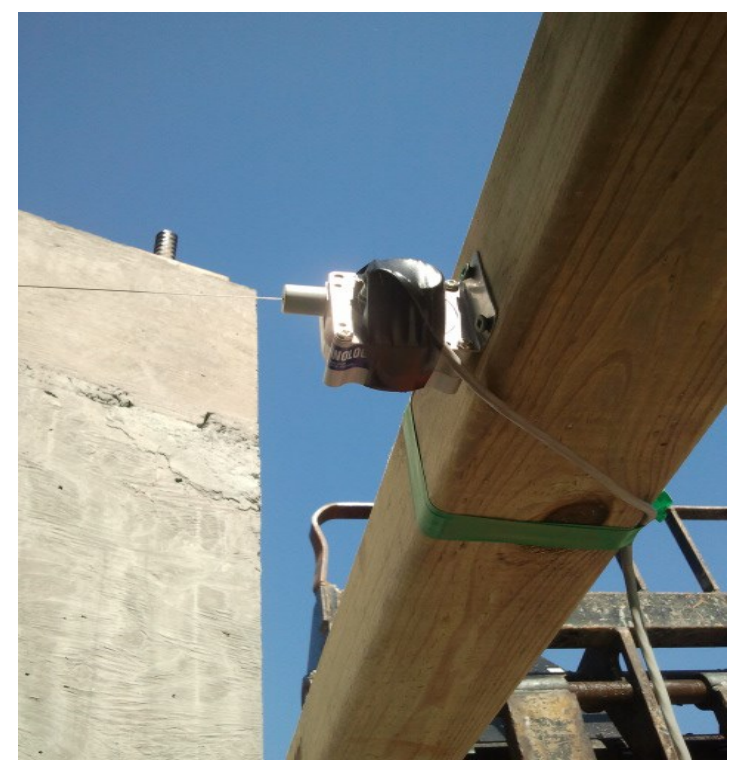

Figure 3-23: Transducer mount on $89 \times 89 \mathrm{~mm}$ wood stud

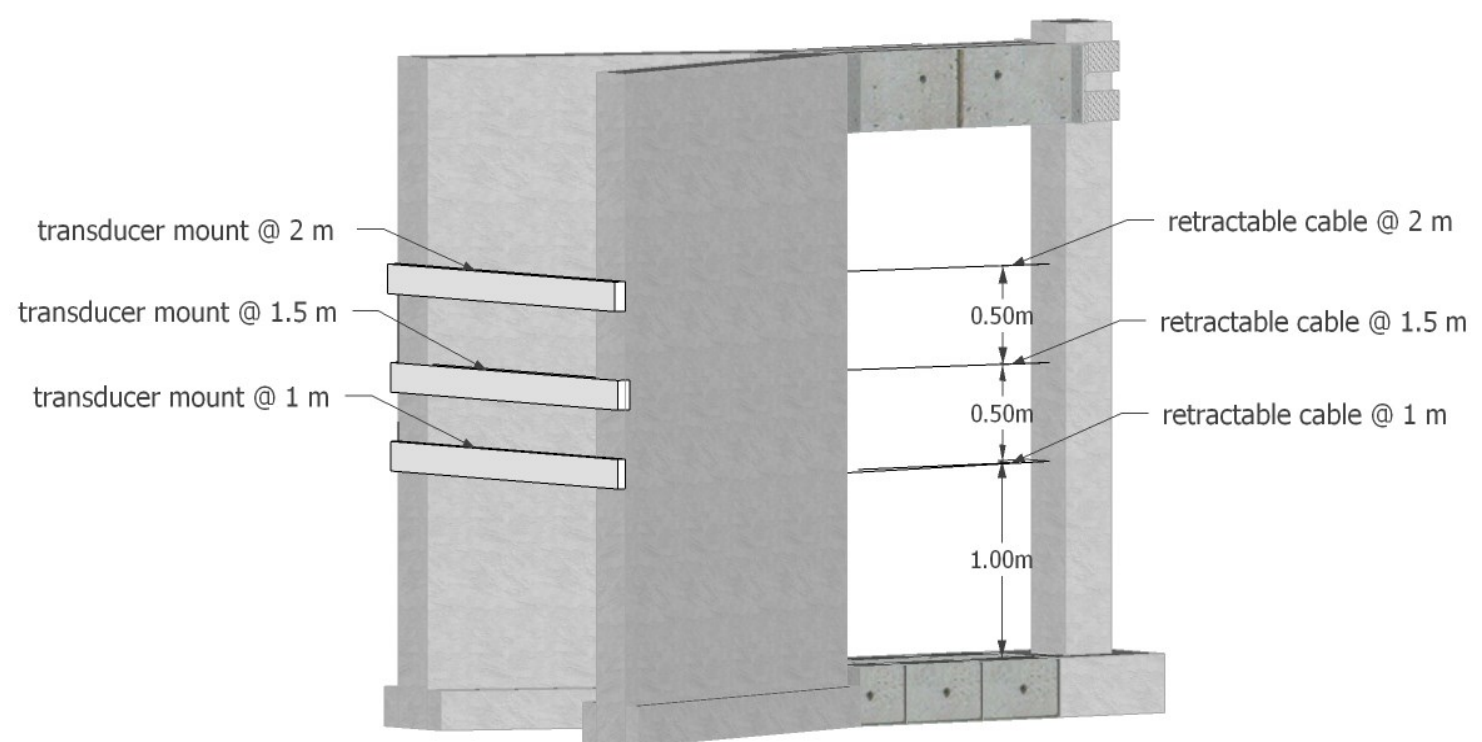

Figure 3-24: A sketch of support structure showing positions of string potentiometers (transducer) 


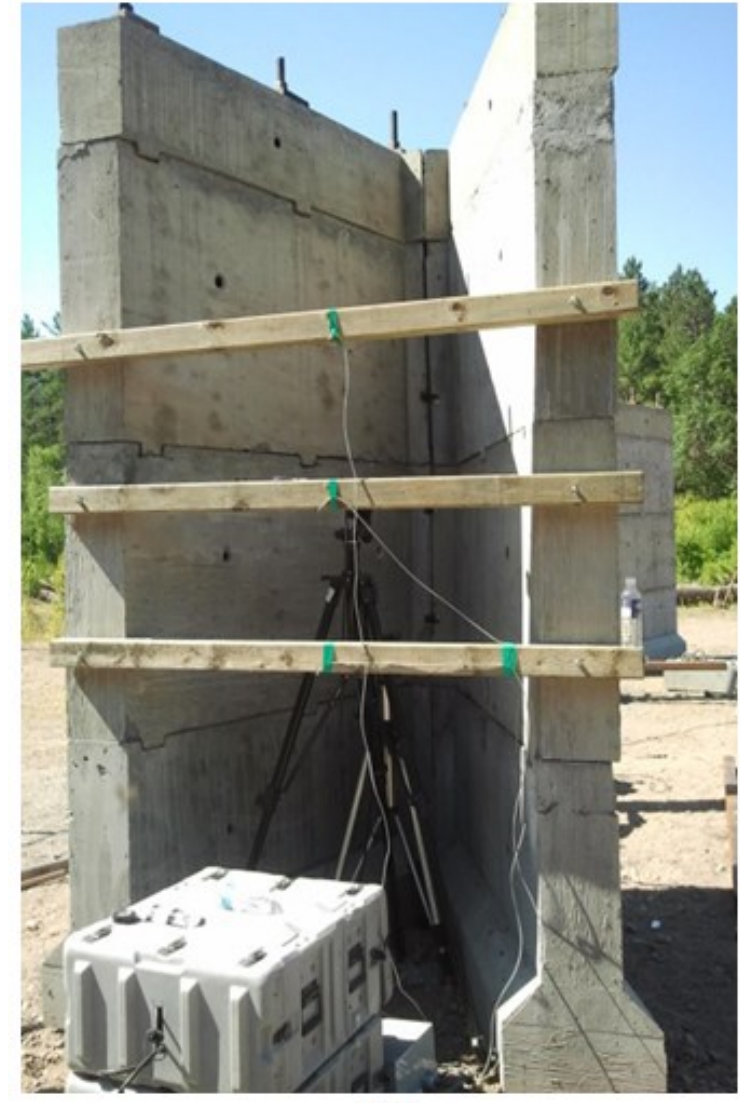

(a)

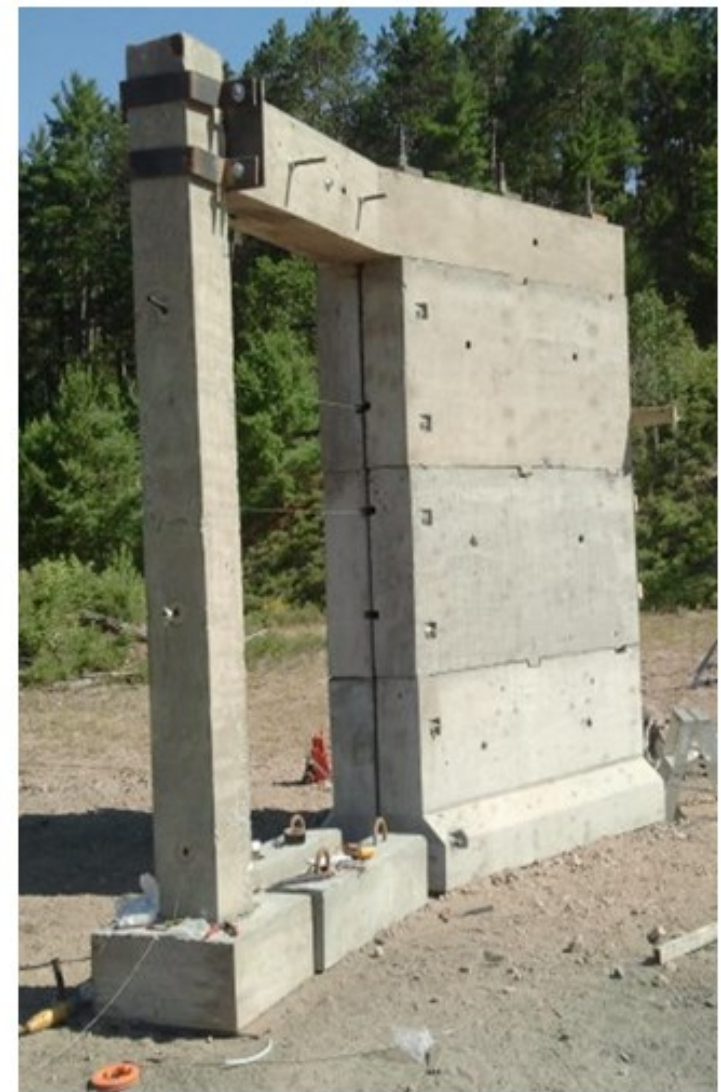

(b)

Figure 3-25: Photographs of support showing (a) $89 \times 89$ wood studs mount for the transducers and (b) Retractable cable of the string potentiometers

\subsection{Data Acquisition}

A high speed data acquisition system (Yokogawa SL1000 model) was used to sample test data at $100 \mathrm{MHz}$. Though Yokogawa SL1000 can work as a standalone data acquisition unit, it was connected to a personal computer and the data backed up onto the hard disk of the computer. Sixteen (16) input-channels recorded strain reading, twelve (12) inputchannels recorded pressure readings, and Six (6) input-channels recorded displacement readings. A fibre optic cable placed in the explosive was used to trigger the data acquisition system. A high speed video camera, NAC Memrecan GX-8, was also used to capture images of the explosions for each test. The same trigger signal was also sent to 
The NAC Memrecan GX-8 to start recording simultaneously. Figure 3-26 and Figure 327 show photographs of SL1000 and NAC Memrecam GX-8 respectively.

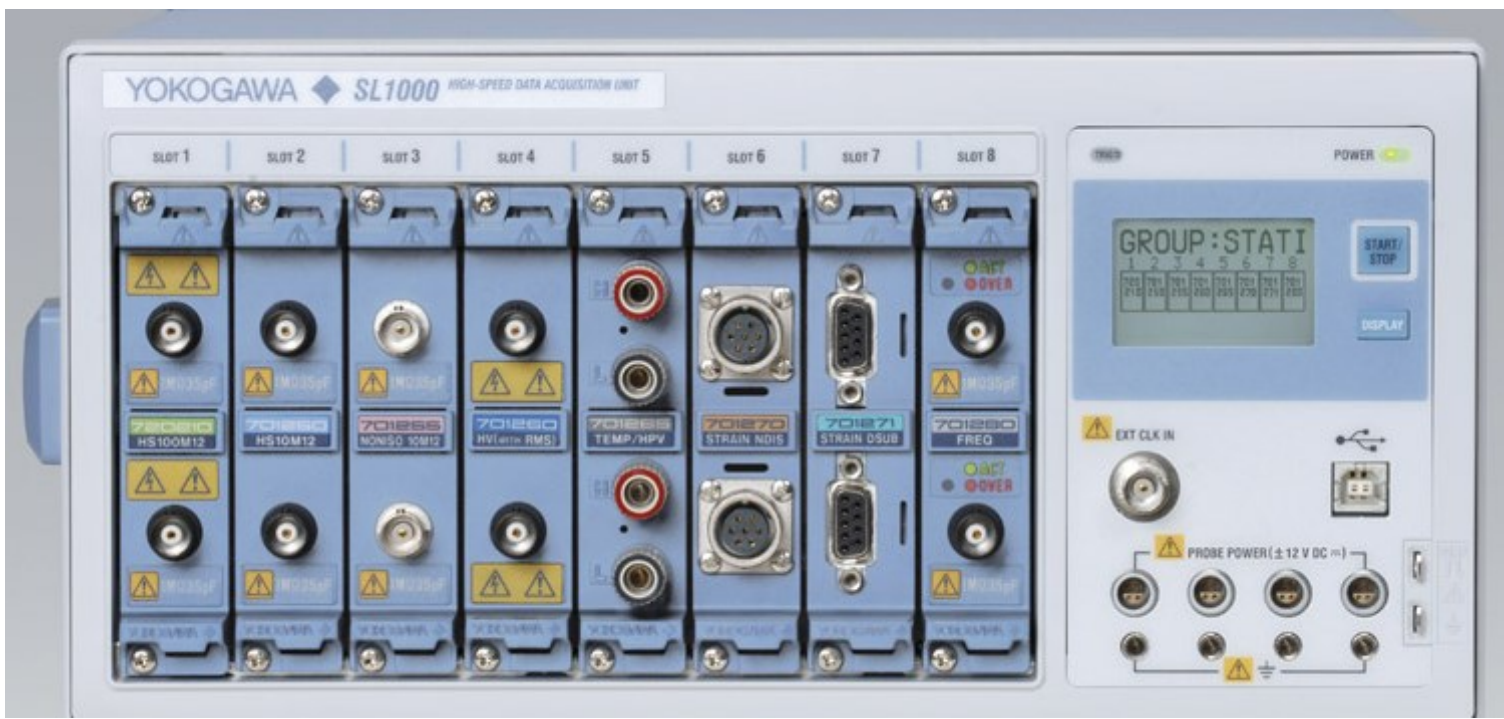

Figure 3-26: Photograph of Yokogawa SL1000 data acquisition system

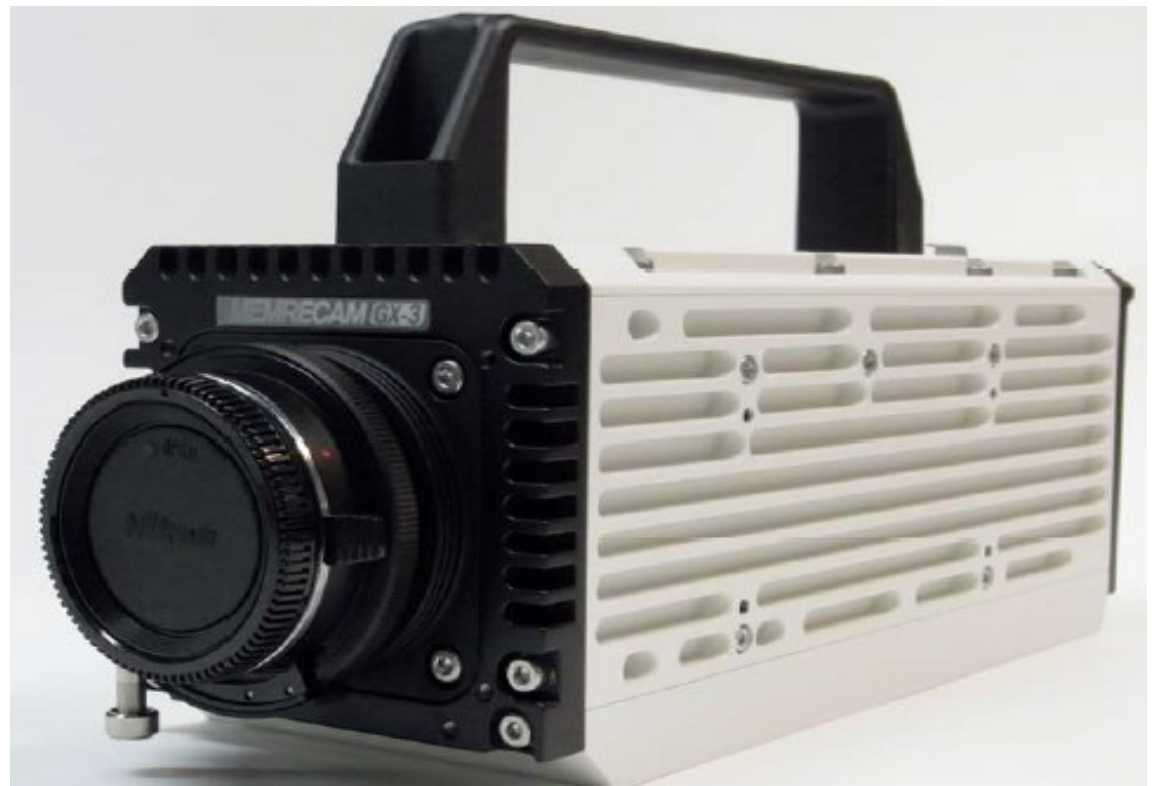

Figure 3-27: NAC Memrecam GX-8 


\section{Chapter: Experimental Results and Discussions}

\subsection{Introduction}

The experimental program consisted of 20 columns designed and detailed as conventional or part of structures' lateral load resisting system. Details of the column design are presented in Chapter 3. Four of the columns were designated for static testing in the structures laboratory at Carleton University while the remainder was tested under close-in explosion testing at the Canadian Forces Base (CFB), Petawawa. The columns were tested in pairs under the same charge mass but with varying standoff distances. The distance between the columns was designed to remain constant while the location of the charge mass was varied to yield the required standoff distances to each column. Table 4-1 presents the designed experimental program with column types and nomenclature, charge mass of ANFO and standoff distances.

Note that the experimental design required the distance between paired columns to be 5.4 m (Table 4-1). However, after test 1 was set up, the measured distance obtained was 5.0 m. Indeed, this distance was used for Test 1. Some support structure sliding occurred during the test, resulting in increased distances between paired columns for each test. Table 4-2 shows the measured distances between columns for each test while Table 4-3 presents the field tests conducted, column types and nomenclature, charge mass of ANFO and standoff distances. 
Table 4-1: Designed experimental program details

\begin{tabular}{|c|c|c|c|c|c|c|c|}
\hline $\begin{array}{c}\text { Test } \\
\text { No. }\end{array}$ & $\begin{array}{c}\text { Column } \\
\text { Designation }\end{array}$ & $\begin{array}{c}\text { Tie } \\
\text { Spacing } \\
(\mathrm{mm})\end{array}$ & ALR & $\begin{array}{c}\text { Standoff } \\
\text { distance } \\
(\mathrm{m})\end{array}$ & $\begin{array}{c}\text { Charge } \\
\text { mass }(\mathrm{kg} \\
\text { ANFO) }\end{array}$ & $\begin{array}{c}\text { Charge } \\
\text { mass }(\mathrm{kg} \\
\text { TNT })\end{array}$ & $\begin{array}{c}z \\
\left(\mathrm{~m} / \mathrm{kg}^{1 / 3}\right)\end{array}$ \\
\hline \multirow{2}{*}{$\mathbf{1}$} & SEIS-8 & 75 & 0 & 2.7 & 100 & 82 & 0.62 \\
\cline { 2 - 8 } & CONV-7 & 300 & 0 & 2.7 & 100 & 82 & 0.62 \\
\hline \multirow{2}{*}{$\mathbf{2}$} & CONV-20 & 300 & 0 & 2.7 & 100 & 82 & 0.62 \\
\cline { 2 - 8 } & SEIS-9 & 75 & 0 & 2.7 & 100 & 82 & 0.62 \\
\hline \multirow{2}{*}{$\mathbf{3}$} & CONV-10 & 300 & 0.32 & 2.7 & 100 & 82 & 0.62 \\
\cline { 2 - 8 } & CONV-6 & 300 & 0 & 2.7 & 100 & 82 & 0.62 \\
\hline \multirow{2}{*}{4} & CONV-1 & 300 & 0 & 1.1 & 100 & 82 & 0.25 \\
\cline { 2 - 8 } & SEIS-13 & 75 & 0 & 4.3 & 100 & 82 & 0.99 \\
\hline \multirow{2}{*}{$\mathbf{5}$} & CONV-2 & 300 & 0 & 1.1 & 100 & 82 & 0.25 \\
\cline { 2 - 8 } & SEIS-14 & 75 & 0 & 4.3 & 100 & 82 & 0.99 \\
\hline \multirow{2}{*}{$\mathbf{6}$} & SEIS-3 & 75 & 0 & 1.1 & 100 & 82 & 0.25 \\
\cline { 2 - 8 } & CONV-11 & 300 & 0 & 4.3 & 100 & 82 & 0.99 \\
\hline \multirow{2}{*}{7} & CONV-5 & 300 & 0.32 & 1.1 & 100 & 82 & 0.25 \\
\cline { 2 - 8 } & CONV-12 & 300 & 0 & 4.3 & 100 & 82 & 0.99 \\
\hline \multirow{2}{*}{$\mathbf{8}$} & SEIS-4 & 75 & 0 & 1.1 & 100 & 82 & 0.25 \\
\cline { 2 - 8 } & CONV-15 & 300 & 0.32 & 4.3 & 100 & 82 & 0.99 \\
\hline
\end{tabular}


Table 4-2: Measured distance between paired columns for each test

\begin{tabular}{|c|c|c|c|}
\hline $\begin{array}{l}\text { Test } \\
\text { No. }\end{array}$ & $\begin{array}{c}\text { Column } \\
\text { Designation }\end{array}$ & $\begin{array}{l}\text { Tie Spacing } \\
\text { (mm) }\end{array}$ & $\begin{array}{l}\text { Measured distance } \\
\text { between paired } \\
\text { columns (m) }\end{array}$ \\
\hline \multirow{2}{*}{1} & SEIS-8 & 75 & \multirow{2}{*}{5.0} \\
\hline & CONV-7 & 300 & \\
\hline \multirow{2}{*}{2} & CONV-20 & 300 & \multirow{2}{*}{5.20} \\
\hline & SEIS-9 & 75 & \\
\hline \multirow{2}{*}{3} & CONV-10 & 300 & \multirow{2}{*}{5.32} \\
\hline & CONV-6 & 300 & \\
\hline \multirow{2}{*}{4} & CONV-1 & 300 & \multirow{2}{*}{5.40} \\
\hline & SEIS-13 & 75 & \\
\hline \multirow{2}{*}{5} & CONV-2 & 300 & \multirow{2}{*}{5.60} \\
\hline & SEIS-14 & 75 & \\
\hline \multirow{2}{*}{6} & SEIS-3 & 75 & \multirow{2}{*}{5.70} \\
\hline & CONV-11 & 300 & \\
\hline \multirow{2}{*}{7} & CONV-5 & 300 & \multirow{2}{*}{5.80} \\
\hline & CONV-12 & 300 & \\
\hline \multirow{2}{*}{8} & SEIS-4 & 75 & \multirow{2}{*}{5.96} \\
\hline & CONV-15 & 300 & \\
\hline
\end{tabular}

Free field gauges were placed at $2.2 \mathrm{~m}, 5 \mathrm{~m}, 10 \mathrm{~m}$ and $20 \mathrm{~m}$ from the centre of detonation (centre of explosive charge). These gauges were to record incident pressures for each test. The column support conditions during testing was modified as excavation was not possible at the site due to a high risk of encountering unexploded ordnances. The procedure of scanning every $50-100 \mathrm{~mm}$ deep layer prior to digging to that level proved time consuming and expensive. Thus, the support structure and the columns were placed on the ground surface and steel pegs nailed to the ground behind the support structure to prevent sliding. The support structure was designed and constructed to restrain the top of the column to simulate a fixed support condition. To achieve this, steel plates were cast into the concrete outriggers from the support structure while two steel collars were placed around the columns and bolted to the steel plates (Figure 3-26(b)). Under explosion 
testing, the column was driven into the outrigger while the steel collars restrained it from rotation. The footings of the columns on the other hand were placed tight to the support structure to prevent sliding. To simulate a fixed support condition, dead weights were loaded onto Hollow Structural Steel (HSS) elements that were used to restrain the footing from rotation and thus to develop the design moment. This worked to varying degrees of success as will be discussed under each test.

Table 4-3: Columns experimental program details

\begin{tabular}{|c|c|c|c|c|c|c|c|}
\hline $\begin{array}{c}\text { Test } \\
\text { No. }\end{array}$ & $\begin{array}{c}\text { Column } \\
\text { Designation }\end{array}$ & $\begin{array}{c}\text { Tie } \\
\text { Spacing } \\
(\mathrm{mm})\end{array}$ & ALR & $\begin{array}{c}\text { Standoff } \\
\text { distance } \\
(\mathrm{m})\end{array}$ & $\begin{array}{c}\text { Charge } \\
\text { mass }(\mathrm{kg} \\
\text { ANFO) }\end{array}$ & $\begin{array}{c}\text { Charge } \\
\text { mass }(\mathrm{kg} \\
\text { TNT })\end{array}$ & $\begin{array}{c}z \\
\left(\mathrm{~m} / \mathrm{kg}^{1 / 3}\right)\end{array}$ \\
\hline \multirow{2}{*}{$\mathbf{1}$} & SEIS-8 & 75 & 0 & 2.5 & 100 & 82 & 0.58 \\
\cline { 2 - 9 } & CONV-7 & 300 & 0 & 2.5 & 100 & 82 & 0.58 \\
\hline \multirow{2}{*}{$\mathbf{2}$} & CONV-20 & 300 & 0 & 2.6 & 150 & 123 & 0.52 \\
\cline { 2 - 9 } & SEIS-9 & 75 & 0 & 2.6 & 150 & 123 & 0.52 \\
\hline \multirow{2}{*}{$\mathbf{3}$} & CONV-10 & 300 & 0.32 & 2.66 & 150 & 123 & 0.53 \\
\cline { 2 - 9 } & CONV-6 & 300 & 0 & 2.66 & 150 & 123 & 0.53 \\
\hline \multirow{2}{*}{$\mathbf{4}$} & CONV-1 & 300 & 0 & 1.3 & 150 & 123 & 0.26 \\
\cline { 2 - 9 } & SEIS-13 & 75 & 0 & 4.1 & 150 & 123 & 0.82 \\
\hline \multirow{2}{*}{5} & CONV-2 & 300 & 0 & 1.3 & 150 & 123 & 0.26 \\
\cline { 2 - 9 } & SEIS-14 & 75 & 0 & 4.3 & 150 & 123 & 0.86 \\
\hline \multirow{2}{*}{6} & SEIS-3 & 75 & 0 & 1.3 & 150 & 123 & 0.26 \\
\cline { 2 - 8 } & CONV-11 & 300 & 0 & 4.4 & 150 & 123 & 0.88 \\
\hline \multirow{2}{*}{7} & CONV-5 & 300 & 0.32 & 1.7 & 150 & 123 & 0.34 \\
\cline { 2 - 8 } & CONV-12 & 300 & 0 & 4.1 & 150 & 123 & 0.82 \\
\hline \multirow{2}{*}{$\mathbf{8}$} & SEIS-4 & 75 & 0 & 1.7 & 150 & 123 & 0.34 \\
\cline { 2 - 9 } & CONV-15 & 300 & 0.32 & 4.26 & 150 & 123 & 0.86 \\
\hline
\end{tabular}

\subsection{Column Test 1 (CONV-7 and SEIS-8)}

In Test 1, two columns, SEIS-8 and CONV-7, were subjected to blast load from the detonation of 100-kg ANFO placed equidistant (standoff distance of $2.5 \mathrm{~m}$ ) from the columns (Table 4-3). This test was used to test out the data acquisition system - pressure gauges, strain gauges, and displacement gauges (string potentiometers). The test was also 
used to investigate the behavior of the support structure and the attachments of the reinforced concrete columns to the support structure. High speed videography, using a NAC Memrecam GX-8 video camera, was used to monitor response of the concrete columns during testing. Figure 4-1 presents a sketch while Figure 4-2 presents a photograph of the experimental setup prior to testing.

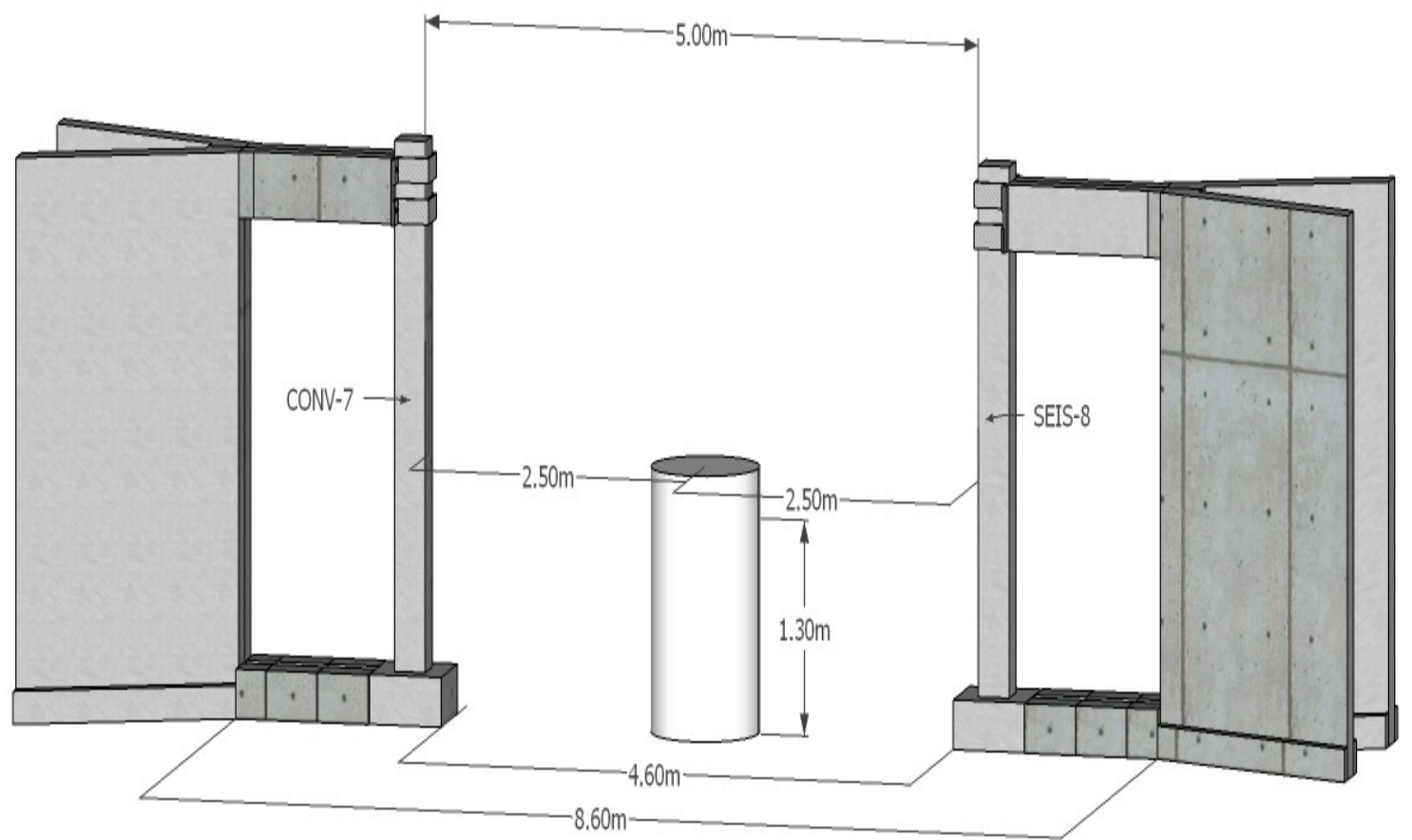

Figure 4-1: Sketch of columns CONV-7 and SEIS-8 experimental setup 


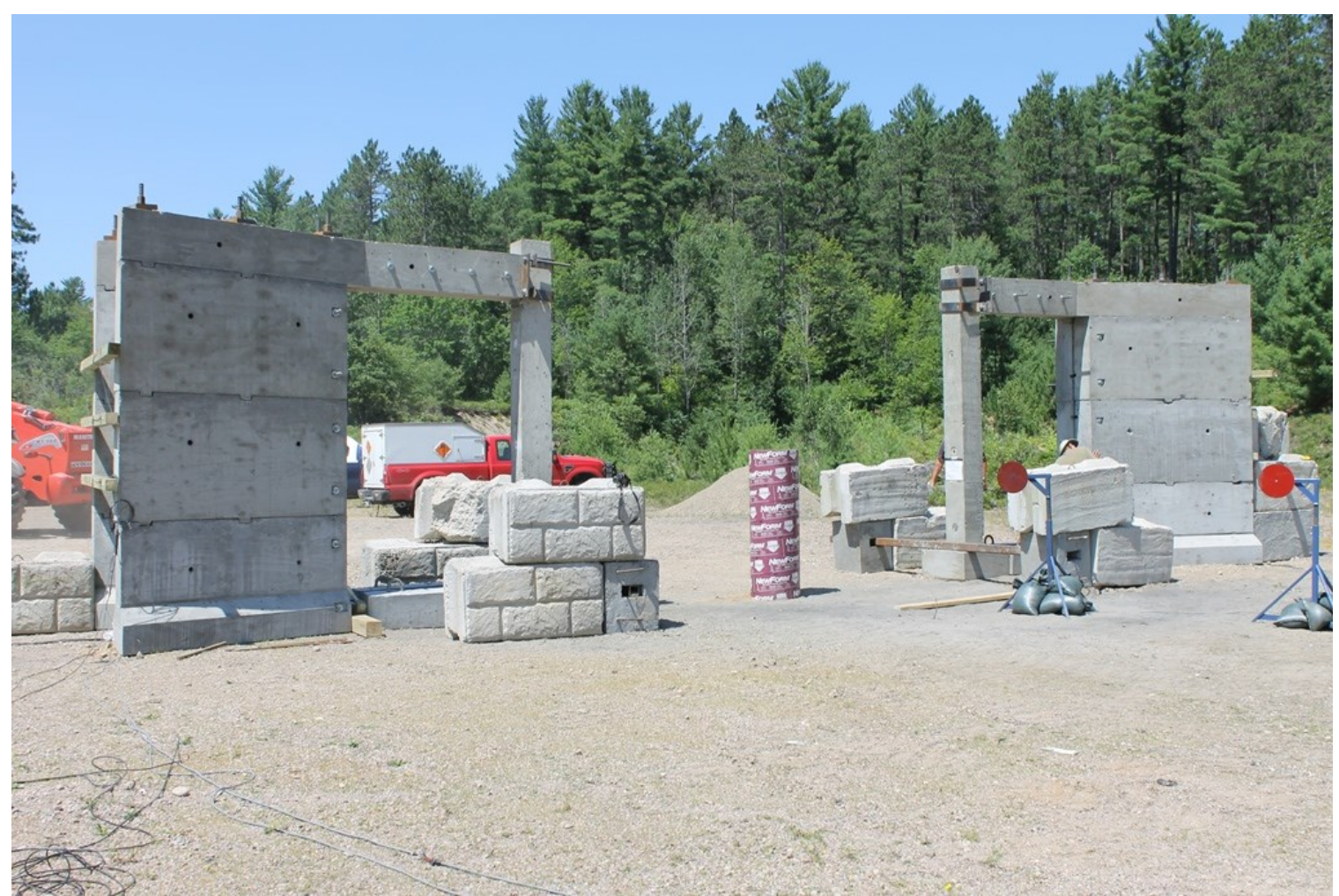

Figure 4-2: Photographs of columns (CONV-7 and SEIS-8) prior to explosion

After detonation of the ANFO explosive, the fireball engulfed the reinforced concrete columns and support structures. Thus, the video recording did not show response of the columns (Figure 4-3), however, the evolution of the blast pressure and fire ball was captured. Figure 4-4 shows a typical blast wave (fireball) evolution during the test. 


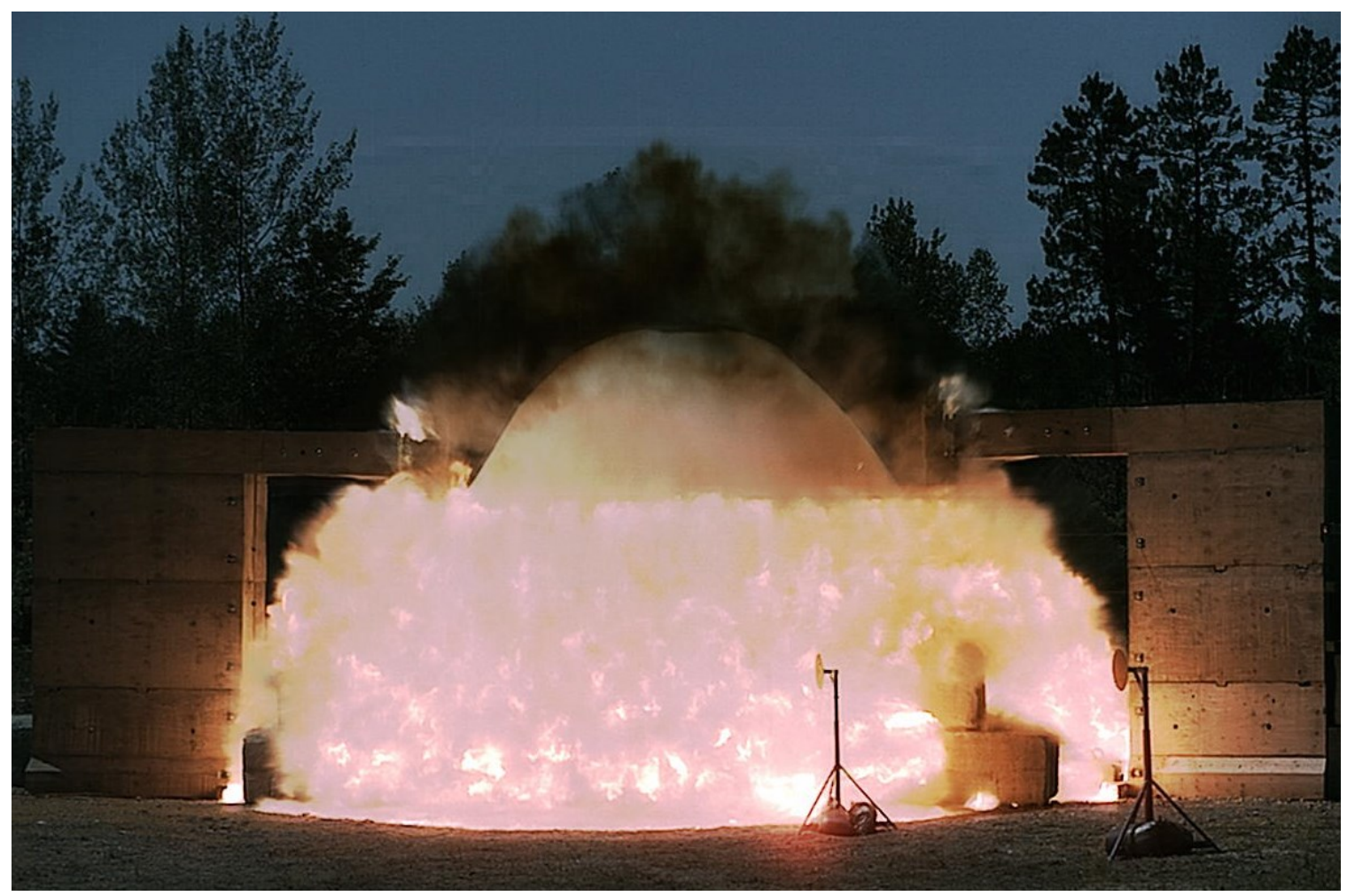

Figure 4-3: Photograph of columns engulfed in the fireball 

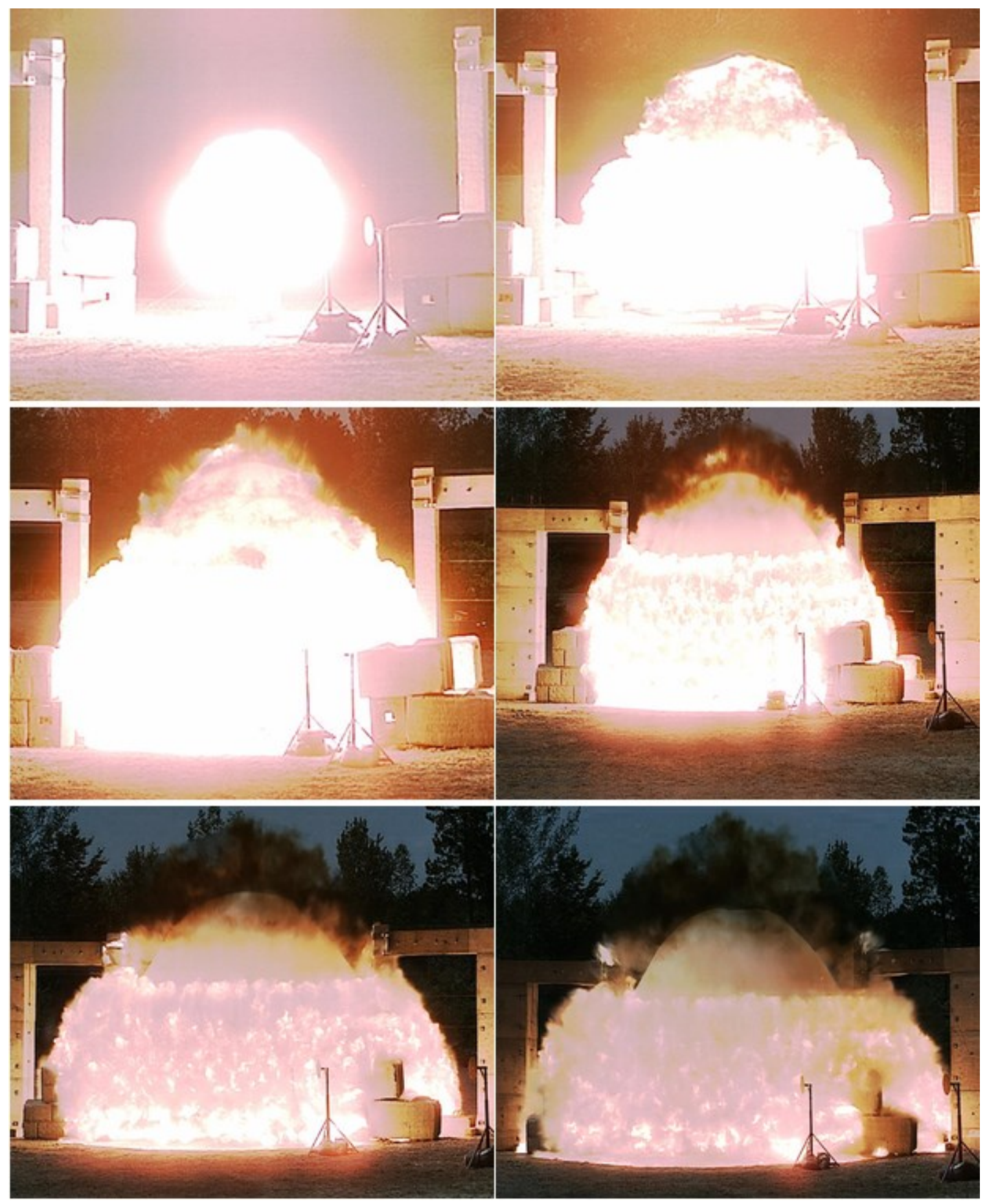

Figure 4-4: Blast wave propagation

Even though all columns were constructed with inserts on the front and rear faces for blast pressure gauges, only one column was instrumented with pressure gauges in tests where columns were equidistant from explosive charge. Thus, in Test 1 , only SEIS-8 was 
instrumented to measure blast pressure. The bottom-front pressure gauge conduit on column SEIS-8 was blocked and so the pressure gauge was placed on the companion column CONV-7. The data acquisition system and gauges were checked prior to testing. All the strain gauges and string potentiometers were found in good working order except strain gauge at the bottom-front-right; which was likely destroyed during concrete pour.

\subsubsection{Blast Loading in Test 1}

When the 100-kg ANFO was detonated, the blast wave arrived at the bottom-front gauge in $0.98 \mathrm{~ms}$, with a peak pressure of 33,133 $\mathrm{kPa}$ (Figure 4-5). The blast arrived at the topfront gauge in $1.36 \mathrm{~ms}$, with a peak pressure of $8,791 \mathrm{kPa}$ (Figure 4-6). The mid-front pressure gauge was damaged during the test (Figure 4-16(a)) as such no data was recorded for at this location. The blast wave arrived at the bottom-back gauge in $1.37 \mathrm{~ms}$, with a peak pressure of 7,084 $\mathrm{kPa}$ (Figure 4-7). At the mid-back, the blast wave arrived at $1.43 \mathrm{~ms}$ with a recorded peak pressure of $8,381 \mathrm{kPa}$ (Figure 4-8). The wave arrived at the top-back gauge in $1.37 \mathrm{~ms}$, with a peak pressure of $8,286 \mathrm{kPa}$ (Figure 4-9). The pressure at the bottom-front is significantly higher than the blast pressure calculated at this location using CONWEP - A collection of conventional weapons effects calculations based on the Kingery-Bulmash Polynomials with appropriate correction for angle of incidence (see Table 4-4(a)). The reason for this is the possible formation of a Mach reflection and the gauge being located within the Mach stem of the explosion. However, the pressures at the top-front, bottom-back, mid-back, and top-back locations were significantly lower than the pressures calculated from the Kingery-Bulmash polynomials with appropriate correction for angle of incidence. Details of Kingery-Bulmash polynomials results is in Table 4-4(a). Free-field pressure gauges were used to record the 
incident pressure remote from the centre of detonation. Figure 4-10 presents the experimental free-field incident pressure profile at standoff distances of $10 \mathrm{~m}$ and $20 \mathrm{~m}$. The free-field gauges at standoff distance of $2.2 \mathrm{~m}$ and $5 \mathrm{~m}$ failed during the test as such no data was recorded for at these locations. The incident overpressure at $10 \mathrm{~m}$ was 253 $\mathrm{kPa}$ with an arrival time of $9.2 \mathrm{~ms}$, while the incident overpressure at $20 \mathrm{~m}$ was $60 \mathrm{kPa}$ with an arrival time of $30.2 \mathrm{~ms}$ (Figure 4-10). The arrival time of the experimental blast wave at $10 \mathrm{~m}$ is shorter than that of CONWEP prediction while the arrival time for the experimental blast wave at $20 \mathrm{~m}$ is longer than that of CONWEP prediction. The experimental peak pressure at $10 \mathrm{~m}$ was higher than the peak incident pressure calculation from CONWEP while peak pressure at $20 \mathrm{~m}$ was lower than the peak incident pressure calculation from CONWEP. The incident pressure gauge at $10 \mathrm{~m}$ failed $10 \mathrm{~ms}$ after recording the peak pressure, while the incident pressure gauge at $20 \mathrm{~m}$ failed just after recording the peak pressure, as a result, the gauges started recording pressures higher than the peak pressure. The strain gauges produced no meaningful data.

The prime objective of Test 1 was to test out the data acquisition system. The data acquired was good except for the damage of the mid-front pressure gauge and one string pot as well as no meaningful data recorded by the strain gauges. 


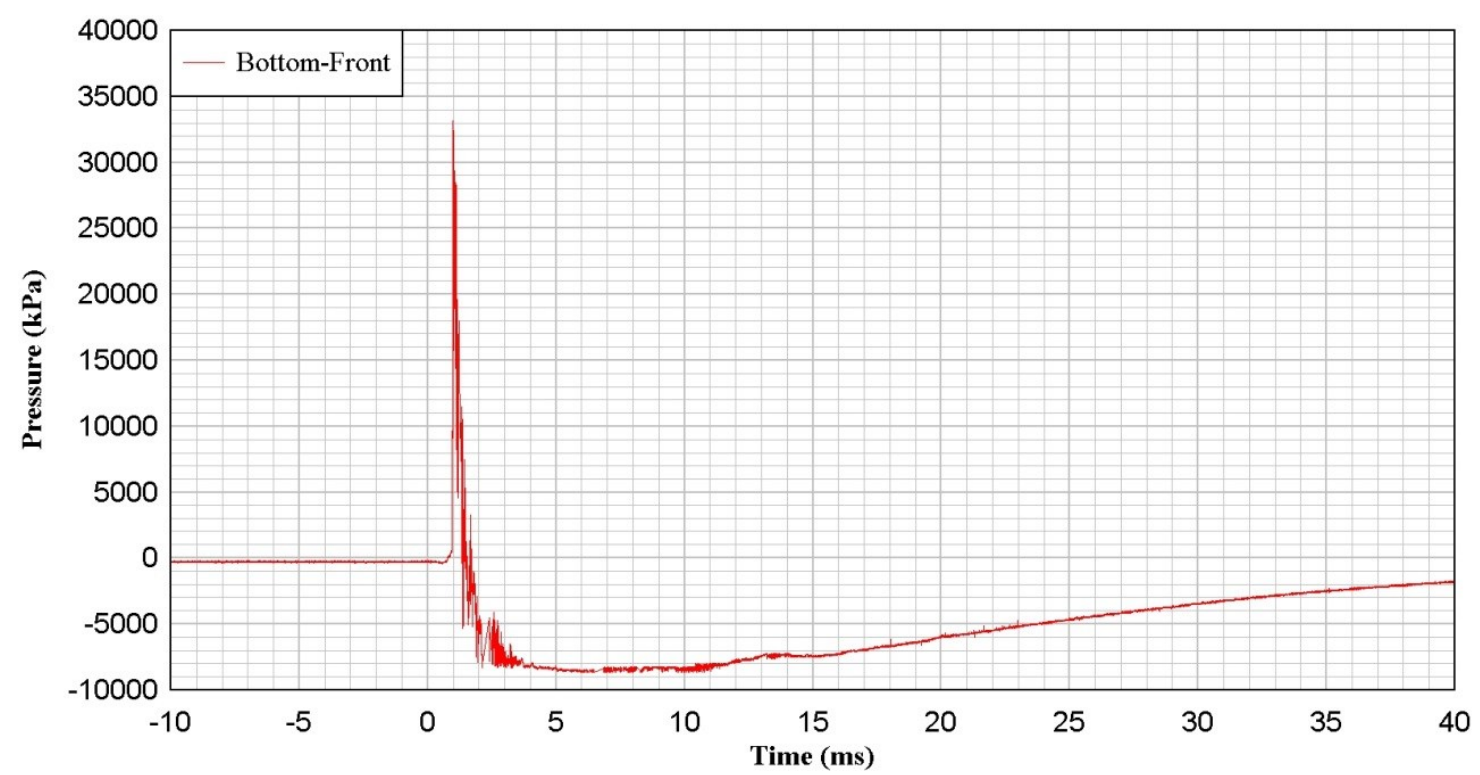

Figure 4-5: Blast pressure profile for Column CONV-7 and SEIS-8 (Bottom front)

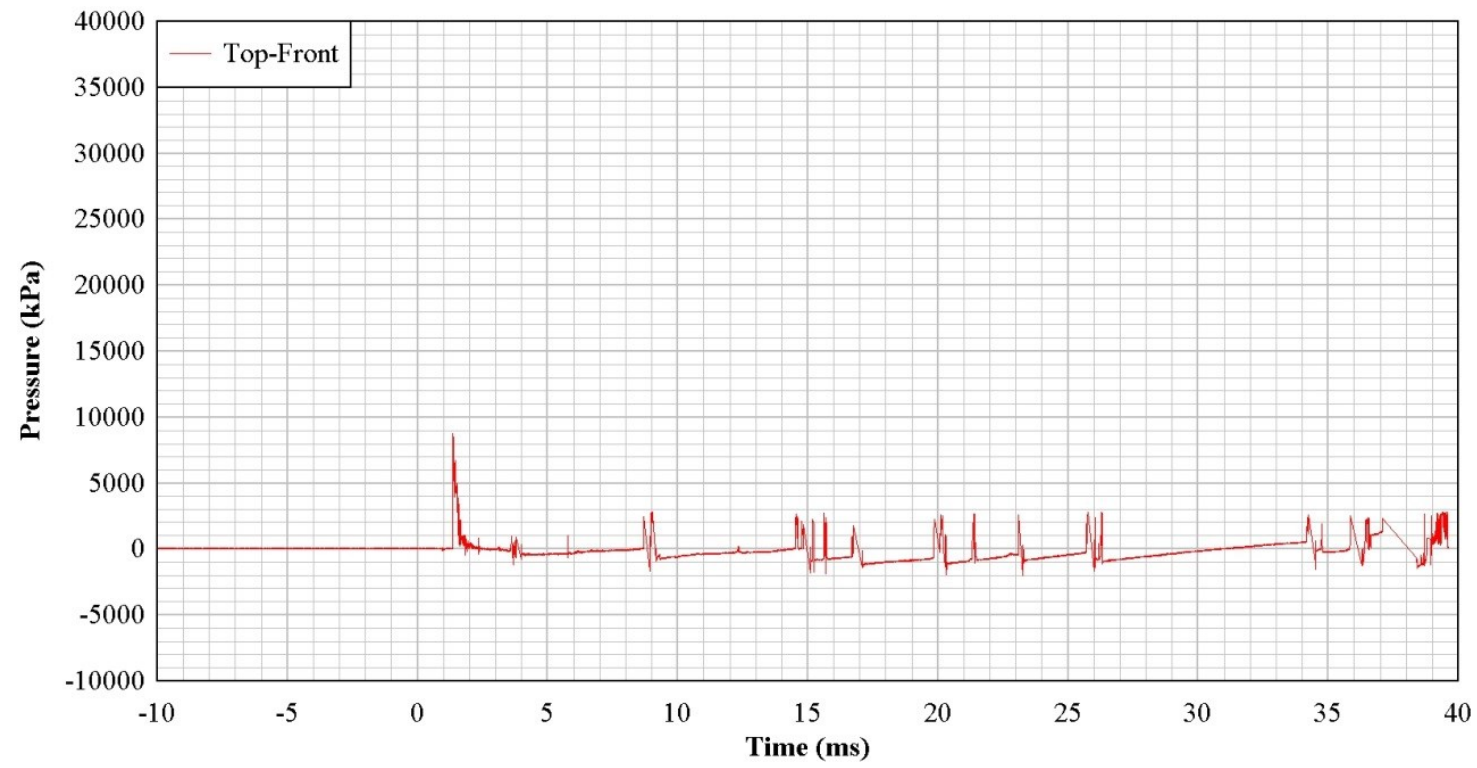

Figure 4-6: Blast pressure profile for Columns CONV-7 and SEIS-8 (Top-front gauge) 


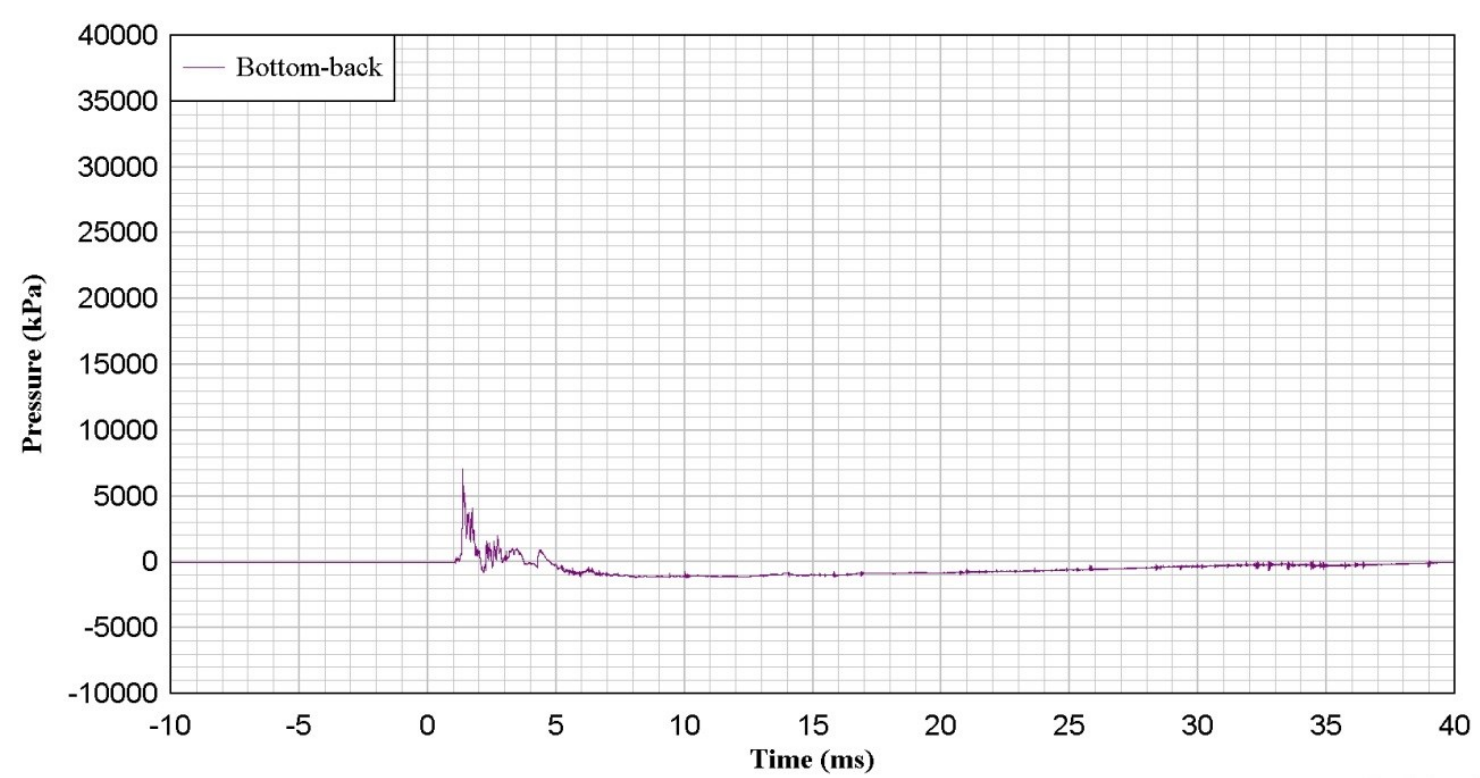

Figure 4-7: Blast pressure profile for Columns CONV-7 and SEIS-8 (Bottom-back pressure gauge)

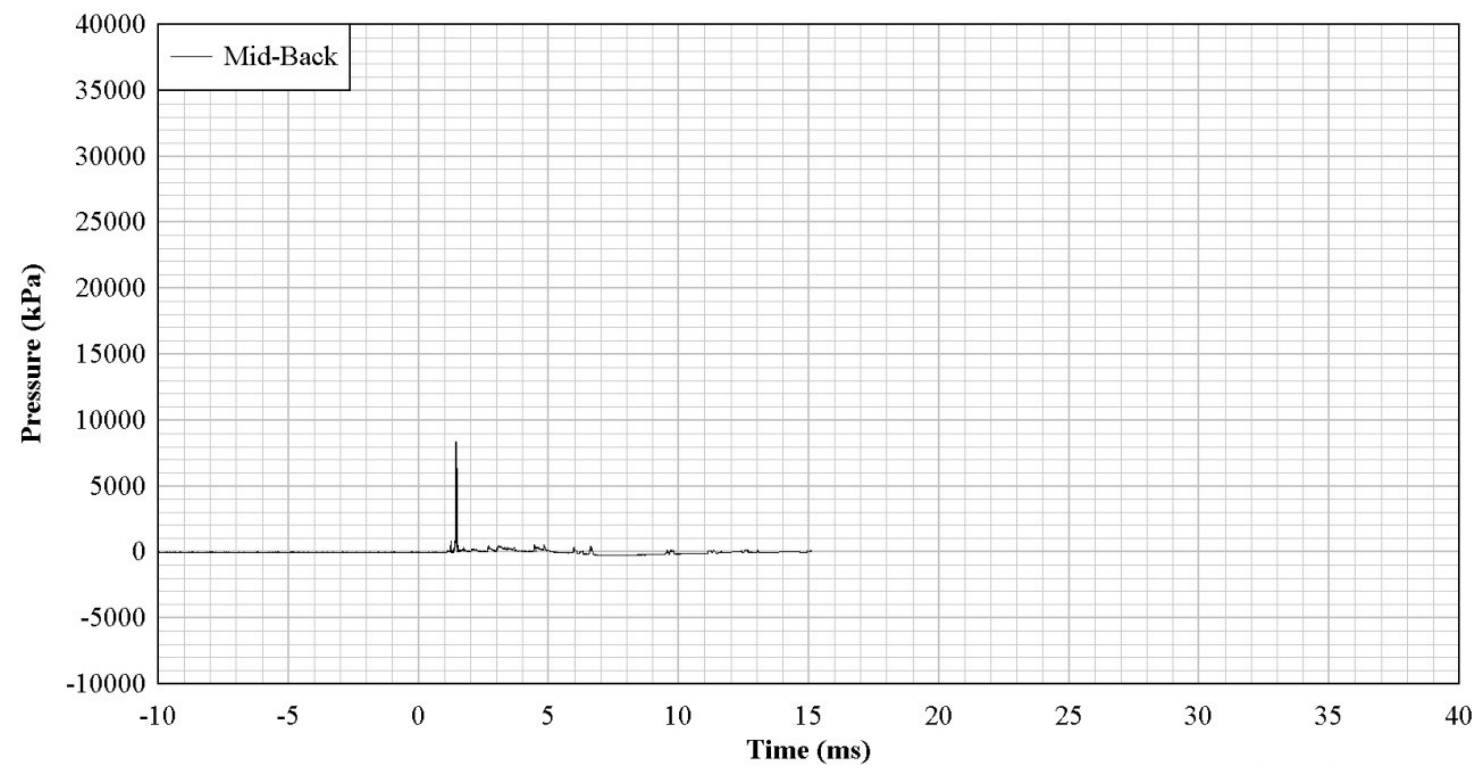

Figure 4-8: Blast pressure profile for Columns CONV-7 and SEIS-8 (Mid-back pressure gauge) 


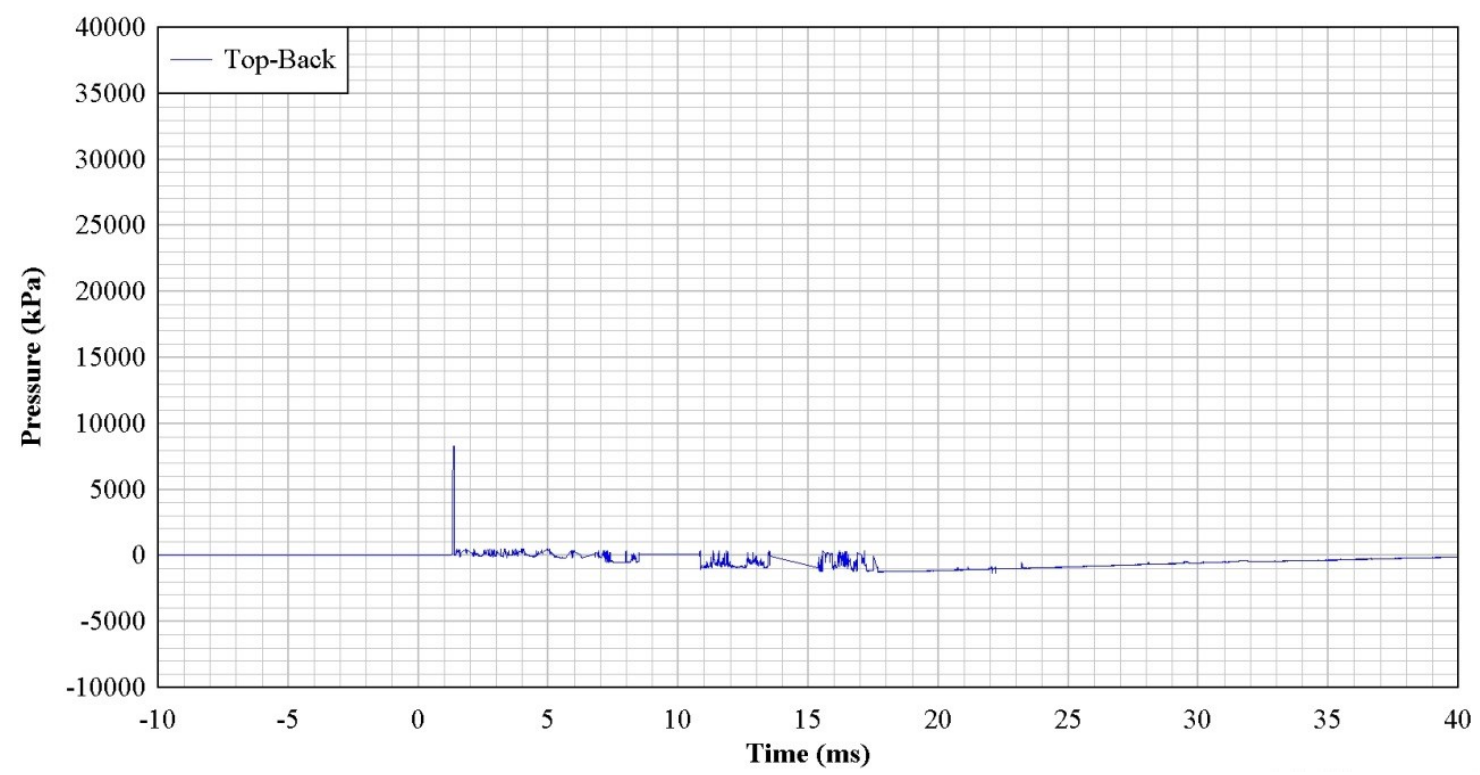

Figure 4-9: Blast pressure profile for Columns CONV-7 and SEIS-8 (Top back pressure gauge)

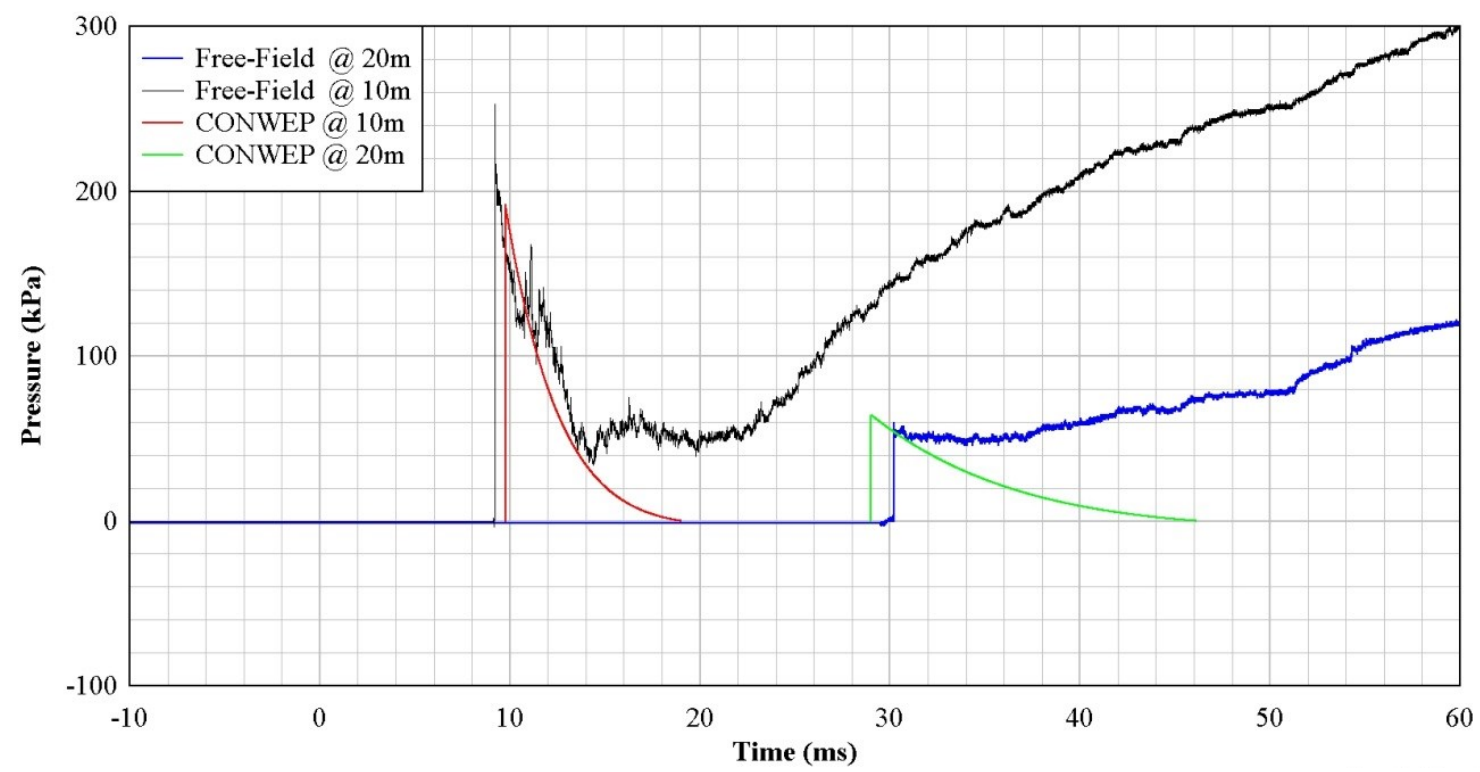

Figure 4-10: Incident pressure profile for Test 1

\subsubsection{Post test observations on Column CONV-7}

Figure 4-11 shows a photograph of column CONV-7 prior to testing, showing the front and side elevations of the column. The figure also shows the pressure gauge positions as well as one visible retractable cable of the string potentiometer (string pot). Only the bottom front pressure gauge location was instrumented to complement the gauges on the 
companion SEIS-8 column. The displacement data for CONV-7 were unreliable with the displacement measured at the upper third-point higher than at mid-height (Figure 4-12). This response is not expected from the nonlinear blast loading measured.

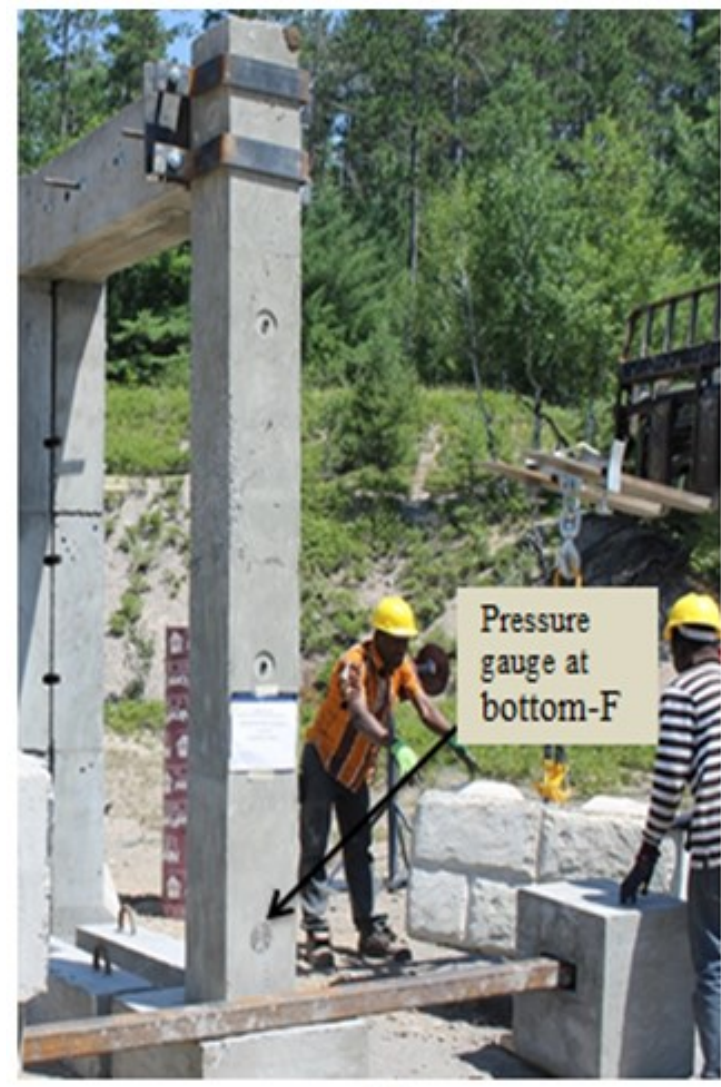

(a)

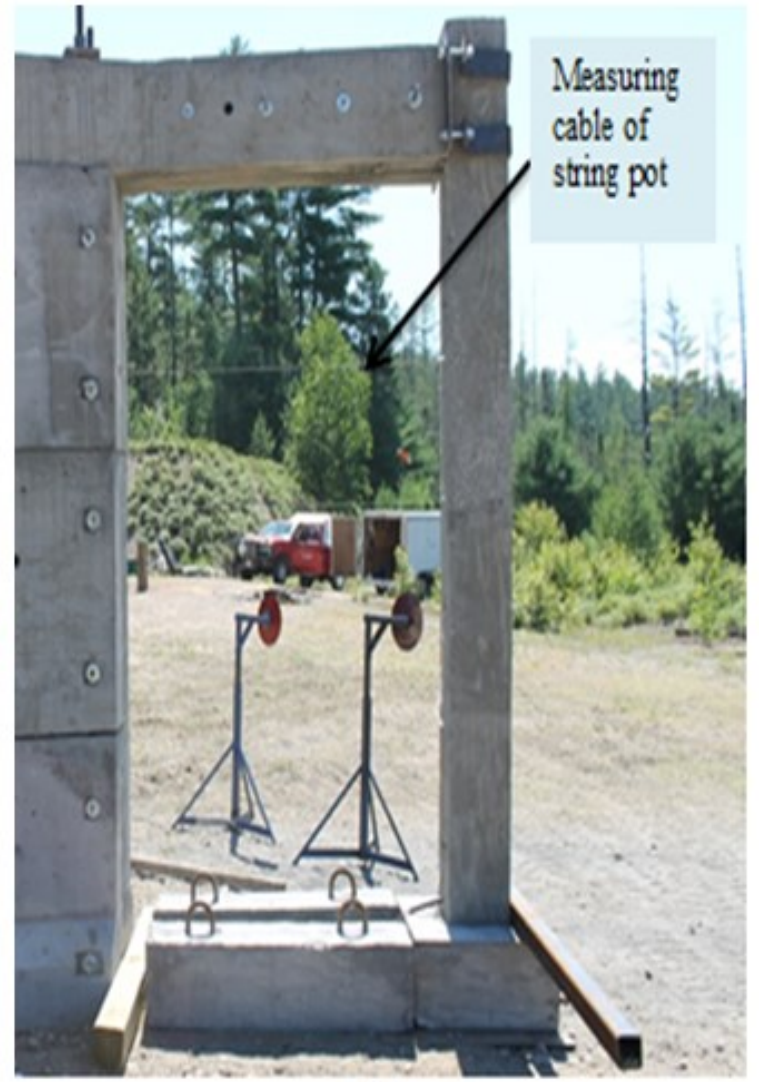

(b)

Figure 4-11: Photograph of Column CONV-7 showing; (a) pressure gauge location (b) measuring cable of string potentiometer at $2 \mathrm{~m}$ from the base of the column 


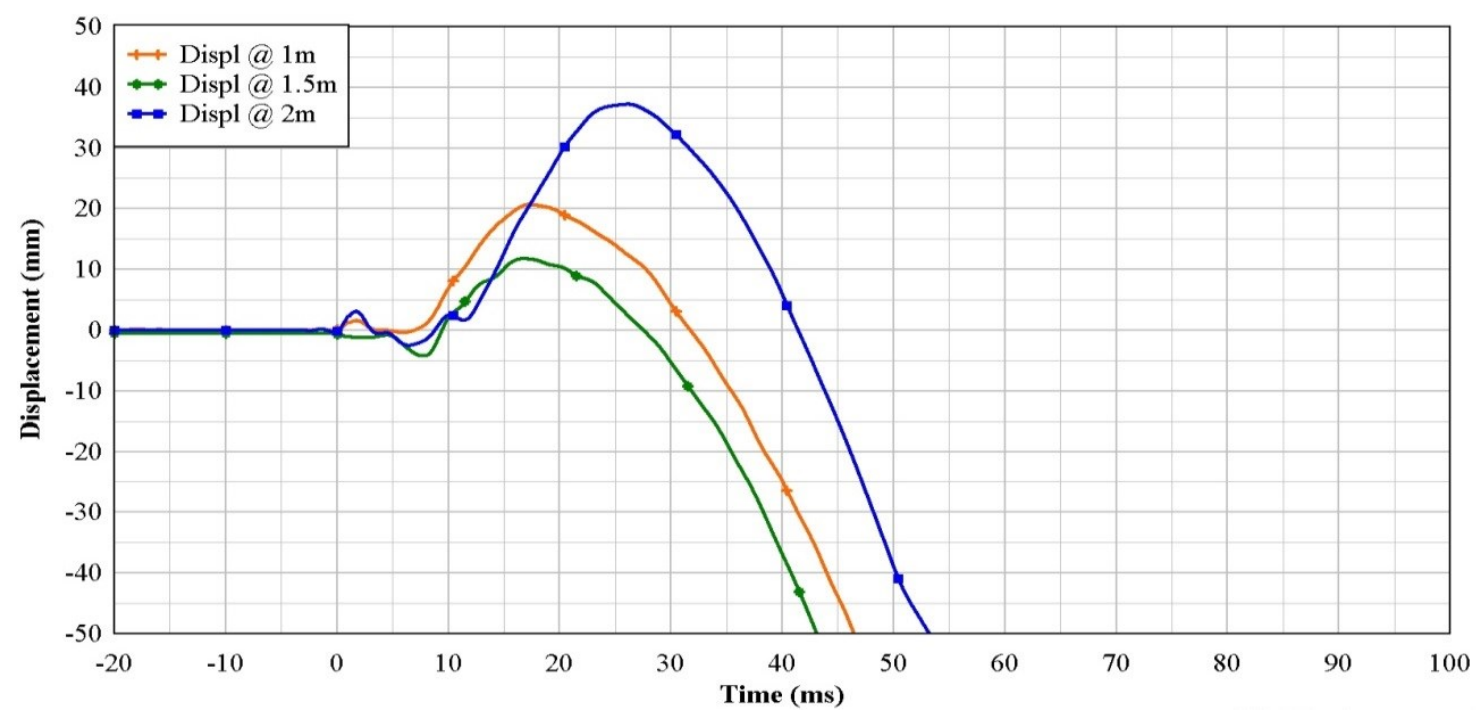

Figure 4-12: Displacement-Time history for Column CONV-7

Figure 4-13 presents the post-test photographs of faces of column CONV-7. No concrete spall on any face nor visible residual cracking was observed on the front face (Figure 413(a)). Flexural cracking was however observed on the back face (Figure 4-13(c)) and sides (Figure 4-13(b) and 4-13(d)) of the column. These cracks were mainly in the midheight region where maximum moment was expected on inbound blast loading. Interestingly, no flexural cracking was observed on the front face towards the ends of the column where maximum moments due to inbound blast loading was expected. This observation could be indicative of the lack of restraint at the ends of the column. 


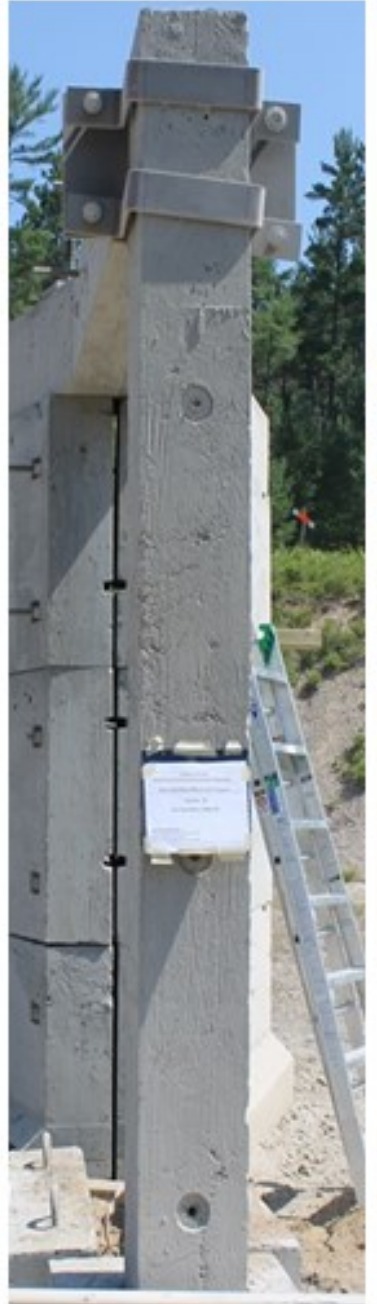

(a)

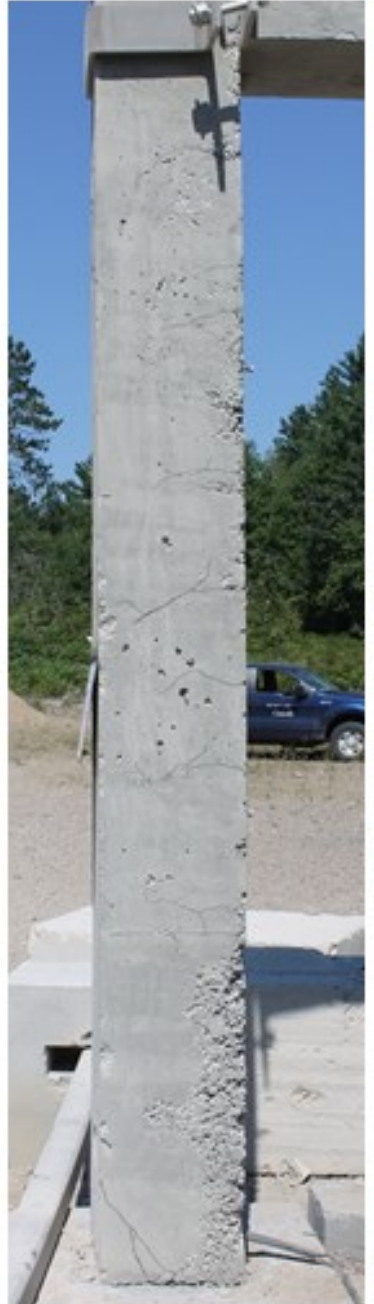

(b)

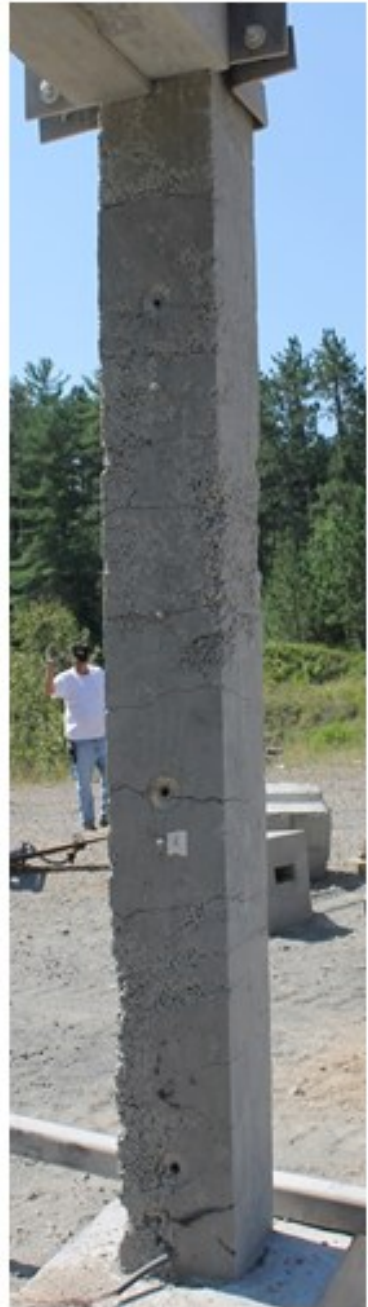

(c)

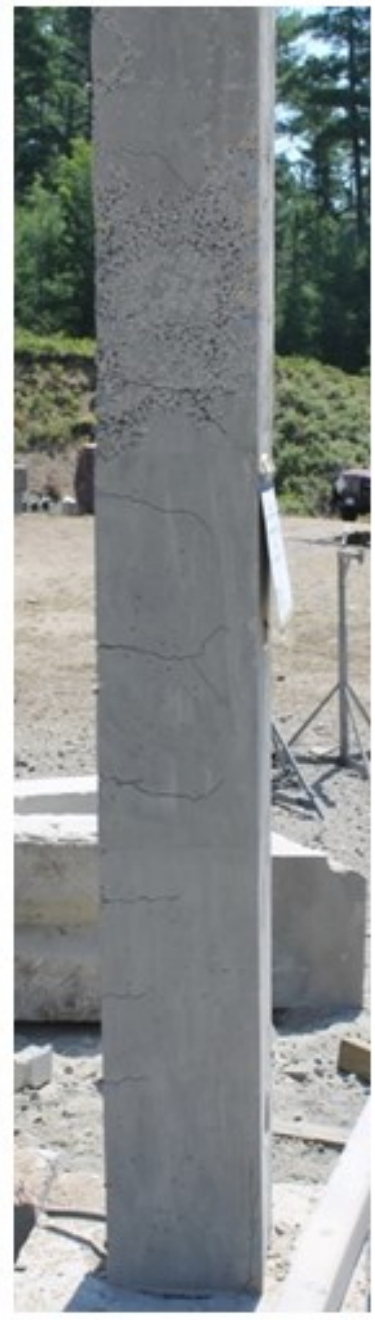

(d)

Figure 4-13: Post-test photograph of Column CONV-7 faces: (a) Front face, (b) Side face (right), (c) Back face, an (d) Side face (left)

\subsubsection{Post-test observations on Column SEIS-8}

Figure 4-14 presents a photograph of Column SEIS-8 prior to test showing front face pressure gauges (Figure 4-14(a)) and back face pressure gauges (Figure 4-14(b)) as well as strain gauge leads from the column. The string pot at lower third and mid-height points (1.0 $\mathrm{m}$ and $1.5 \mathrm{~m}$ respectively) were destroyed and retracted without measuring any displacements. The max displacement at the upper third-point $(2.0 \mathrm{~m})$ was $24.9 \mathrm{~mm}$ (Figure 4-15). 


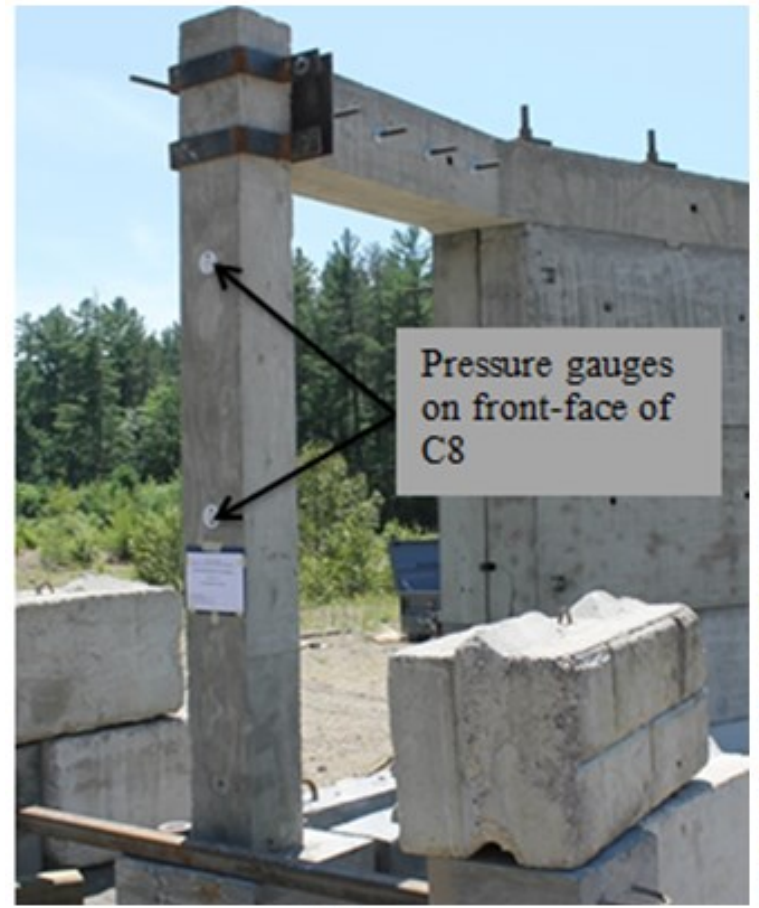

(a)

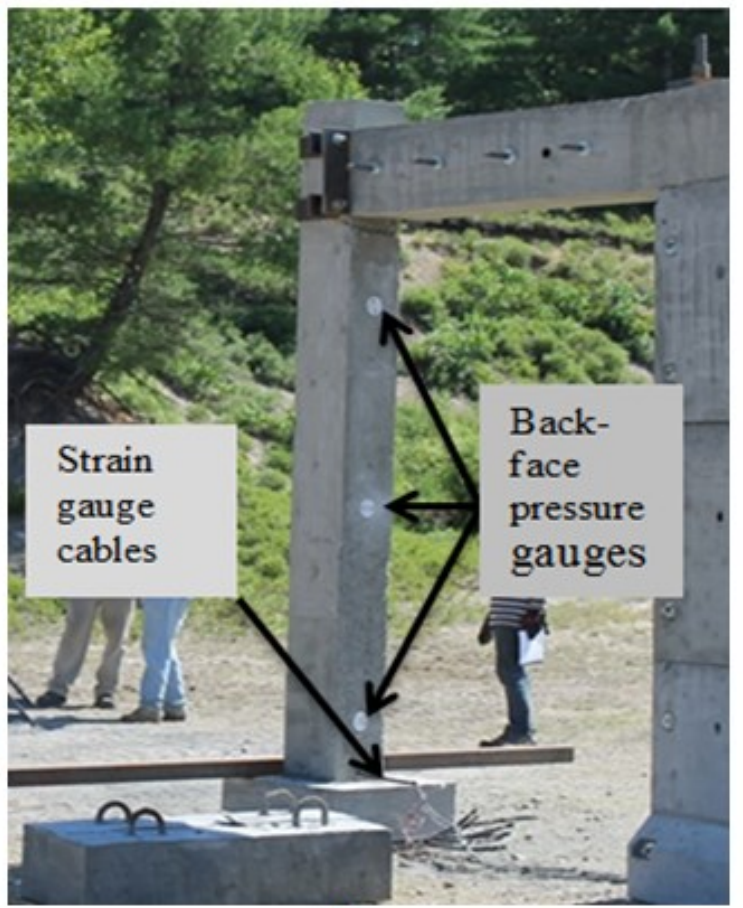

(b)

Figure 4-14: Photograph of Column SEIS-8 before test: (a) Front face with pressure gauges (b) Back face with pressure gauges and strain gauge leads

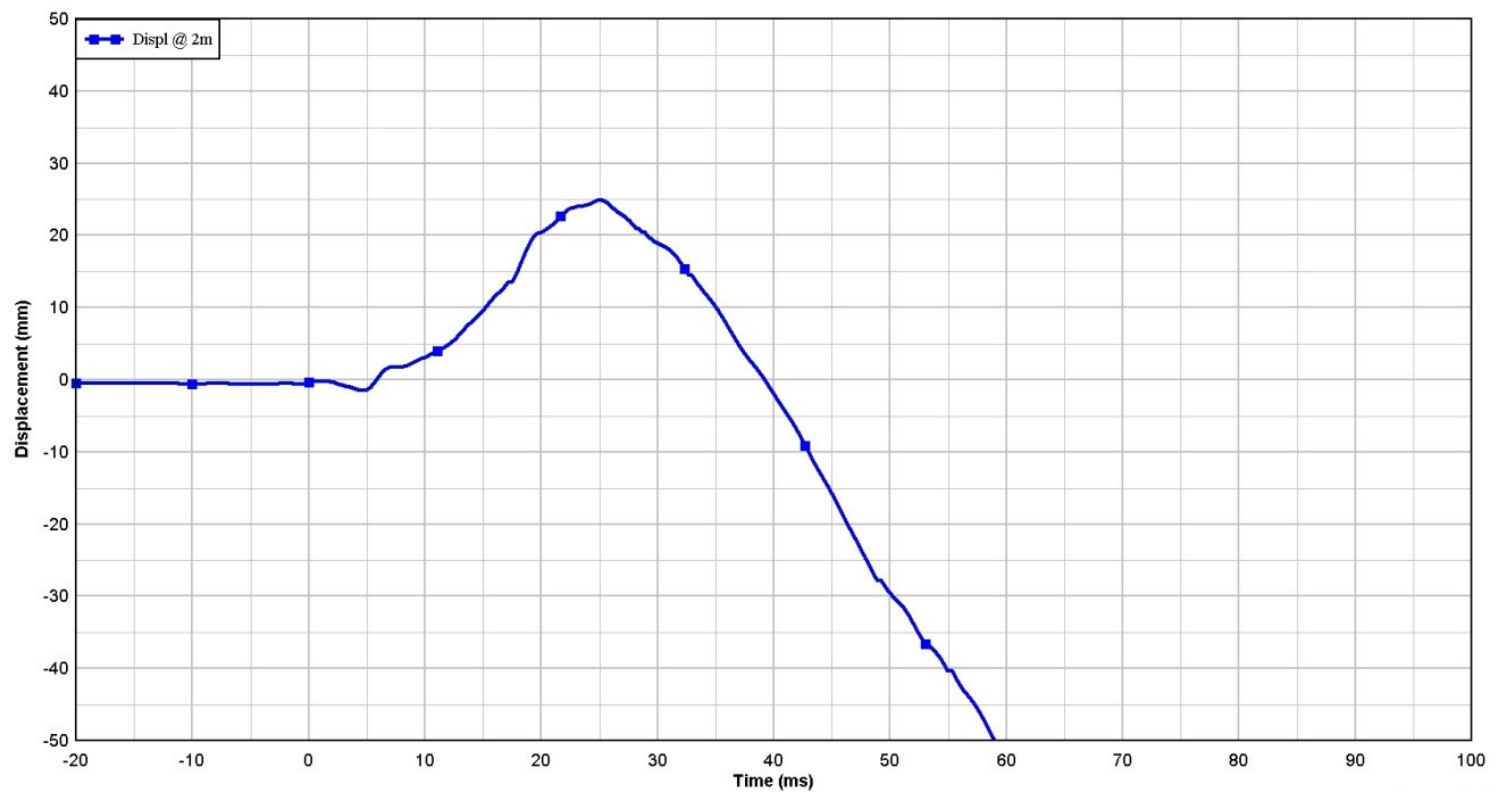

Figure 4-15: Displacement-Time history for Column SEIS-8

Inspection of the column after the test showed no obvious spalling of concrete. Minimal cracks occurred on the back and sides of the column. These cracks were relatively smaller than those observed on the companion Column CONV-7 (Figure 4-16). It was 
observed that, mid-front pressure gauge (Figure 4-16(a)) on column SEIS-8 got damaged during the test as such no blast pressure data was recorded for at this location. While the other gauges produced data, some of them were spurious and could not be used. In order to elevate the charge to a height of burst of $1.0 \mathrm{~m}$, the sonotube used to contain the ANFO explosive was pre-filled with sand to a pre-determined height and then the explosive added to fill the sonotube to the top. The ratio of the diameter of the sonotube to the height of explosive was 1:1. This was to simulate shape of a spherical charge to produce uniform spherically expanding shock front. To a larger degree, this was achieved (see Figure 4-4) however, upon detonation the sand was dispersed and thrown from the centre of detonation. It is suspected that the sand cloud striking the pressure gauges lead to the spurious data read from some of the pressure gauges. 


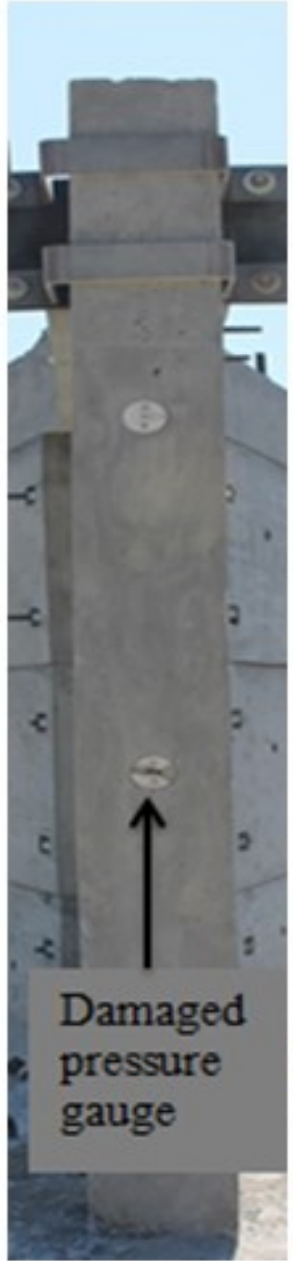

(a)

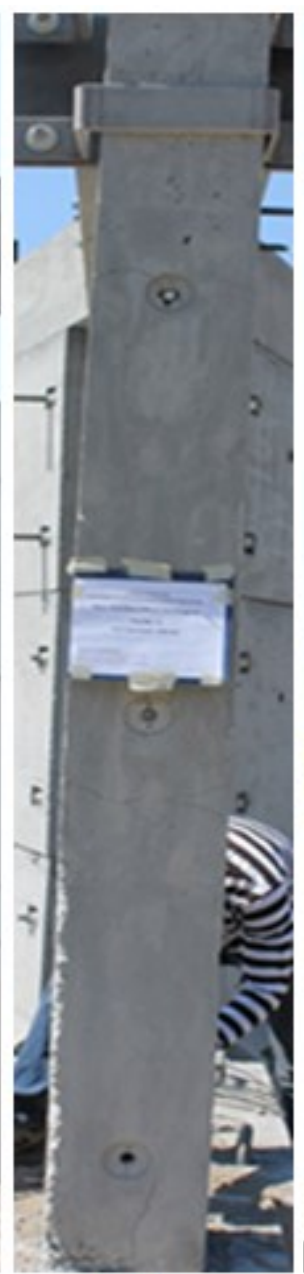

(b)

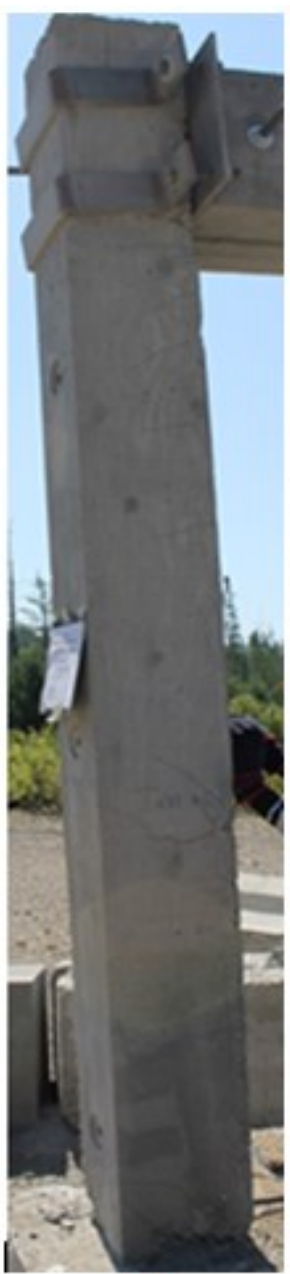

(c)

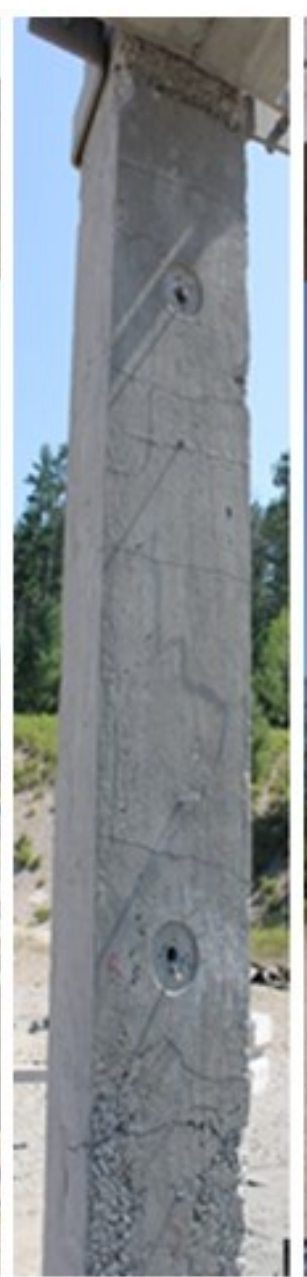

(d)

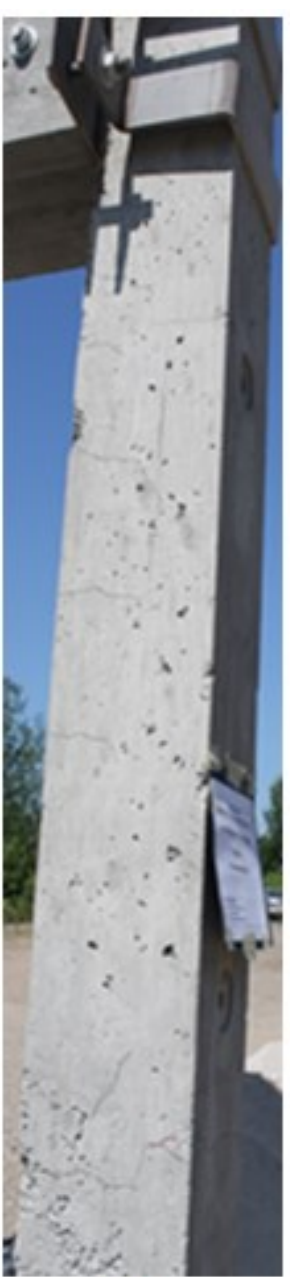

(e)

Figure 4-16: Post-test photograph of Column SEIS-8 faces: (a, b) Front face, (b) Side face (right) (c) Back face, ad (d) Side face (left)

Table 4-4 present a summary of the results from Test 1 . The pressure on the front face of the columns vary significantly from $33,133 \mathrm{kPa}$ at the bottom to $8,791 \mathrm{kPa}$ at the top. The high reflected pressure at the bottom of the column is attributed to blast pressure amplification due to shock front reflection off the ground. The pressure on the back face of the column is relatively uniform; varying between $7,084 \mathrm{kPa}$ at the bottom to 8,286 $\mathrm{kPa}$ at the top slightly higher at mid-height (closest to the centre of detonation) at 8,381 $\mathrm{kPa}$. 
During the testing the retractable cables of the string potentiometers, made of lead-core lines, were engulfed by the explosion fireball. The gauge at mid-height of SEIS- 8 was damaged and retracted before column deformation. The other gauges recorded some displacements. The recorded maximum displacement of Column CONV-7 occurred at different times, with the displacement at the upper third-point occurring much later. Since the column did not fail, a uniform deformed shape and simultaneous maximum displacements are expected at the measuring station. The displacement at the upper-third point (at $2 \mathrm{~m}$ ) of $41.1 \mathrm{~mm}$ is suspected to be erroneous. The maximum displacement at the lower-third point (at $1 \mathrm{~m}$ ) is higher than that at mid-height (at $1.5 \mathrm{~m}$ ). The measured displacement of Column SEIS-8 was at upper-third point (Table 4-4(b)). 
Table 4-4: Summary of test 1 (CONV-7 and SEIS-8) results

\begin{tabular}{|c|c|c|c|c|c|c|c|c|}
\hline \multicolumn{9}{|c|}{ (a) Blast Pressure Results } \\
\hline Test Specimens & \multicolumn{8}{|c|}{ CONV-7 and SEIS-8 } \\
\hline \multirow{2}{*}{ Test Details } & \multicolumn{2}{|c|}{ Charge Mass } & \multicolumn{2}{|c|}{ Standoff } & \multicolumn{2}{|c|}{$\mathrm{z}\left(\mathrm{m} / \mathrm{kg}^{1 / 3}\right)$} & ALR & \\
\hline & \multicolumn{2}{|c|}{ 100-kg ANFO } & \multicolumn{2}{|c|}{$2.5 \mathrm{~m}$} & \multicolumn{2}{|c|}{0.58} & 0 & \\
\hline \multirow{2}{*}{ Gauge } & \multicolumn{2}{|c|}{ Bottom-Front } & \multicolumn{2}{|c|}{ Top-Front } & \multicolumn{2}{|c|}{ Bottom-Back } & Mid-Back & Top-Back \\
\hline & Exp. & CONWEP & Exp. & CONWEP & Exp. & CONWEP & Exp. & Exp. \\
\hline Location $\left(\mathrm{mm}^{*}\right)$ & \multicolumn{2}{|c|}{255} & \multicolumn{2}{|c|}{2250} & \multicolumn{2}{|c|}{280} & 1300 & 2250 \\
\hline Range (mm) & \multicolumn{2}{|c|}{2608.6} & \multicolumn{2}{|c|}{2795.1} & \multicolumn{2}{|c|}{3047} & 2960 & 3240 \\
\hline Incident Angle & \multicolumn{2}{|c|}{$16.6^{0}$} & \multicolumn{2}{|c|}{$26.6^{0}$} & & & & \\
\hline $\mathrm{P}_{\mathrm{r}}(\mathrm{kPa})$ & 33,133 & 18,290 & 8,791 & 14,372 & 7,084 & 13,340 & 8,381 & 8,286 \\
\hline $\mathrm{T}_{\mathrm{a}}(\mathrm{ms})$ & 0.98 & 0.9 & 1.36 & 1.0 & 1.37 & 1.21 & 1.43 & 1.37 \\
\hline $\mathrm{T}_{\mathrm{d}}(\mathrm{ms})$ & 0.51 & 2.2 & 1.78 & 2.7 & 0.73 & 3.65 & - & - \\
\hline \multicolumn{9}{|c|}{ (b) Displacement Results } \\
\hline & \multicolumn{2}{|c|}{ Displ@1m } & \multicolumn{2}{|c|}{ Displ@1.5m } & \multicolumn{2}{|c|}{ Displ@2m } & & \\
\hline CONV-7 & \multicolumn{2}{|c|}{$24.0 \mathrm{~mm}$} & \multicolumn{2}{|c|}{$17.0 \mathrm{~mm}$} & \multicolumn{2}{|c|}{$41.1 \mathrm{~mm}$} & & \\
\hline SEIS-8 & \multicolumn{2}{|c|}{ Damaged } & \multicolumn{2}{|c|}{ Damaged } & \multicolumn{2}{|c|}{$24.9 \mathrm{~mm}$} & & \\
\hline
\end{tabular}

*dimensions measured from top of concrete footing 


\subsection{Column Test 2 (SEIS-9 and CONV-20)}

Since the response of the columns in Test 1, using 100-kg ANFO explosive charge, resulted in minimal damage, special permission was requested to exceed the charge mass limitation of the test site. Test 2 was, thus conducted with 150-kg ANFO charge mass. The two columns (SEIS-9 and CONV-e20) tested in Test 2 were placed equidistant from the centre of explosion; yielding standoff distance of $2.60 \mathrm{~m}$ and scaled distance of $0.52 \mathrm{~m} / \mathrm{kg}^{1 / 3}$. Figure 417 presents a sketch while Figure 4-18 presents a photograph of the experimental setup. Two columns (column SEIS-9 and column CONV-20) were instrumented with pressure gauges, string potentiometers and strain gauges. High speed videography, using a NAC Memrecam GX-8 video camera, was also used to monitor the response of the concrete columns during testing. Column CONV-20 was designed as a conventional column, while Column SEIS-9 was designed as a seismic force resisting column.

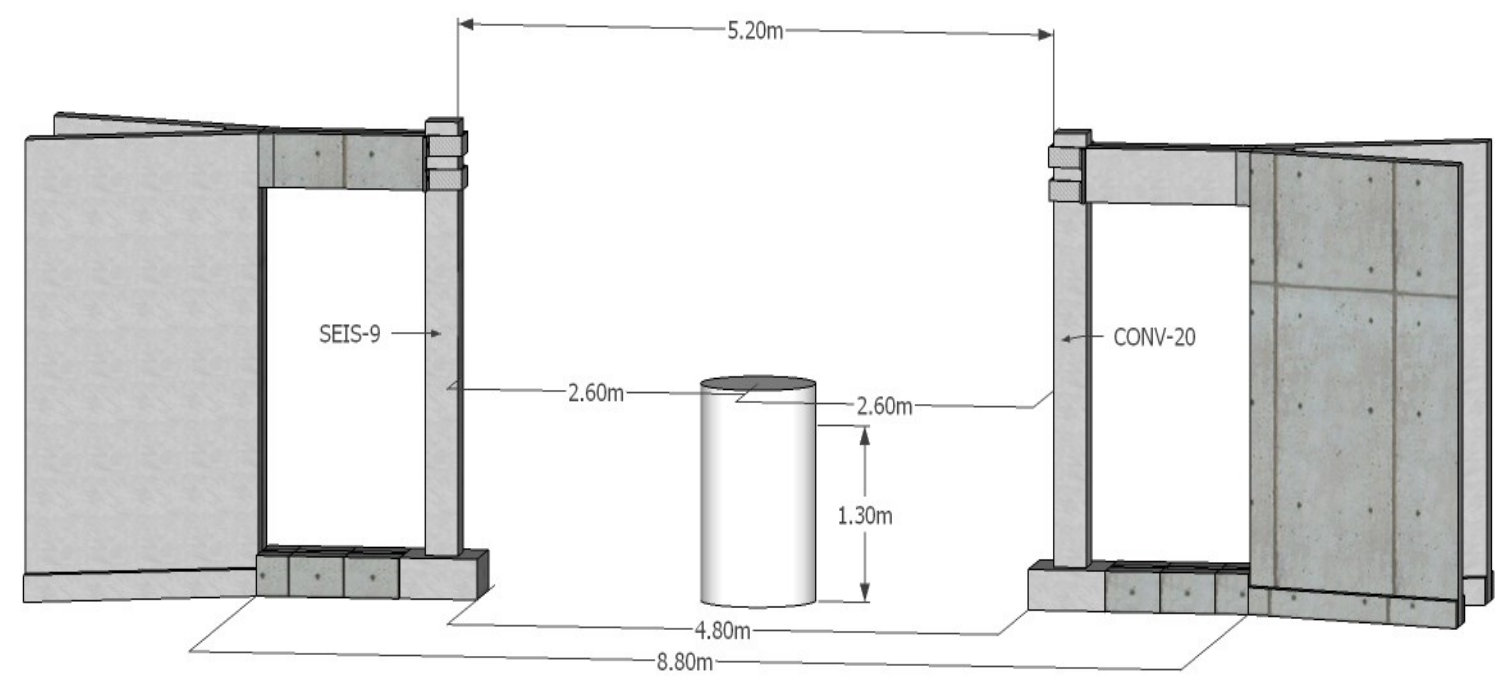

Figure 4-17: Sketch of SEIS-9 and CONV-20 experimental setup 


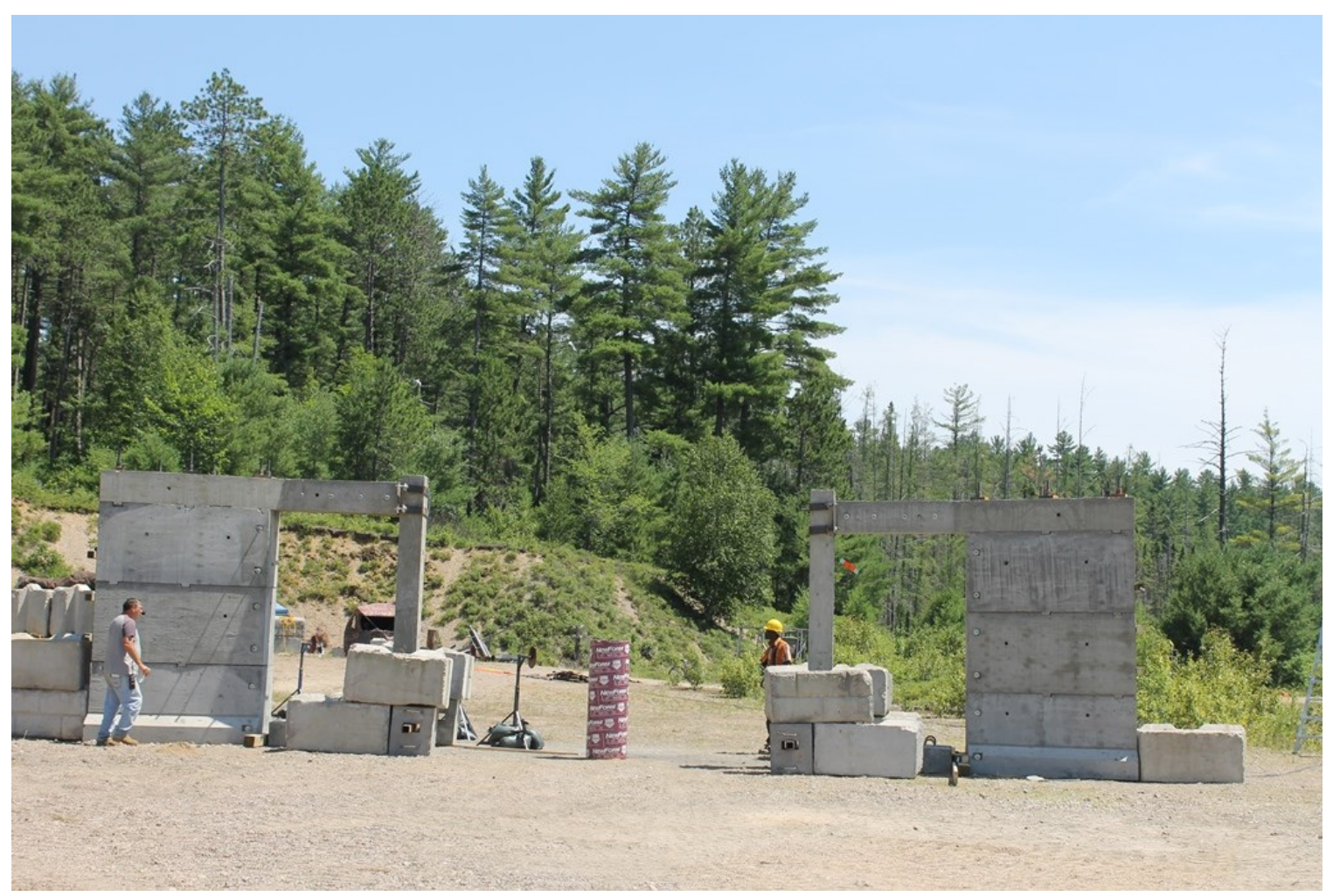

\section{Figure 4-18: Pre-test setup of Test 2 (SEIS-9 and CONV-20)}

\subsubsection{Blast Loading in Test 2}

The front face of CONV-20 was instrumented with pressure gauges (Figure 4-20) while only the mid-back of column SEIS-9 was instrumented (Figure 4-19). Since the columns were equidistant from the charge mass, the blast loading from the gauges on SEIS-9 and CONV20 are representative of blast loading on the two columns.

Figure 4-19, Figure 4-20, and Figure 4-21 present the reflected pressure profiles at the bottom-front, mid-front, and top-front of the columns respectively. The peak reflected pressure at the bottom of the column was $35,555 \mathrm{kPa}$ with an arrival time of $1.0 \mathrm{~ms}$, while the reflected pressure at mid-height of the column was $26,531 \mathrm{kPa}$ with arrival time of 1.1 ms. The reflected pressure at the top of the column was substantially lower at 2,598 $\mathrm{kPa}$ with arrival time of $1.48 \mathrm{~ms}$. 
The pressure at the bottom-front is significantly higher than the blast pressure calculated at this location using CONWEP - A collection of conventional weapons effects calculations based on the Kingery-Bulmash polynomials with corrected angle of incidence (Table 4-5). The reason for this is the possible formation of a Mach reflection and the gauge being located within the Mach stem of the explosion. The reflected pressure at the mid-front pressure gauge of $26,531 \mathrm{kPa}$ was comparable to the pressure calculation from CONWEP with appropriate correction for angle of incidence (Table 4-5). The peak pressure at the top-front gauge location was significantly lower than the pressures calculated from the KingeryBulmash polynomials with appropriate correction for angle of incidence. Details of KingeryBulmash polynomials results are in Table 4-5. Free-field pressure gauges were used to record the incident overpressure remote from the centre of detonation. Figure 4-22 presents the experimental free-field incident pressure profile at standoff distances of $10 \mathrm{~m}$ and $20 \mathrm{~m}$. The incident overpressure at $10 \mathrm{~m}$ was $404 \mathrm{kPa}$ at an arrival time of $7.9 \mathrm{~ms}$, while the incident overpressure at $20 \mathrm{~m}$ was $81 \mathrm{kPa}$ at an arrival time of $27.3 \mathrm{~ms}$.

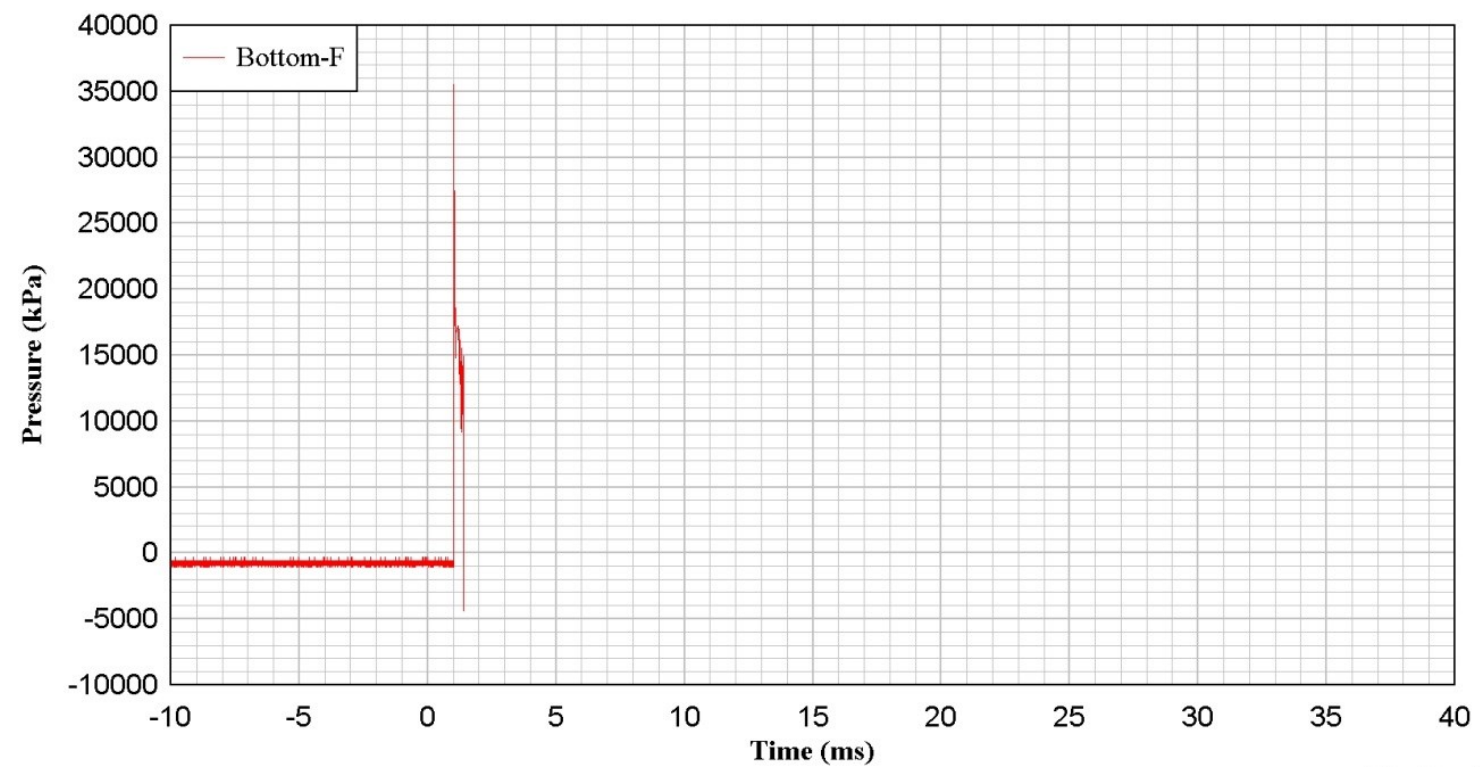

Figure 4-19: Blast pressure profile for Column SEIS-9 and CONV-20 (bottom-front pressure gauge) 


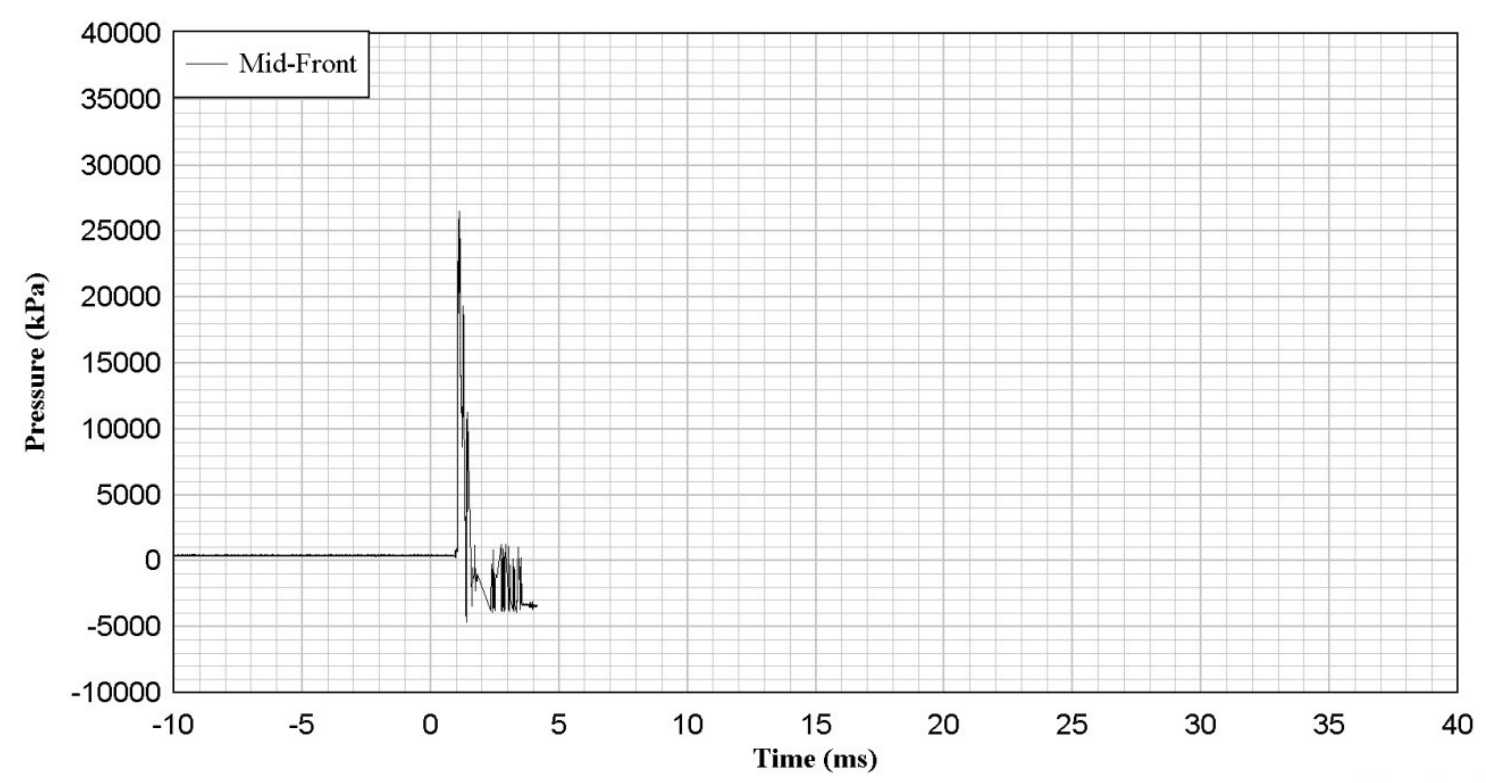

Figure 4-20: Blast pressure profile for Column SEIS-9 and CONV-20 (Mid-front pressure gauge)

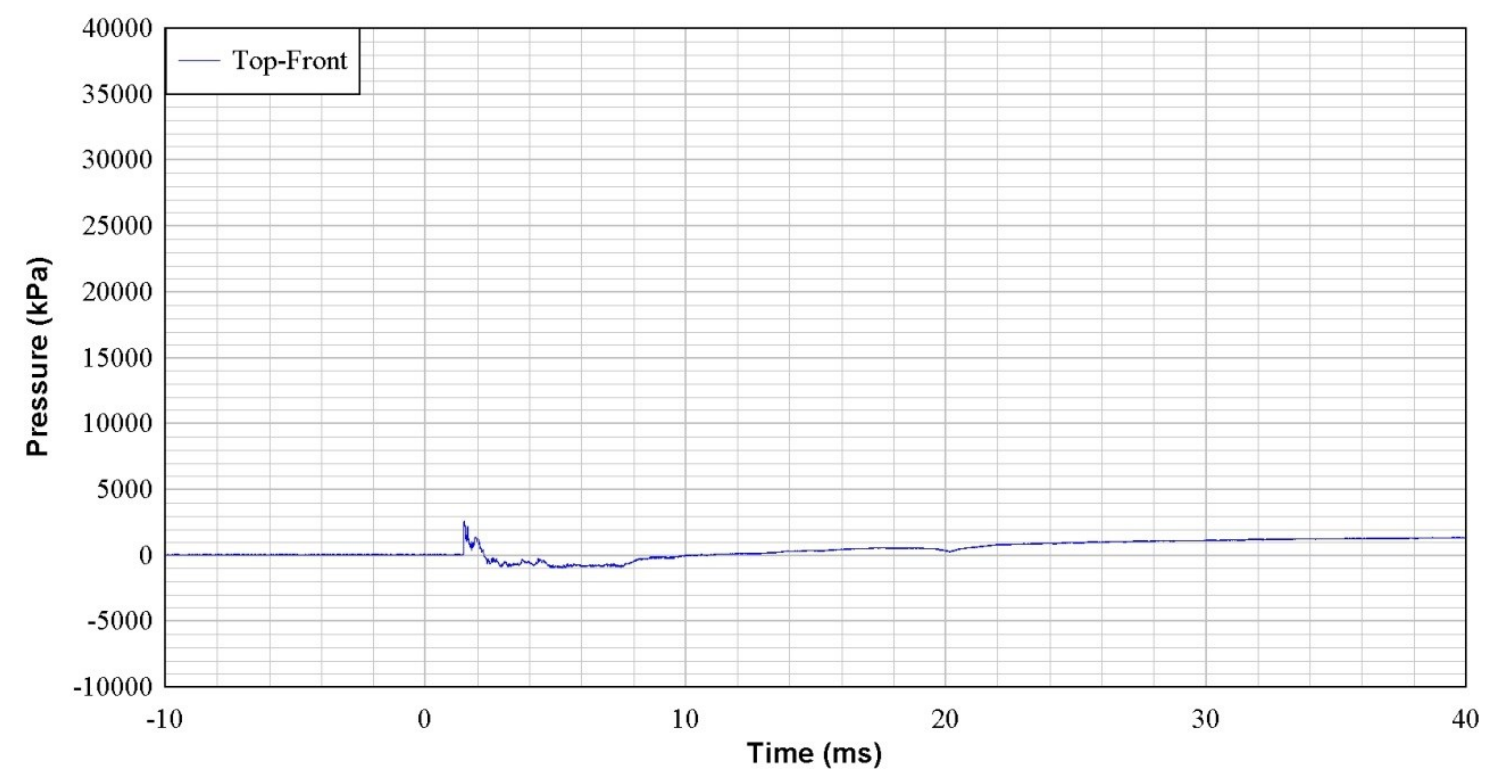

Figure 4-21: Blast pressure profile for Column SEIS-9 and CONV-20 (Top-front pressure gauge) 


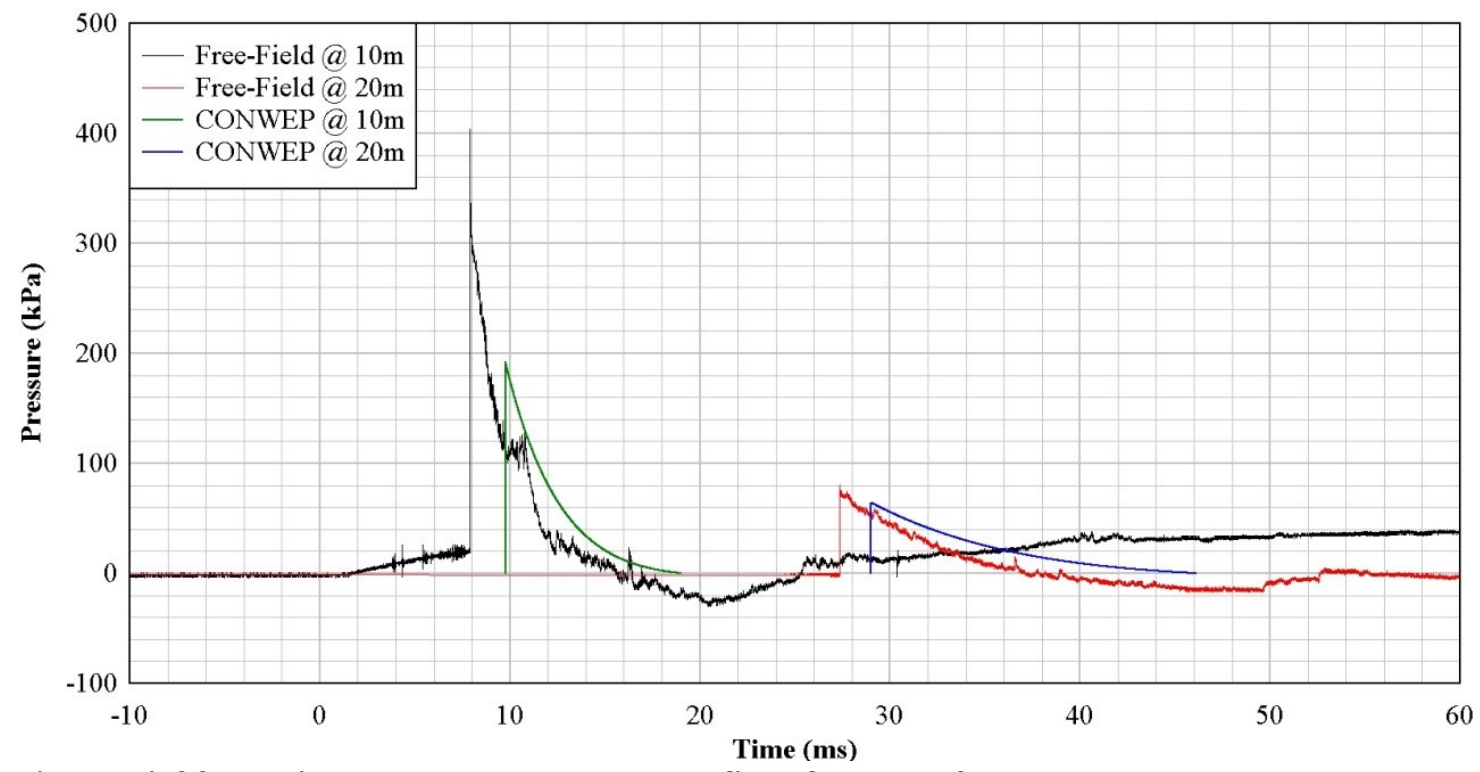

Figure 4-22: Incident blast pressure profiles for Test 2

\subsubsection{Column SEIS-9}

Column SEIS-9, detailed as a seismic force resisting column, was instrumented with string potentiometers connected to the back face at $1.0 \mathrm{~m}, 1.5 \mathrm{~m}$, and $2.0 \mathrm{~m}$ from top of the footing. Figure 4-23 shows a photograph of column SEIS-9 prior to test, showing the mid-back pressure gauge and one retractable cable of string potentiometer column at mid-height. The string pot at lower third-point $(1.0 \mathrm{~m})$ failed during the test, as such no data was recorded for at this location. The displacement data at mid-height and upper third-points for SEIS-9 were unreliable with the displacement measured at the upper third-point higher than at mid-height (Figure 4-24). The raw data for the displacement is included in the Appendix A. 


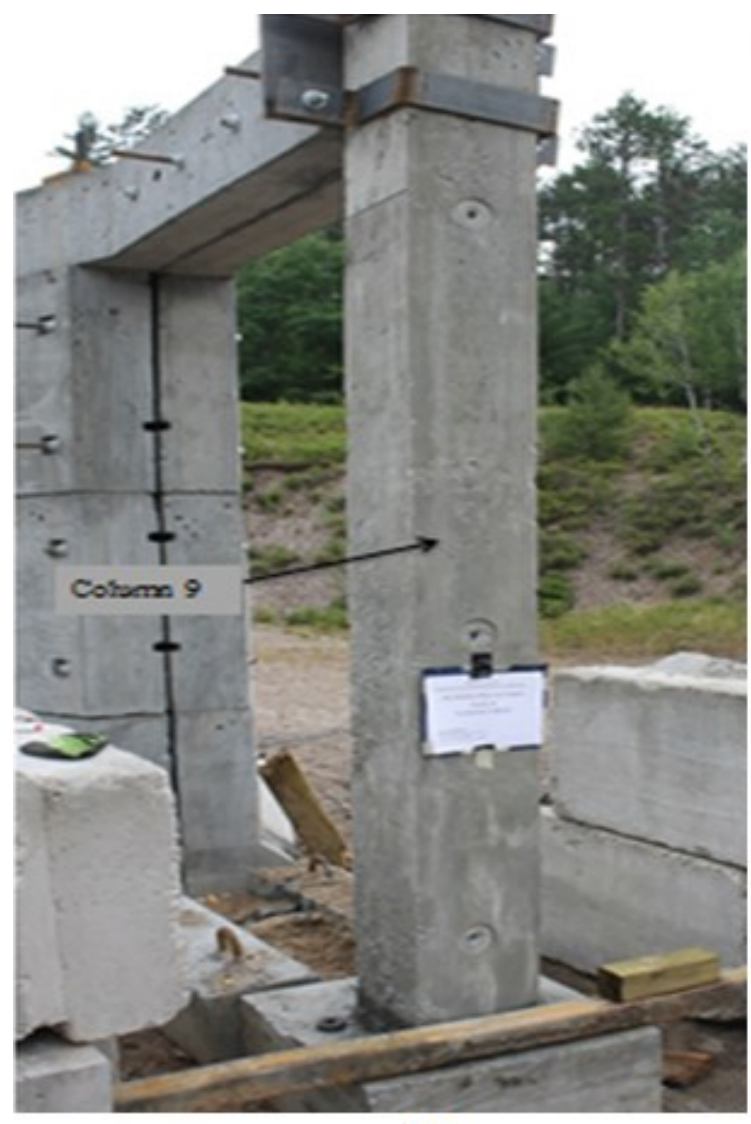

(a)

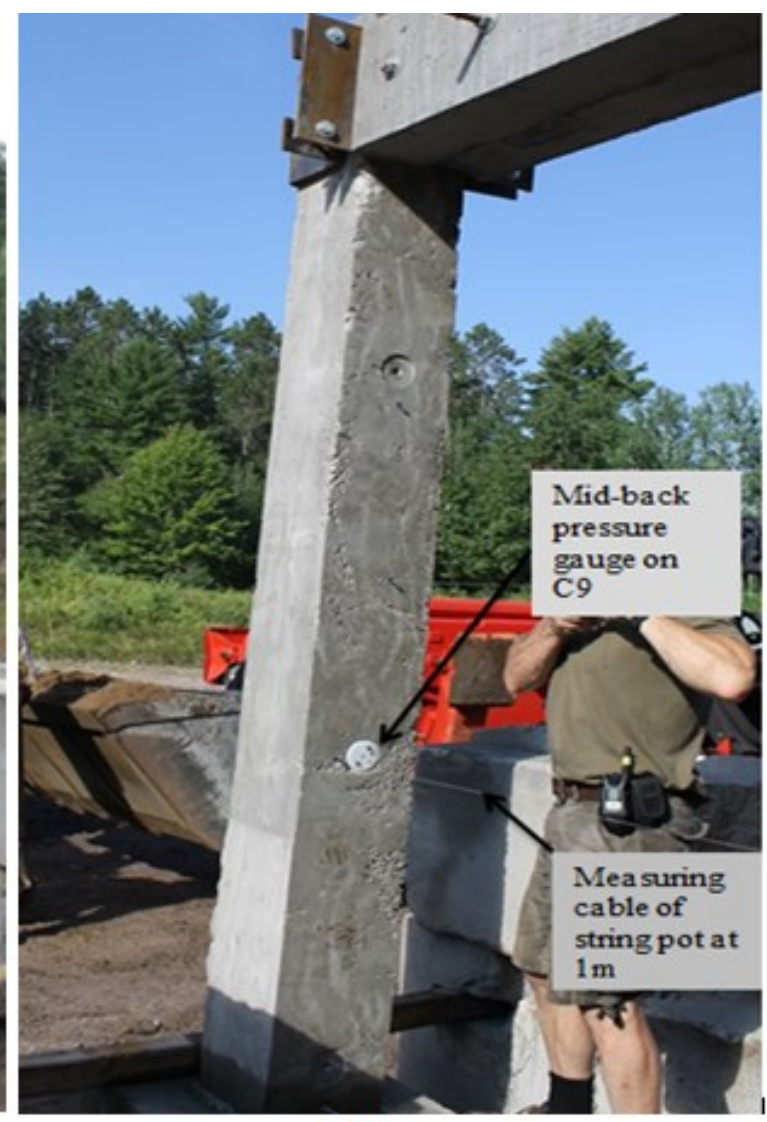

(b)

Figure 4-23: Photograph of Column SEIS-9 before test: (a) Front face (b) Back face with mid-back pressure gauge and a retractable cable of string pot at $1 \mathrm{~m}$

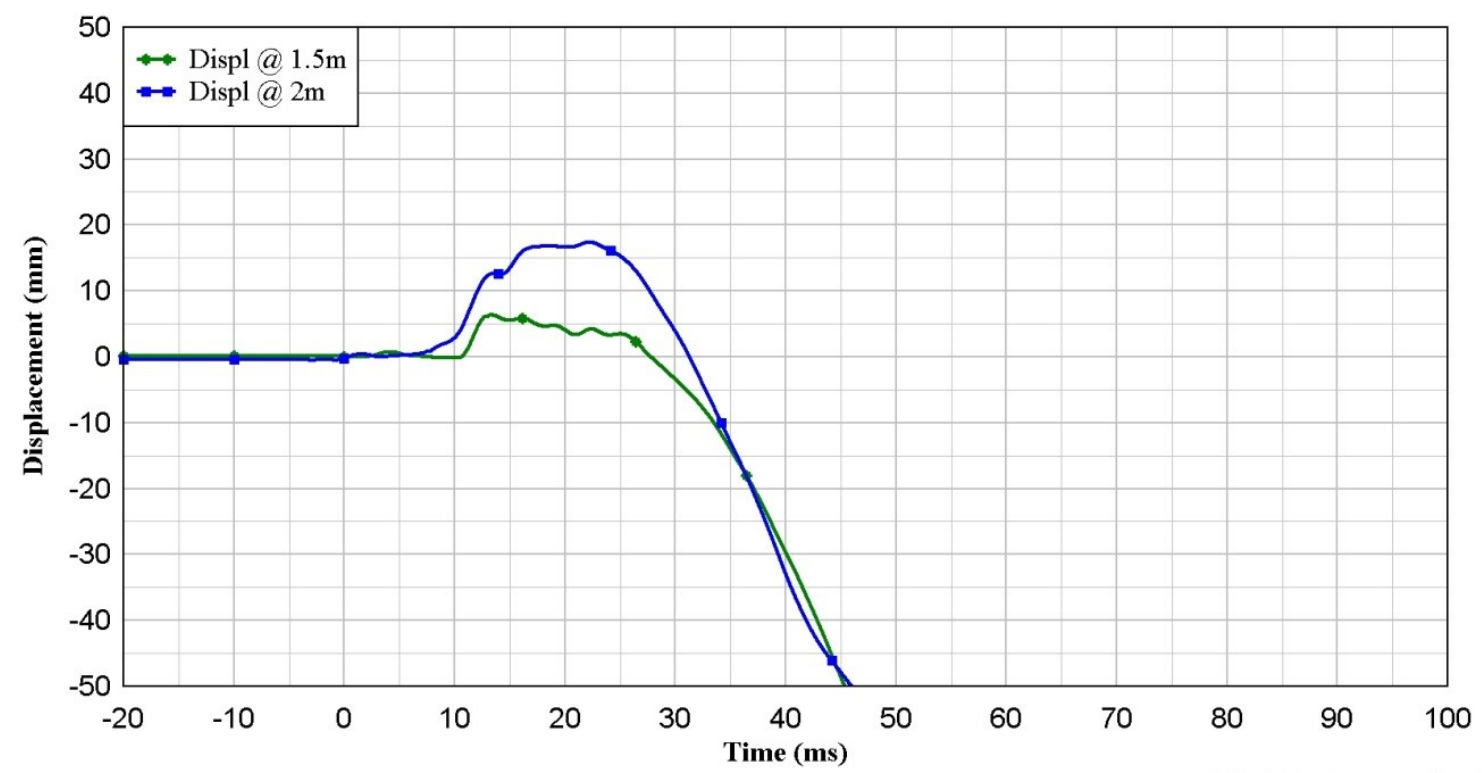

Figure 4-24: Displacement-Time history for Column SEIS-9 
Figure 4-25 presents the post-test photographs of SEIS-9. Severe flexural cracking and spalling of the concrete at mid-height were observed (Figure 4-25(c)). The height of spall is $660 \mathrm{~mm}$, with a depth of $140 \mathrm{~mm}$. There were also minimal shear cracks in the lower bottom (near the support) of the column (Figure 4-25(b) and (d)). Because of lack of cracking at top support in comparison to bottom, it appears there was higher fixity at the bottom support. Along the entire height of column, flexural cracks occurred at the back and sides of the column (Figure 4-25(b), (c), and (d)).

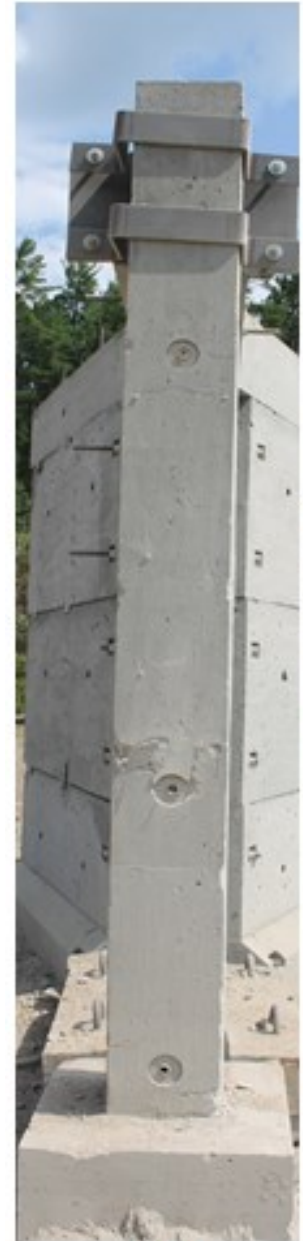

(a)

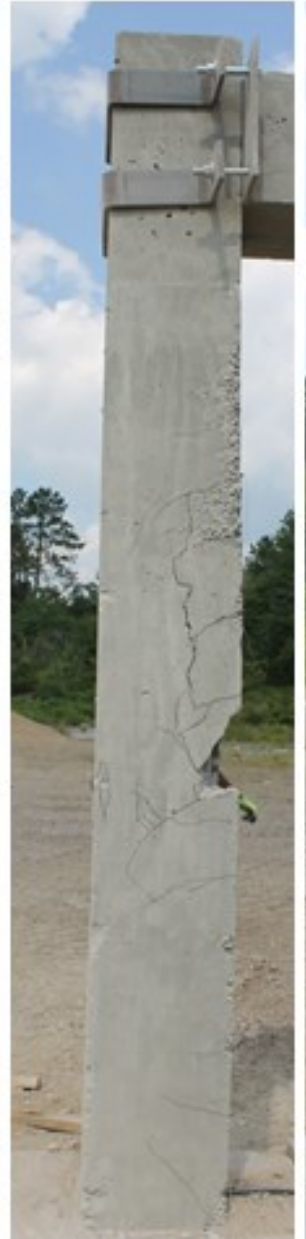

(b)

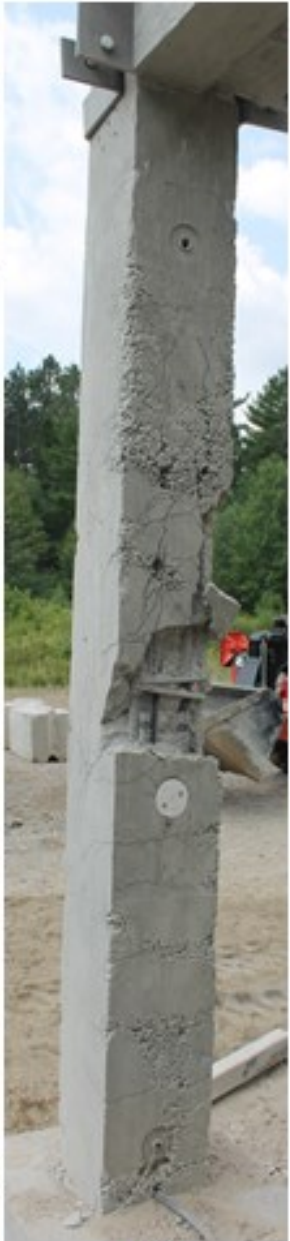

(c)

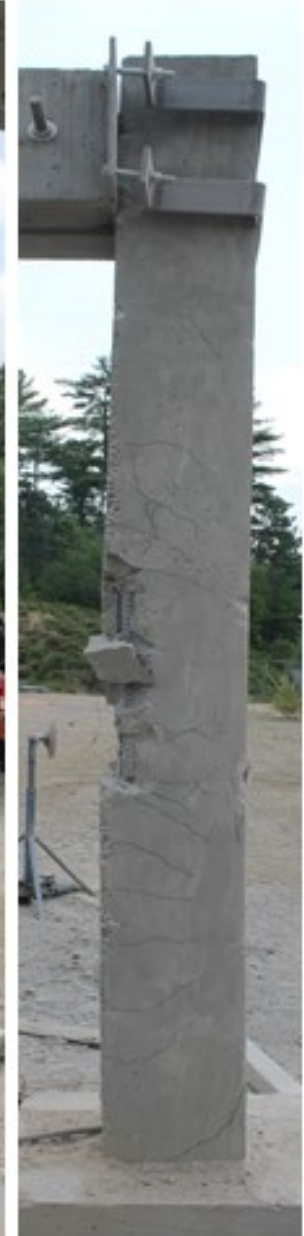

(d)

Figure 4-25: Post-test photograph of Column SEIS-9 faces: (a) Front face, (b) Side face (right) (c) Back face, and (d) Side face (left) 


\subsubsection{Column CONV-20}

Figure 4-26 shows a photograph of column CONV-20 prior to testing, while Figure 4-28 shows post-test photographs of column CONV-20 with extensive cracking and spalling of concrete revealing reinforcement in the lower one-third region of the column. Buckling of the $25 \mathrm{M}$ rebar in the back face of the column was observed. Minimal flexural cracks were also observed on the column. These cracks were wider on the back face and sides of the column (Figure 4-28(b), (c), and (d)). The spalling and cracking of concrete in the lower part of the column, close to the concrete footing, likely led to the damage of the bottom-front pressure gauge. The maximum displacement of $14.3 \mathrm{~mm}$ of CONV-20 was measured at mid-height (Figure 4-27).

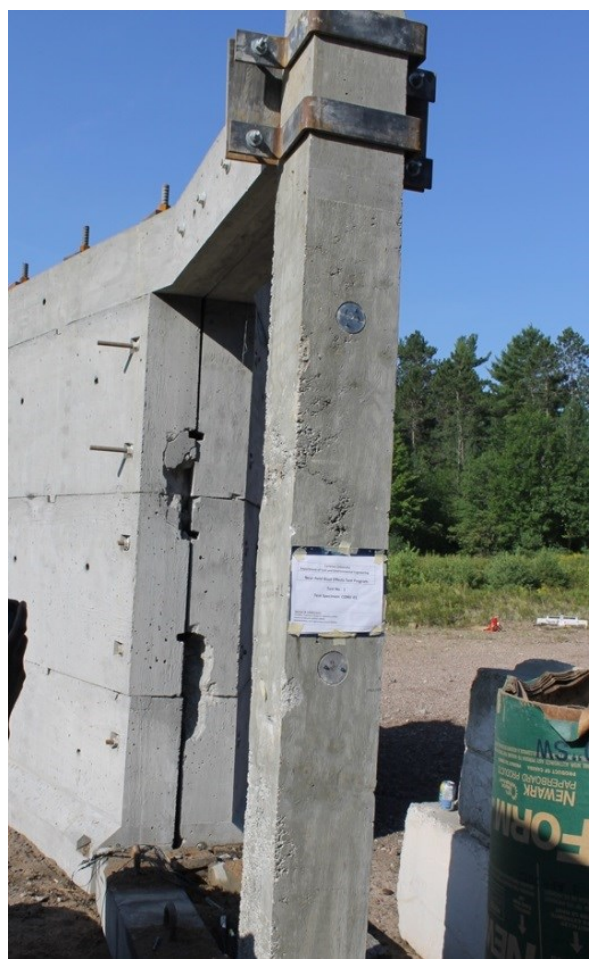

Figure 4-26: Photograph of column CONV-20 prior to test 


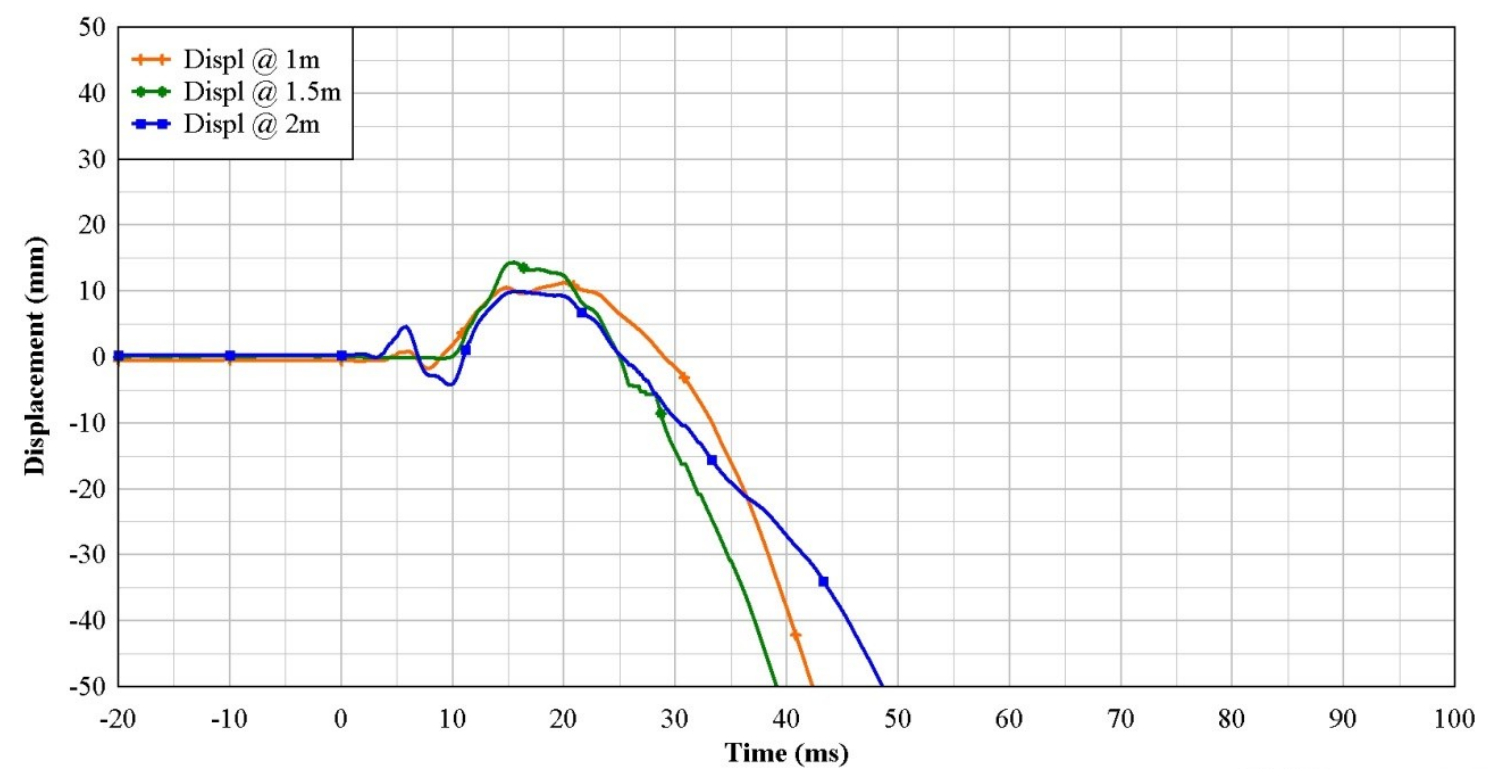

Figure 4-27: Displacement-Time history for Column CONV-20

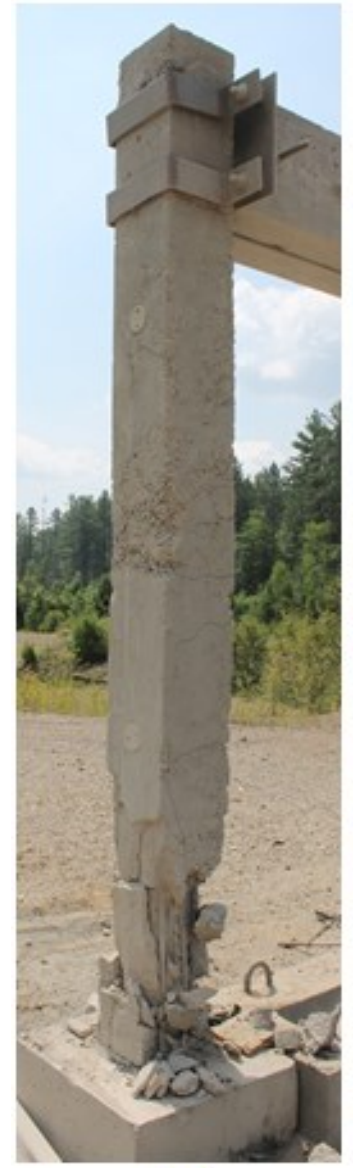

(a)

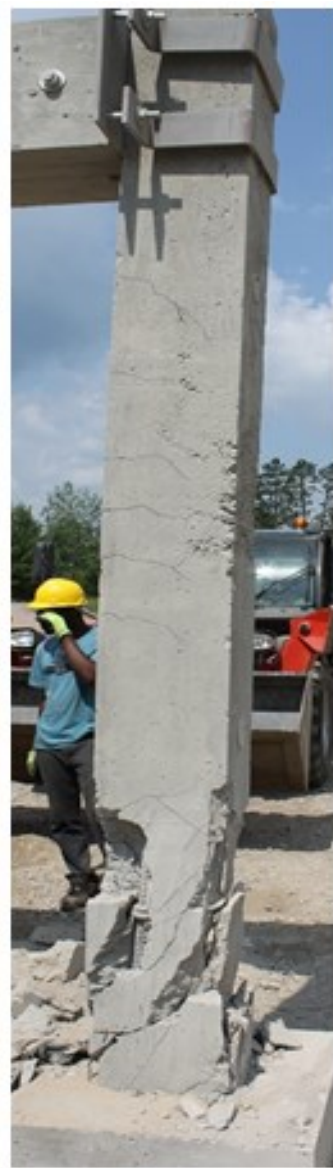

(b)

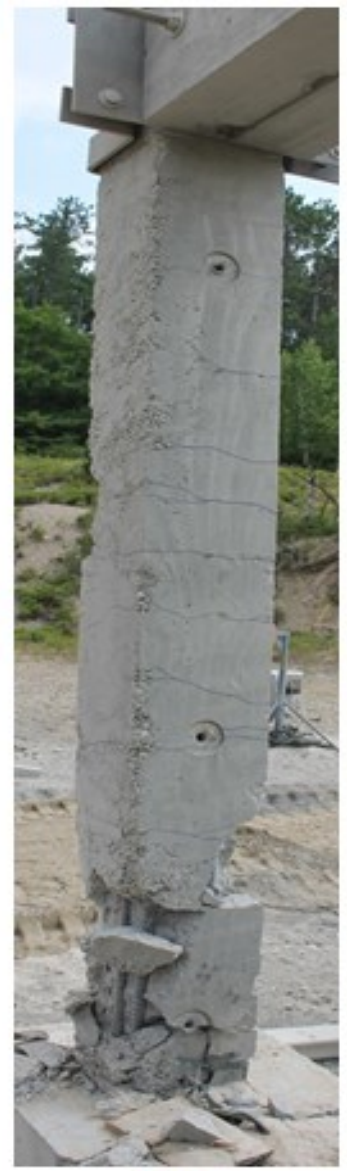

(c)

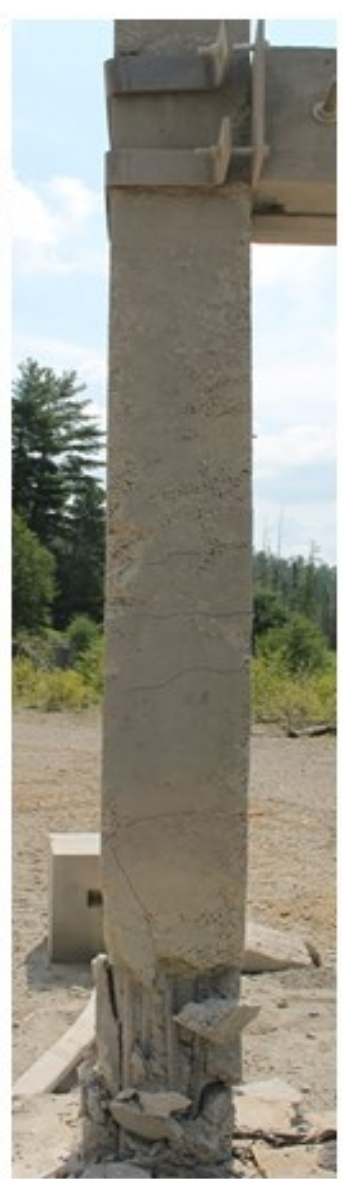

(d)

Figure 4-28: Post-test photograph of Column CONV-20 faces: (a) Front face, (b) Side face (right), (c) Back face, and (d) Side face (left) 
Table 4-5 presents summary of the results from Test 2 . The blast loading varied across the front face of the column from $35,555 \mathrm{kPa}$ at the bottom-front to $26,531 \mathrm{kPa}$ at the mid-front pressure gauge. The pressure at the bottom-front gauge is significantly higher than the blast pressure calculated for this location using the Kingery-Bulmash polynomials with correction for the angle of incidence of $23,120 \mathrm{kPa}$. The reason for this is the possible formation of a Mach reflection and the gauge being located within the Mach stem of the explosion. The reflected pressure at the mid-front pressure gauge of $26,531 \mathrm{kPa}$ was comparable to the pressure calculated from the Kingery-Bulmash polynomials with appropriate correction for incidence angle of 27,136 kPa. The reflected pressure at the top-front gauge of 2,598 $\mathrm{kPa}$ was significantly lower than the pressure calculated from the Kingery-Bulmash polynomials with appropriate correction for incidence angle of 19,137 kPa. Mid-back pressure gauge failed. The blast loading at the bottom of the columns was almost thirteen times higher than at the top.

The displacement data for SEIS-9 were unreliable with the displacement measured at the upper third-point higher than at mid-height (Figure 4-23). The maximum displacement of 14.3 mm of CONV-20 was measured at mid-height (Figure 4-24).

The damage to the columns were markedly different. Whereas SEIS-9 experienced flexural cracking and concrete spall at about mid-height (Figure 4-26), CONV-20 experienced concrete crushing at the lower part of the column (Figure 4-28) and flexural cracking at midheight. This behaviour is attributed to the closely spaced transverse reinforcement in SEIS-9 compared to CONV-20. Also, the longitudinal reinforcement splices in CONV-20 were above the column to footing joint and at mid-height for SEIS-9. CONV-20 failed due to shear 
Table 4-5: Summary of test 2 (SEIS-9 and CONV-20) results

\begin{tabular}{|c|c|c|c|c|c|c|c|}
\hline \multicolumn{8}{|c|}{ (a) Blast Pressure Results } \\
\hline Test Specimens & \multicolumn{7}{|c|}{ CONV-20 and SEIS-9 } \\
\hline \multirow{2}{*}{ Test Details } & \multicolumn{2}{|c|}{ Charge Mass } & \multicolumn{2}{|c|}{ Standoff } & \multicolumn{2}{|c|}{$\mathrm{z}\left(\mathrm{m} / \mathrm{kg}^{1 / 3}\right)$} & $\overline{A L R}$ \\
\hline & \multicolumn{2}{|c|}{ 150-kg ANFO } & \multicolumn{2}{|c|}{$2.6 \mathrm{~m}$} & \multicolumn{2}{|c|}{0.52} & 0 \\
\hline \multirow{2}{*}{ Gauge } & \multicolumn{2}{|c|}{ Bottom-Front } & \multicolumn{2}{|c|}{ Mid-Front } & \multicolumn{2}{|c|}{ Top-Front } & Mid-Back \\
\hline & Exp. & CONWEP & Exp. & CONWEP & Exp. & CONWEP & Exp. \\
\hline Location $\left(\mathrm{mm}^{*}\right)$ & \multicolumn{2}{|c|}{210} & \multicolumn{2}{|c|}{1250} & \multicolumn{2}{|c|}{2200} & 1300 \\
\hline Range (mm) & \multicolumn{2}{|c|}{2717.4} & \multicolumn{2}{|c|}{2612} & \multicolumn{2}{|c|}{2863.6} & \\
\hline Incident Angle & \multicolumn{2}{|c|}{$16.9^{0}$} & \multicolumn{2}{|c|}{$5.5^{0}$} & \multicolumn{2}{|c|}{$24.8^{0}$} & \\
\hline $\mathrm{P}_{\mathrm{r}}(\mathrm{kPa})$ & 35,555 & 23,120 & 26,531 & 27,136 & 2,598 & 19,137 & Failed \\
\hline $\mathrm{T}_{\mathrm{a}}(\mathrm{ms})$ & 1.0 & 0.9 & 1.1 & 0.8 & 1.48 & 1.0 & - \\
\hline $\mathrm{T}_{\mathrm{d}}(\mathrm{ms})$ & 0.41 & 1.9 & 0.26 & 1.8 & 0.82 & 2.2 & - \\
\hline \multicolumn{8}{|c|}{ (b) Displacement Results } \\
\hline & \multicolumn{2}{|c|}{ Displ@1m } & \multicolumn{2}{|c|}{ Displ@1.5m } & \multicolumn{2}{|c|}{ Displ@2m } & \\
\hline CONV-20 & \multicolumn{2}{|c|}{$11.2 \mathrm{~mm}$} & \multicolumn{2}{|c|}{$14.3 \mathrm{~mm}$} & \multicolumn{2}{|c|}{$9.9 \mathrm{~mm}$} & \\
\hline SEIS-9 & \multicolumn{2}{|c|}{ Failed } & \multicolumn{2}{|c|}{$6.36 \mathrm{~mm}$} & \multicolumn{2}{|c|}{$17.4 \mathrm{~mm}$} & \\
\hline
\end{tabular}




\subsection{Column Test 3 (CONV-6 and CONV-10)}

Test 3 was conducted on two conventional columns with different axial load ratios and subjected to blast loading from 150-kg ANFO explosive charge. The columns (CONV-6 and CONV-10) were placed equidistant from the centre of explosion at a standoff distance of $2.66 \mathrm{~mm}\left(\mathrm{z}=0.53 \mathrm{~m} / \mathrm{kg}^{1 / 3}\right)$. The support structures displaced about $12 \mathrm{~mm}$ after Test 2 resulting in the increased standoff distance for Test 3.

Figure 4-29 presents the experimental setup for Test 3 . The two columns (CONV-6 and CONV-10) were instrumented with pressure gauges, string potentiometers and strain gauges. High speed videography, using a NAC Memrecam GX-8 video camera, was also used to monitor the response of the concrete columns during testing. Column CONV-6 was designed as a conventional column, while Column CONV-10 though conventionally designed, was prestressed (post-tensioned) to achieve an axial load ratio of 0.32 .

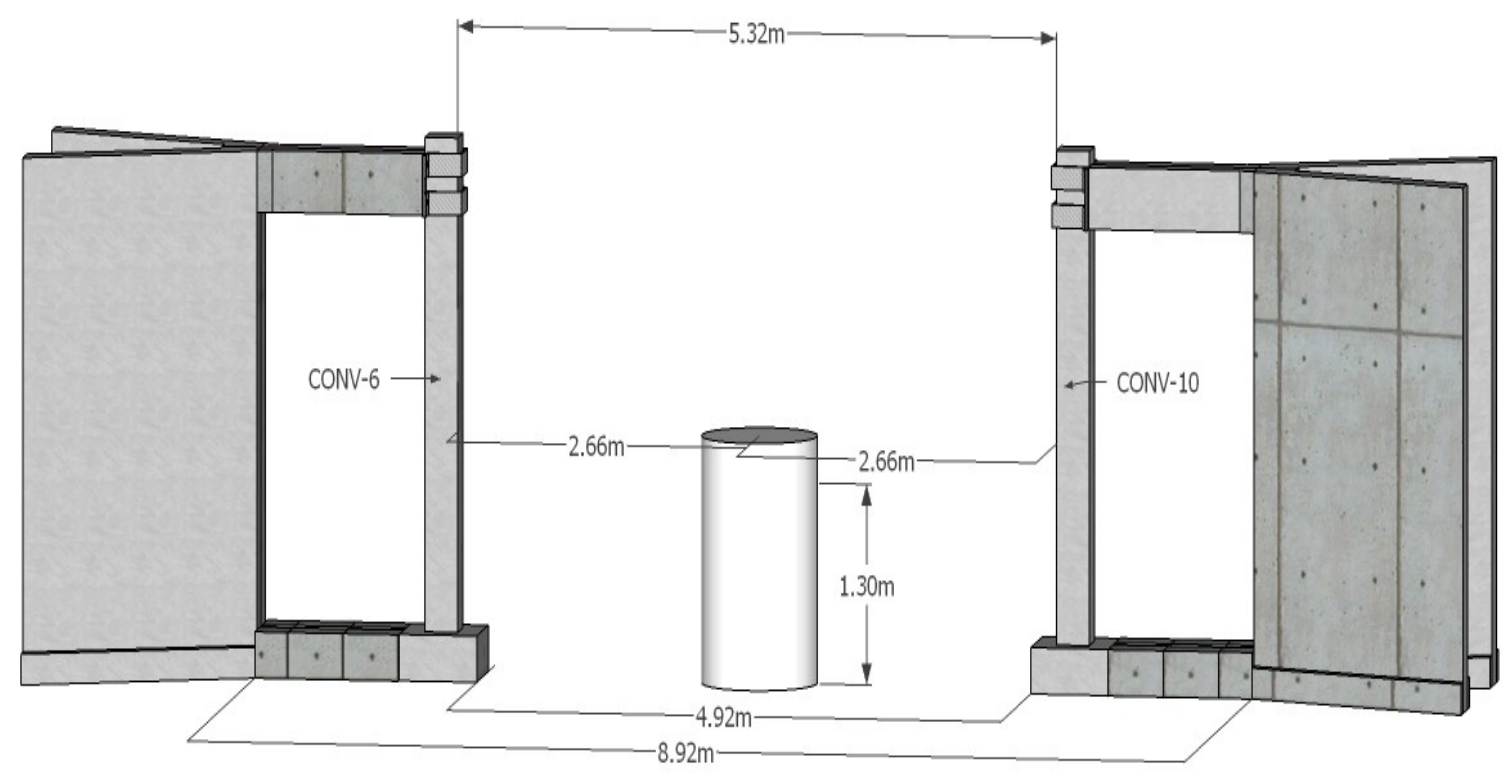

Figure 4-29: A sketch of Test 3 (CONV-6 and CONV-10) experimental setup 


\subsubsection{Blast Loading in Test 3}

Column CONV-10 was instrumented with pressure gauges on the front face (bottomfront, mid-front, and top-front) and at the mid-height on the back face, while the companion column CONV-6 was not instrumented with pressure gauges.

Figure 4-30 and Figure 4-31 present the blast pressure profile at the mid-front and topfront respectively. When the 150-kg ANFO was detonated, the blast wave arrived at the mid-front face of the column at $1.09 \mathrm{~ms}$ with peak pressure of $30,376 \mathrm{kPa}$ (Figure 4-30). The wave arrived at the top-front gauge at $1.40 \mathrm{~ms}$ with a peak pressure of $8,796 \mathrm{kPa}$ (Figure 4-31). The pressure gauges at the bottom-front and mid-back face of the column failed during the test, as such no data was recorded for at these locations. Free-field pressure gauges were used to record the incident overpressure remote from the centre of detonation. Figure 4-32 presents the experimental free-field incident pressure profile at standoff distances of $10 \mathrm{~m}$ and $20 \mathrm{~m}$. The incident overpressure at $10 \mathrm{~m}$ was $273 \mathrm{kPa}$ with an arrival time of $8.05 \mathrm{~ms}$, while the incident overpressure at $20 \mathrm{~m}$ was $80.6 \mathrm{kPa}$ with an arrival time of $27.7 \mathrm{~ms}$ (Figure 4-32). The arrival time of the experimental blast wave is shorter than that of CONWEP prediction. The peak incident pressures are higher than the peak incident pressure calculation from CONWEP. 


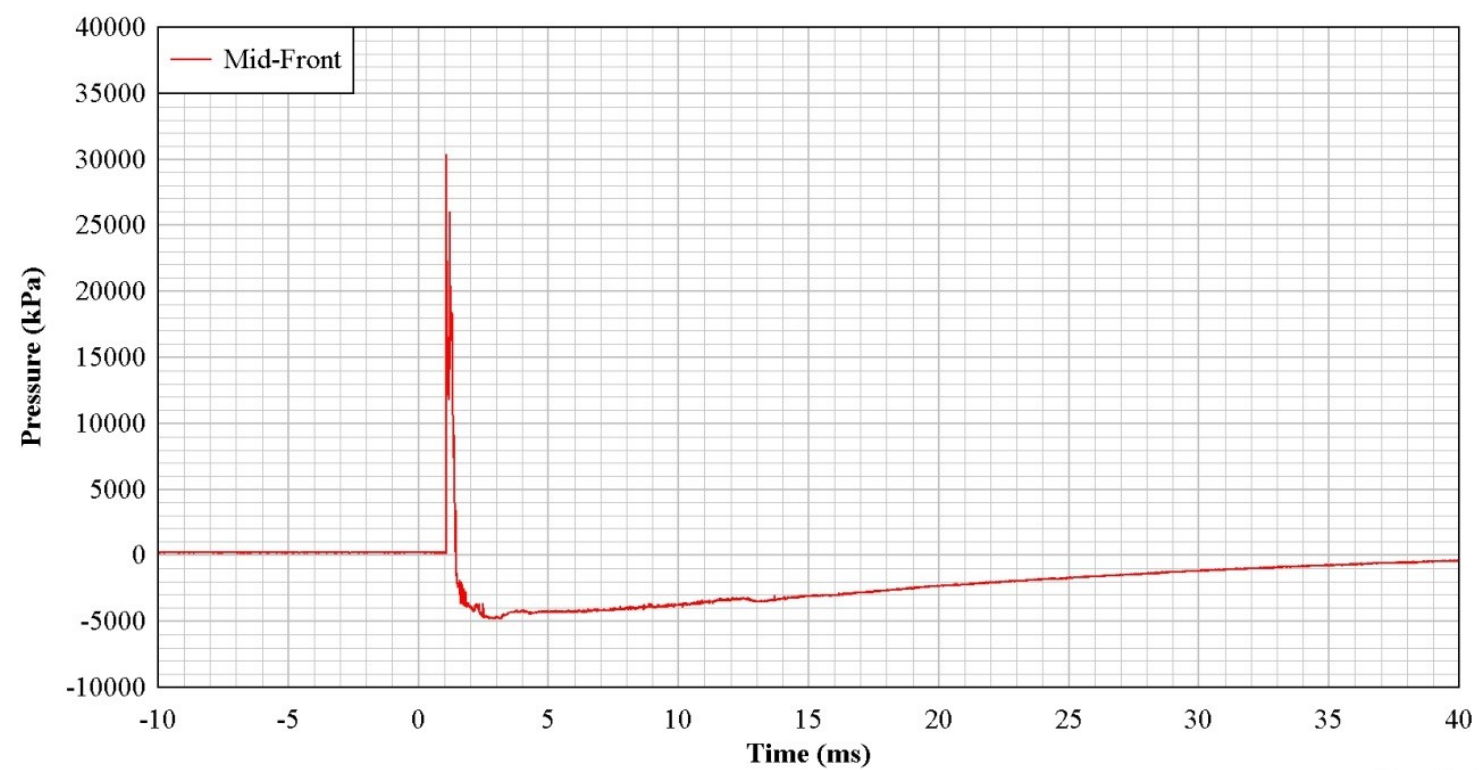

Figure 4-30: Blast pressure profile for Column CONV-6 and CONV-10 (mid-front pressure gauge)

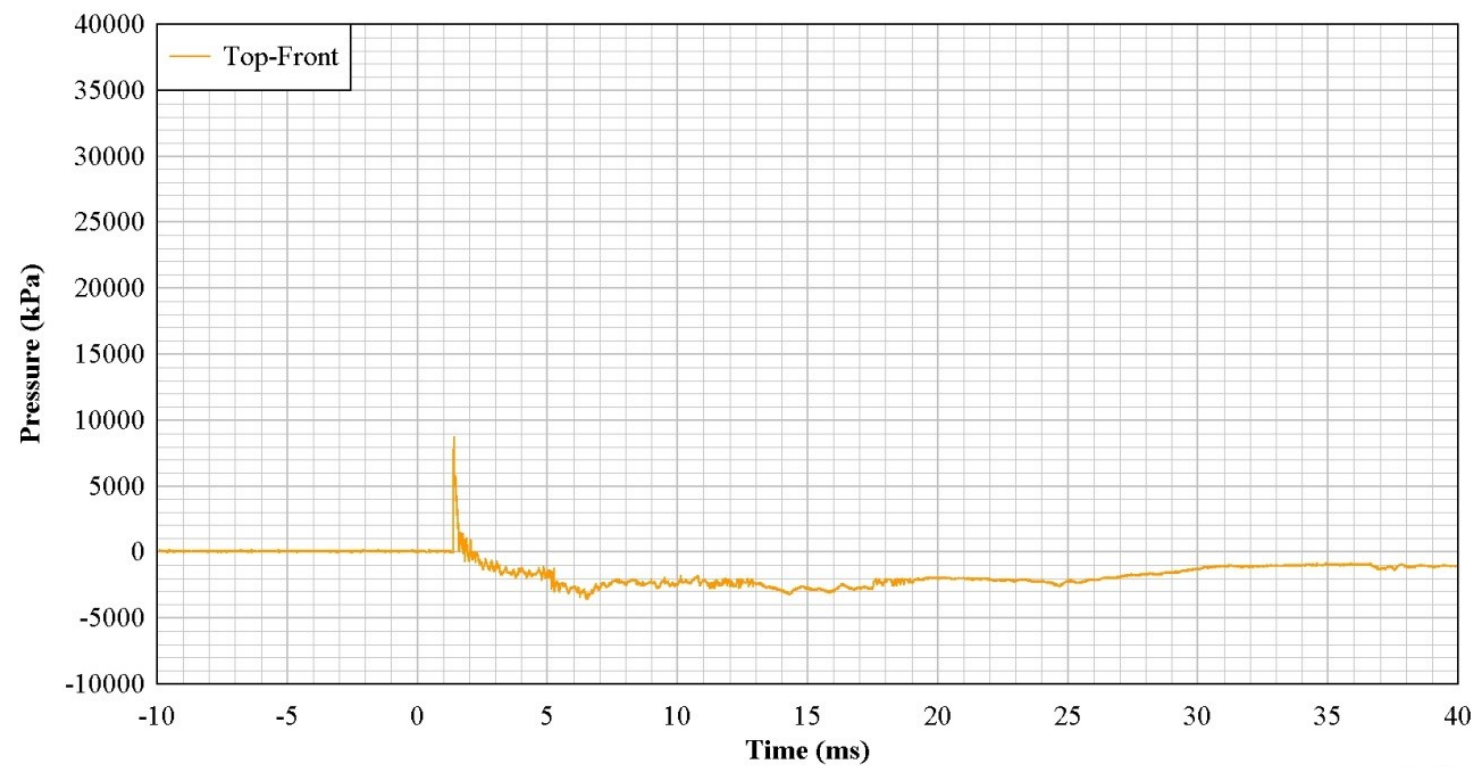

Figure 4-31: Blast pressure profile for Column CONV-6 and CONV-10 (top-front pressure gauge) 


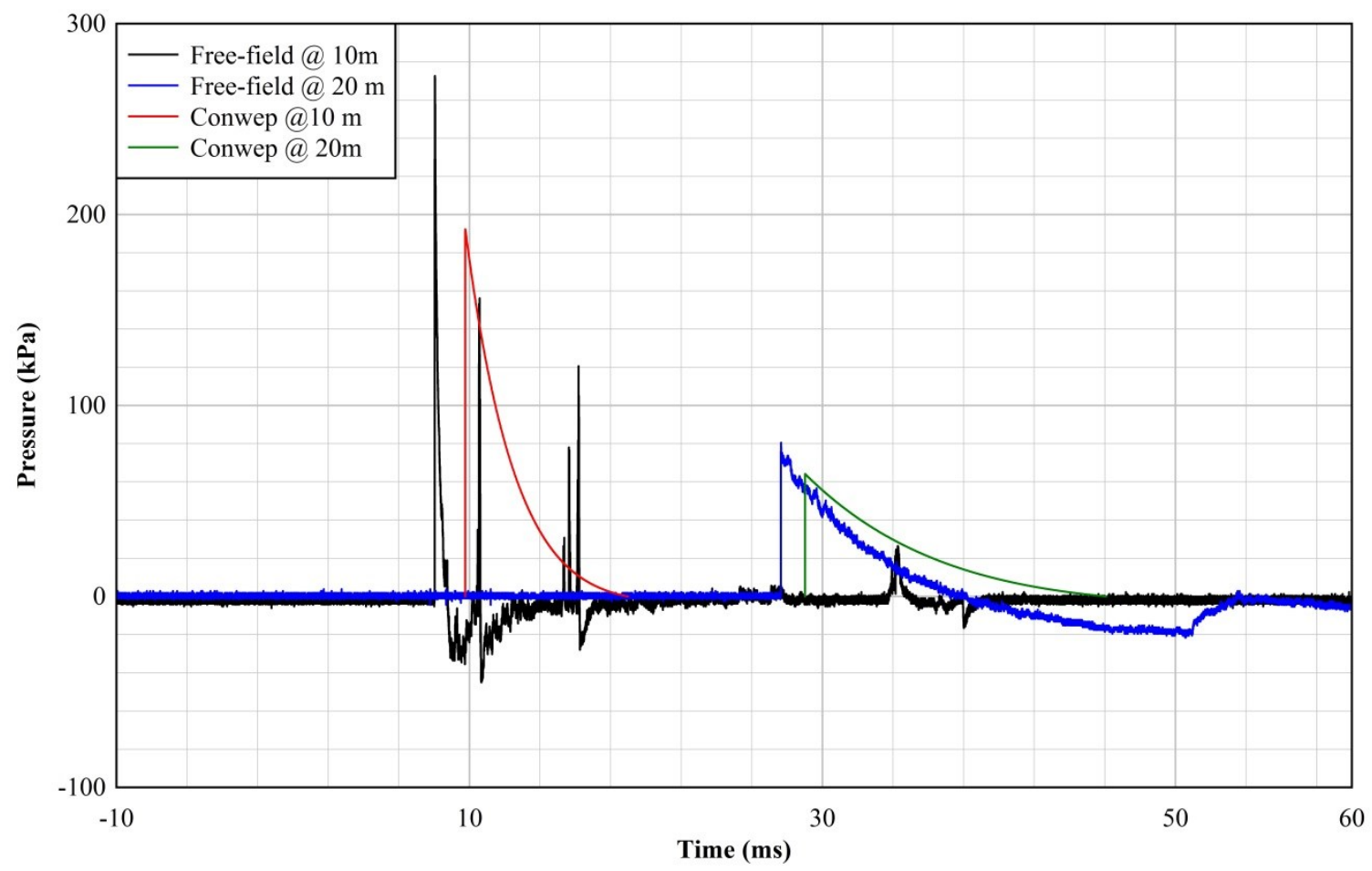

Figure 4-32: Incident blast pressure profiles for Test 3

\subsubsection{CONV-6}

String potentiometers were connected to the back face of each column at $1 \mathrm{~m}, 1.5 \mathrm{~m}$, and $2 \mathrm{~m}$ of CONV-6 to record displacement-time history of the column. Figure 4-33 present the pre-test photograph of column CONV-6.

Figure 4-34 presents the displacement-time response of CONV-6. The string potentiometer at the lower third-point was damaged during the testing and thus no data is provided. The maximum displacement of $17.2 \mathrm{~mm}$ occurred at mid-height of the column. The upper third-point displacement was $13.2 \mathrm{~mm}$ (Table 4-6(b)). 


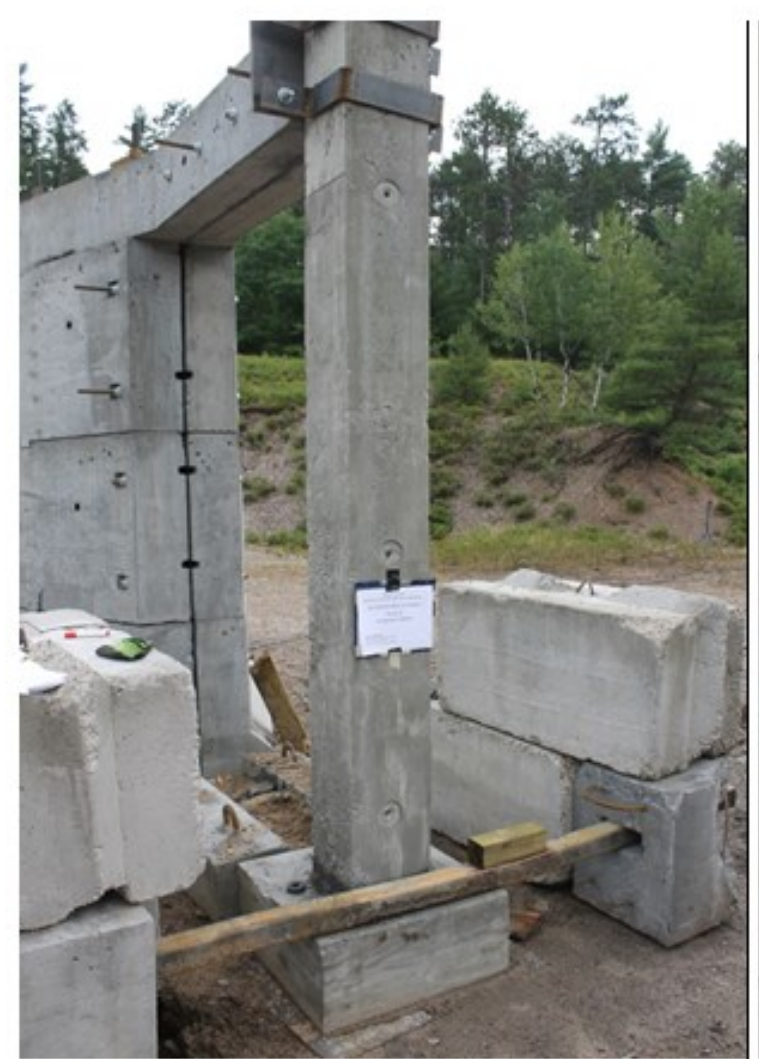

(a)

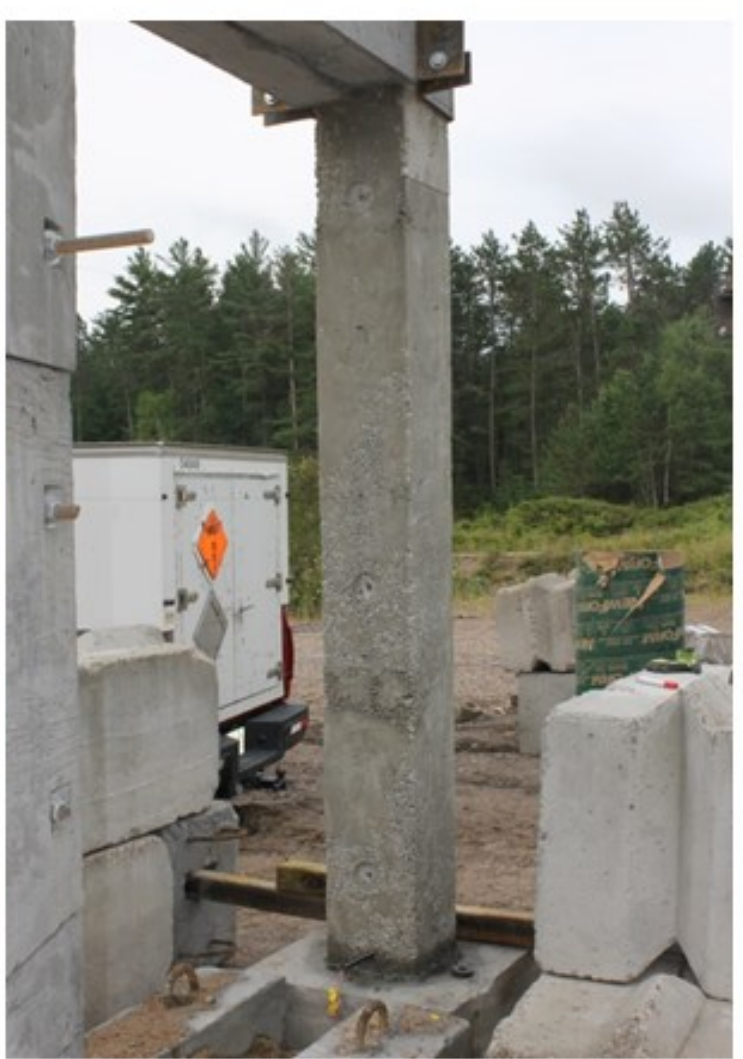

(b)

Figure 4-33: Photograph of Column CONV-6 before test: (a) Front face (b) Back face

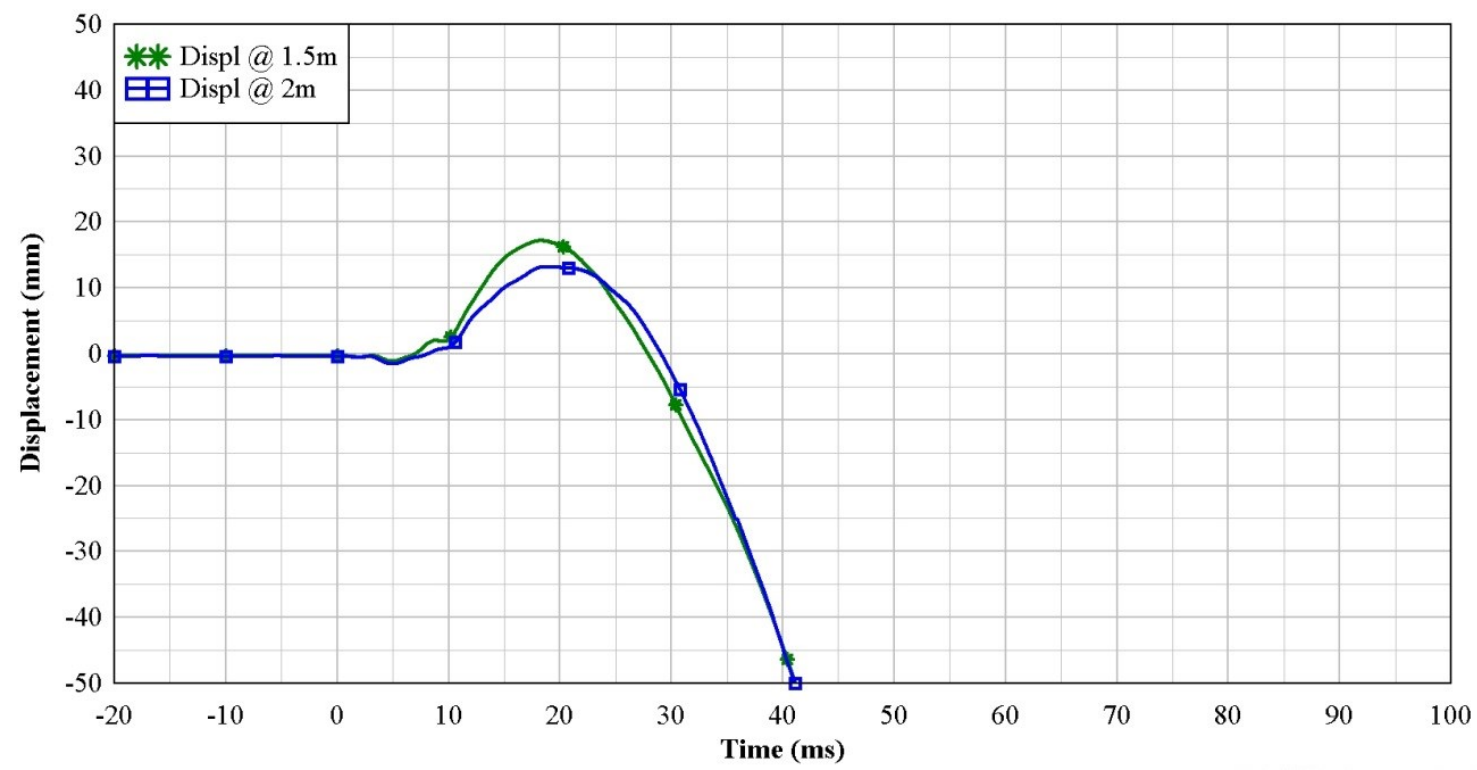

Figure 4-34: Displacement-Time history for Column CONV-6 
Post test observation of column CONV-6 revealed cracking and spalling of concrete at the lower one-third region of the column (Figure 4-35(a)). Shear cracks were observed near the bottom support of the column (Figure 4-35(b) and (c)). The cracks are visible on the side faces of the column, while wide flexural cracks visible on the back face and sides of the column (Figure 4-35). No discernible data was recorded from the strain gauges. Figure 4-34 is a photograph of column CONV-6 prior to test.

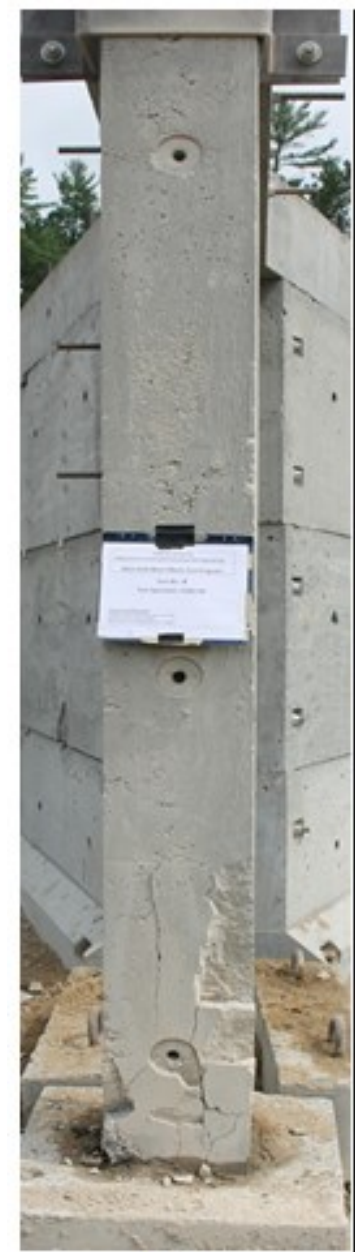

(a)

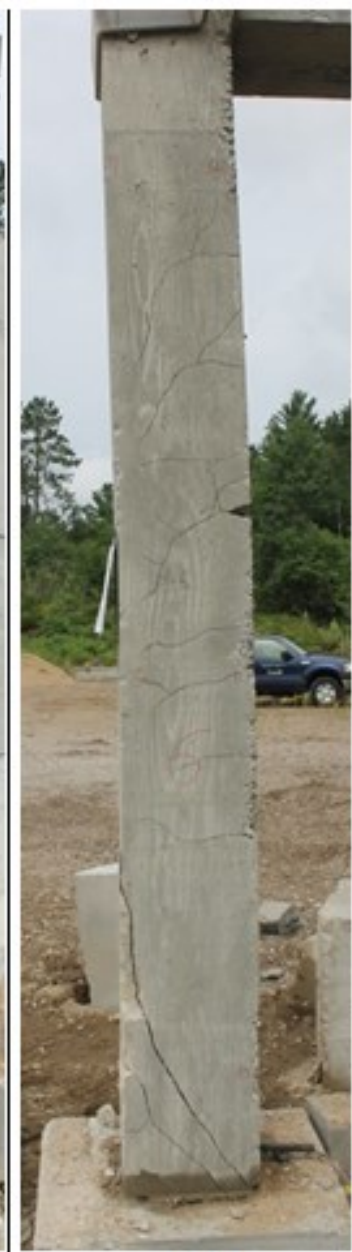

(b)

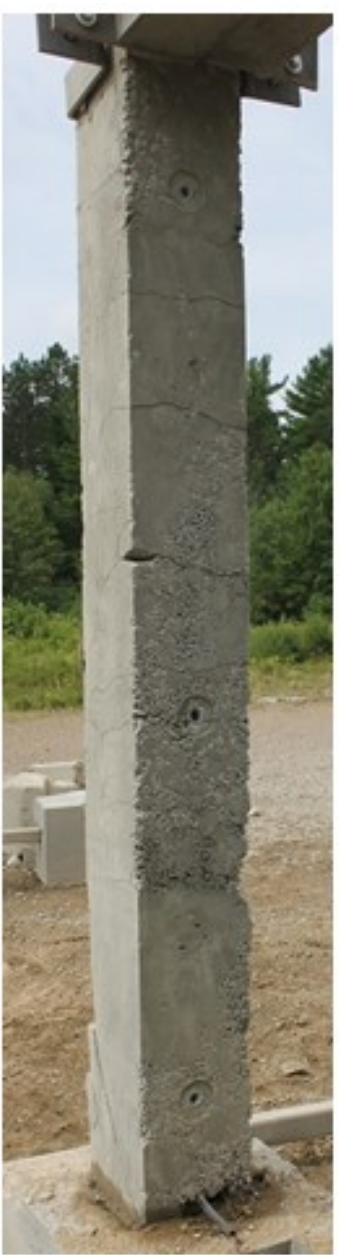

(c)

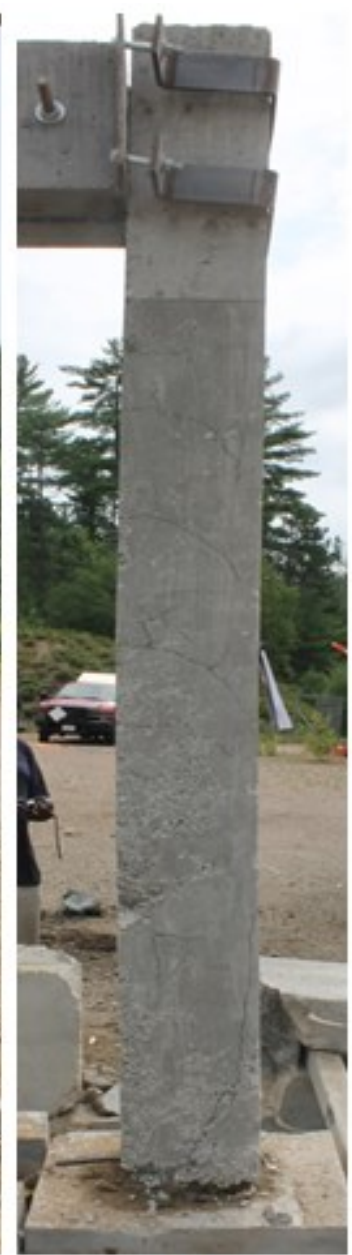

(d)

Figure 4-35: Post-test photograph of Column CONV-6 faces: (a) Front face, (b) Side face (right), (c) Back face, and (d) Side face (left) 


\subsubsection{CONV-10}

String potentiometers were connected to the back face of each column at $1 \mathrm{~m}, 1.5 \mathrm{~m}$ and $2 \mathrm{~m}$ of CONV-10 to record displacement-time history of the column. Figure 4-36 present the pre-test photograph of column CONV-10.

Figure 4-37 presents the displacement-time response of CONV-10. The maximum displacement of $39.3 \mathrm{~mm}$ occurred at lower third-point of the column. The mid-height and upper third-points displacements were $20 \mathrm{~mm}$ and $7.4 \mathrm{~mm}$ respectively.

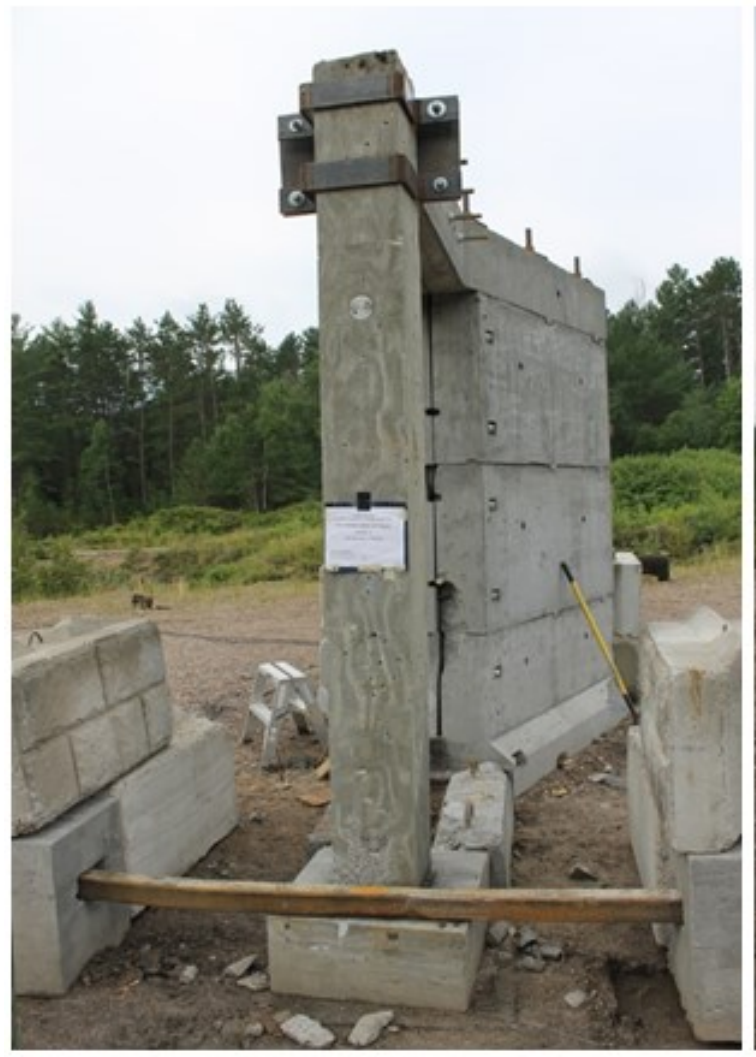

(a)

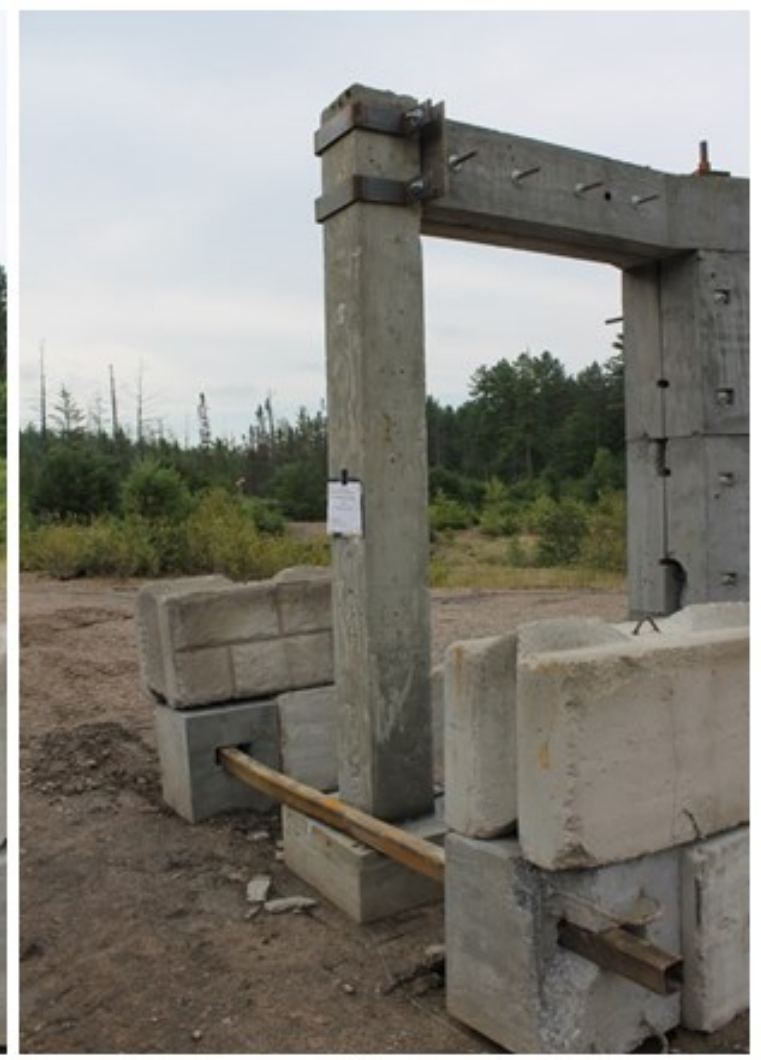

(b)

Figure 4-36: Photograph of Column CONV-10 before test: (a) Front face (b) Side face 


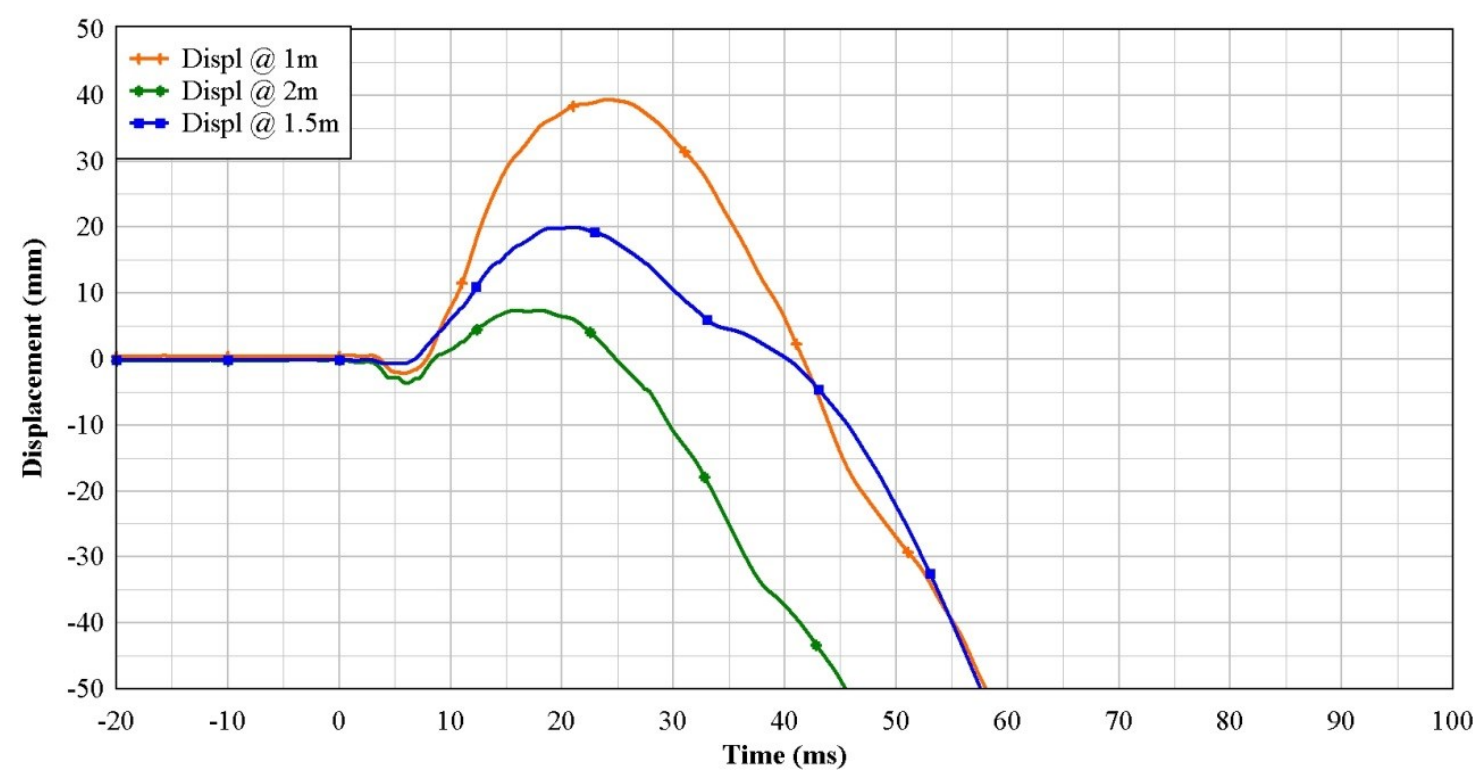

Figure 4-37: Displacement-Time history for Column CONV-10

Physical observation on column CONV-10 after the blast impact showed substantial cracking and spalling of concrete cover revealing longitudinal reinforcement in the lower one-third region of the column (Figure 4-38). Minimal flexural cracks were observed on the back face column. Within the lower one-third region, substantial shear cracks were observed. Figure 4-38 shows post-test damage on the column. 


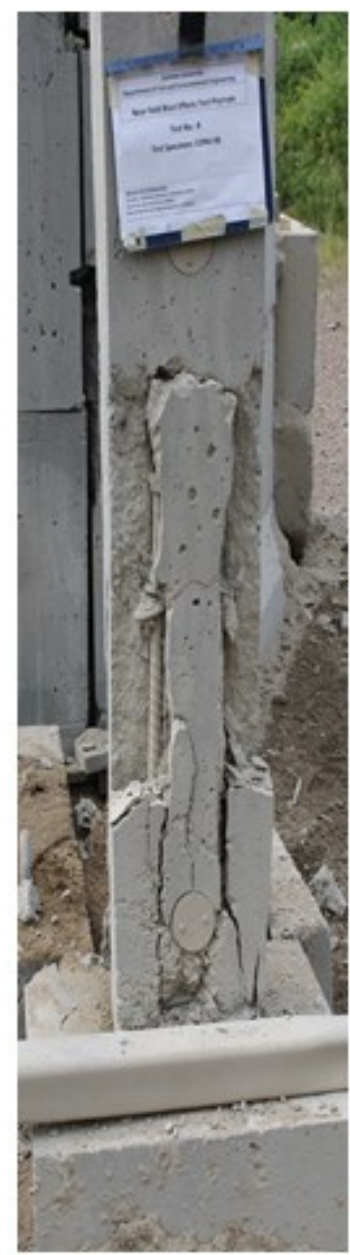

(a)

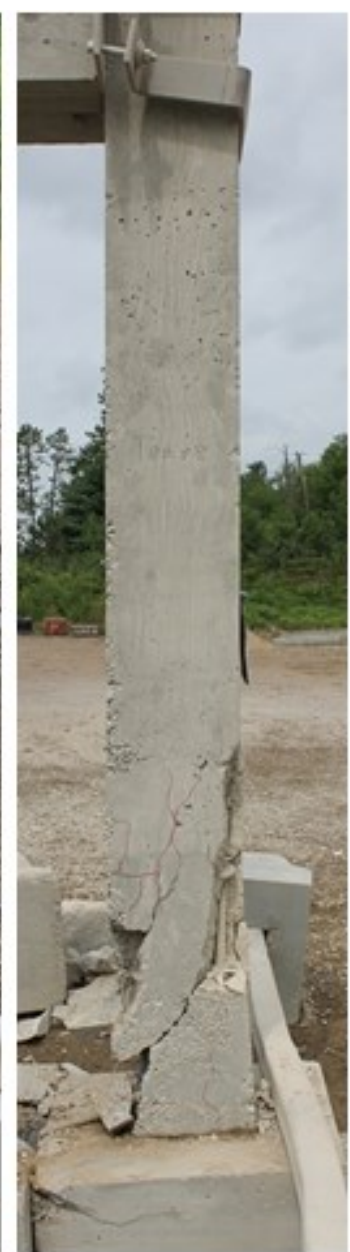

(b)

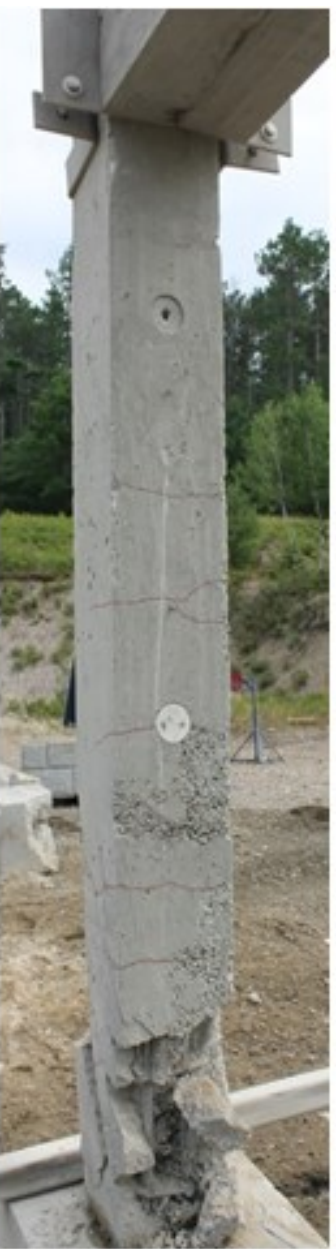

(c)

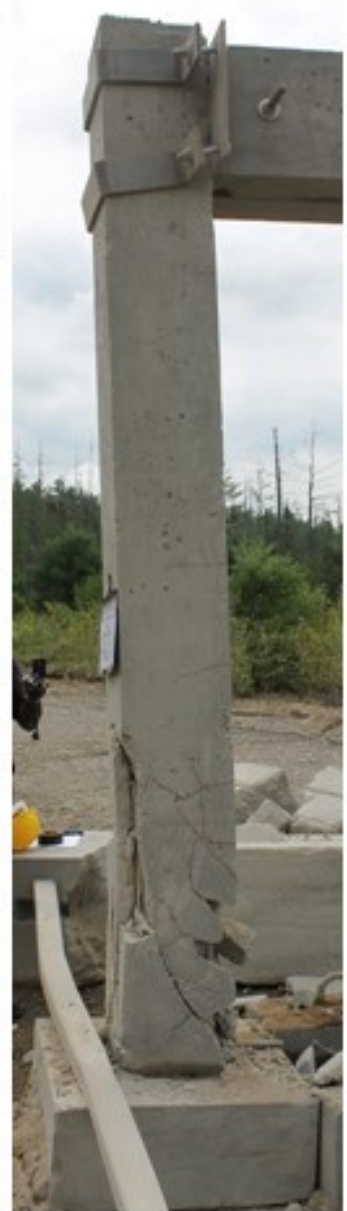

(d)

Figure 4-38: Post-test photograph of Column CONV-10 faces: (a) Front face, (b) Side face (right), (c) Back face, and (d) Side face (left)

Table 4-6 presents a summary of Test 3 results. The columns were both conventionally designed columns however CONV-10 had an ALR of 0.32 from the $1027 \mathrm{kN}$ posttension force. The maximum displacement of CONV-6 (17.2 mm) occurred at mid-height while the maximum displacement of CONV-10 (39.3 mm) occurred at the lower thirdpoint. Also, the maximum displacement in CONV-10 was significantly higher than in the companion column with ALR of 0 . The ALR resulted in severe damage to CONV-10 in comparison to CONV-6. This is likely the reason for the higher displacement at the lower third-point of CONV-10. 
Table 4-6: Summary of test 3 (CONV-6 and CONV-10) results

\begin{tabular}{|c|c|c|c|c|c|c|c|c|}
\hline \multicolumn{9}{|c|}{ (a) Summary of Blast Pressure Results } \\
\hline Test Specimens & \multicolumn{8}{|c|}{ CONV-6 and CONV-10 } \\
\hline \multirow{2}{*}{ Test Details } & \multicolumn{2}{|c|}{ Charge Mass } & \multicolumn{2}{|c|}{ Standoff } & $\mathrm{z}\left(\mathrm{m} / \mathrm{kg}^{1 / 3}\right)$ & \multicolumn{2}{|c|}{ ALR (CONV-6) } & $\begin{array}{c}\text { ALR } \\
(\mathrm{CONV}-10)\end{array}$ \\
\hline & \multicolumn{2}{|c|}{ 150-kg ANFO } & \multicolumn{2}{|c|}{$2.66 \mathrm{~m}$} & 0.53 & \multicolumn{2}{|c|}{0} & 0.32 \\
\hline \multirow{2}{*}{ Gauge } & \multicolumn{3}{|c|}{ Bottom-Front } & \multicolumn{2}{|c|}{ Mid-Front } & \multicolumn{2}{|c|}{ Top-Front } & Mid-Back \\
\hline & Exp. & $\mathrm{CO}$ & EP & Exp. & CONWEP & Exp. & CONWEP & Exp. \\
\hline Location $\left(\mathrm{mm}^{*}\right)$ & \multicolumn{3}{|c|}{250} & \multicolumn{2}{|c|}{1250} & \multicolumn{2}{|c|}{2200} & 1250 \\
\hline Range (mm) & \multicolumn{3}{|c|}{2763.7} & \multicolumn{2}{|c|}{2671.7} & \multicolumn{2}{|c|}{2918.2} & \\
\hline Incident Angle & \multicolumn{3}{|c|}{$15.7^{0}$} & \multicolumn{2}{|c|}{$5.4^{0}$} & \multicolumn{2}{|c|}{$24.3^{0}$} & \\
\hline $\mathrm{P}_{\mathrm{r}}(\mathrm{kPa})$ & Failed & \multicolumn{2}{|c|}{22309} & 30,376 & 25825 & 8,796 & 19796 & Failed \\
\hline $\mathrm{T}_{\mathrm{a}}(\mathrm{ms})$ & - & \multicolumn{2}{|c|}{0.9} & 1.09 & 0.9 & 1.4 & 1.0 & - \\
\hline $\mathrm{T}_{\mathrm{d}}(\mathrm{ms})$ & - & \multicolumn{2}{|c|}{2.0} & 0.37 & 1.9 & 0.69 & 2.3 & - \\
\hline \multicolumn{9}{|c|}{ (b) Summary of Displacement Results } \\
\hline & \multicolumn{3}{|c|}{ Displ@1m } & \multicolumn{2}{|c|}{ Displ@1.5m } & \multicolumn{2}{|c|}{ Displ@2m } & \\
\hline CONV-6 & \multicolumn{3}{|c|}{ Failed } & \multicolumn{2}{|c|}{$17.2 \mathrm{~mm}$} & \multicolumn{2}{|c|}{$13.2 \mathrm{~mm}$} & \\
\hline CONV-10 & \multicolumn{3}{|c|}{$39.3 \mathrm{~mm}$} & \multicolumn{2}{|c|}{$20 \mathrm{~mm}$} & \multicolumn{2}{|c|}{$7.4 \mathrm{~mm}$} & \\
\hline
\end{tabular}

*dimensions measured from the top of the footing 


\subsection{Column Test 4 (CONV-1 and SEIS-13)}

Test 4 was conducted on two columns (CONV-1 and SEIS-13) subjected to $150 \mathrm{~kg}$ ANFO explosive. The distance from the center of detonation to column CONV-1 was 1.3 $\mathrm{m}$ while column SEIS-13 was at $4.1 \mathrm{~m}$ from the center of detonation (Figure 4-36). The explosive charge mass and corresponding standoff distances yielded scaled distances of $0.26 \mathrm{~m} / \mathrm{kg}^{1 / 3}$ for CONV-1 and $0.82 \mathrm{~m} / \mathrm{kg}^{1 / 3}$ for SEIS-13.

Figure 4-39 presents a sketch while Figure 4-40 is a photograph of the experimental setup for Test 4. The two columns (column CONV-1 and column SEIS-13) were instrumented with pressure gauges, string potentiometers and strain gauges. High speed videography, using a NAC Memrecam GX-8 video camera, was also used to monitor the response of the concrete columns during testing. Column CONV-1 was designed as a conventional column, while column SEIS-13 was designed as part of a structures lateral load resisting system.

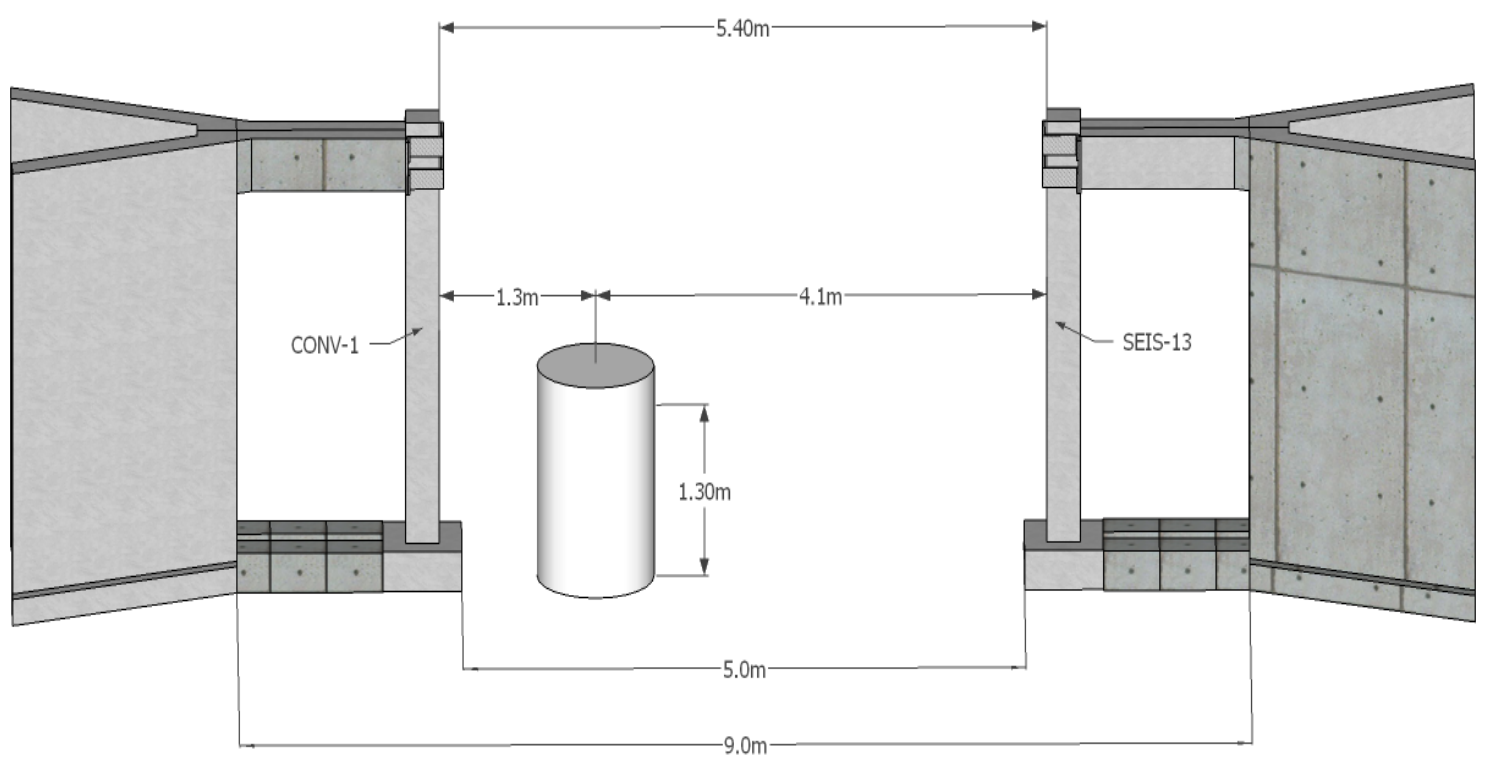

Figure 4-39: Pre-test setup of columns SEIS-13 and CONV-1 (sketch up drawing) 


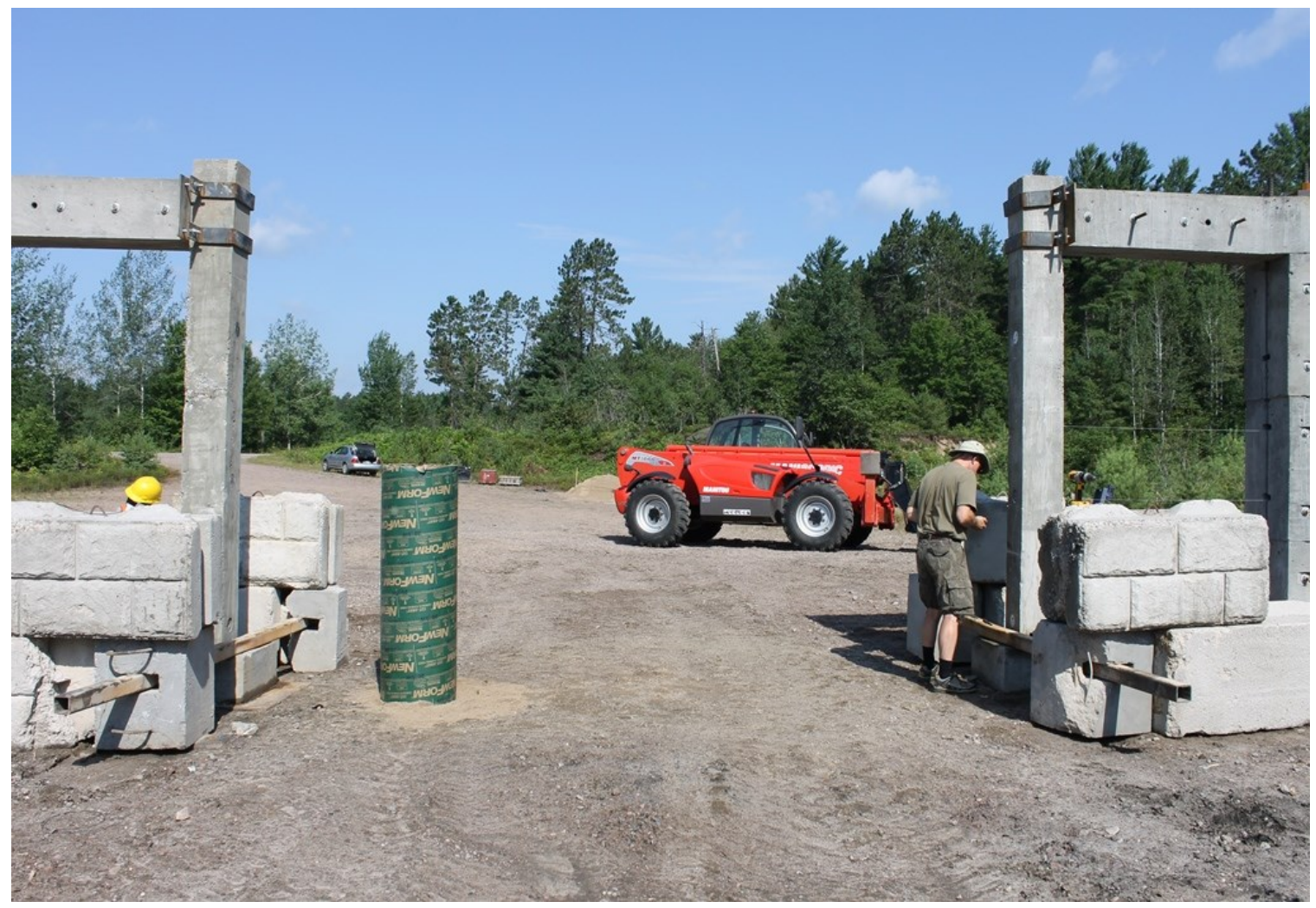

Figure 4-40: Pre-test setup of test 4 (CONV-1 and SEIS-13)

Most of the pressure gauges did not function during Test 4. Table 4-7 presents the pressure at the bottom-front, mid-front and top-front of the columns calculated with the Kingery-Bulmash polynomials and corrected for the angle of incidence.

\subsubsection{Column CONV-1}

The pressure gauges on CONV-1 did not give very good results. With the explosive charge at about $1.3 \mathrm{~m}$ from the face of the column, the sand cloud from the detonation impacting the pressure gauge affected the reading. Nonetheless, the pressure gauge at the mid-front location gave some blast pressure data before being saturated. Figure 4-42 presents the reflected pressure-time history at mid-front of CONV-1, and shows a peak reflected pressure of $96,127 \mathrm{kPa}$. Using CONWEP - A collection of conventional weapons effects calculations based on the Kingery-Bulmash polynomials with corrected angle of incidence of $4.4^{\circ}$, the peak reflected pressure is higher $(101,447 \mathrm{kPa})$. Figure 4- 
41 shows a photograph of CONV-1 before testing. Free field gauges failed as such no data was recorded.

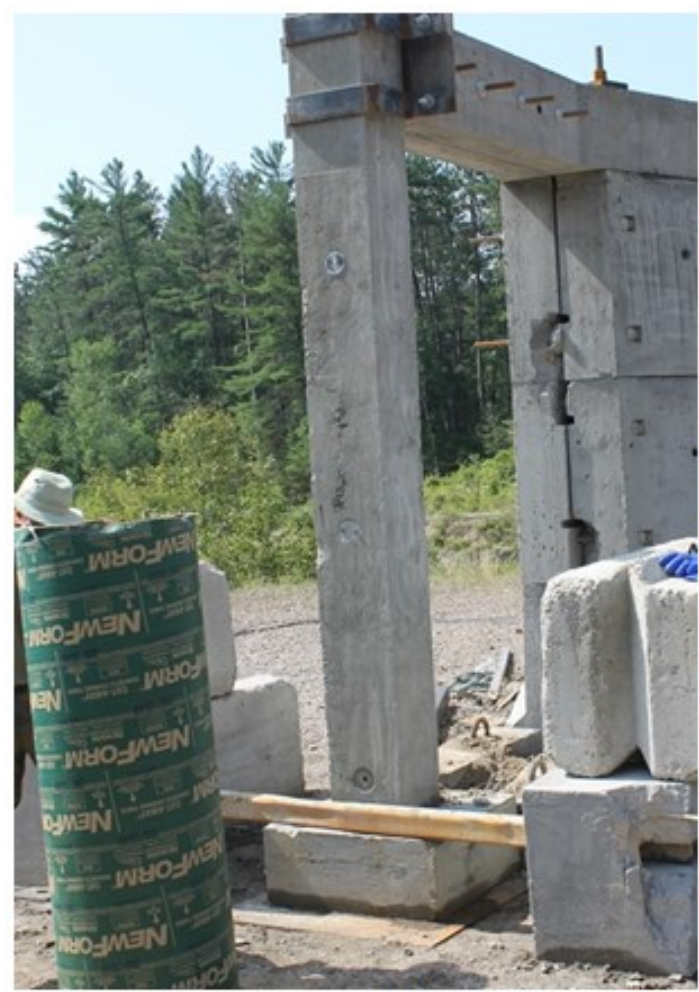

(a)

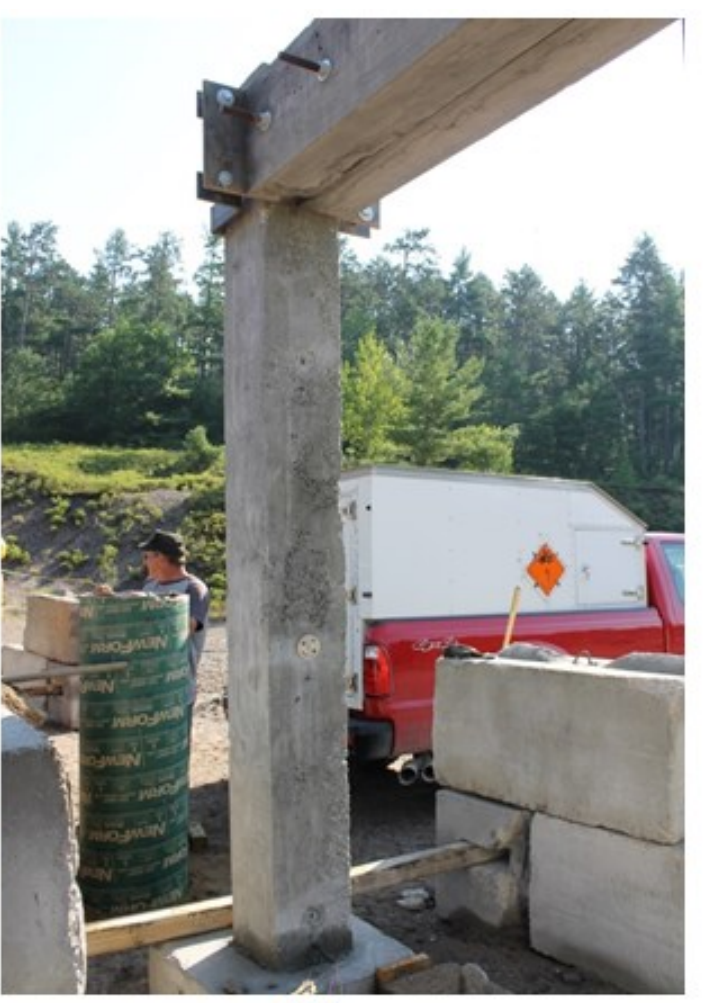

(b)

Figure 4-41: Photograph of Column CONV-1 before test: (a) Front face (b) Back face of column with mid-back pressure gauge

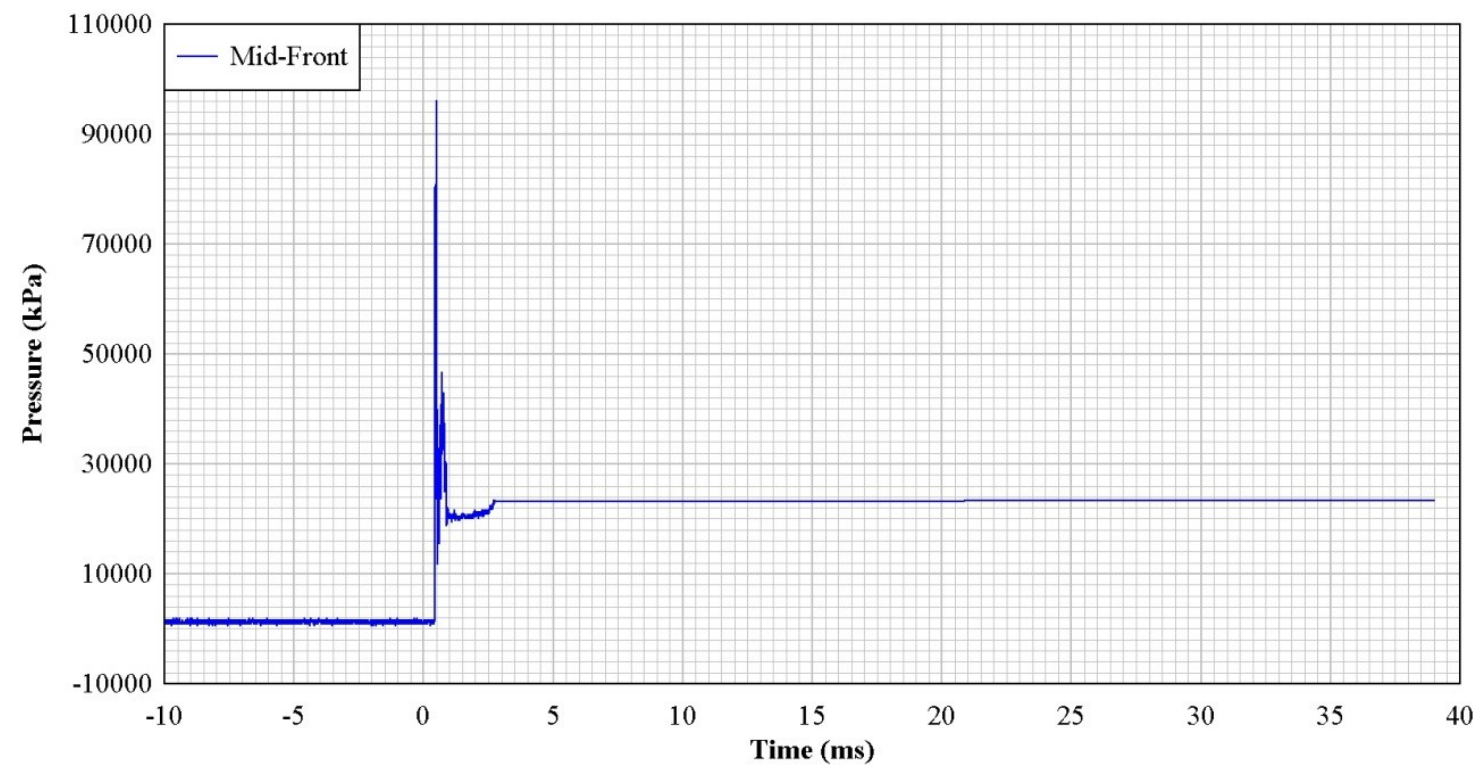

Figure 4-42: Blast pressure profile for Column CONV-1 (mid-front pressure gauge) 
Figure 4-43 presents the displacement-time response of CONV-1 at three locations on the back face: lower third-point $(1.0 \mathrm{~m})$, mid-height $(1.5 \mathrm{~m})$, and upper third-point $(2.0 \mathrm{~m})$. The displacements recorded were $29.6 \mathrm{~mm}, 21.9 \mathrm{~mm}$ and $9.2 \mathrm{~mm}$ at the lower-third point, mid-height and upper third-point respectively (Figure 4-40). The maximum displacement of CONV-1 occurred at the lower third-point at $29.6 \mathrm{~ms}$. These displacements are the instantaneous displacements prior to column failure.

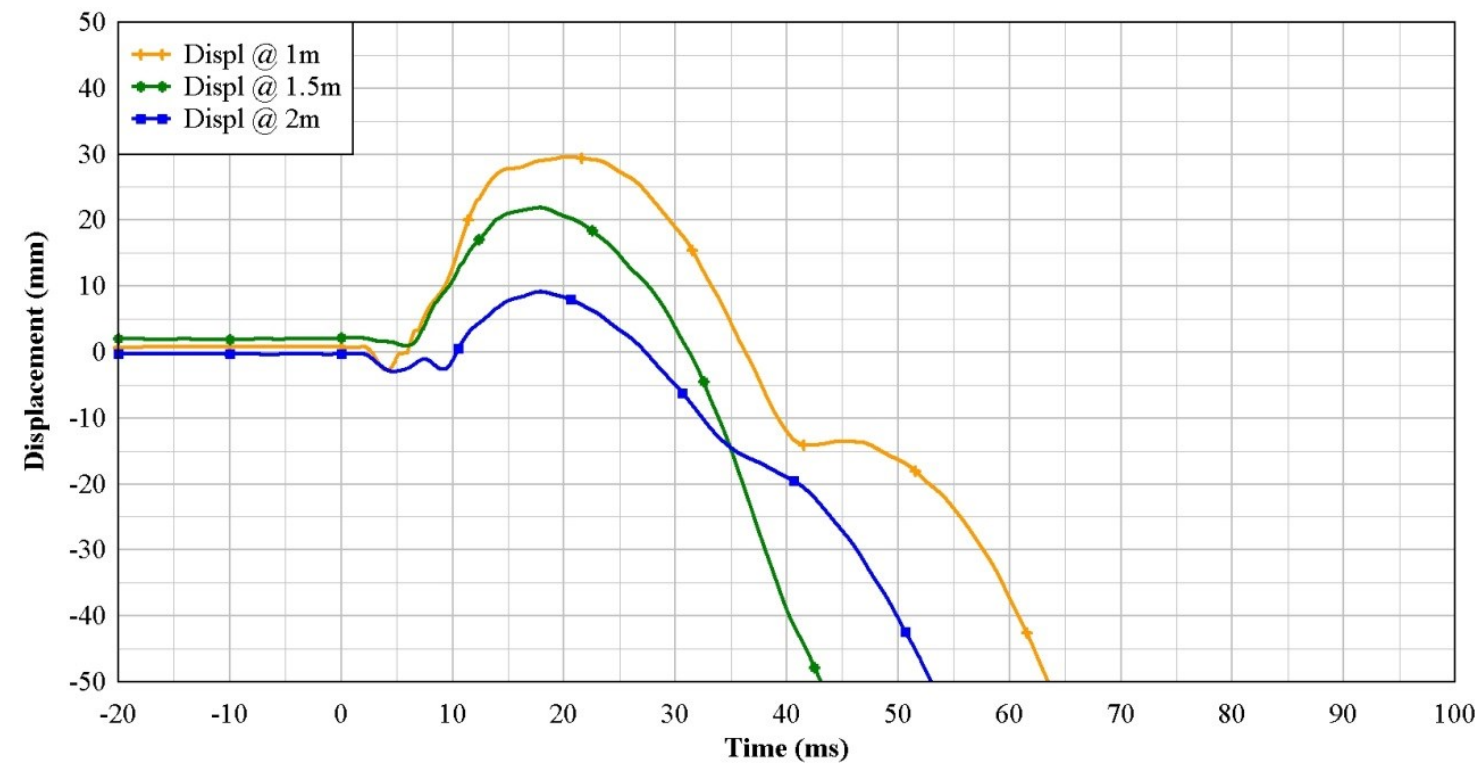

Figure 4-43: Displacement-Time history for Column CONV-1

Figure 4-44 shows the post-test photographs of the column. The column suffered catastrophic failure after the blast impact. Concrete in the lap-zone was striped and blown off rebar. Consequently, the column severed in two at the column-footing joint (Figure 444). The top brackets on the support structure, used to develop moment restraint of the columns, sheared off with no noticeable damage to top of column. The brackets probably failed early in loading stage and thus the top support behaved as a pin support. 


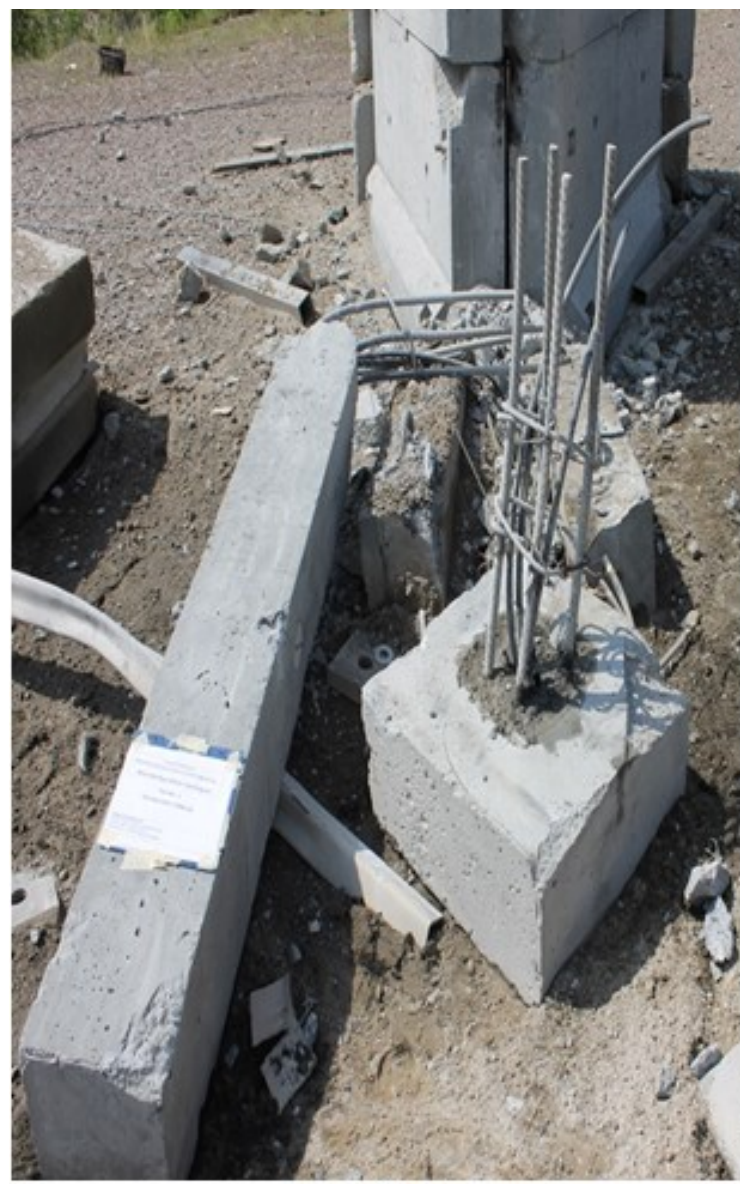

(a)

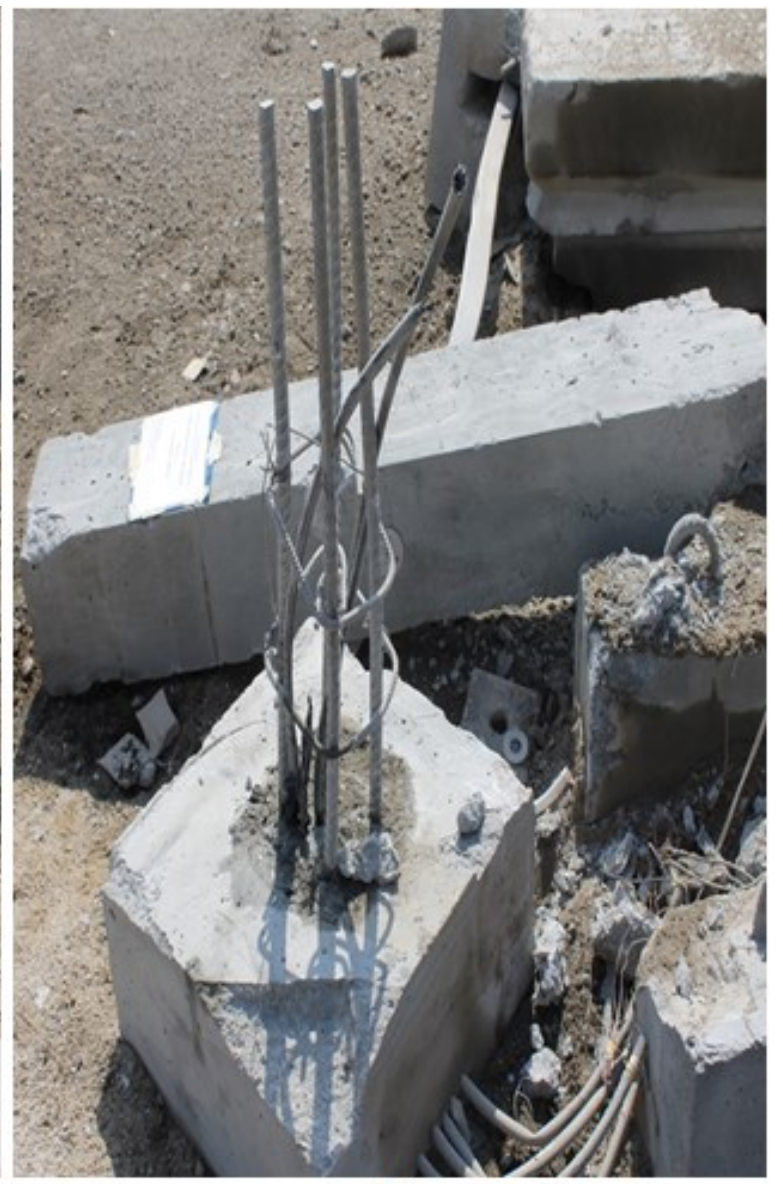

(b)

Figure 4-44: Post-test photograph of column CONV-1

\subsubsection{Column SEIS-13}

Column SEIS-13, designed as part of a structures' lateral load resisting system, was instrumented with pressure gauges on the front face of the column (bottom-front, midfront and top-front) and at mid-back location (Figure 4-45). String potentiometers were attached to the back of the column at $1.0 \mathrm{~m}$ (lower third-point), $1.5 \mathrm{~m}$ (mid-height) and $2.0 \mathrm{~m}$ (upper third-point) measured from top of footing to record displacement-time history of the column. Figure 4-45 presents photographs of SEIS-13 before explosion testing. 


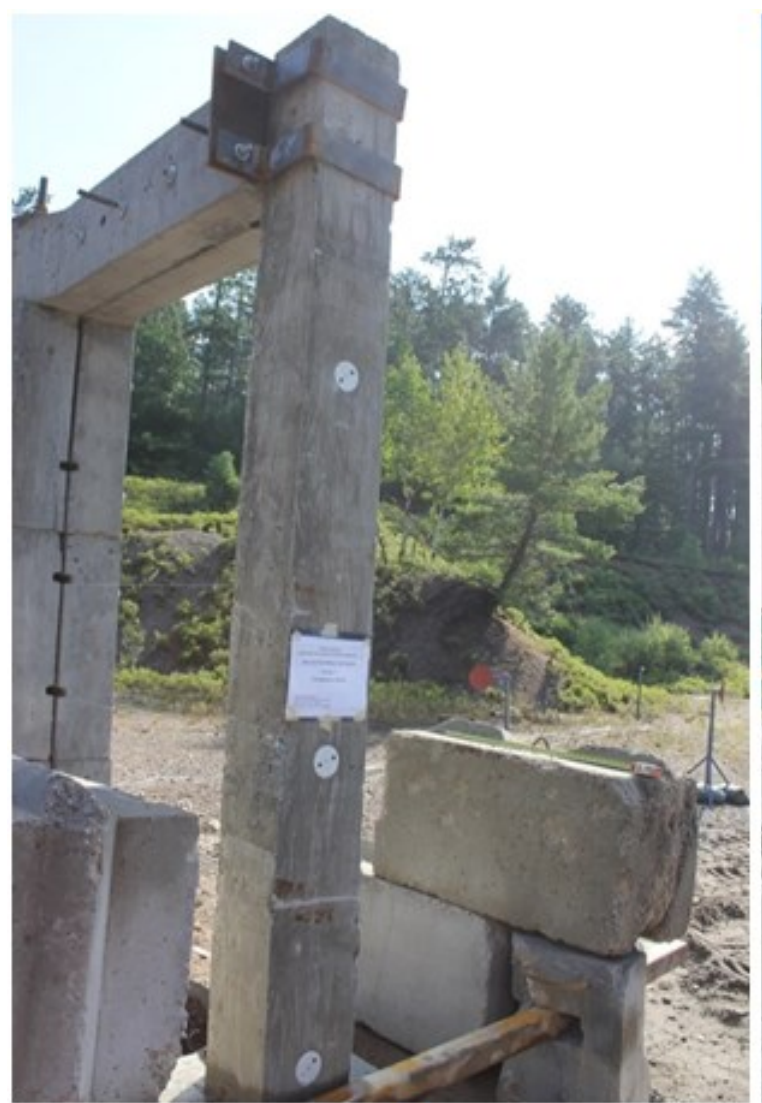

(a)

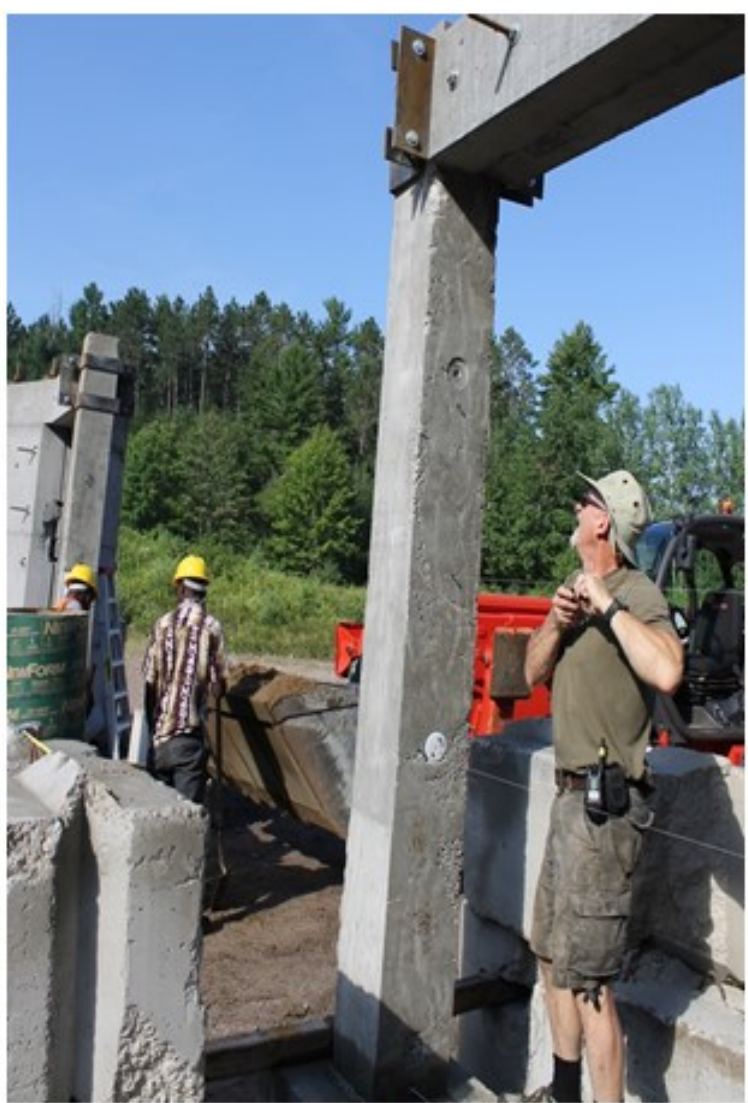

(b)

Figure 4-45: Photograph of Column SEIS-13 before test: (a) Front face of column with pressure gauges (b) back-face column with mid-back pressure gauge and retractable cable of string pot at $1 \mathrm{~m}$

The pressure gauges on SEIS-13 did not function during the test and thus no pressure data was recorded. Using CONWEP - A collection of conventional weapons effects calculations based on the Kingery-Bulmash polynomials with corrected angle of incidence, the reflected blast pressure data presented in Table 4-7 were calculated. The peak blast pressure at mid-height of $13,400 \mathrm{kPa}$ was relatively higher than the peak pressures at bottom-front and top-front gauge positions. Maximum pressure was expected at the lower one-third height of the column. However, since CONWEP does not consider $\mathrm{MACH}$ stem effects, the highest pressure was recorded at mid-height location of the shortest range. 
The string potentiometer at the lower third-point was damaged during the test. The displacement data for SEIS-13 were unreliable with the displacement measured at the upper third-point was higher than at mid-height (Figure 4-26). The raw data for the displacement is included in the Appendix A.

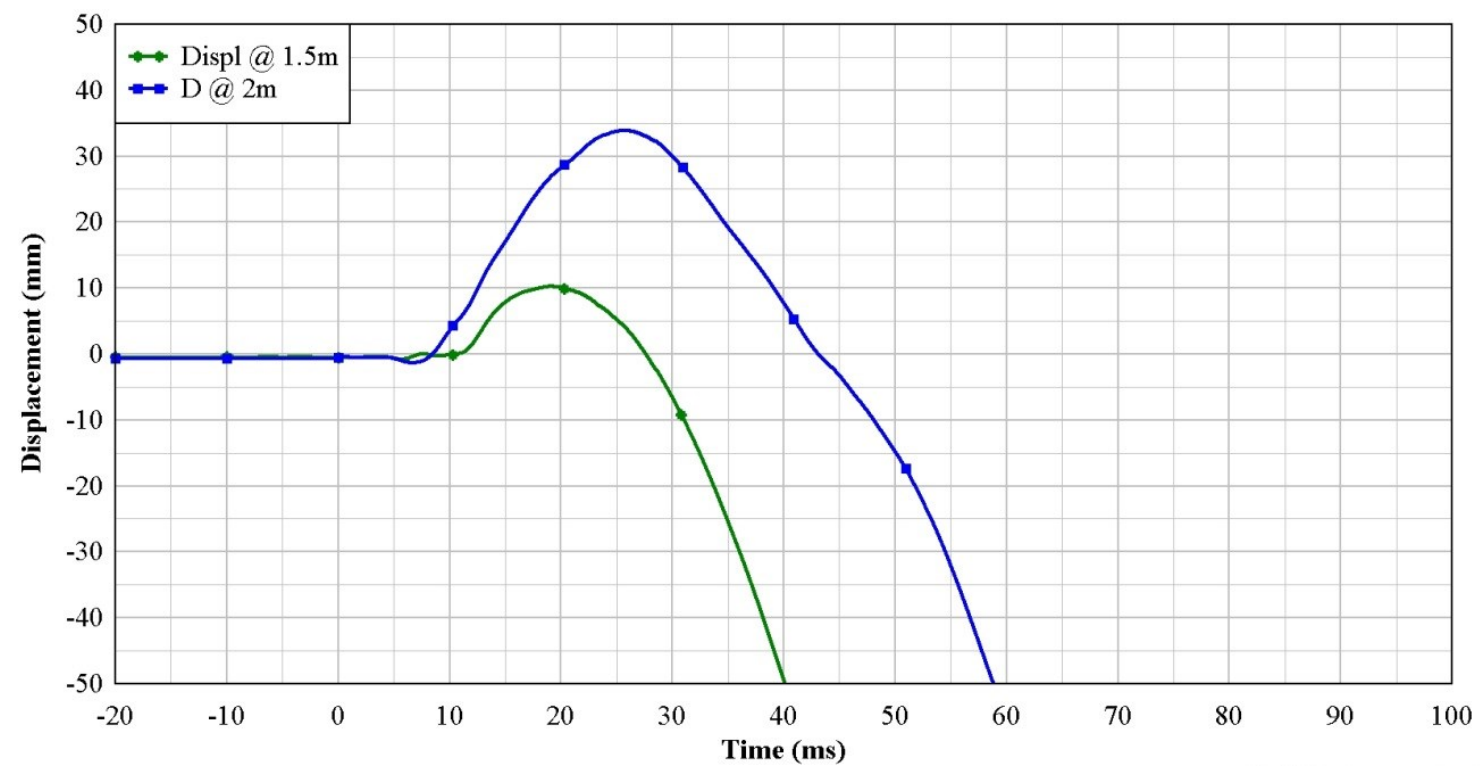

Figure 4-46: Displacement-Time history for column SEIS-13

Figure 4-47 presents the post-test photographs. Post-test observation of column SEIS-13 showed minimal cracking on the back face of the column. The few cracks on the surface appeared to be flexural. 


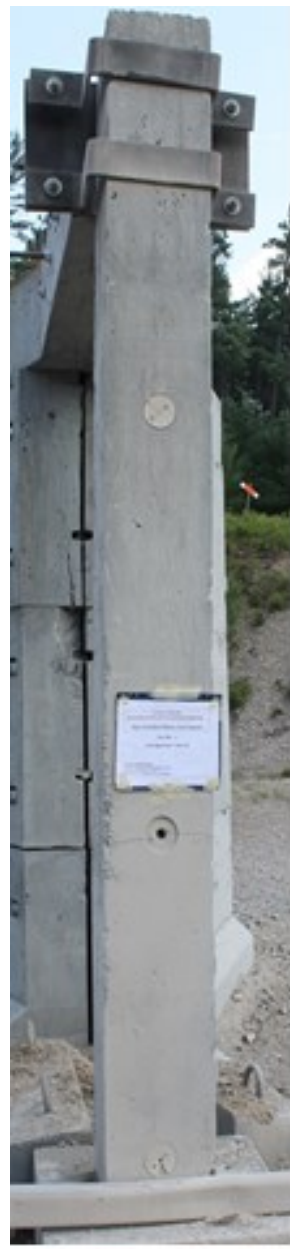

(a)

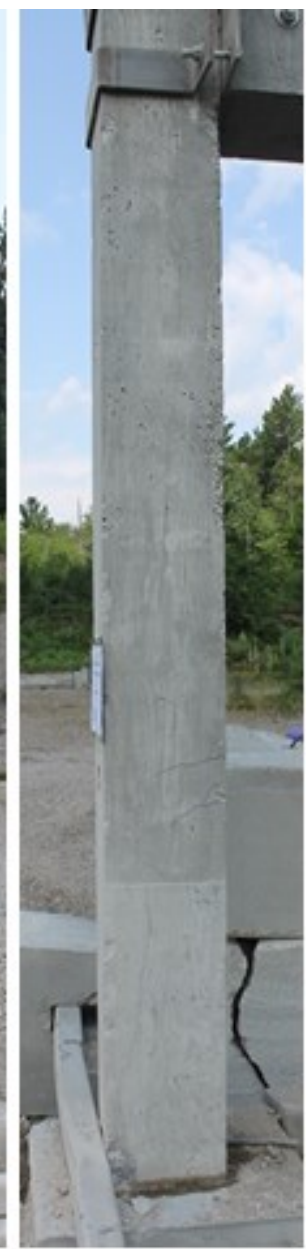

(b)

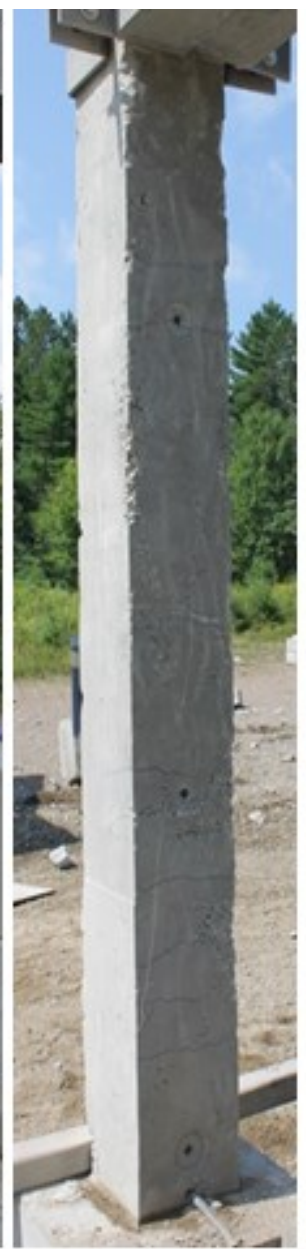

(c)

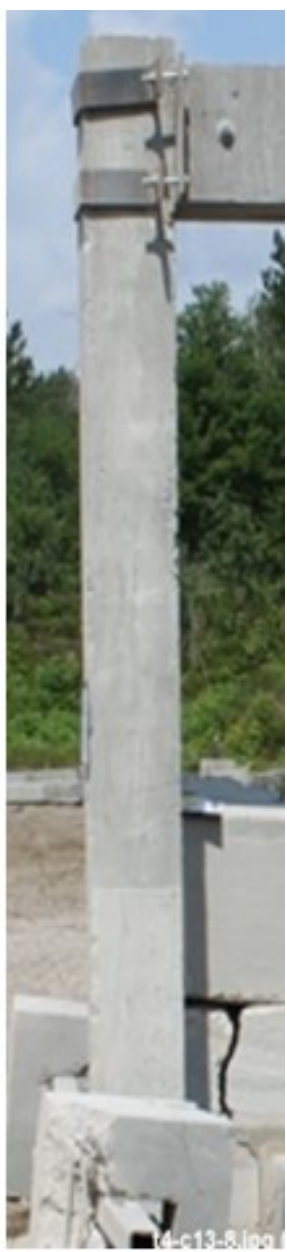

(d)

Figure 4-47: Post-test photograph of Column SEIS-13 faces: (a) Front face, (b) and (d) Side face (right), and (c) Back face

Table 4-7 presents a summary of the results from Test 4 . Most of the pressure gauges did not function during the test thus the reflected blast pressures are estimated using CONWEP. CONV-1 was tested at a scaled distance of $0.26 \mathrm{~m} / \mathrm{kg}^{1 / 3}$ while SEIS-13 was tested under a scaled distance of $0.82 \mathrm{~m} / \mathrm{kg}^{1 / 3}$. Thus very high reflected pressures were recorded at CONV-1 leading to total collapse. The peak blast pressure on SEIS-13 calculated with CONWEP was $13,400 \mathrm{kPa}$ at the mid-front pressure gauge. 
Table 4-7: Summary of test 4 (CONV-1 and SEIS-13) results

\begin{tabular}{|c|c|c|c|c|c|c|c|}
\hline \multicolumn{8}{|c|}{ (a) Blast Pressure Results } \\
\hline Test Specimen & \multicolumn{7}{|c|}{ CONV-1 } \\
\hline \multirow{2}{*}{ Test Details } & \multicolumn{2}{|c|}{ Charge Mass } & \multicolumn{2}{|c|}{ Standoff } & \multicolumn{2}{|c|}{$\mathrm{z}\left(\mathrm{m} / \mathrm{kg}^{1 / 3}\right)$} & ALR \\
\hline & \multicolumn{2}{|c|}{ 150-kg ANFO } & \multicolumn{2}{|c|}{$1.3 \mathrm{~m}$} & \multicolumn{2}{|c|}{0.26} & 0 \\
\hline \multirow{2}{*}{ Gauge } & \multicolumn{2}{|c|}{ Bottom-Front } & \multicolumn{2}{|c|}{ Mid-Front } & \multicolumn{2}{|c|}{ Top-Front } & Mid-Back \\
\hline & Exp. & CONWEP & Exp. & CONWEP & Exp. & CONWEP & Exp. \\
\hline Location $\left(\mathrm{mm}^{*}\right)$ & \multicolumn{2}{|c|}{160} & \multicolumn{2}{|c|}{1100} & \multicolumn{2}{|c|}{2100} & 1250 \\
\hline Range (mm) & \multicolumn{2}{|c|}{1547.8} & \multicolumn{2}{|c|}{1303.8} & \multicolumn{2}{|c|}{1702.9} & \\
\hline Incident Angle & \multicolumn{2}{|c|}{$32.9^{0}$} & \multicolumn{2}{|c|}{$4.4^{0}$} & \multicolumn{2}{|c|}{$40.2^{0}$} & \\
\hline $\mathrm{P}_{\mathrm{r}}(\mathrm{kPa})$ & Failed & 65676 & 96,127 & 101447 & Failed & 45251 & Failed \\
\hline $\mathrm{T}_{\mathrm{a}}(\mathrm{ms})$ & - & 0.4 & 0.48 & 0.3 & - & 0.4 & - \\
\hline $\mathrm{T}_{\mathrm{d}}(\mathrm{ms})$ & - & 0.9 & - & 0.9 & - & 1.0 & - \\
\hline Test Specimen & \multicolumn{7}{|c|}{ SEIS-13 } \\
\hline \multirow{2}{*}{ Test Details } & \multicolumn{2}{|c|}{ Charge Mass } & \multicolumn{2}{|c|}{ Standoff } & \multicolumn{2}{|c|}{$\mathrm{z}\left(\mathrm{m} / \mathrm{kg}^{1 / 3}\right)$} & ALR \\
\hline & \multicolumn{2}{|c|}{ 150-kg ANFO } & \multicolumn{2}{|c|}{$4.1 \mathrm{~m}$} & \multicolumn{2}{|c|}{0.82} & 0 \\
\hline Gauge & \multicolumn{2}{|c|}{ Bottom-Front } & \multicolumn{2}{|c|}{ Mid-Front } & \multicolumn{2}{|c|}{ Top-Front } & Mid-Back \\
\hline & Exp. & CONWEP & Exp. & CONWEP & Exp. & CONWEP & Exp. \\
\hline Location $\left(\mathrm{mm}^{*}\right)$ & \multicolumn{2}{|c|}{150} & & 010 & & 100 & $\mathrm{~N} / \mathrm{A}$ \\
\hline Range (mm) & & 37.2 & & 100 & & 245 & \\
\hline Incident Angle & & $.7^{0}$ & & $.0^{0}$ & & $5.0^{0}$ & \\
\hline $\mathrm{P}_{\mathrm{r}}(\mathrm{kPa})$ & Failed & 11393 & Failed & 13400 & Failed & 11086 & Failed \\
\hline $\mathrm{T}_{\mathrm{a}}(\mathrm{ms})$ & - & 1.7 & - & 1.7 & - & 1.8 & - \\
\hline $\mathrm{T}_{\mathrm{d}}(\mathrm{ms})$ & - & 4.8 & - & 4.5 & - & 5.0 & - \\
\hline
\end{tabular}




\begin{tabular}{|c|c|c|c|c|}
\hline \multicolumn{5}{|c|}{ (b) Displacement Results $^{1}$} \\
\hline & Displ @ $1 \mathrm{~m}$ & Displ @ $1.5 \mathrm{~m}$ & Displ @ 2m & \\
\hline CONV-1 & $29.6 \mathrm{~mm}$ & $21.9 \mathrm{~mm}$ & $9.2 \mathrm{~mm}$ & \\
\hline SEIS-13 & Failed & $12.7 \mathrm{~mm}$ & $35.0 \mathrm{~mm}$ & \\
\hline
\end{tabular}

*dimensions measured from top of concrete footing

${ }^{1}$ displacement table results is part of Table 4-7 


\subsection{Column Test 5 (CONV-2 and SEIS-14)}

Test 5 was conducted on two columns CONV-2 and SEIS-14 and subjected to $150 \mathrm{~kg}$ ANFO explosive. The distance from the center of detonation to column CONV-2 was 1.3 $\mathrm{m}$ and to SEIS-14 was at $4.3 \mathrm{~m}$ (Figure 4-48). The scaled distances from the explosive charge mass and corresponding standoff distances were $0.26 \mathrm{~m} / \mathrm{kg}^{1 / 3}$ for CONV-2 and $0.86 \mathrm{~m} / \mathrm{kg}^{1 / 3}$ for SEIS-14.

Figure 4-48 presents a sketch of the experimental setup. The two columns (CONV-2 and SEIS-14) were instrumented with pressure gauges, string potentiometers and strain gauges. Column CONV-2 was designed as a conventional column, while column SEIS14 was designed as part of a structures' lateral load resisting system.

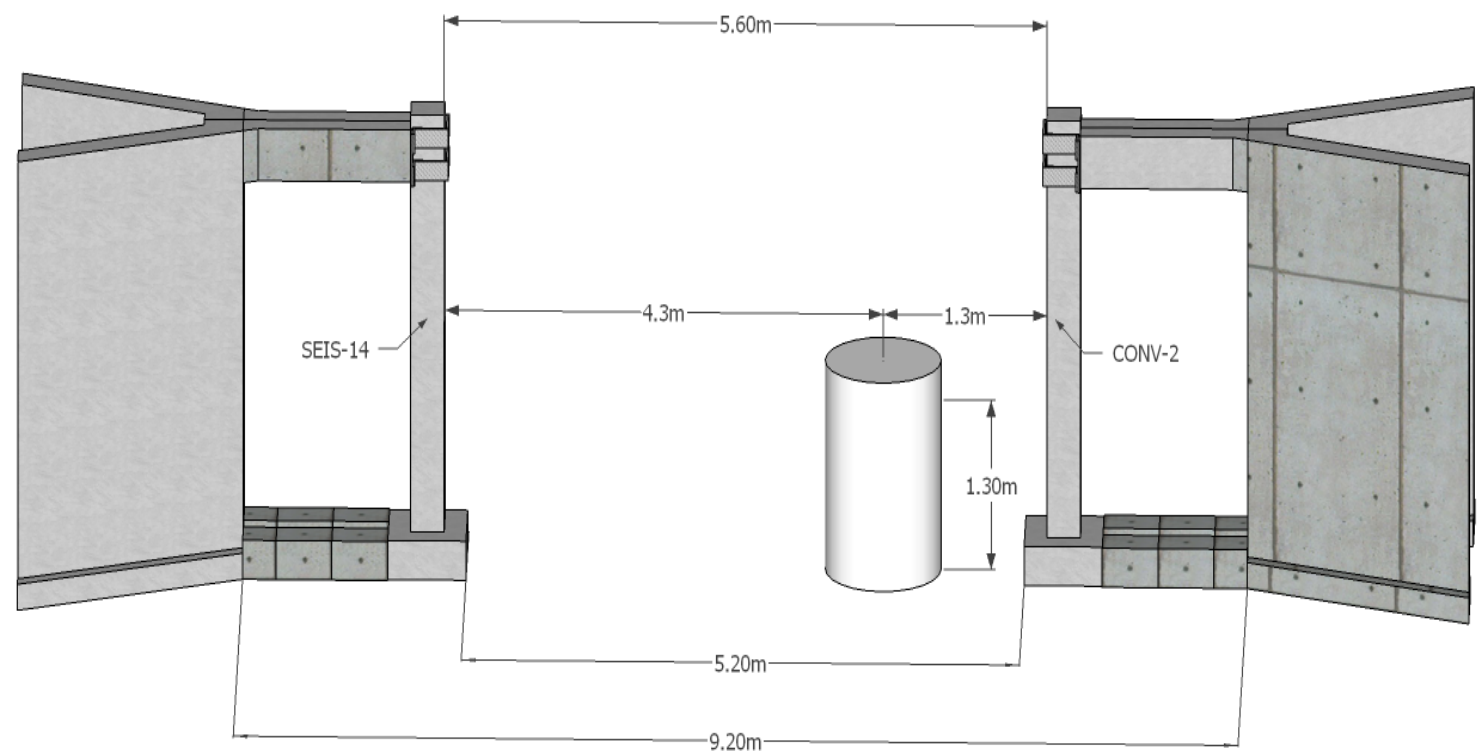

Figure 4-48: A sketch of columns SEIS-14 and CONV-2 experimental setup

\subsubsection{Column CONV-2}

Column CONV-2 was tested in the support structure with damaged moment restraint brackets. The top of the column was restrained with a steel chain furnished with a "comealong" winch (Figure 4-49). This modification to the top support of the column provided a simulated fixed-connection with a centre of rotation at the bottom edge of the outrigger 
of the support structure and a restraint force at the chain location. The moment restraint in this connection will be slightly less than in the case of the steel brackets.

The data acquisition system did not trigger during Test 5. Thus, no pressure or displacement data were recorded for CONV-2. Using CONWEP - A collection of conventional weapons effects calculations based on the Kingery-Bulmash polynomials with corrected angle of incidence, the pressure at the bottom-front, mid-front and topfront gauges are 65,721.6 $\mathrm{kPa}, 95,049 \mathrm{kPa}$ and 45,097.1 $\mathrm{kPa}$ respectively (Table 4-8). Maximum pressures occurred at lower one-third height of the column, with pressures varying from $65,721.6 \mathrm{kPa}$ to $95,049 \mathrm{kPa}$ at arrival time of $0.3-\mathrm{ms}$. Table $4-8$ presents reflected pressure data for the front face of CONV-2 calculated with CONWEP.

Table 4-8: Reflected pressure results for the front face of CONV-2 using CONWEP Kingery-Bulmash Polynomials (CONWEP) Results

\begin{tabular}{|c|c|c|c|}
\hline Test Specimen & \multicolumn{3}{|c|}{ Column CONV-2 } \\
\hline \multirow{3}{*}{ Test Details } & Tie-Spacing & Charge Mass & Standoff \\
\cline { 2 - 4 } & $300 \mathrm{~mm}$ & 150 -kg ANFO & $1.3 \mathrm{~m}$ \\
\cline { 2 - 4 } & $\mathrm{z}\left(\mathrm{m} / \mathrm{kg}^{1 / 3}\right)$ & ALR & Height of Burst \\
\cline { 2 - 4 } & 0.26 & 0 & $1.0 \mathrm{~m}^{*}$ \\
\hline & Bottom-Front & Mid-Front & Top-Front \\
\hline Gauge location & $300 \mathrm{~mm}^{*}$ & $1200 \mathrm{~mm}^{*}$ & $2400 \mathrm{~mm}^{*}$ \\
\hline Range $(\mathrm{mm})$ & 1476.5 & 1315.3 & 1910.5 \\
\hline Incidence angle & $28.3^{0}$ & $8.7^{0}$ & $47.1^{0}$ \\
\hline $\mathrm{P}_{\mathrm{r}}(\mathrm{kPa})$ & $65,721.6$ & 95,049 & $45,097.1$ \\
\hline $\mathrm{T}_{\mathrm{a}}(\mathrm{ms})$ & 0.3 & 0.3 & 0.5 \\
\hline $\mathrm{T}_{\mathrm{d}}(\mathrm{ms})$ & 0.9 & 0.9 & 1.0 \\
\hline
\end{tabular}

*dimensions measured from top of concrete footing 


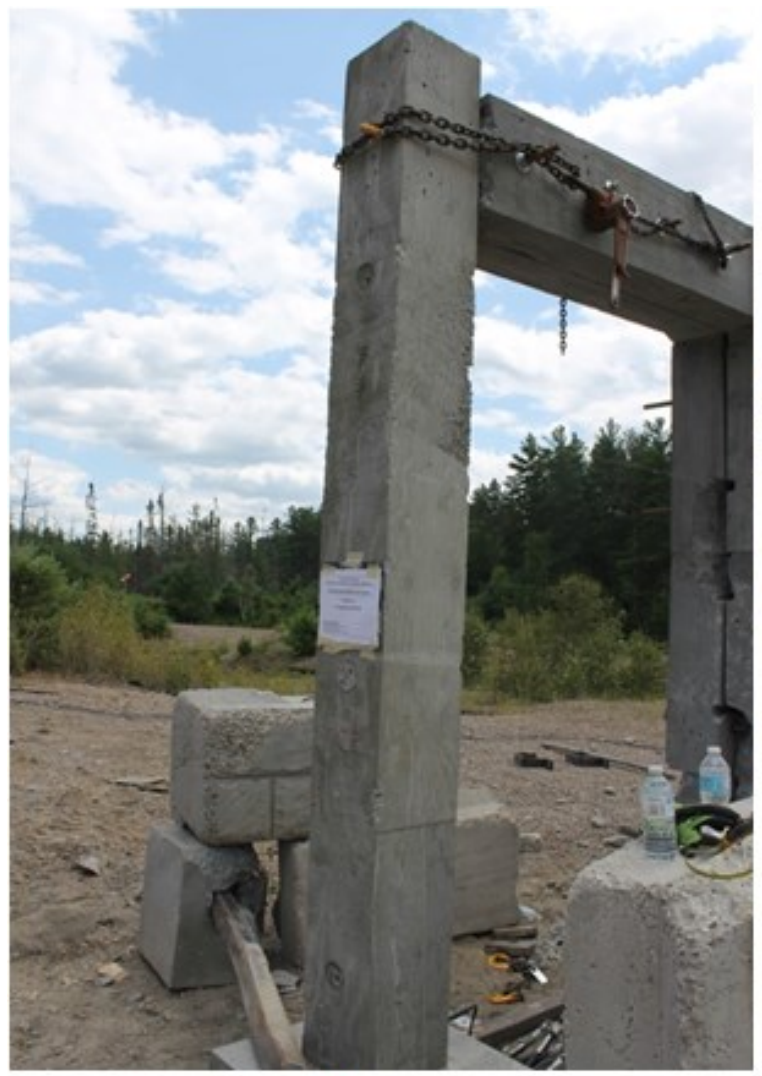

(a)

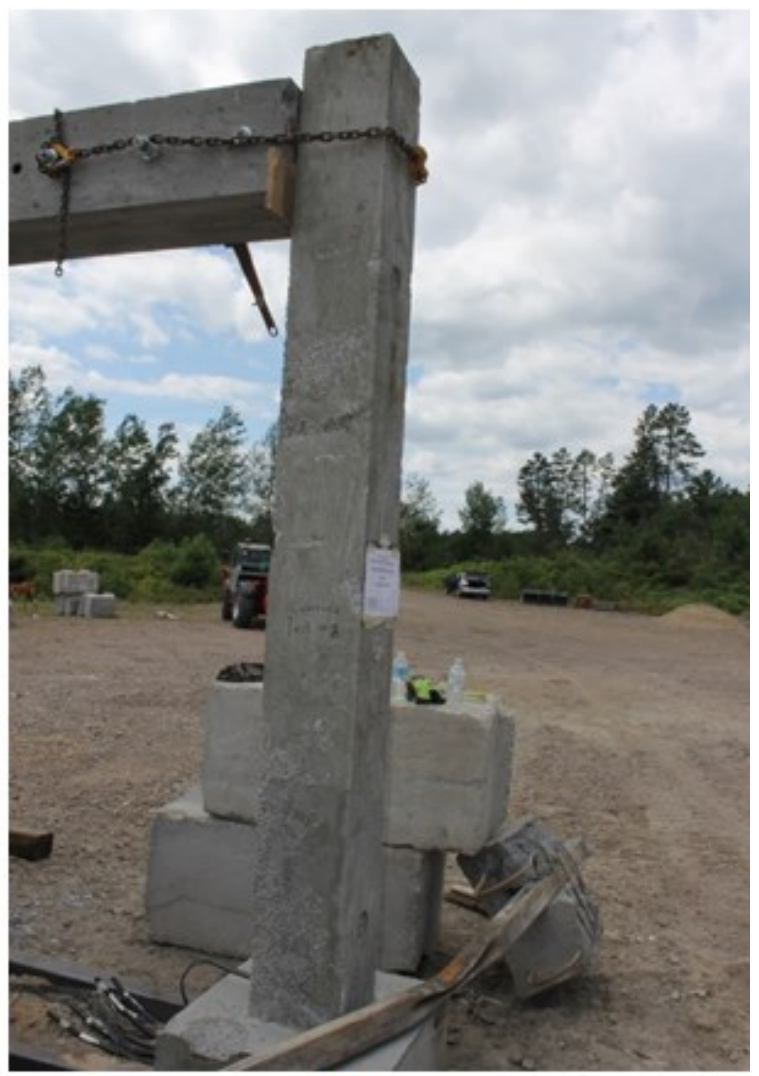

(b)

Figure 4-49: Photograph of Column CONV-2 before test: (a) Front face (b) Side face

Figure 4-49 shows pre-test photograph of CONV-2 while Figure 4-50 shows a post-test photograph. CONV-2 was tested at a scaled distance of $0.26 \mathrm{~m} / \mathrm{kg}^{1 / 3}$ resulting in very high blast pressures on the column. The column failed catastrophically after the blast pressure impact. The concrete in the lap-splice zone was striped and blown off rebar. Consequently, the column severed into two at the column-footing joint (Figure 4-50). 


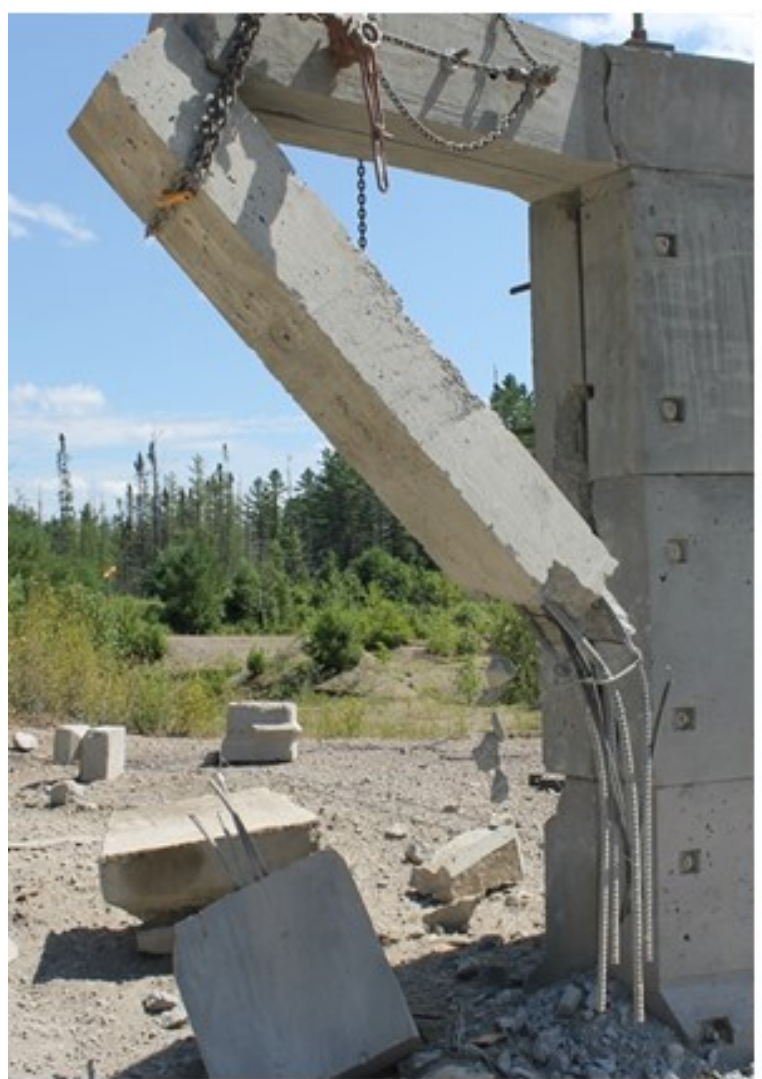

(a)

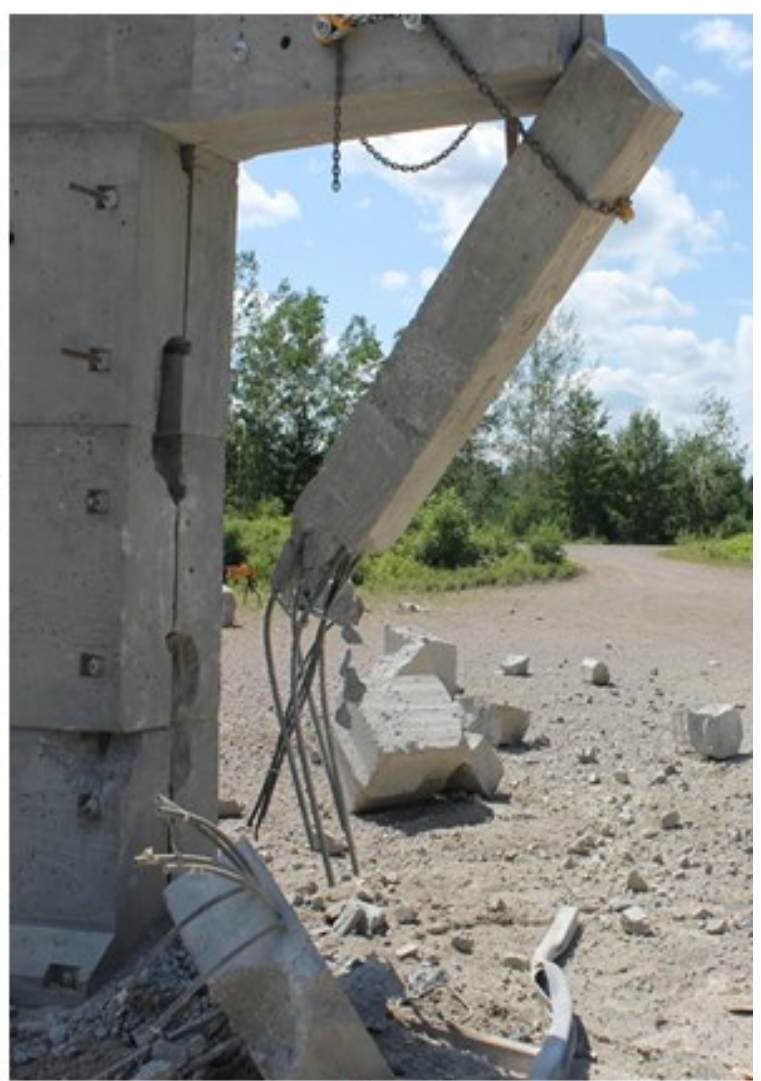

(b)

Figure 4-50: Post-test photograph of column CONV-2

\subsubsection{Column SEIS-14}

No data was recorded for SIES-14. Using CONWEP - A collection of conventional weapons effects calculations based on the Kingery-Bulmash polynomials with appropriate correction for incidence angle, the pressure at the bottom-front, mid-front and top-front gauges are $11,694 \mathrm{kPa}, 12,743 \mathrm{kPa}$ and 10,759 $\mathrm{kPa}$ respectively (Table 4-9). The maximum pressure calculated with a corrected incidence angle of $2^{0}$ was at mid-front gauge with an arrival time of $1.6 \mathrm{~ms}$. Table 4-9 presents reflected pressure data for the front face of SEIS-14. Figure 4-51 shows a pre-test photograph of SEIS-14 while Figure 4-52 shows a post-test photograph. The blast loading from the scaled distance of 0.86 $\mathrm{m} / \mathrm{kg}^{1 / 3}$ (150 $\mathrm{kg}$ of ANFO explosive charge at $4.3 \mathrm{~m}$ standoff) resulted in minimal 
damage to the column. Flexural cracking was observed on the back face and sides of the column.

Table 4-9: Reflected pressure results for the front face of SEIS-14 using CONWEP Kingery-Bulmash Polynomials (CONWEP) Results

\begin{tabular}{|c|c|c|c|}
\hline \multirow{2}{*}{ Test Specimen } & \multicolumn{3}{|c|}{ Column SEIS-14 } \\
\hline \multirow{3}{*}{ Test Details } & Tie-Spacing & Charge Mass & Standoff \\
\cline { 2 - 4 } & $75 \mathrm{~mm}$ & $150-\mathrm{kg}$ ANFO & $4.3 \mathrm{~m}$ \\
\cline { 2 - 4 } & $\mathrm{z}\left(\mathrm{m}^{\mathrm{kg}}{ }^{1 / 3}\right)$ & ALR & Height of Burst \\
\cline { 2 - 4 } & 0.86 & 0 & $1.0 \mathrm{~m}^{*}$ \\
\hline & Bottom-Front & Mid-Front & Top-Front \\
\hline Gauge location & $250 \mathrm{~mm} *$ & $1150 \mathrm{~mm}^{*}$ & $2200 \mathrm{~mm}^{*}$ \\
\hline Range $(\mathrm{mm})$ & 4364.9 & 4302.6 & 4464.3 \\
\hline Incidence angle & 9.9 & 2.0 & $15.6^{0}$ \\
\hline $\mathrm{P}_{\mathrm{r}}(\mathrm{kPa})$ & 11,694 & 12,743 & 10,759 \\
\hline $\mathrm{T}_{\mathrm{a}}(\mathrm{ms})$ & 1.7 & 1.6 & 1.8 \\
\hline $\mathrm{T}_{\mathrm{d}}(\mathrm{ms})$ & 4.7 & 4.5 & 5.1 \\
\hline
\end{tabular}

*dimensions measured from top of concrete footing 


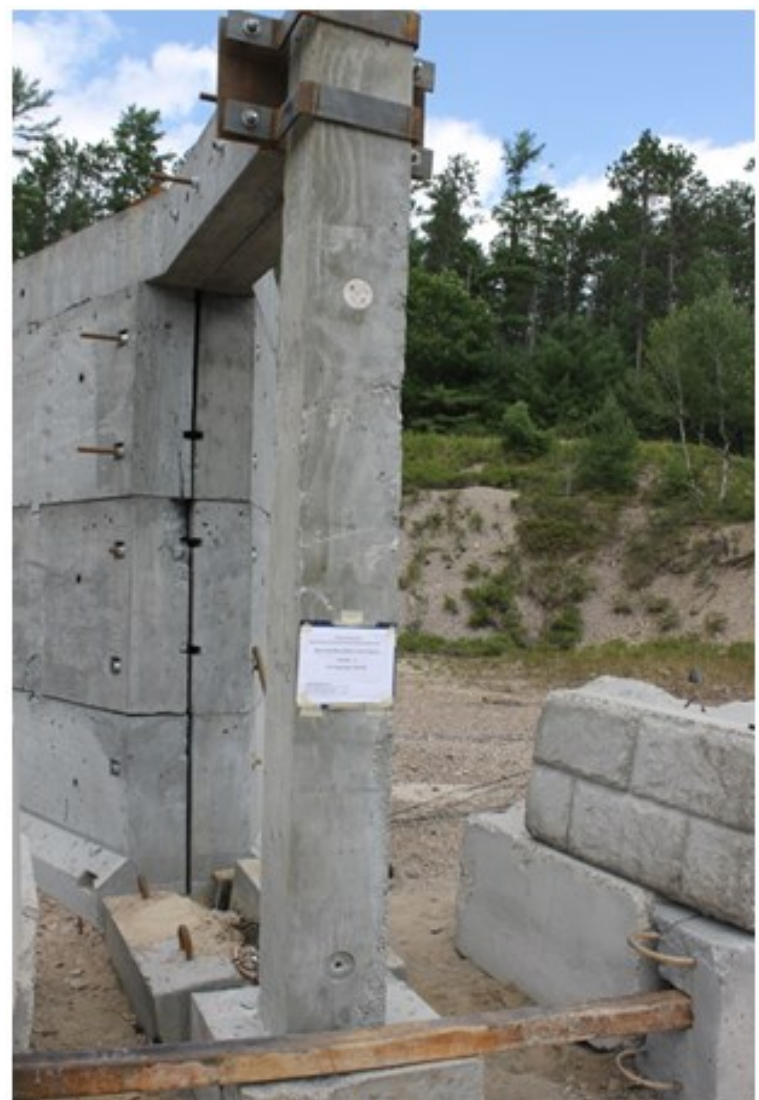

(a)

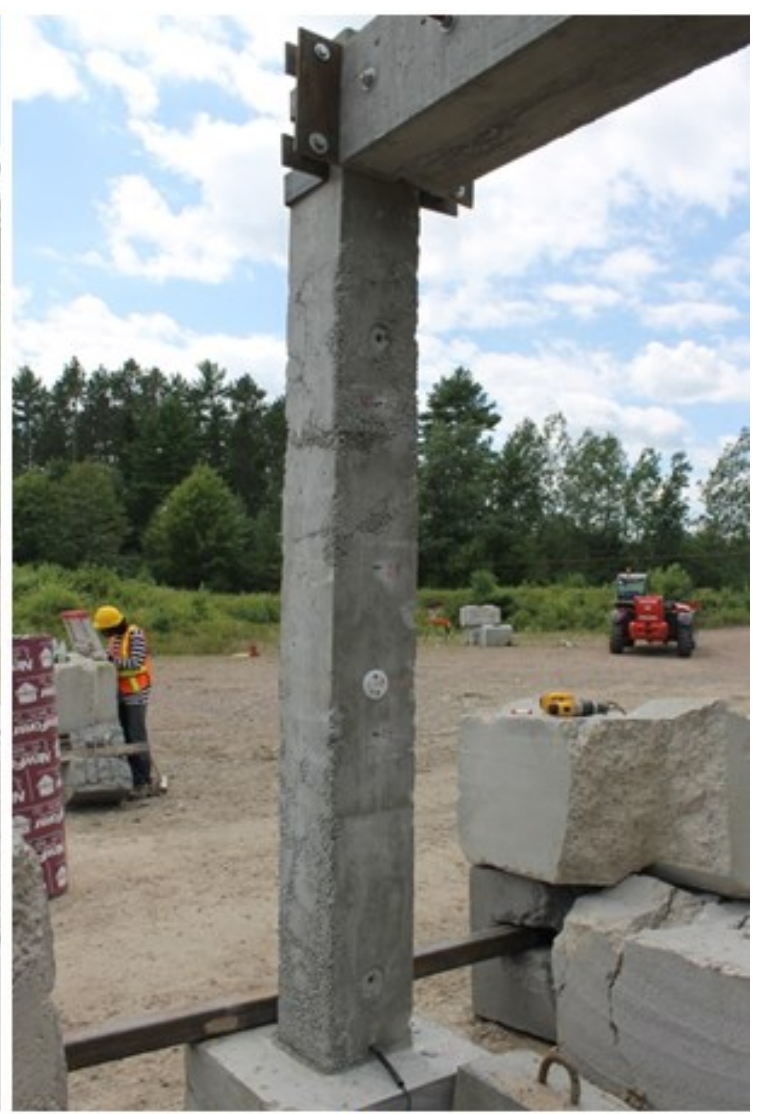

(b)

Figure 4-51: Photograph of Column SEIS-14 before test: (a) Front face of column with top-front pressure gauge (b) Back face column with mid-back pressure gauge 


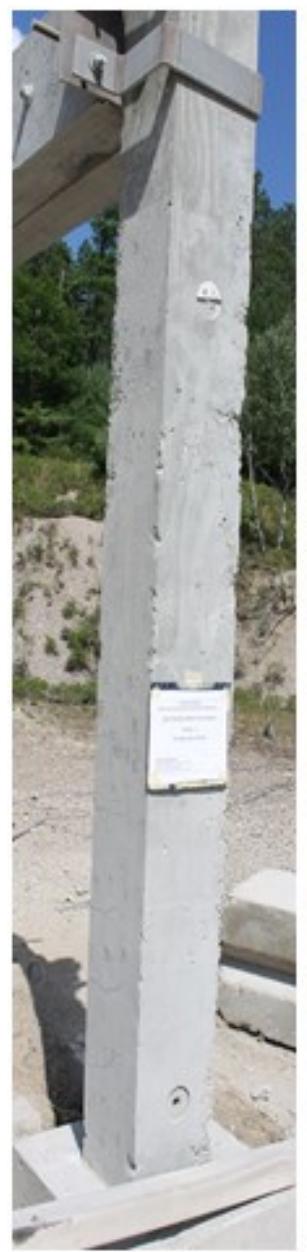

(a)

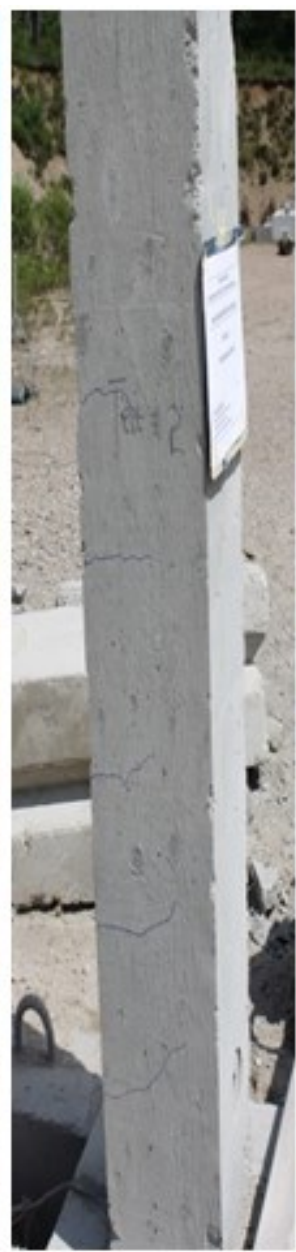

(b)

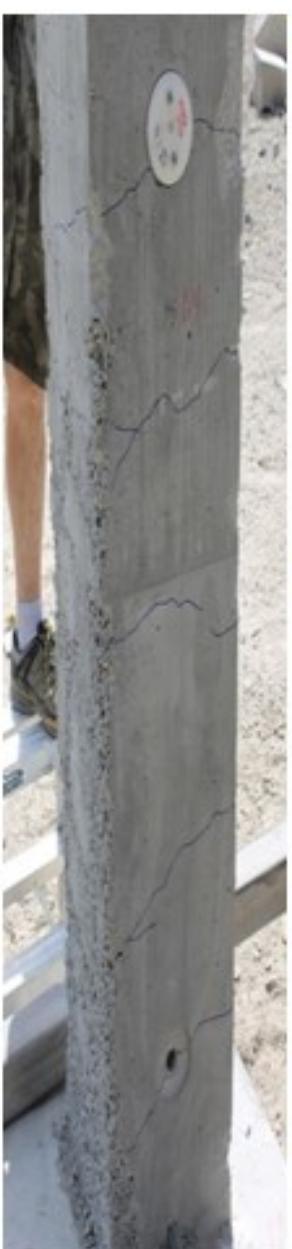

(c)

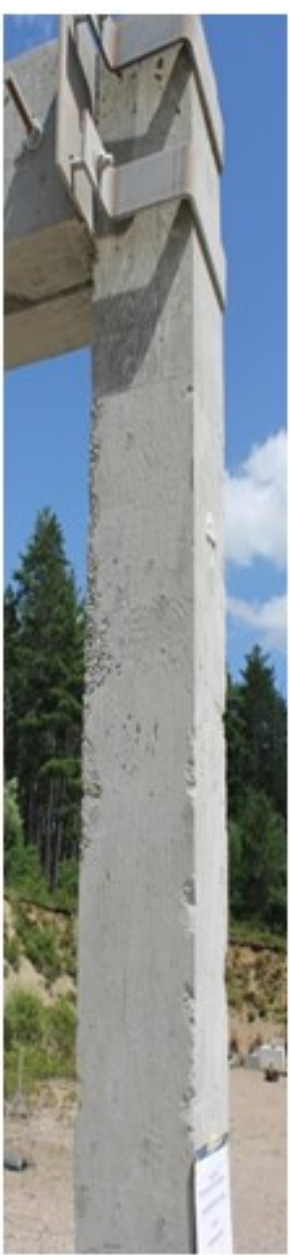

(d)

Figure 4-52: Post-test photograph of column SEIS-14 faces: (a) Front face, (b) Side face (right), (c) Back face, and (d) Side face (left)

\subsection{Column Test 6 (SEIS-3 and CONV-11)}

Test 6 was conducted on two columns (SEIS-3 and CONV-11) subjected to $150-\mathrm{kg}$ ANFO explosive. The distance from the center of detonation to column SEIS-3 was 1.3 $\mathrm{m}$ while column CONV-11 was at $4.4 \mathrm{~m}$ from the center of detonation (Figure 4-53).

Figure 4-53 is a sketch of the experimental setup while Figure 4-54 is a photograph of the experimental setup prior to explosion test. The two columns (SEIS-3 and CONV-11) were instrumented with pressure gauges, string potentiometers and strain gauges. However, no data was recorded during the test. 


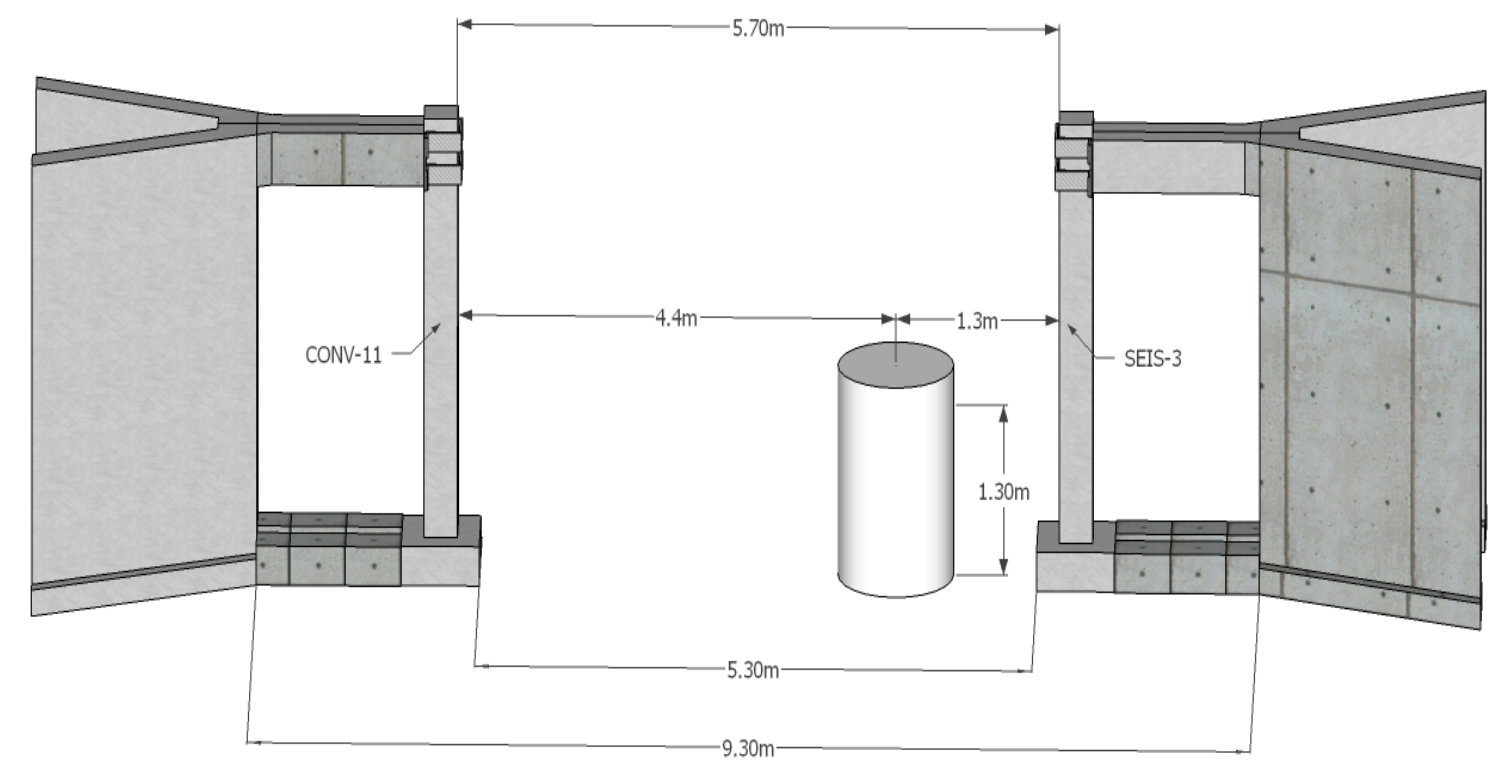

Figure 4-53: Pre-test setup of columns CONV-11 and SEIS-3

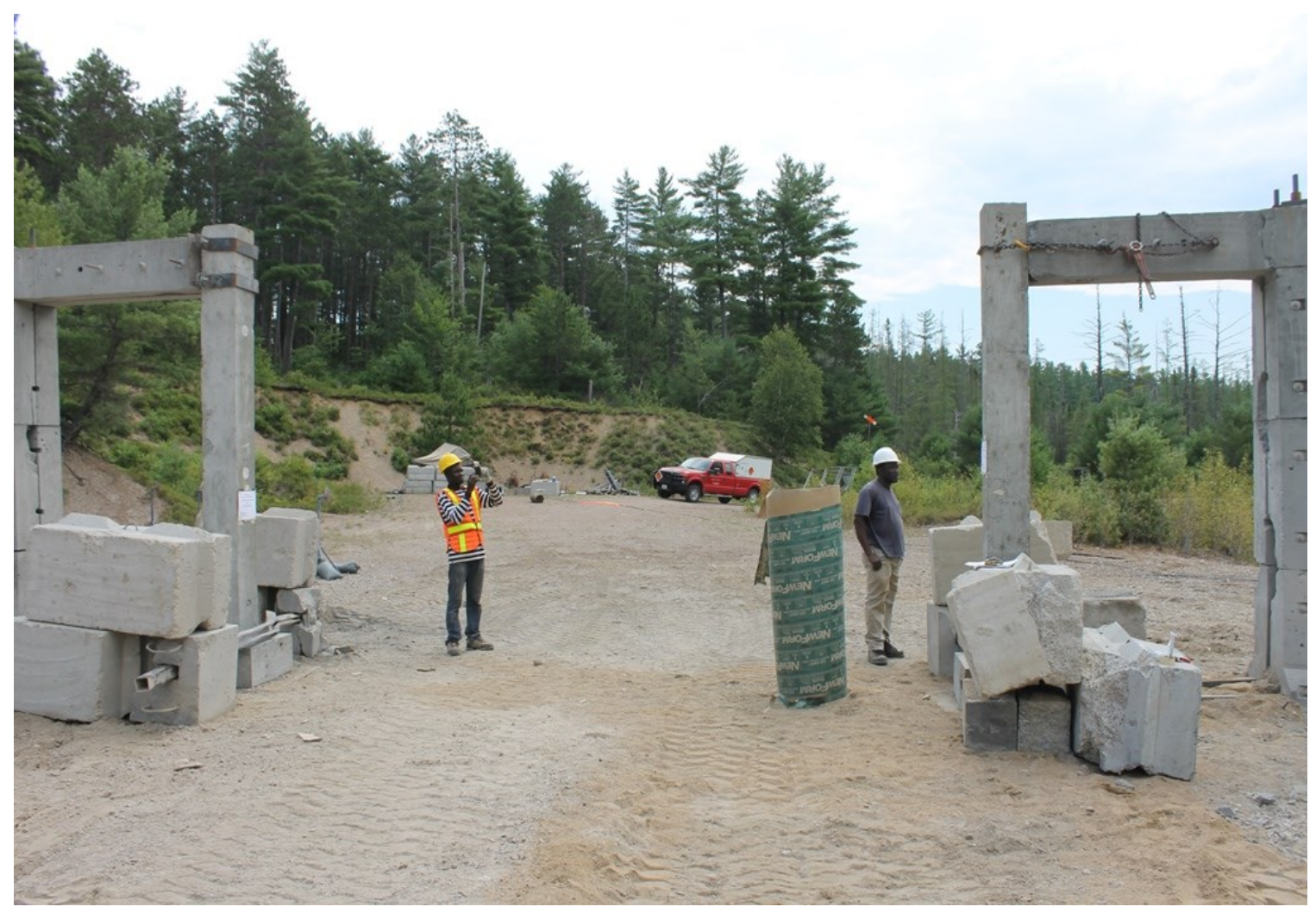

Figure 4-54: Pre-test setup of test 6 (CONV-11 and SEIS-3) 


\subsubsection{Column SEIS-3}

SEIS-3 was subjected to blast loading from a scaled distance of $0.26 \mathrm{~m} / \mathrm{kg}^{1 / 3}(150 \mathrm{~kg}$ ANFO at a standoff of $1.3 \mathrm{~m}$ ). The data acquisition system did not trigger during Test 6 . Thus, no pressure or displacement data were recorded. Pressures on the front face of the column were calculated using CONWEP - A collection of conventional weapons effects calculations based on the Kingery-Bulmash polynomials with appropriate correction for incidence angle. The pressures at the bottom-front, mid-front and top-front gauges from CONWEP are 65,721.6 kPa, 91,912.5 $\mathrm{kPa}$, and 48,286.3 $\mathrm{kPa}$ respectively (Table 4-10). Maximum pressure was expected at lower one-third height of the column due to MACH stem effects. However, since CONWEP does not consider MACH stem effects, the highest pressure was recorded at mid-height (the location of shortest range). The pressures varied from $65,721.6 \mathrm{kPa}$ to $91,912.5 \mathrm{kPa}$ at arrival time of $0.3 \mathrm{~ms}$. Table 4-10 presents reflected pressure data for the front face of CONV-2 calculated with CONWEP. Figure 4-55 presents the pre-test photograph of SEIS-3 while Figure 4-58 presents a posttest photograph. SEIS-3 was tested in the support structure with damaged top support restraint, thus a simulated support with a steel chain and "come-along" winch was used. The blast pressure produced severe damage to the column, pushing it into the support structure (Figure 4-56). 
Table 4-10: Reflected pressure results for the front face of SEIS-3 using CONWEP Kingery-Bulmash Polynomials (CONWEP) Results

\begin{tabular}{|c|c|c|c|}
\hline \multirow{2}{*}{ Test Specimen } & \multicolumn{3}{|c|}{ Column SEIS-3 } \\
\hline \multirow{3}{*}{ Test Details } & Tie-Spacing & Charge Mass & Standoff \\
\cline { 2 - 4 } & $300 \mathrm{~mm}$ & $150-\mathrm{kg}$ ANFO & $1.3 \mathrm{~m}$ \\
\cline { 2 - 4 } & $\mathrm{z}\left(\mathrm{m} / \mathrm{kg}^{1 / 3}\right)$ & ALR & Height of Burst \\
\cline { 2 - 4 } & 0.26 & 0 & $1.0 \mathrm{~m}^{*}$ \\
\hline & Bottom-Front & Mid-Front & Top-Front \\
\hline Gauge location & $300 \mathrm{~mm}^{*}$ & $1200 \mathrm{~mm}^{*}$ & $2400 \mathrm{~mm}^{*}$ \\
\hline Range $(\mathrm{mm})$ & 1476.5 & 1313.8 & 1838.5 \\
\hline Incidence angle & $28.3^{0}$ & $8.3^{0}$ & $45^{0}$ \\
\hline $\mathrm{P}_{\mathrm{r}}(\mathrm{kPa})$ & 65721.6 & 91912.5 & 48286.3 \\
\hline $\mathrm{T}_{\mathrm{a}}(\mathrm{ms})$ & 0.3 & 0.3 & 0.5 \\
\hline $\mathrm{T}_{\mathrm{d}}(\mathrm{ms})$ & 0.9 & 0.9 & 1.0 \\
\hline
\end{tabular}

*dimensions measured from top of concrete footing

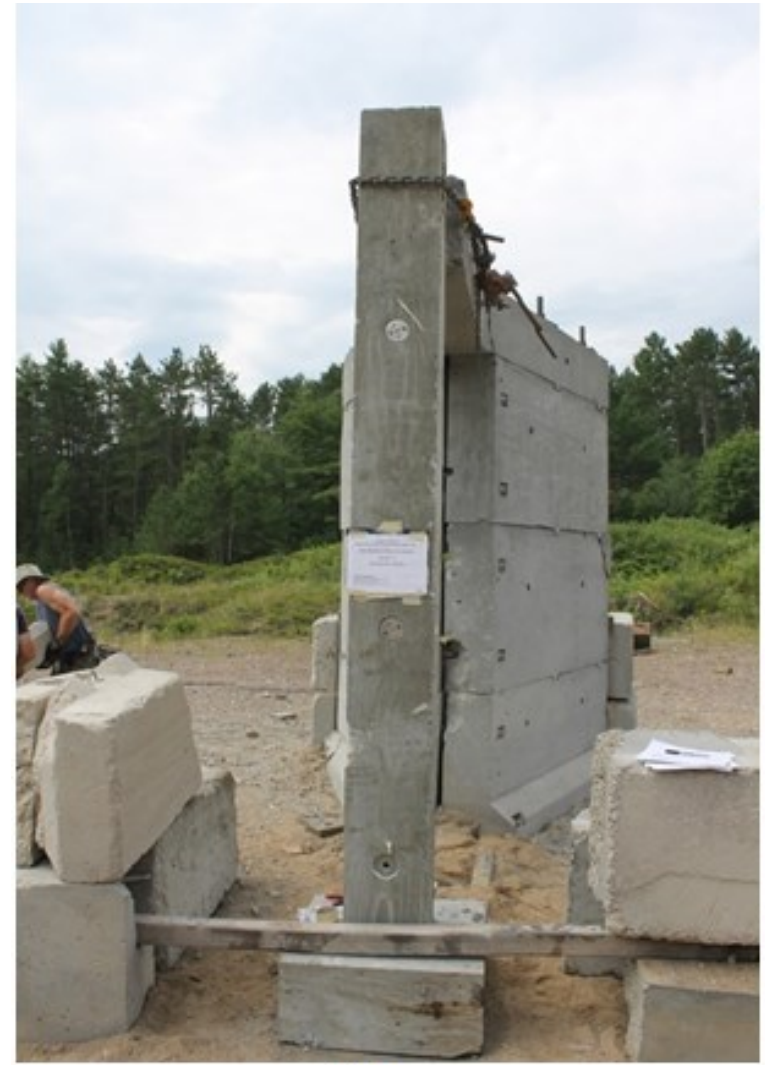

(a)

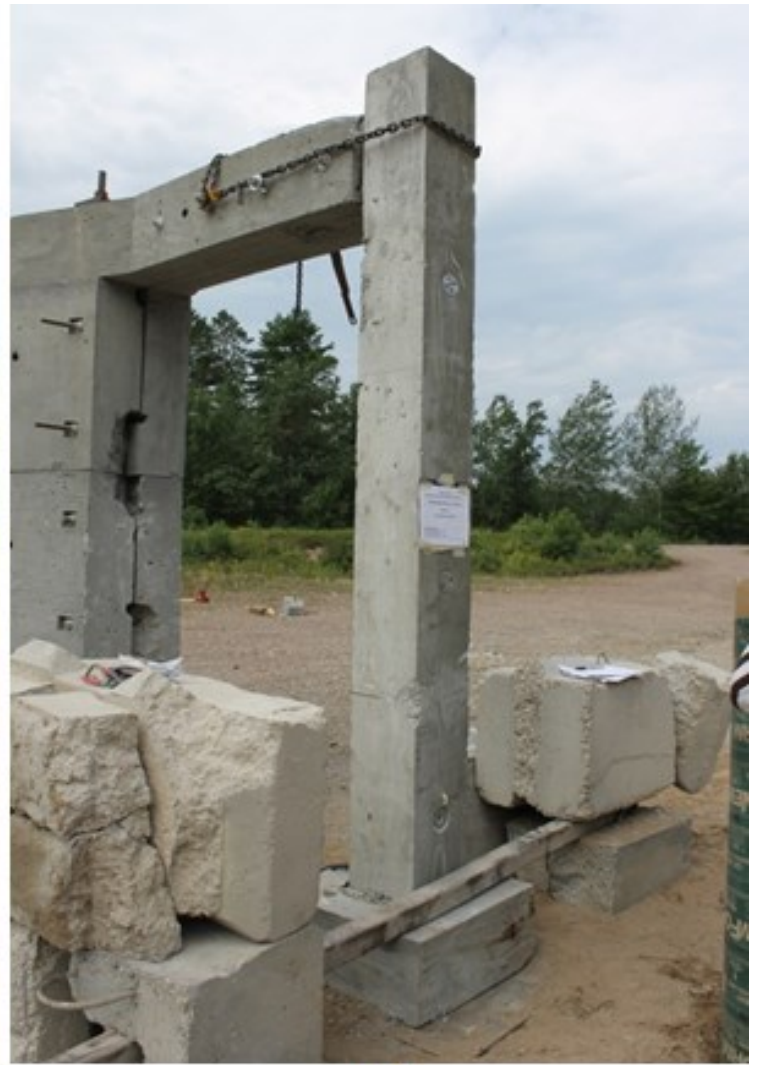

(b)

Figure 4-55: Photograph of Column SEIS-3 before test: (a) Front face (b) Side face 
Concrete crushing and spalling was observed in the lower half of the column. Unlike in the conventional columns, concrete confinement precluded catastrophic failure. Even though the column was severely bent, it stayed in one piece (Figure 4-56). The 75-mm transverse reinforcement spacing evidently made the column more ductile, with only concrete cover spalling. Beyond the $75 \mathrm{~mm}$ tie spacing region to $150 \mathrm{~mm}$ tie spacing region, severe core concrete crushing was observed (Figure 4-56).

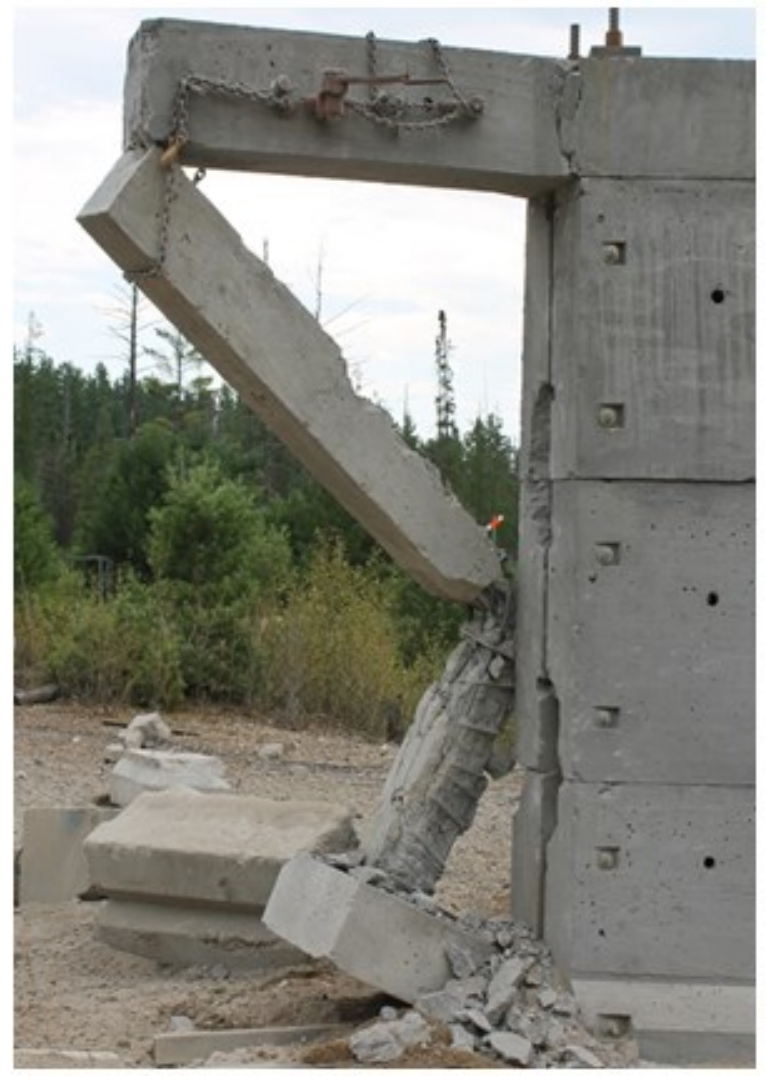

(a)

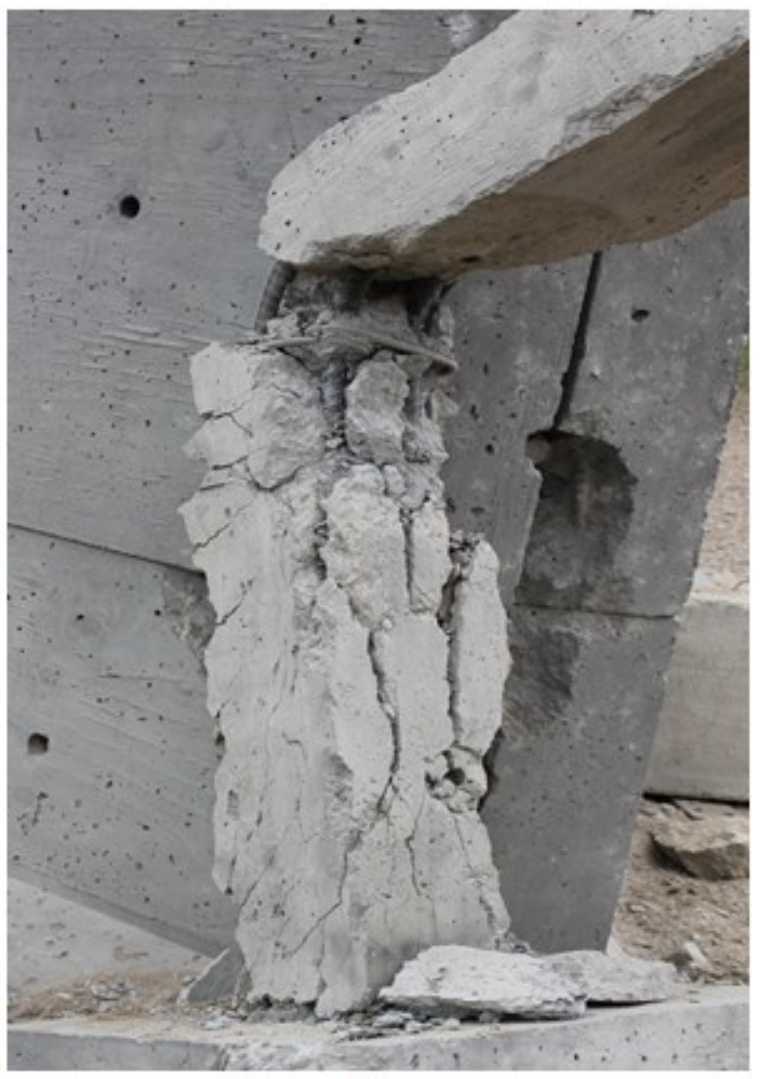

(b)

Figure 4-56: Post-test photograph of column SEIS-3

\subsubsection{Column CONV-11}

Table 4-11 presents blast pressure on the front face of the column calculated using CONWEP - A collection of conventional weapons effects calculations based on the Kingery-Bulmash polynomials at corrected incidence angles. The pressures at the bottom-front, mid-front and top-front gauges are $10,212 \mathrm{kPa}, 10,788 \mathrm{kPa}$ and $9,193 \mathrm{kPa}$ 
respectively (Table 4-11). A peak pressure of 10,788 $\mathrm{kPa}$ with an arrival time of $1.9 \mathrm{~ms}$ was calculated at the mid-height of the column. The $150-\mathrm{kg}$ ANFO charge was at a standoff distance of $4.4 \mathrm{~m}$ (scaled distance of $0.88 \mathrm{~m} / \mathrm{kg}^{1 / 3}$ ).

Figure 4-57 presents the pre-test photograph of CONV-11 while Figure 4-58 presents a post-test photograph.

Table 4-11: Reflected pressure results for the front face of CONV-11 using CONWEP

\begin{tabular}{|c|c|c|c|}
\hline \multicolumn{4}{|c|}{ Kingery-Bulmash Polynomials (CONWEP) Results } \\
\hline Test Specimen & \multicolumn{3}{|c|}{ Column CONV-11 } \\
\hline \multirow{3}{*}{ Test Details } & Tie-Spacing & Charge Mass & Standoff \\
\cline { 2 - 4 } & $300 \mathrm{~mm}$ & 150 -kg ANFO & $4.4 \mathrm{~m}$ \\
\cline { 2 - 4 } & $\mathrm{z}\left(\mathrm{m}^{\mathrm{kg}}{ }^{1 / 3}\right)$ & ALR & Height of Burst \\
\cline { 2 - 4 } & 0.88 & 0 & $1.0 \mathrm{~m}^{*}$ \\
\hline \multirow{2}{*}{ Gauge location } & Bottom-Front & Mid-Front & Top-Front \\
\hline Range $(\mathrm{mm})$ & $480 \mathrm{~mm} *$ & $1300 \mathrm{~mm} *$ & $2400 \mathrm{~mm} *$ \\
\hline Incidence angle & $9.3^{0}$ & 4410.2 & 4617.4 \\
\hline $\mathrm{P}_{\mathrm{r}}(\mathrm{kPa})$ & 10,212 & $3.9^{0}$ & $17.7^{0}$ \\
\hline $\mathrm{T}_{\mathrm{a}}(\mathrm{ms})$ & 1.9 & 10,788 & 9,193 \\
\hline $\mathrm{T}_{\mathrm{d}}(\mathrm{ms})$ & 5.9 & 1.9 & 2 \\
\hline
\end{tabular}

*dimensions measured from top of concrete footing 


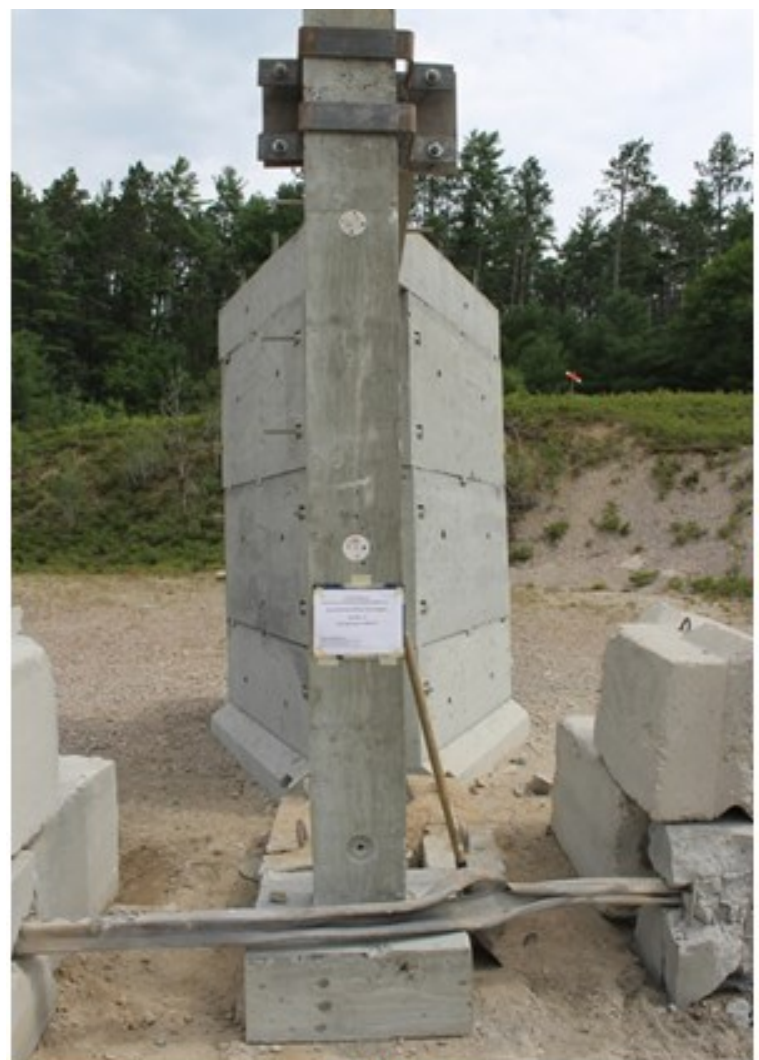

(a)

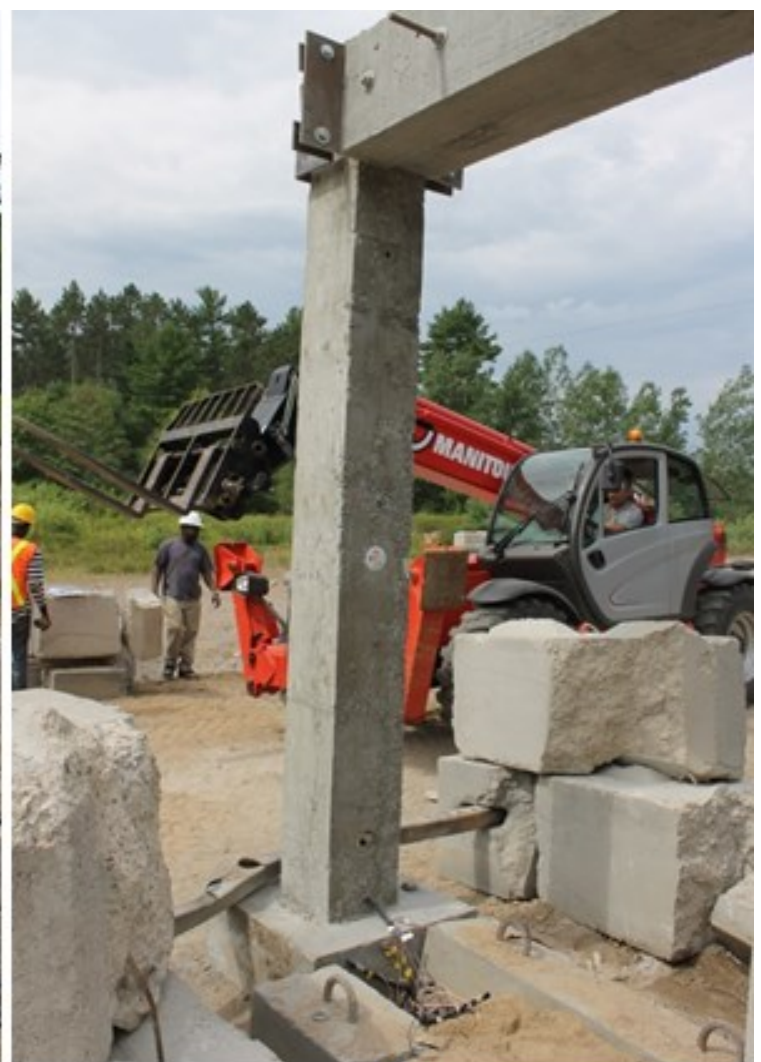

(b)

Figure 4-57: Photograph of Column CONV-11 before test: (a) Front face of column with mid-front and top-front pressure gauges (b) back-face column with mid-back pressure gauge

Minimal cracking was observed on the column after the explosion test. The cracks were

predominantly flexural cracks developed on the sides and back of the column (Figure 458). 


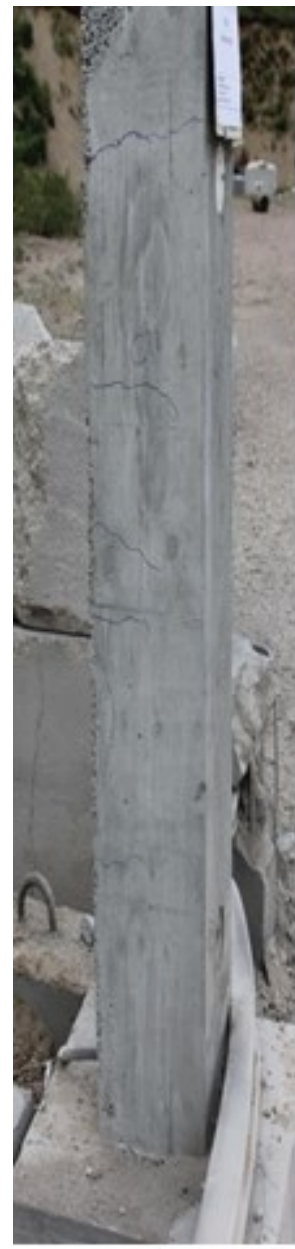

(a)

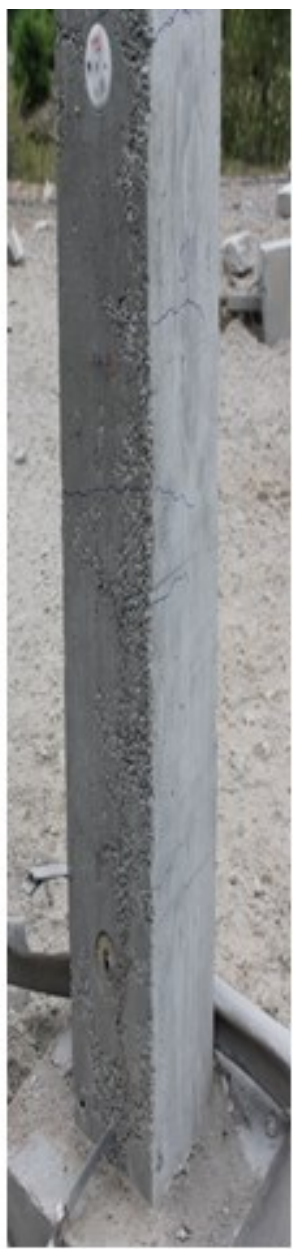

(b)

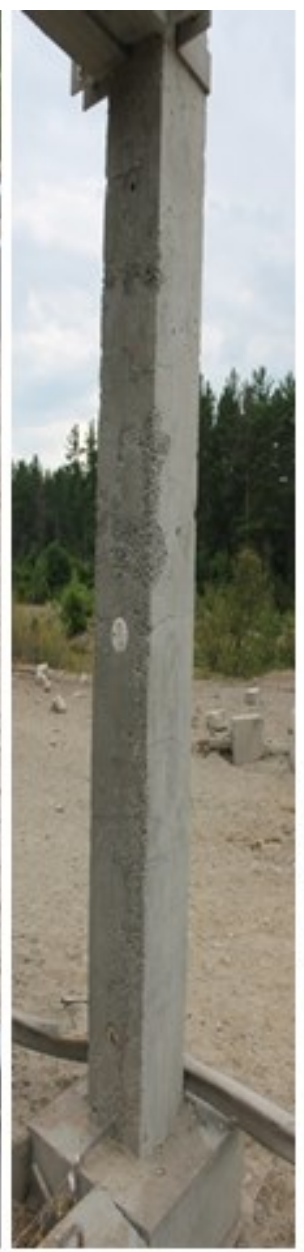

(c)

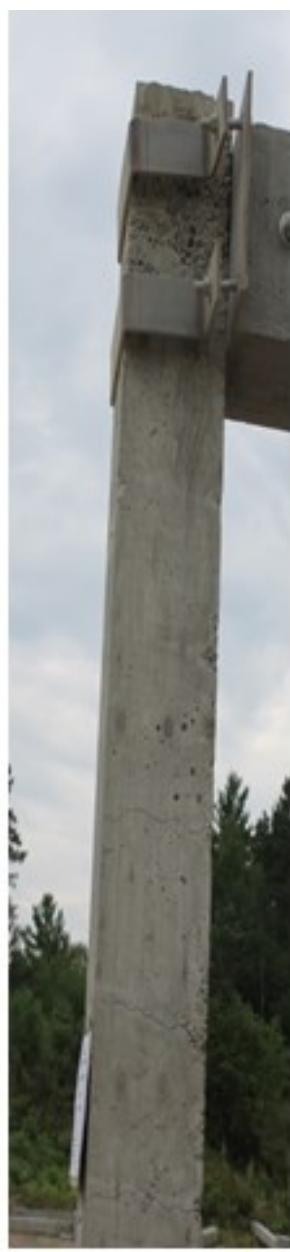

(d)

Figure 4-58: Post-test photograph of Column SEIS-11 face: (a) Side face (right), (b, c) Back face, and (d) Side face (left)

\subsection{Column Test 7 (CONV-5 and CONV-12)}

Test 7 was conducted on two columns (CONV-5 and CONV-12) subjected to $150 \mathrm{~kg}$ ANFO explosive. The distance from the center of detonation to column CONV-5 was 1.7 $\mathrm{m}$ while column CONV-12 was at $4.1 \mathrm{~m}$ from the center of detonation. CONV-5 was post-tensioned to induce a precompressed state of the concrete.

Figure 4-59 shows a sketch of the experimental setup, while Figure 4-60 shows a photograph of the experimental setup prior to explosion testing. The two columns (CONV-5 and CONV-12) were instrumented with pressure gauges, string potentiometers 
and strain gauges. By Test 7, the pressure gauges and string potentiometers had developed various levels of damage and no data was recorded during Test 7.

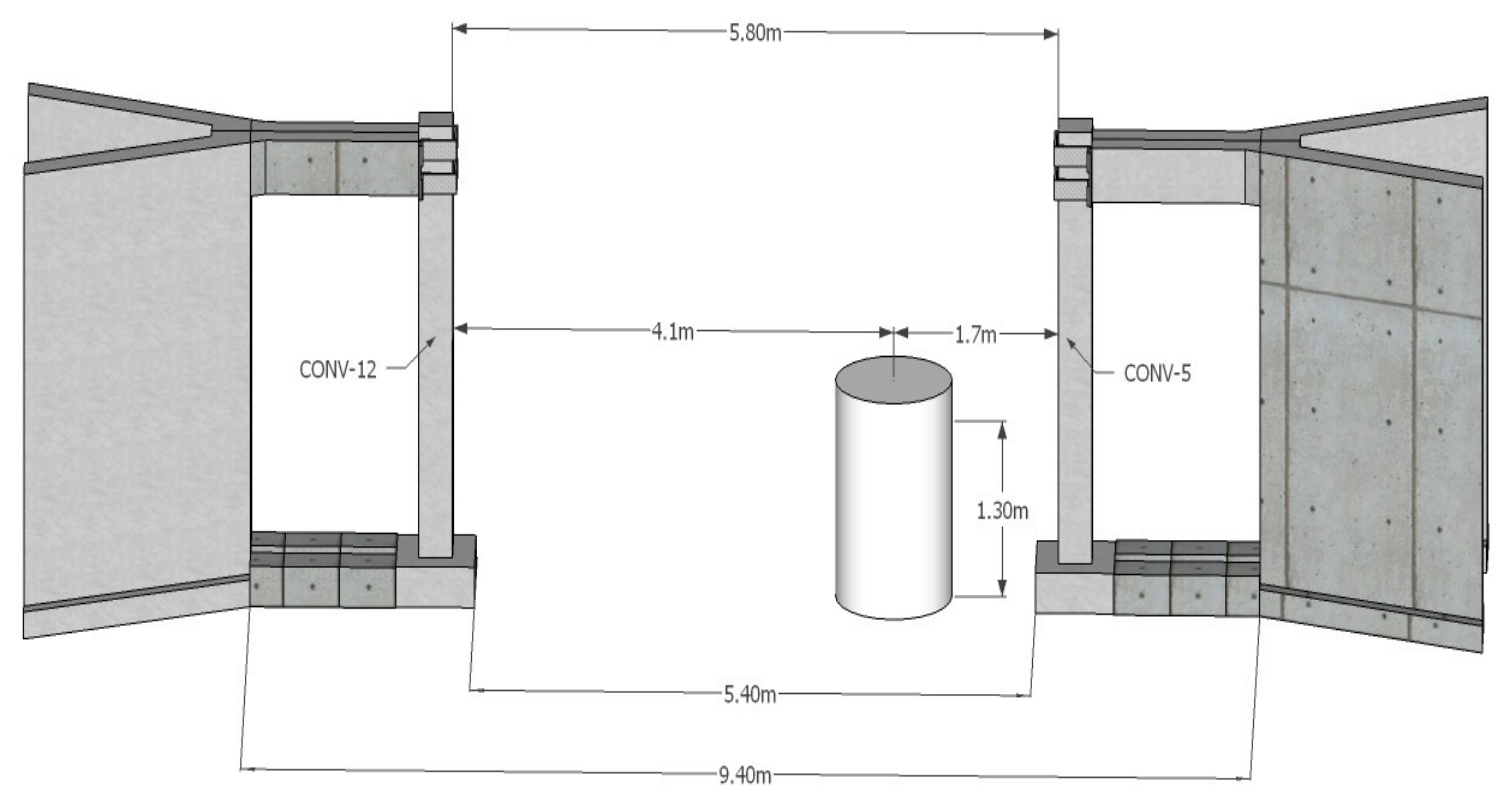

Figure 4-59: A sketch columns CONV-12 and CONV-5 experimental setup

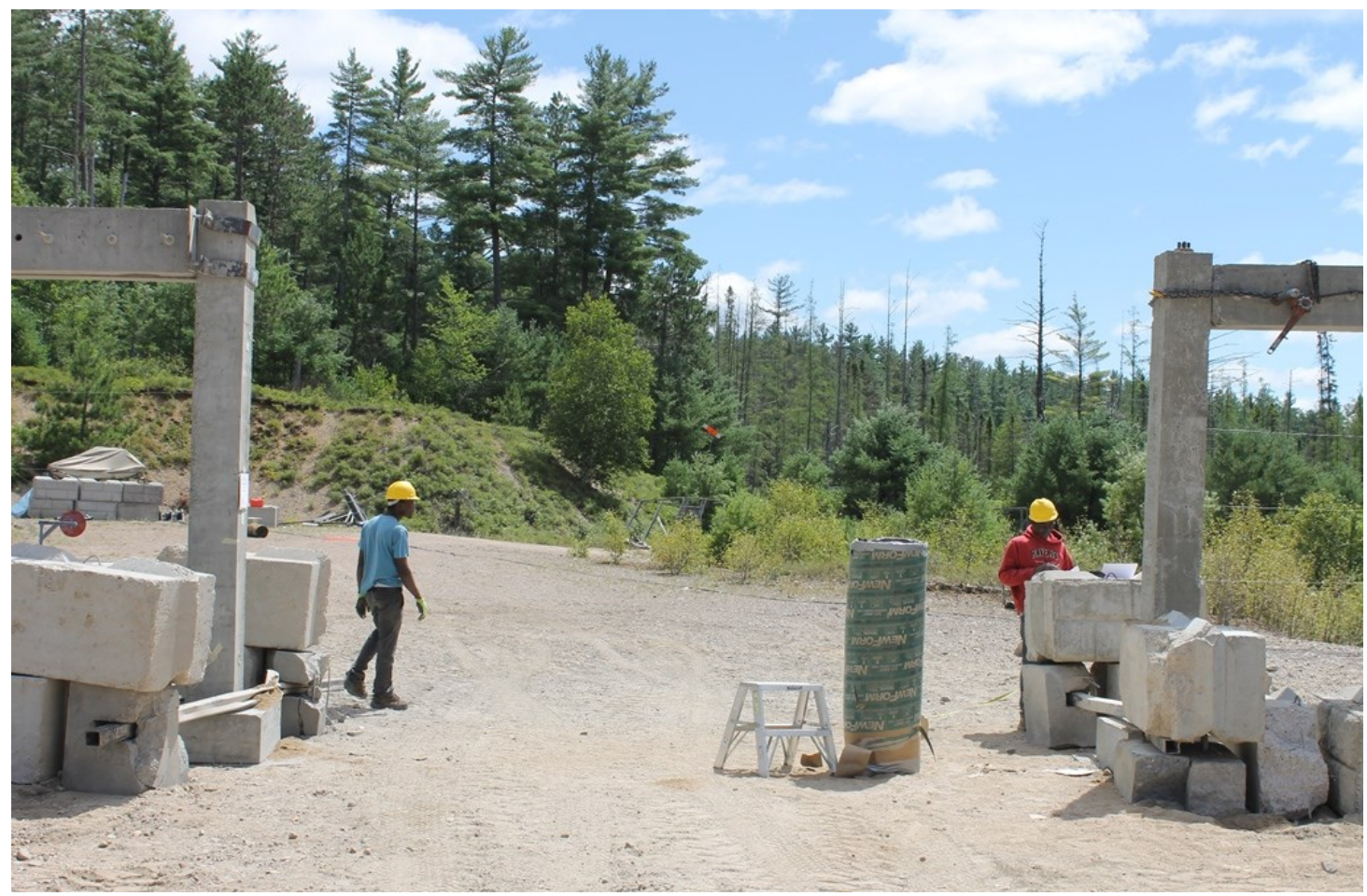

Figure 4-60: Photograph of test 7 (CONV-12 and CONV-5) setup prior to detonation 


\subsubsection{Column CONV-5}

Figure 4-61 presents a pre-test photo of CONV-5 while Figure 4-62 shows a post-test photo. Table 4-12 presents blast pressures on the front face of CONV-5 calculated using CONWEP - A collection of conventional weapons effects calculations based on the Kingery-Bulmash polynomials and corrected for the angles of incidence. The calculated blast pressures at bottom-front, mid-front and top-front gauges are 59,128.4 kPa, 83,334 $\mathrm{kPa}$ and $37,622.9 \mathrm{kPa}$. With corresponding arrival times of $0.5,0.4$ and $0.6 \mathrm{~ms}$ for bottom-front, mid-front and top-front gauges respectively (Table 4-12). The blast loads were determined from the 150-kg ANFO explosive charge at a standoff distance of $1.7 \mathrm{~m}$ (scaled distance of $0.34 \mathrm{~m} / \mathrm{kg}^{1 / 3}$ ). CONV-5 was tested in the damage support structure and thus the top support of the column was furnished with a steel chain and "comealong" winch (Figure 4-61).

Table 4-12: Reflected pressure results for the front face of CONV-5 using CONWEP Kingery-Bulmash Polynomials (CONWEP) Results

\begin{tabular}{|c|c|c|c|}
\hline \multirow{3}{*}{ Test Specimen } & \multicolumn{3}{|c|}{ Column CONV-5 } \\
\hline \multirow{3}{*}{ Test Details } & Tie-Spacing & Charge Mass & Standoff \\
\cline { 2 - 4 } & $300 \mathrm{~mm}$ & 150 -kg ANFO & $1.7 \mathrm{~m}$ \\
\cline { 2 - 4 } & $\mathrm{z}\left(\mathrm{m} / \mathrm{kg}^{1 / 3}\right)$ & ALR & Height of Burst \\
\cline { 2 - 4 } & 0.34 & 0 & $1.0 \mathrm{~m}^{*}$ \\
\hline & Bottom-Front & Mid-Front & Top-Front \\
\hline Gauge location & $250 \mathrm{~mm} *$ & $1210 \mathrm{~mm}^{*}$ & $2210 \mathrm{~mm}^{*}$ \\
\hline Range $(\mathrm{mm})$ & 1858.1 & 1712.9 & 2086.6 \\
\hline Incidence angle & $23.8^{0}$ & $7.0^{0}$ & $35.4^{0}$ \\
\hline $\mathrm{P}_{\mathrm{r}}(\mathrm{kPa})$ & 59128.4 & 83334 & 37622.9 \\
\hline $\mathrm{T}_{\mathrm{a}}(\mathrm{ms})$ & 0.5 & 0.4 & 0.6 \\
\hline $\mathrm{T}_{\mathrm{d}}(\mathrm{ms})$ & 1.1 & 1.0 & 1.2 \\
\hline
\end{tabular}

*dimensions measured from top of concrete footing 


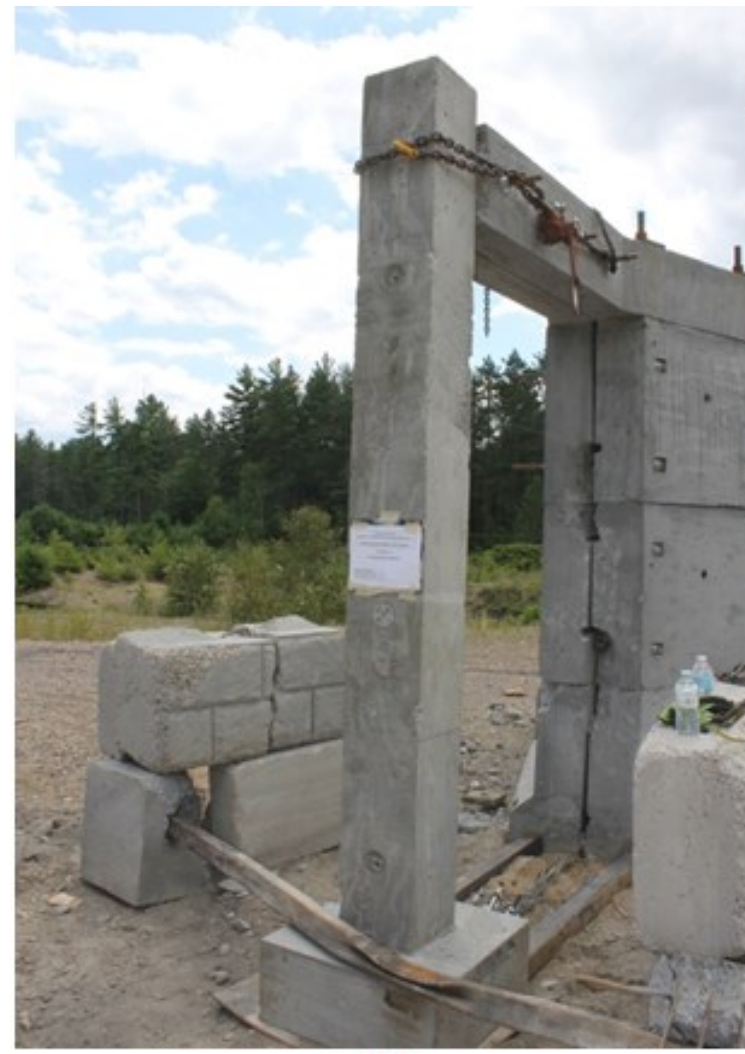

(a)

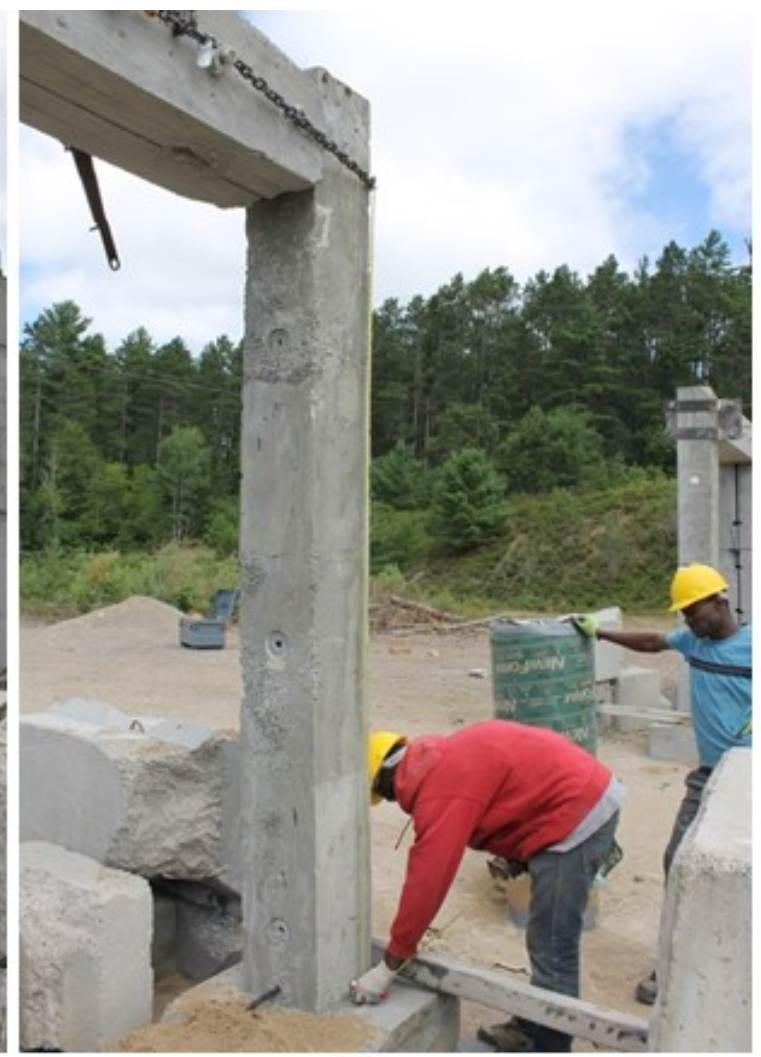

(b)

Figure 4-61: Photograph of Column CONV-5 prior to test: (a) Front face of column with mid-front pressure gauge (b) Back-face

After the 150-kg ANFO was detonated, the concrete in the lap-splice region was severely damaged (Figure 4-62). As with the other conventional columns tested at the $0.26 \mathrm{~m} / \mathrm{kg}^{1 / 3}$ scaled distance, CONV-5 was severely bent. The corrugated post-tension duct and the seven-wire prestressing strands prevented the column failing into two pieces even though the concrete was stripped off the reinforcement in the lower-third (Figure 4-62). 


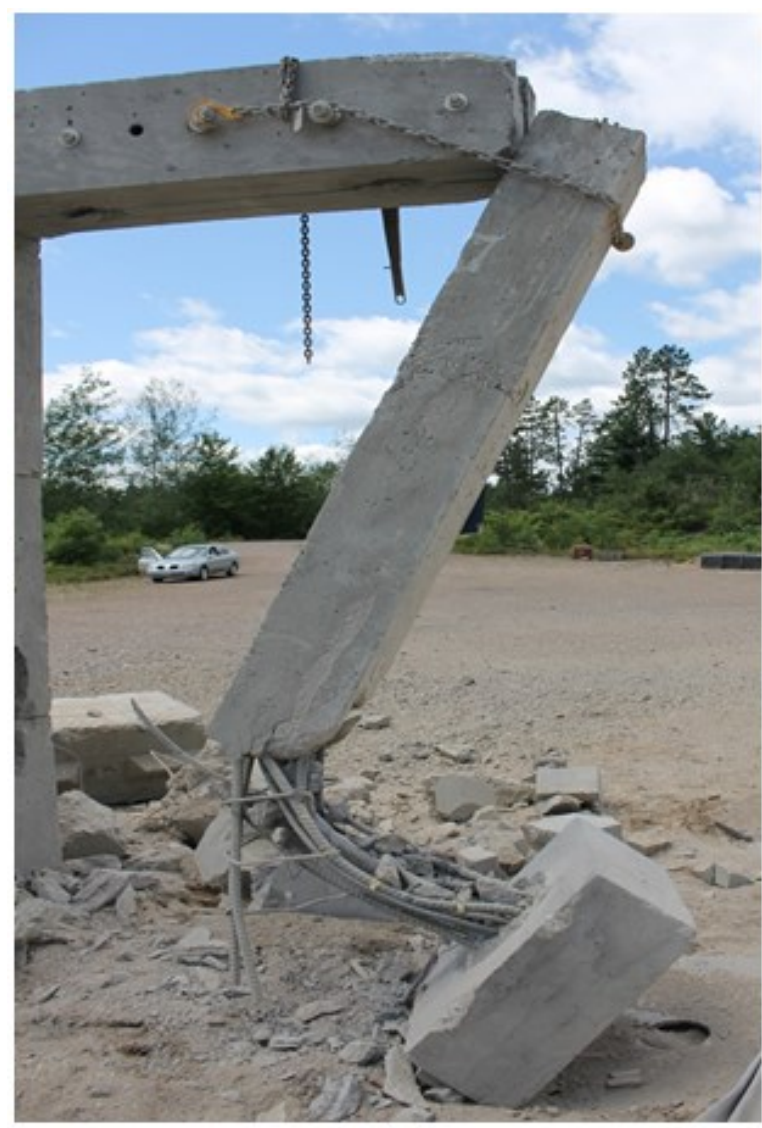

(a)

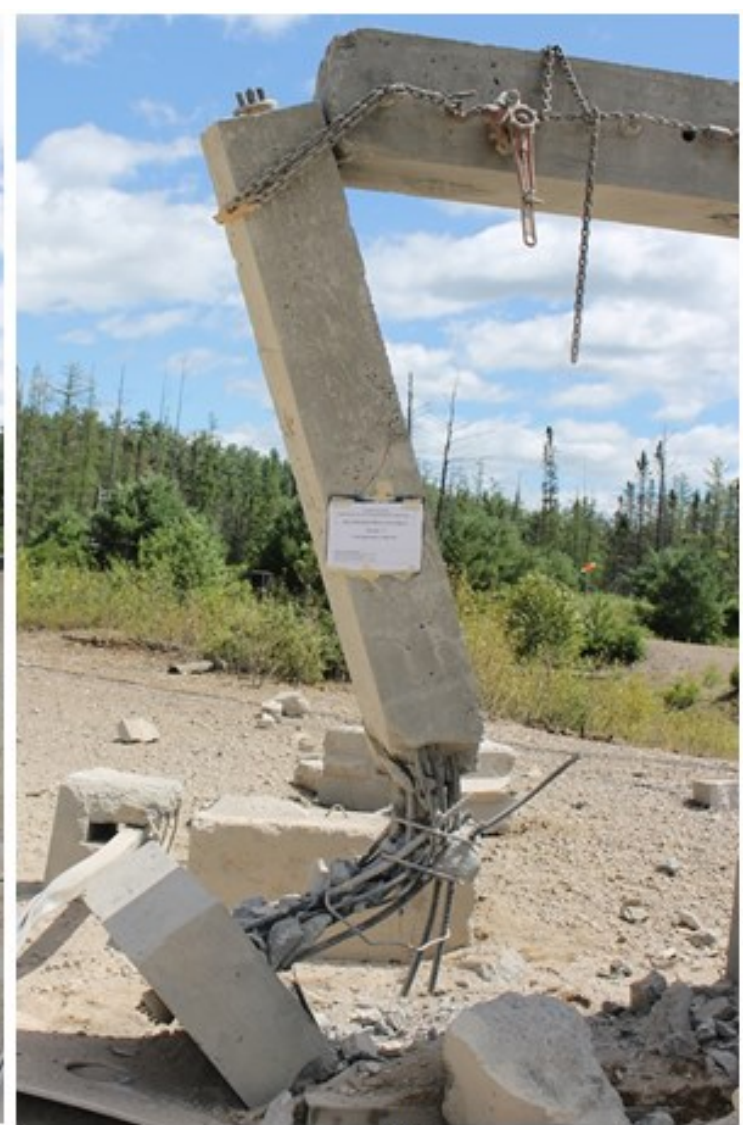

(b)

Figure 4-62: Post-test photograph of column CONV-5

\subsubsection{Column CONV-12}

Column CONV-12 was subjected to blast loading from 150-kg ANFO explosive charge at a standoff distance of $4.1 \mathrm{~m}$ (scaled distance of $0.82 \mathrm{~m} / \mathrm{kg}^{1 / 3}$ ). No data was recorded during Test 7 thus, the blast pressure loading on the front face was calculated using CONWEP - A collection of conventional weapons effects calculations based on the Kingery-Bulmash polynomials with correction for the angles of incidence. The calculated blast pressures varied from 10,614 $\mathrm{kPa}$ to $12,449.6 \mathrm{kPa}$. The calculated maximum pressure $(12,449.6 \mathrm{kPa})$ occurred at the mid-front pressure gauge at $1.7 \mathrm{~ms}$ (Table 4-13). The bottom-front and top-front pressures are 11,943.8 $\mathrm{kPa}$ and 10,614 $\mathrm{kPa}$ respectively. Table 4-13 presents blast pressures on the front face of CONV-12. 
Table 4-13: Reflected pressure results for the front face of CONV-12 using CONWEP

\begin{tabular}{|c|c|c|c|}
\hline \multicolumn{3}{|c|}{ Kingery-Bulmash Polynomials (CONWEP) Results } \\
\hline Test Specimen & \multicolumn{3}{|c|}{ Column CONV-12 } \\
\hline \multirow{3}{*}{ Test Details } & Tie-Spacing & Charge Mass & Standoff \\
\cline { 2 - 4 } & $300 \mathrm{~mm}$ & 150 -kg ANFO & $4.1 \mathrm{~m}$ \\
\cline { 2 - 4 } & $\mathrm{z}\left(\mathrm{m}^{\mathrm{k}} \mathrm{kg}^{1 / 3}\right)$ & ALR & Height of Burst \\
\cline { 2 - 4 } & 0.82 & 0 & $1.0 \mathrm{~m}^{*}$ \\
\hline & Bottom-Front & Mid-Front & Top-Front \\
\hline Gauge location & $310 \mathrm{~mm} *$ & $1200 \mathrm{~mm}{ }^{*}$ & $2300 \mathrm{~mm}$ \\
\hline Range $(\mathrm{mm})$ & 4157.7 & 4104.9 & 4301.2 \\
\hline Incidence angle & $9.6^{0}$ & $2.8^{0}$ & $17.6^{0}$ \\
\hline $\mathrm{P}_{\mathrm{r}}(\mathrm{kPa})$ & $11,943.8$ & $12,449.6$ & 10,614 \\
\hline $\mathrm{T}_{\mathrm{a}}(\mathrm{ms})$ & 1.7 & 1.7 & 1.8 \\
\hline $\mathrm{T}_{\mathrm{d}}(\mathrm{ms})$ & 4.7 & 4.5 & 5.2 \\
\hline
\end{tabular}

*dimensions measured from top of concrete footing 


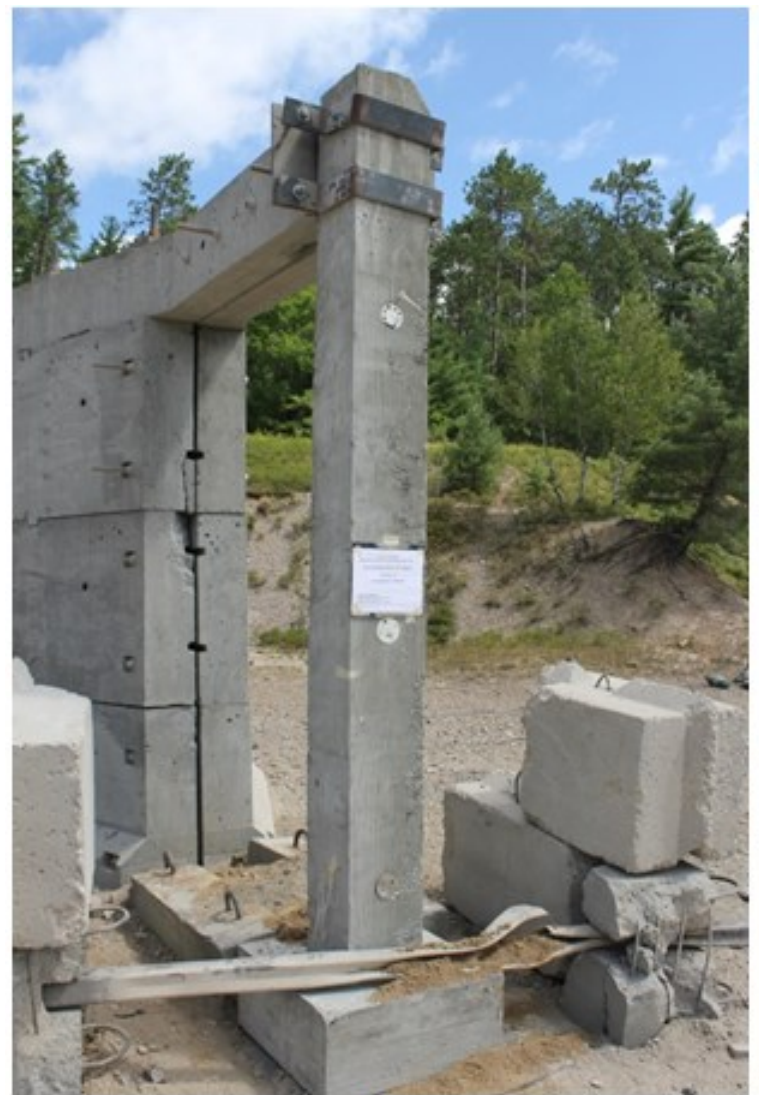

(a)

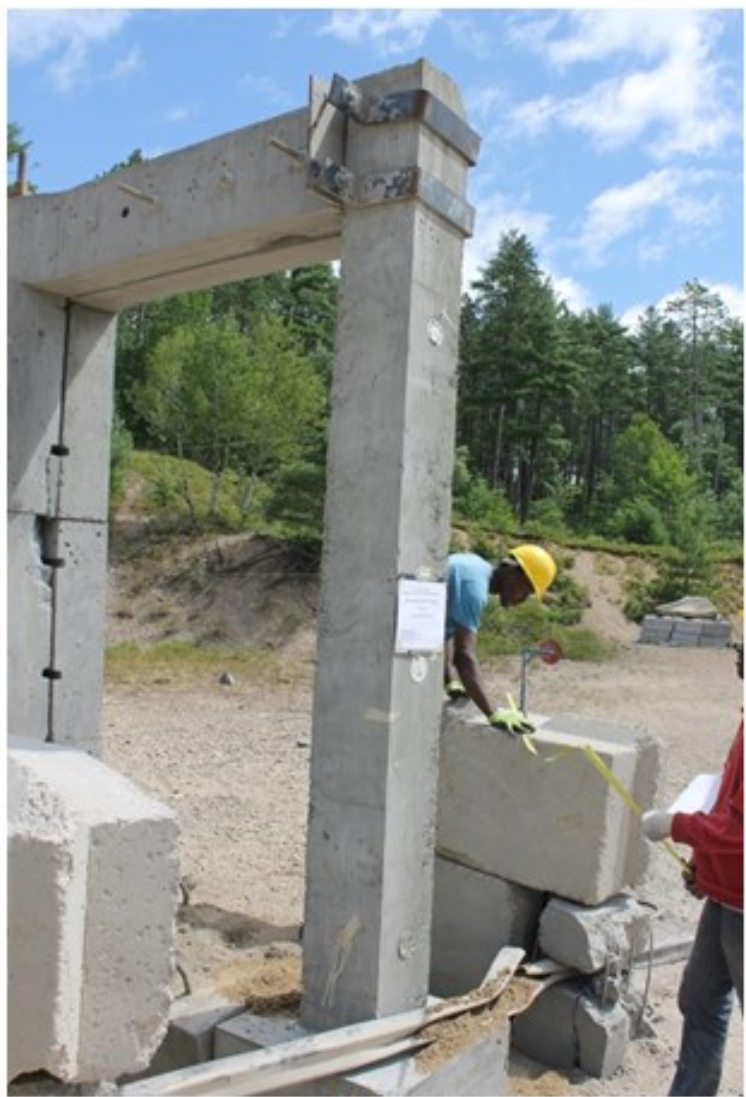

(b)

Figure 4-63: Photograph of Column CONV-12 prior to test: (a, b) Front face of column with pressure gauges

Figure 4-63 presents a pre-test photograph of CONV-12 while Figure 4-64 shows the post-test photograph. Minimal flexural cracking developed on the column (Figure 4-64). 


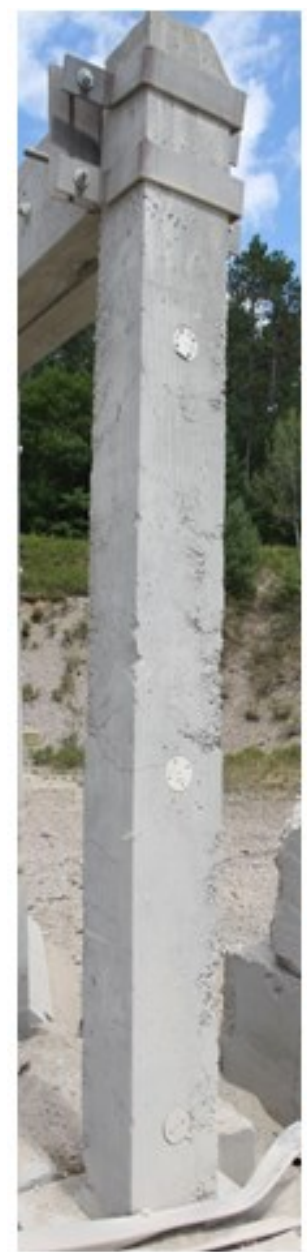

(a)

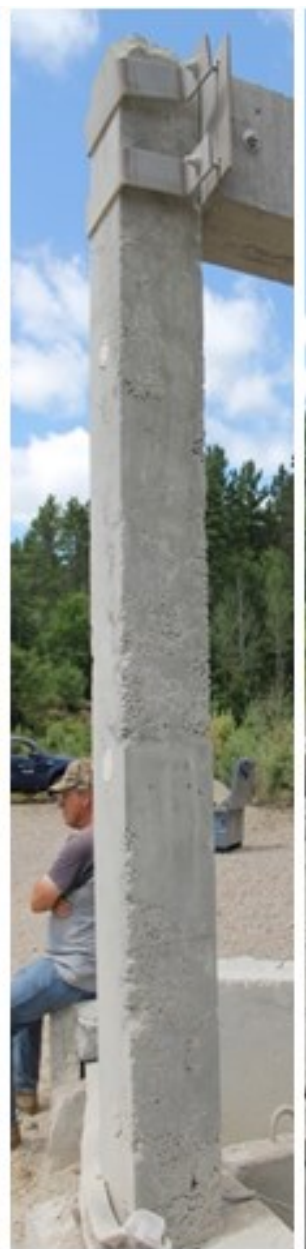

(b)

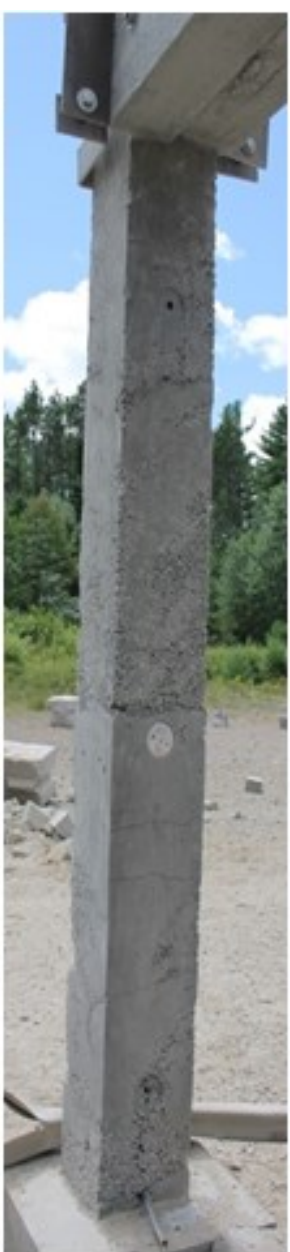

(c)

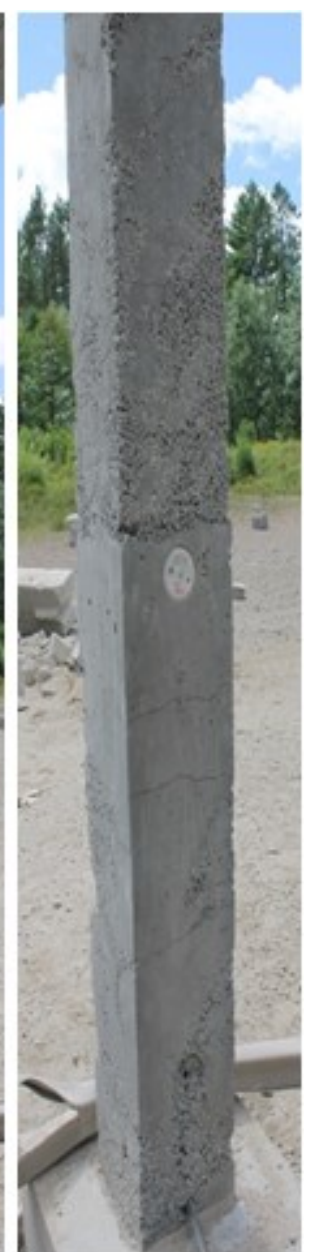

(d)

Figure 4-64: Post-test photograph of Column CONV-12 faces: (a) Front face, (b) Side face (right), and (c, d) Back face

\subsection{Column Test 8 (SEIS-4 and CONV-15)}

Test 8 was conducted on two columns (SEIS-4 and CONV-15) subjected to $150 \mathrm{~kg}$ ANFO explosive. The distance from the center of detonation to column SEIS-4 was 1.7 $\mathrm{m}$ while column CONV-15 was at $4.26 \mathrm{~m}$ from the center of detonation (Figure 4-65). The corresponding scaled distances were $0.34 \mathrm{~m} / \mathrm{kg}^{1 / 3}$ for SEIS-4 and $0.86 \mathrm{~m} / \mathrm{kg}^{1 / 3}$ for CONV-15.

Figure 4-65 presents a sketch of the experimental setup. The two columns (SEIS-4 and CONV-15) were instrumented with pressure gauges, string potentiometers and strain 
gauges. However, the data acquisition system failed to trigger and thus no data was available for blast pressures and column displacements.

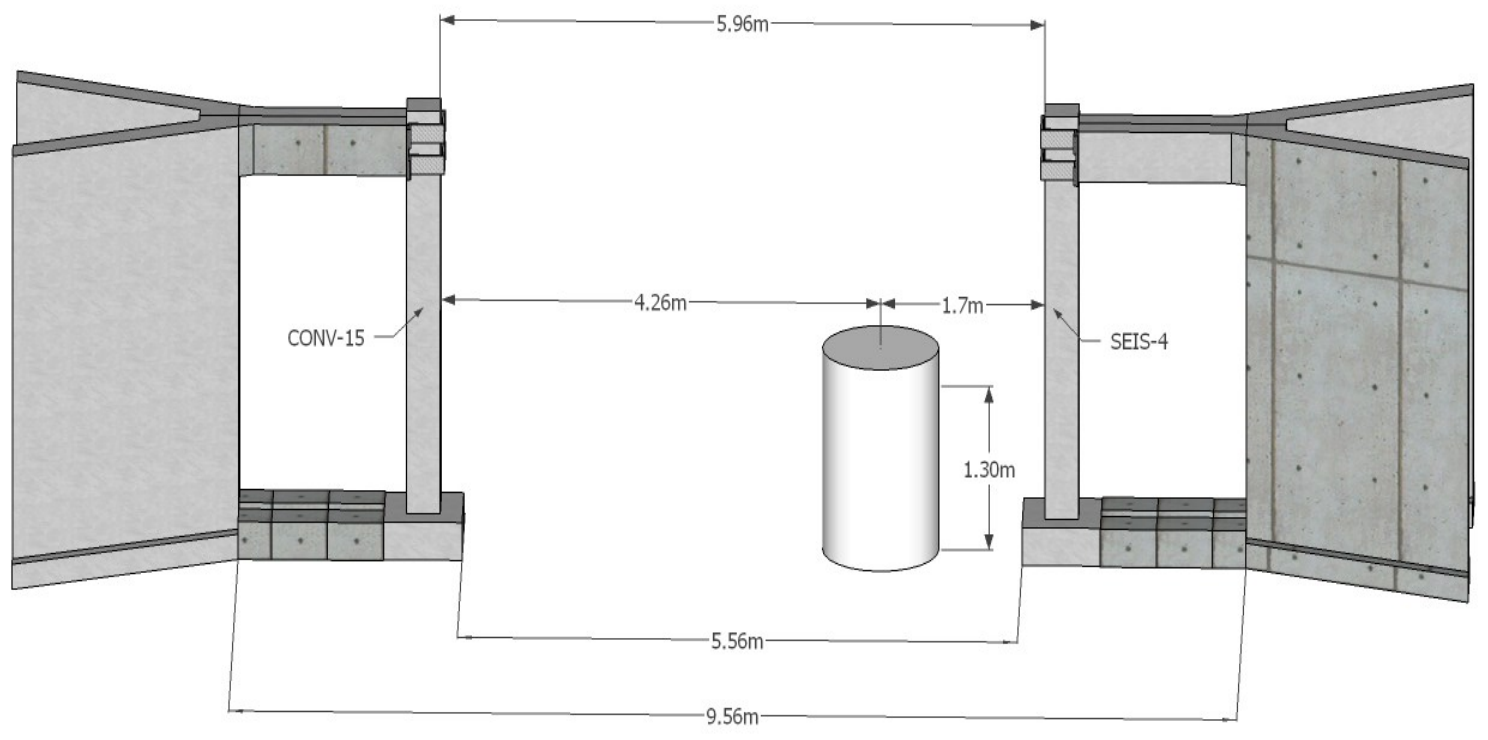

Figure 4-65: Pre-test setup of columns CONV-15 and SEIS-4 


\subsubsection{Column SEIS-4}

Table 4-14 presents the blast pressures on the front face of column SEIS-4 calculated with CONWEP - A collection of conventional weapons effects calculations based on the Kingery-Bulmash polynomials and corrected for the angles of incidence of the blast wave. The calculated blast pressures varied from $37,807.5 \mathrm{kPa}$ to $84,018 \mathrm{kPa}$. The maximum pressure calculated occurred at mid-front pressure gauge and at an arrival time of $0.4 \mathrm{~ms}$. The calculated blast pressures at bottom-front and top-front gauges are $59,128.4 \mathrm{kPa}$ and $37,807.5 \mathrm{kPa}$. With corresponding arrival times of $0.5 \mathrm{~ms}$ and $0.6 \mathrm{~ms}$ for bottom-front and top-front gauges respectively (Table 4-14). Figure 4-66 shows a photograph of column SEIS-4 prior to testing while Figure 4-67 presents a post-test photograph. SEIS-4 was tested in the damaged support structure and thus the top support of the column was furnished with a steel chain and a "come-along" winch.

Table 4-14: Reflected pressure results for the front face of SEIS-4 using CONWEP Kingery-Bulmash Polynomials (CONWEP) Results

\begin{tabular}{|c|c|c|c|}
\hline \multirow{3}{*}{ Test Specimen } & \multicolumn{3}{|c|}{ Column SEIS-4 } \\
\hline \multirow{3}{*}{ Test Details } & Tie-Spacing & Charge Mass & Standoff \\
\cline { 2 - 4 } & $75 \mathrm{~mm}$ & 150 -kg ANFO & $1.7 \mathrm{~m}$ \\
\cline { 2 - 4 } & $\mathrm{z}\left(\mathrm{m} / \mathrm{kg}^{1 / 3}\right)$ & ALR & Height of Burst \\
\cline { 2 - 4 } & 0.34 & 0 & $1.0 \mathrm{~m}^{*}$ \\
\hline & Bottom-Front & Mid-Front & Top-Front \\
\hline Gauge location & $250 \mathrm{~mm} *$ & $1120 \mathrm{~mm}^{*}$ & $2200 \mathrm{~mm}^{*}$ \\
\hline Range $(\mathrm{mm})$ & 1858.1 & 1704.2 & 2080.9 \\
\hline Incidence angle & $23.8^{0}$ & $4.0^{0}$ & $35.2^{0}$ \\
\hline $\mathrm{P}_{\mathrm{r}}(\mathrm{kPa})$ & 59128.4 & 84018 & 37807.5 \\
\hline $\mathrm{T}_{\mathrm{a}}(\mathrm{ms})$ & 0.5 & 0.4 & 0.6 \\
\hline $\mathrm{T}_{\mathrm{d}}(\mathrm{ms})$ & 1.1 & 1.0 & 1.2 \\
\hline
\end{tabular}

*dimensions measured from top of concrete footing 


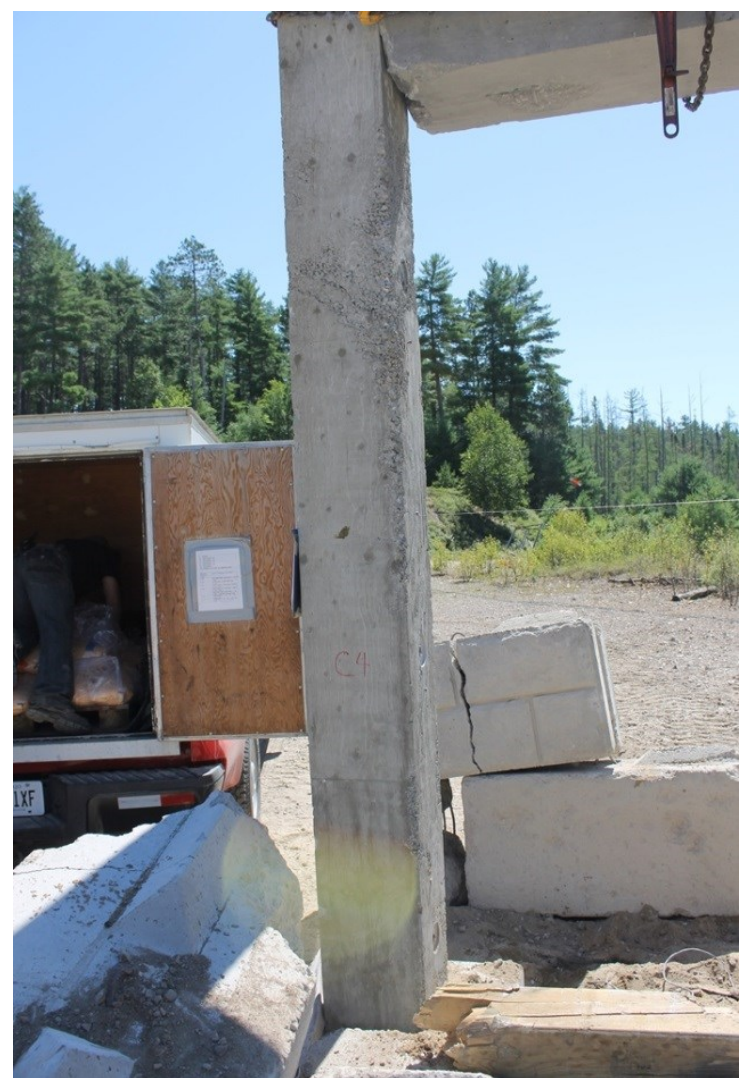

Figure 4-66: Photograph of Column SEIS-4 prior to test

After the $150-\mathrm{kg}$ ANFO was detonated, the lower $1.2 \mathrm{~m}$ of column SEIS-4 was observed to be severely cracked and spalled. The concrete core was well confined by the transverse reinforcement (10M ties @ $75 \mathrm{~mm}$ ). Shear (Diagonal) cracks appeared within the upper half of the column (Figure 4-67(d)) but not crushing or spalling of the concrete was observed at this location. 


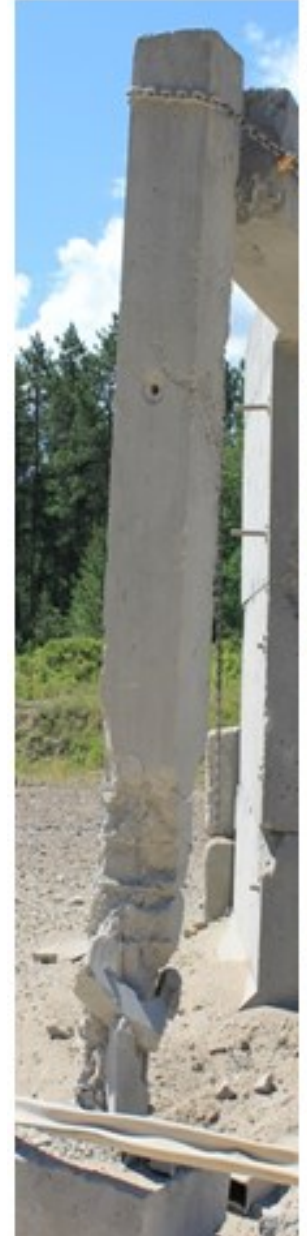

(a)

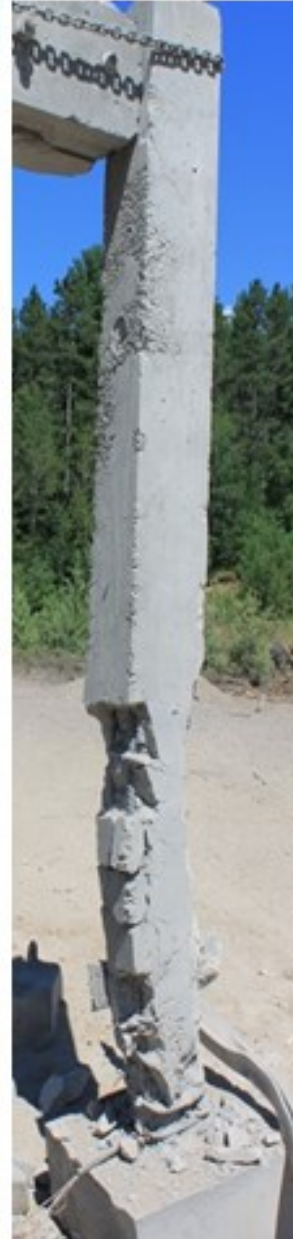

(b)

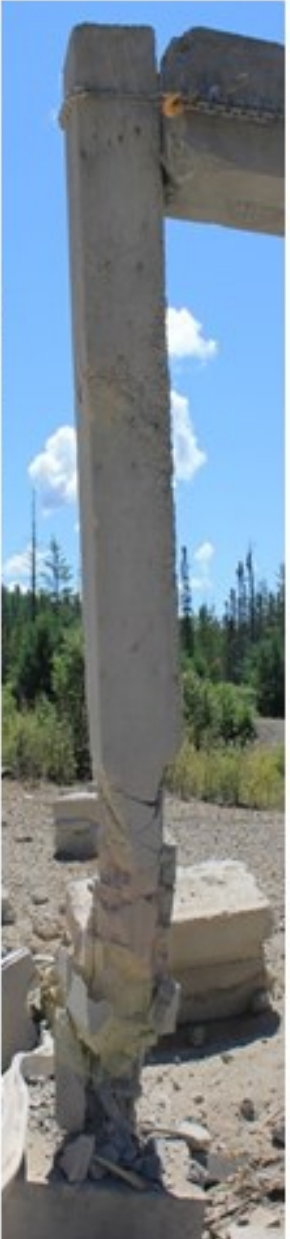

(c)

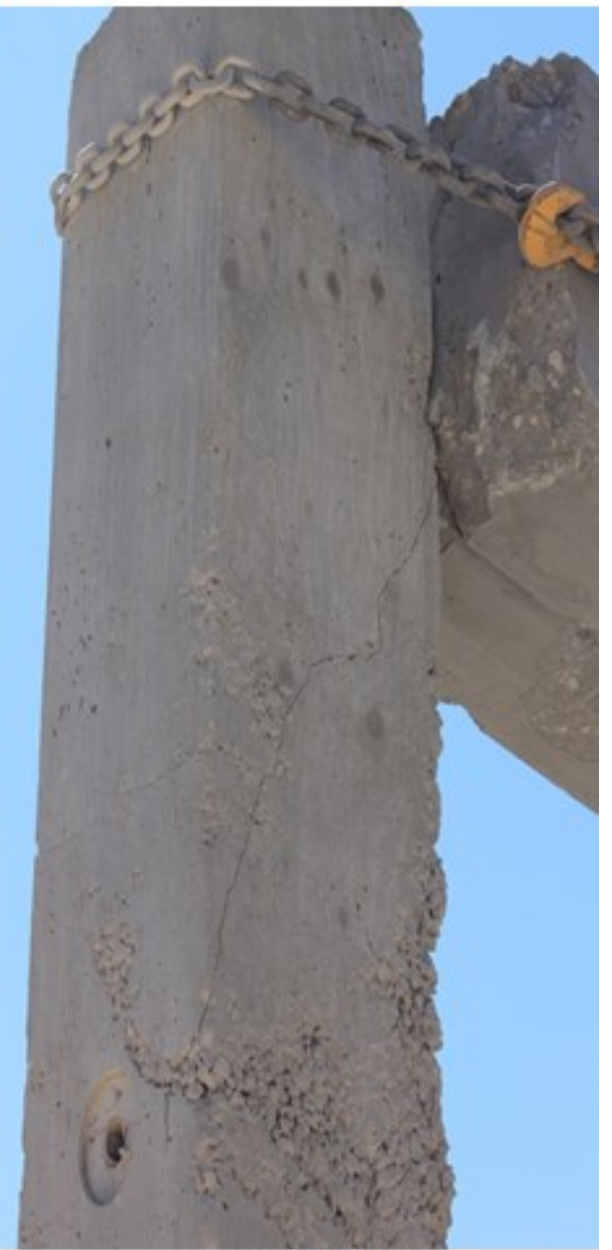

(d)

Figure 4-67: Post-test photograph of Column SEIS-4 faces: (a) Front face, (b) Back face, (c, d) Side face (left)

\subsubsection{Column CONV-15}

Table 4-15 presents blast pressures on the front face of column CONV-15, calculated with the Kingery-Bulmash polynomials. The calculated blast pressures at bottom-front, mid-front and top-front gauges are $11034.9 \mathrm{kPa}, 11532 \mathrm{kPa}$ and $10022.4 \mathrm{kPa}$. With corresponding arrival times of $1.8 \mathrm{~ms}, 1.8 \mathrm{~ms}$ and $1.9 \mathrm{~ms}$ for bottom-front, mid-front and top-front gauges respectively (Table 4-15). Figure 4-68 shows a photograph of column CONV-15 prior to test while Figure 4-69 presents a post-test photograph. 
Table 4-15: Reflected pressure results for the front face of CONV-15 using CONWEP

\begin{tabular}{|c|c|c|c|}
\hline \multicolumn{4}{|c|}{ Kingery-Bulmash Polynomials (CONWEP) Results } \\
\hline Test Specimen & \multicolumn{3}{|c|}{ Column CONV-15 } \\
\hline \multirow{3}{*}{ Test Details } & Tie-Spacing & Charge Mass & Standoff \\
\cline { 2 - 4 } & $300 \mathrm{~mm}$ & 150 -kg ANFO & $4.26 \mathrm{~m}$ \\
\cline { 2 - 4 } & $\mathrm{z}\left(\mathrm{m}^{\mathrm{k}} \mathrm{kg}^{1 / 3}\right)$ & ALR & Height of Burst \\
\cline { 2 - 4 } & 0.86 & 0 & $1.0 \mathrm{~m}^{*}$ \\
\hline & Bottom-Front & Mid-Front & Top-Front \\
\hline Gauge location & $250 \mathrm{~mm} *$ & $1250 \mathrm{~mm} \mathrm{~m}^{*}$ & $2200 \mathrm{~mm}$ \\
\hline Range $(\mathrm{mm})$ & 4325.5 & 4267.3 & 4425.8 \\
\hline Incidence angle & $10^{0}$ & $3.4^{0}$ & $15.7^{0}$ \\
\hline $\mathrm{P}_{\mathrm{r}}(\mathrm{kPa})$ & 11034.9 & 11532 & 10022.4 \\
\hline $\mathrm{T}_{\mathrm{a}}(\mathrm{ms})$ & 1.8 & 1.8 & 1.9 \\
\hline $\mathrm{T}_{\mathrm{d}}(\mathrm{ms})$ & 5.3 & 5.1 & 5.8 \\
\hline
\end{tabular}

*dimensions measured from top of concrete footing

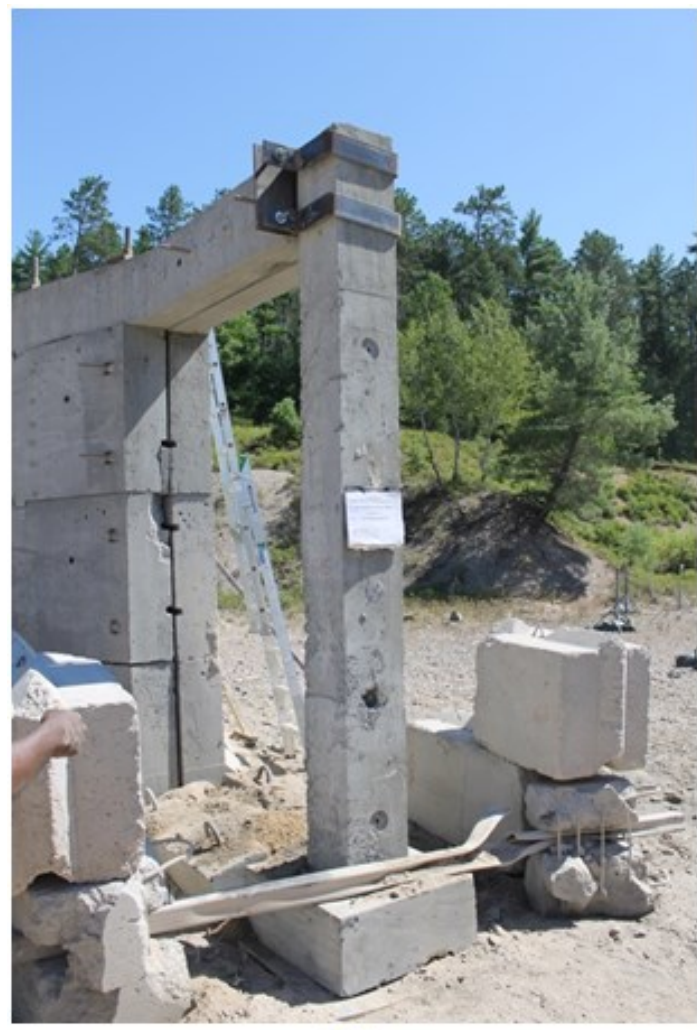

(a)

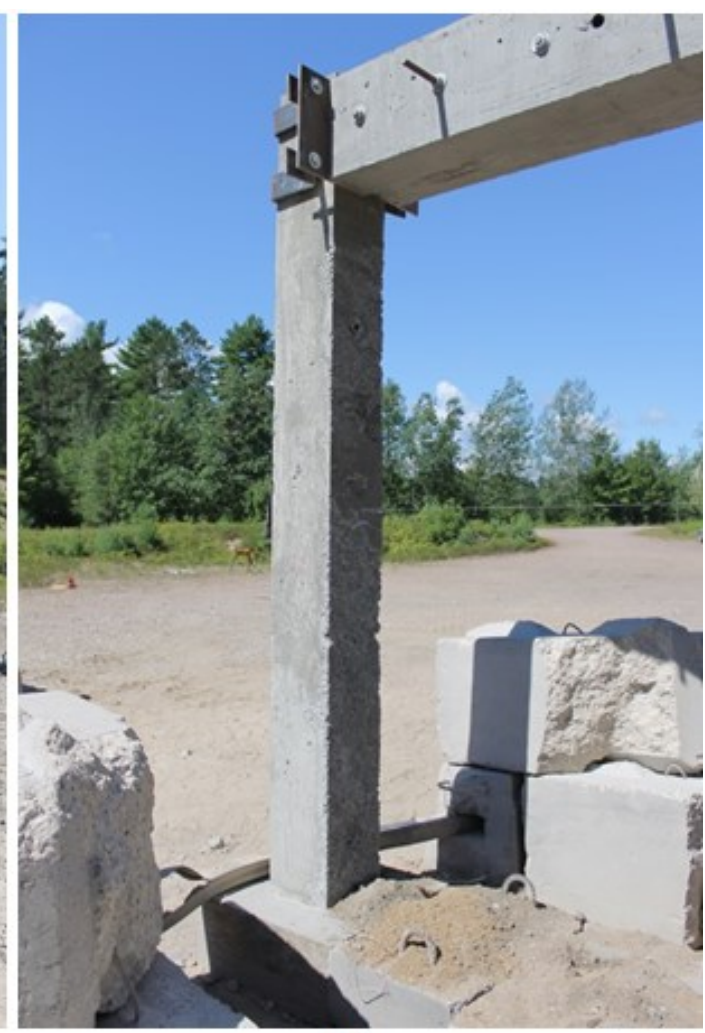

(b)

Figure 4-68: Photograph of Column CONV-15 prior to test: (a) Front and Side (right) face, (b) Side (left) and Back face 
After the 150-kg ANFO was detonated, inspection of CONV15 showed that minimal cracks developed at the sides and back of the column (Figure 4-71).

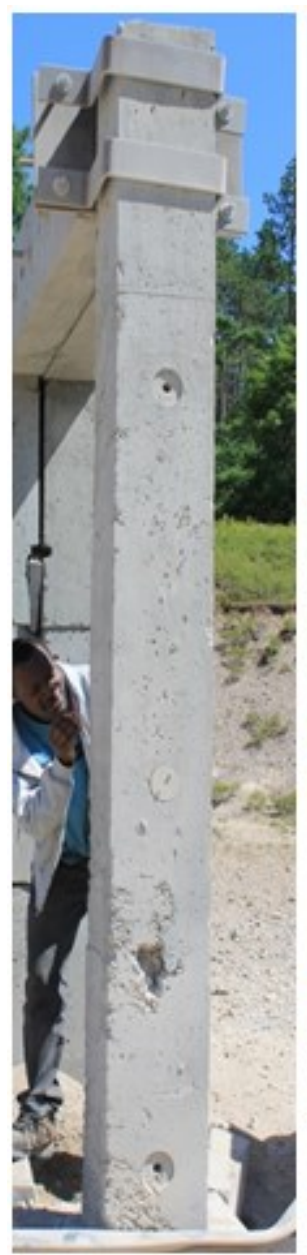

(a)

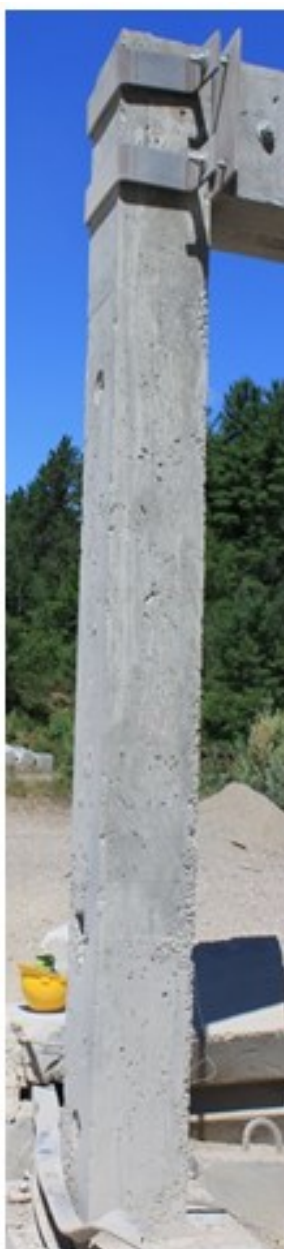

(b)

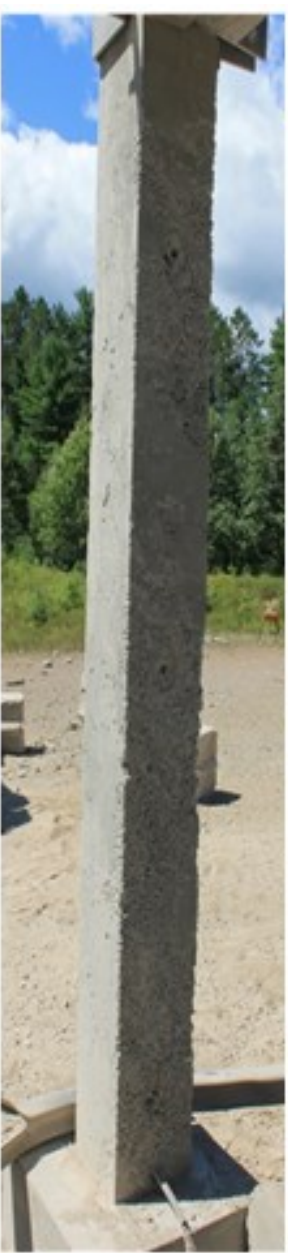

(c)

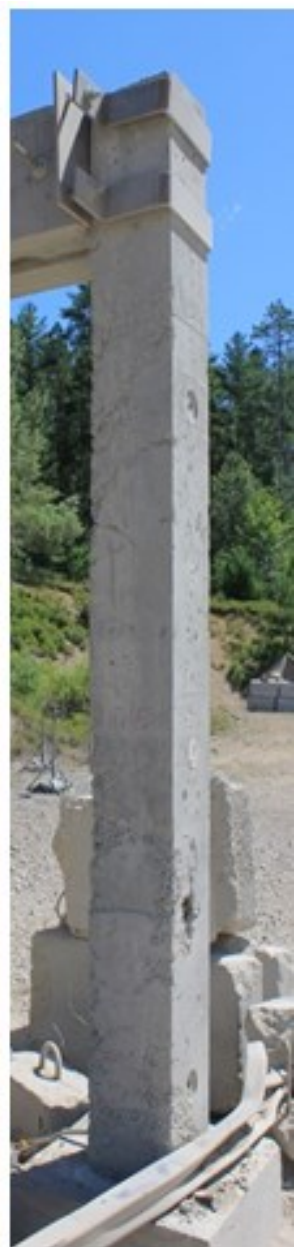

(d)

Figure 4-69: Post-test photograph of Column CONV-15 faces: (a) Front face, (b) Side face (left), (c) Back face, and (d) Side face (right) 


\subsection{Discussion of Results}

The results of the experimental investigation reveal the difficulty with instrumentation at the close-in explosion range. The blast pressure gauges, string potentiometers, and strain gauges worked to varying degrees of success. The strain gauges were affected by the blast induced shock in the concrete columns and thus the readings were dominated with spikes with amplitudes greater than the strain values that were being measured. Thus no meaningful data was obtained for reinforcement strains. The string potentiometers were chosen for the project due to a perceived increase in their survivability. Even though the main housing of the string potentiometers were outside the fireball the retractable cables were engulfed by the fireball and likely affected accuracy of the readings.

These challenges notwithstanding, valuable data was obtained from the test program. The basic parameters investigated in the test program: effects of scaled distance, transverse reinforcement detailing, and gravity loads on the column response are discussed below.

\subsubsection{Effect of Scaled Distance of Column Response}

The reinforced concrete columns in the experimental program were design to be tested at three scaled distances: $0.25 \mathrm{~m} / \mathrm{kg}^{1 / 3}, 0.62 \mathrm{~m} / \mathrm{kg}^{1 / 3}$, and $1.0 \mathrm{~m} / \mathrm{kg}^{1 / 3}$ from a $100-\mathrm{kg}$ ANFO explosive charge at corresponding standoff distances. However, the charge mass was increased to $150 \mathrm{~kg}$ ANFO after the first test to give scaled distances of $0.22 \mathrm{~m} / \mathrm{kg}^{1 / 3}, 0.54$ $\mathrm{m} / \mathrm{kg}^{1 / 3}$, and $0.86 \mathrm{~m} / \mathrm{kg}^{1 / 3}$. For $150-\mathrm{kg}$ ANFO explosive, breach (hole through the reinforced concrete) threshold is $1.5 \mathrm{~m}$ (as calculated from CONWEP - a conventional weapons effects calculations using Kingery-Bulmash polynomials). At standoff distances greater than $5.9 \mathrm{~m}$, no damage is expected on columns subjected to $150-\mathrm{kg}$ ANFO explosive (CONWEP). Between standoff distances of $1.5 \mathrm{~m}$ and $5.9 \mathrm{~m}$, spalling is 
expected on reinforced concrete columns subjected to 150-kg ANFO explosive (CONWEP). McVay (1998) stated that, the threshold at which brisance effect (blowing out of concrete) occurs is $0.6 \mathrm{~m} / \mathrm{kg}^{1 / 3}$. The scaled distances achieved for each test are presented in Table 4-3. This section describes the effect of scaled distance on the column types as well as stating whether the columns experienced breaching, spalling or brisance effect.

\subsubsection{Conventional Columns}

The effect of scaled distance was evident in the experimental tests. At the close-in scaled distance of $0.22 \mathrm{~m} / \mathrm{kg}^{1 / 3}$, the columns suffered total failure. CONV-1 and CONV-2 subjected to 150-kg ANFO charge failed catastrophically (Table 4-16). For 150-kg ANFO explosive at standoff distance of $1.3 \mathrm{~m}$, breach (hole through the reinforced concrete) was expected, although this did not occur.

At the scaled distance of $\mathrm{z}=0.54 \mathrm{~m} / \mathrm{kg}^{1 / 3}, \mathrm{CONV}-20$ and CONV-6 subjected to blast loading from 150-kg ANFO at standoff distances of $2.60 \mathrm{~m}\left(\mathrm{z}=0.52 \mathrm{~m} / \mathrm{kg}^{1 / 3}\right)$ and $2.66 \mathrm{~m}$ $\left(\mathrm{z}=0.53 \mathrm{~m} / \mathrm{kg}^{1 / 3}\right)$ respectively, show substantial cracking and spalling within the lower third of the columns (Table 4-16). At scaled distance of $0.54 \mathrm{~m} / \mathrm{kg}^{1 / 3}$, brisance effect was expected, although this did not occur.

Finally, columns CONV-11 and CONV-12 that were subjected to a $150-\mathrm{kg}$ ANFO explosive at standoff distances of $4.4 \mathrm{~m}\left(\mathrm{z}=0.88 \mathrm{~m} / \mathrm{kg}^{1 / 3}\right)$ and $4.1 \mathrm{~m}\left(\mathrm{z}=0.82 \mathrm{~m} / \mathrm{kg}^{1 / 3}\right)$ respectively experienced minimal cracks on the back and sides of the columns (Table 4$16)$.

In general, the response of the columns detailed to resist gravity loads depends on the scaled distance. The severity of damage increasing with decrease in scaled distance. The 
displacement of columns increases as scaled distance decreases. At scaled distance of $\mathrm{z}=0.26 \mathrm{~m} / \mathrm{kg}^{1 / 3}, \mathrm{CONV}-1$ had a maximum lower-third point displacement of $29.6 \mathrm{~mm}$ prior to failure. CONV-6 at a scaled distance of $\mathrm{z}=0.53 \mathrm{~m} / \mathrm{kg}^{1 / 3}$ had a maximum midheight displacement of $17.2 \mathrm{~mm}$.

\subsubsection{Seismic Columns}

The columns detailed to resist seismic loading were also subjected to a $150-\mathrm{kg}$ ANFO explosive at different scaled distances $\left(\mathrm{z}=0.22 \mathrm{~m} / \mathrm{kg}^{1 / 3}, \mathrm{z}=0.54 \mathrm{~m} / \mathrm{kg}^{1 / 3}, \mathrm{z}=0.86\right.$ $\left.\mathrm{m} / \mathrm{kg}^{1 / 3}\right)$.

SEIS-3 and SEIS-4 were subjected to 150-kg ANFO explosive at standoff distance of 1.3 $\mathrm{m}\left(\mathrm{z}=0.26 \mathrm{~m} / \mathrm{kg}^{1 / 3}\right)$ and $1.7 \mathrm{~m}\left(\mathrm{z}=0.34 \mathrm{~m} / \mathrm{kg}^{1 / 3}\right)$ respectively. The Post-blast inspection revealed that; concrete cover within the lower one-third of the columns was severely crushed, however, core concrete was well confined by the ties (Table 4-16). Though, both columns (SEIS-3 and SEIS-4) failed, the columns did not disintegrate as the conventionally detailed columns. This is due to the location of the lap splices and the closely spaced transverse reinforcement in plastic hinge region. For 150-kg ANFO explosive at standoff distance of $1.3 \mathrm{~m}$, breach (hole through the reinforced concrete) was expected, although this did not occur.

Columns SEIS-8 and SEIS-9 were subjected to 100-kg and 150-kg ANFO explosive at standoff distances $2.5 \mathrm{~m}\left(\mathrm{z}=0.58 \mathrm{~m} / \mathrm{kg}^{1 / 3}\right)$ and $2.6 \mathrm{~m}\left(\mathrm{z}=0.52 \mathrm{~m} / \mathrm{kg}^{1 / 3}\right)$ respectively.

Post-blast inspection revealed, cracking and spalling of concrete at mid-height (rear) exposing the longitudinal rebars (Table 4-16). There were minimal shear and flexural cracks on the columns. ). At scaled distance of $0.54 \mathrm{~m} / \mathrm{kg}^{1 / 3}$, brisance effect was expected, although this did not occur. 
Columns SEIS-13 and SEIS-14 which were subjected to 150-kg ANFO explosive at standoff distances $4.1 \mathrm{~m}\left(\mathrm{z}=0.82 \mathrm{~m} / \mathrm{kg}^{1 / 3}\right)$ and $4.3 \mathrm{~m}\left(\mathrm{z}=0.86 \mathrm{~m} / \mathrm{kg}^{1 / 3}\right)$ respectively on the other hand showed minimal flexural cracks on the rear face of the columns (Table 416).

In general, as with the conventionally detailed columns, the seismic columns exhibited more damage at the smaller scaled distances and almost no damage at the larger scaled distances.

\subsubsection{Conventional Columns with Axial Load Ratio (0.3)}

Three of the conventional columns (CONV-5, CONV-10 and COV-15) were posttensioned to induce a precompressed state of concrete. CONV-5 was subjected to $150-\mathrm{kg}$ ANFO explosive at standoff distance of $1.7 \mathrm{~m}\left(\mathrm{z}=0.34 \mathrm{~m} / \mathrm{kg}^{1 / 3}\right)$ and exhibited severe damage at the lower third (lap-zone) of the column (Table 4-16).

CONV-10 was subjected to a 150-kg ANFO explosive at standoff distance $2.66 \mathrm{~m} \mathrm{(z=}$ $0.53 \mathrm{~m} / \mathrm{kg}^{1 / 3}$ ) experienced substantial cracking and spalling of concrete exposing the longitudinal rebars within the lower third (hinge zone) of the column (Table 4-16). Wide shear cracks were observed within the column-footing region. Column CONV-15 was subjected to a 150-kg ANFO explosive at standoff distance of $4.26 \mathrm{~m}\left(\mathrm{z}=0.86 \mathrm{~m} / \mathrm{kg}^{1 / 3}\right)$. Post blast inspection showed minimal cracks on the back and sides of the column (Table 4-16).

From the foregoing, the response of the concrete columns irrespective of the column type (Conventional, Seismic or Prestressed) failed at the scaled distance of $0.22 \mathrm{~m} / \mathrm{kg}^{1 / 3}$. As 
the scaled distance increases, the severity of damage is less. At higher scaled distance of $0.86 \mathrm{~m} / \mathrm{kg}^{1 / 3}$, the response for all columns was relatively the same.

\subsubsection{Effect of Transverse Detailing on Column Response}

The reinforced concrete columns were designed and detailed as either conventional column or part of structures' lateral load resisting system. Thus, conventional columns were designed to resist predominantly gravity loads, while seismic columns were detailed to undergo lateral drifts in addition to resisting gravity loads. These sets of columns (conventional and seismic) were tested within three different scaled distances of 0.22 $\mathrm{m} / \mathrm{kg}^{1 / 3}, 0.54 \mathrm{~m} / \mathrm{kg}^{1 / 3}$, and $0.86 \mathrm{~m} / \mathrm{kg}^{1 / 3}$.

\subsubsection{Transverse Detailing effect at $\mathrm{z}=0.22 \mathrm{~m} / \mathrm{kg}^{1 / 3}$}

Two conventional columns (CONV-1 and CONV-2) and two seismic columns (SEIS-3 and SEIS-4) were tested at a scaled distance of $0.22 \mathrm{~m} / \mathrm{kg}^{1 / 3}$. Columns CONV-1 and CONV-2 were subjected to a 150-kg ANFO explosive at a standoff distance of $1.3 \mathrm{~m}(\mathrm{z}=$

$0.22 \mathrm{~m} / \mathrm{kg}^{1 / 3}$ ) while columns SEIS-3 and SEIS-4 were subjected to $150-\mathrm{kg}$ ANFO explosive at standoff distance of $1.3 \mathrm{~m}\left(\mathrm{z}=0.22 \mathrm{~m} / \mathrm{kg}^{1 / 3}\right)$ and $1.7 \mathrm{~m}\left(\mathrm{z}=0.34 \mathrm{~m} / \mathrm{kg}^{1 / 3}\right)$ respectively. The Post-blast inspection revealed that; conventional columns (CONV-1 and CONV-2) suffered substantially more damage relative to seismic columns (SEIS-3 and SEIS-4), even though both failed. The concrete in the bottom half (lap-zone) of the conventional columns were totally destroyed and severed in two pieces at the columnfooting joint (Table 4-16). In the case of the seismic columns (SEIS-3 and SEIS-4), the concrete cover within the bottom half of the columns was severely crushed, however, core concrete was well confined by the ties (Table 4-16). 


\subsubsection{Transverse Detailing effect at $\mathrm{z}=0.54 \mathrm{~m} / \mathrm{kg}^{1 / 3}$}

Three conventional columns (CONV-7, CONV-20, and CONV-6) and two seismic columns (SEIS-8 and SEIS-9) were tested within the scaled distance of $0.54 \mathrm{~m} / \mathrm{kg}^{1 / 3}$. Column CONV-7 was subjected to a 100-kg ANFO at a standoff distance of $2.5 \mathrm{~m} \mathrm{(z=}$ $0.58 \mathrm{~m} / \mathrm{kg}^{1 / 3}$ ). CONV-20 and CONV-6 were subjected to a 150-kg ANFO explosive at standoff distances of $2.6 \mathrm{~m}\left(\mathrm{z}=0.52 \mathrm{~m} / \mathrm{kg}^{1 / 3}\right)$ and $2.66 \mathrm{~m}\left(\mathrm{z}=0.53 \mathrm{~m} / \mathrm{kg}^{1 / 3}\right)$ respectively. Columns SEIS-8 and SEIS-9 were subjected to 100-kg and 150-kg ANFO explosive at standoff distances $2.5 \mathrm{~m}\left(\mathrm{z}=0.58 \mathrm{~m} / \mathrm{kg}^{1 / 3}\right)$ and $2.6 \mathrm{~m}\left(\mathrm{z}=0.52 \mathrm{~m} / \mathrm{kg}^{1 / 3}\right)$ respectively.

Post-blast inspection revealed substantial cracking and spalling of the concrete, exposing the longitudinal rebars in the lower one-third region (hinge zone) of the conventional columns (Table 4-16). In the case of the seismic columns, cracking and spalling occurred at mid-height (rear) exposing the longitudinal rebars (Table 4-16). There were fewer shear cracks on the seismic columns compared to the conventional columns.

\subsubsection{Transverse Detailing effect at $\mathrm{z}=0.86 \mathrm{~m} / \mathrm{kg}^{1 / 3}$}

Two conventional columns (CONV-11 and CONV-12) and two seismic columns (SEIS13 and SEIS-14) were tested within the scaled distance of $0.86 \mathrm{~m} / \mathrm{kg}^{1 / 3}$. Columns CONV11 and CONV-12 were subjected to a 150-kg ANFO explosive at standoff distances of $4.4 \mathrm{~m}\left(\mathrm{z}=0.88 \mathrm{~m} / \mathrm{kg}^{1 / 3}\right)$ and $4.1 \mathrm{~m}\left(\mathrm{z}=0.82 \mathrm{~m} / \mathrm{kg}^{1 / 3}\right)$ respectively. Columns SEIS-13 and SEIS-14 were detailed as seismic force resisting columns and were subjected to $150-\mathrm{kg}$ ANFO explosive at standoff distances $4.1 \mathrm{~m}\left(\mathrm{z}=0.82 \mathrm{~m} / \mathrm{kg}^{1 / 3}\right)$ and $4.3 \mathrm{~m}(\mathrm{z}=0.86$ $\mathrm{m} / \mathrm{kg}^{1 / 3}$ ) respectively. Minimal cracks were observed on all sides of the conventional columns, while the seismic columns developed minimal cracks on the rear face (Table 4- 
16). The response of both the seismic columns and conventional columns is relatively the same within this scaled distance.

\subsubsection{Effect of Axial Load Ratio on Column Response}

Ten reinforced concrete columns were designed as conventional columns. Three of these conventional columns were post-tensioned to $1027 \mathrm{kN}$ and yielded a compression of 11.4 $\mathrm{MPa}$. This precompression gives an axial load ratio of 0.32 on the columns, simulating columns in the lower stories of multi-story buildings. For lower blast loads and deflections, the steel prestressing strands will tend to resist applied load and consequently tend to stiffen the column. For high loads, there will be crushing of concrete and reduction in stiffness. The axial load ratio of other conventional columns is 0 . These sets of conventional columns with axial ratios of 0.32 and 0 were tested within three different scaled distances of $0.22 \mathrm{~m} / \mathrm{kg}^{1 / 3}, 0.54 \mathrm{~m} / \mathrm{kg}^{1 / 3}$, and $0.86 \mathrm{~m} / \mathrm{kg}^{1 / 3}$.

\subsubsection{Axial Load Ratio effect at $\mathrm{z}=0.22 \mathrm{~m} / \mathrm{kg}^{1 / 3}$}

Two conventional columns (CONV-1 and CONV-2) with axial load ratio of 0.0 and a prestressed column CONV-5 with axial load ratio of 0.32 were tested within the scaled distance of $0.22 \mathrm{~m} / \mathrm{kg}^{1 / 3}$. Post blast inspection revealed that, both sets of columns were totally destroyed. However, while Columns CONV-1 and CONV-2 severed into two pieces at the column-footing joint, CONV-5 did not severe into two pieces (Table 4-16). This is as a result of the corrugated post-tension duct and seven-wire prestressing strands that prevented column CONV-5 from failing into two pieces.

\subsubsection{Axial Load Ratio effect at $\mathrm{z}=0.54 \mathrm{~m} / \mathrm{kg}^{1 / 3}$}


Three conventional columns (CONV-7, CONV-20 and CONV-6) with axial load ratio of 0.0 and a prestressed column CONV-10 with axial load ratio of 0.32 were tested within the scaled distance of $0.54 \mathrm{~m} / \mathrm{kg}^{1 / 3}$. Post blast inspection revealed that, the conventional columns suffered substantial cracking and spalling of concrete within the lower one-third region (hinge zone) of the column. Prestressed column CONV-10 also suffered substantial cracking and spalling of concrete within the lower one-third region (hinge zone) of the column (Table 4-16). But the severity of crack and spall in the prestressed column is higher relative to the conventional columns. This is as a result of the ALR. The prestressed column had a lower third-point displacement of $39.3 \mathrm{~mm}$, while conventional column CONV-6 had a mid-height displacement of $17.2 \mathrm{~mm}$ (Table 4-16).

\subsubsection{Axial Load Ratio effect at $\mathrm{z}=0.86 \mathrm{~m} / \mathrm{kg}^{1 / 3}$}

Two conventional columns (CONV-11 and CONV-12) with axial load ratio of 0.0 and a prestressed column CONV-15 with axial load ratio of 0.32 were tested within the scaled distance of $0.86 \mathrm{~m} / \mathrm{kg}^{1 / 3}$. Minimal cracks were observed on all sides of the conventional columns and prestressed columns (Table 4-16). Indeed, the response of both the prestressed and conventional columns is relatively the same within this scaled distance. 
Table 4-16: Summary of column details

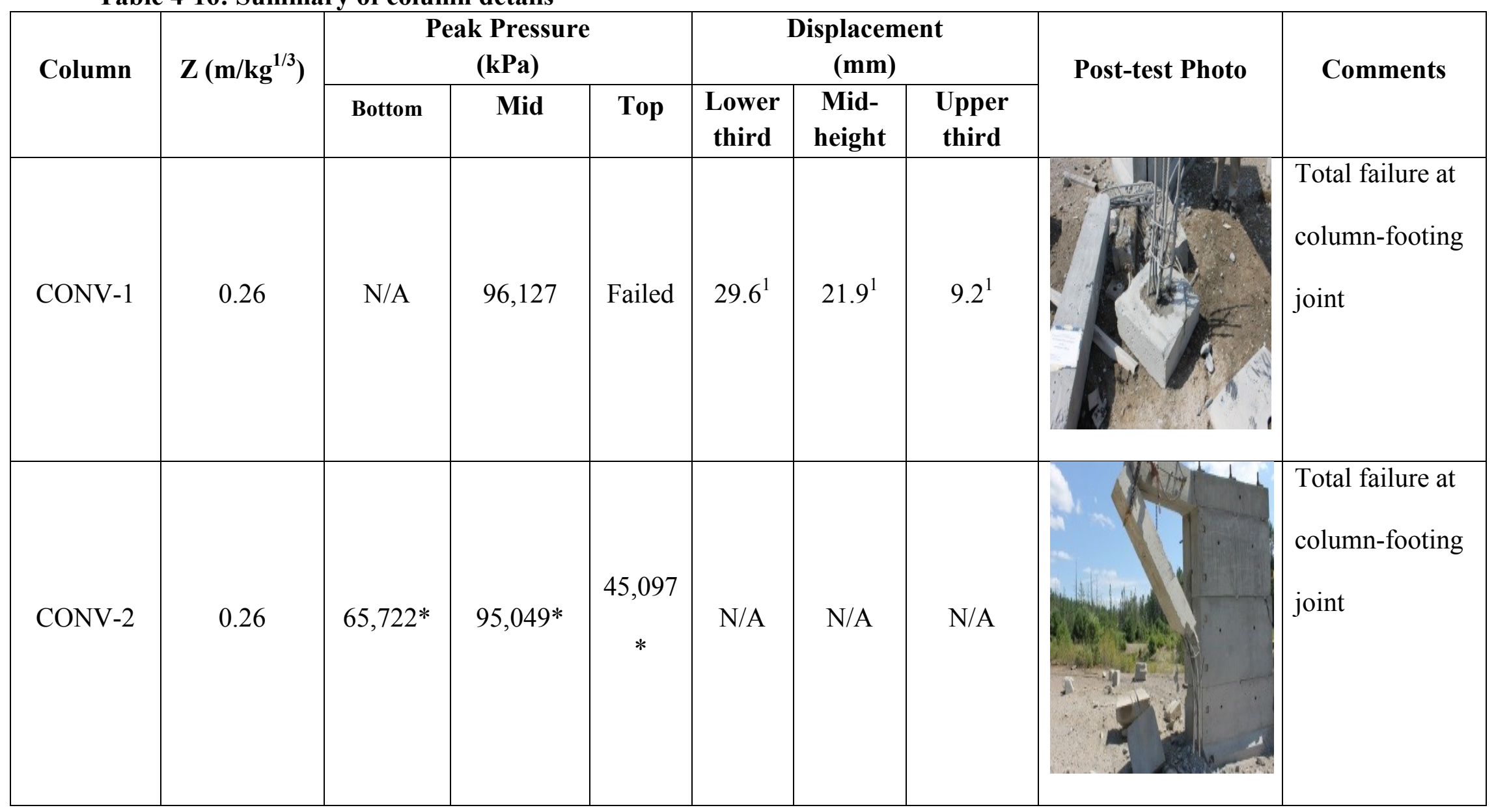




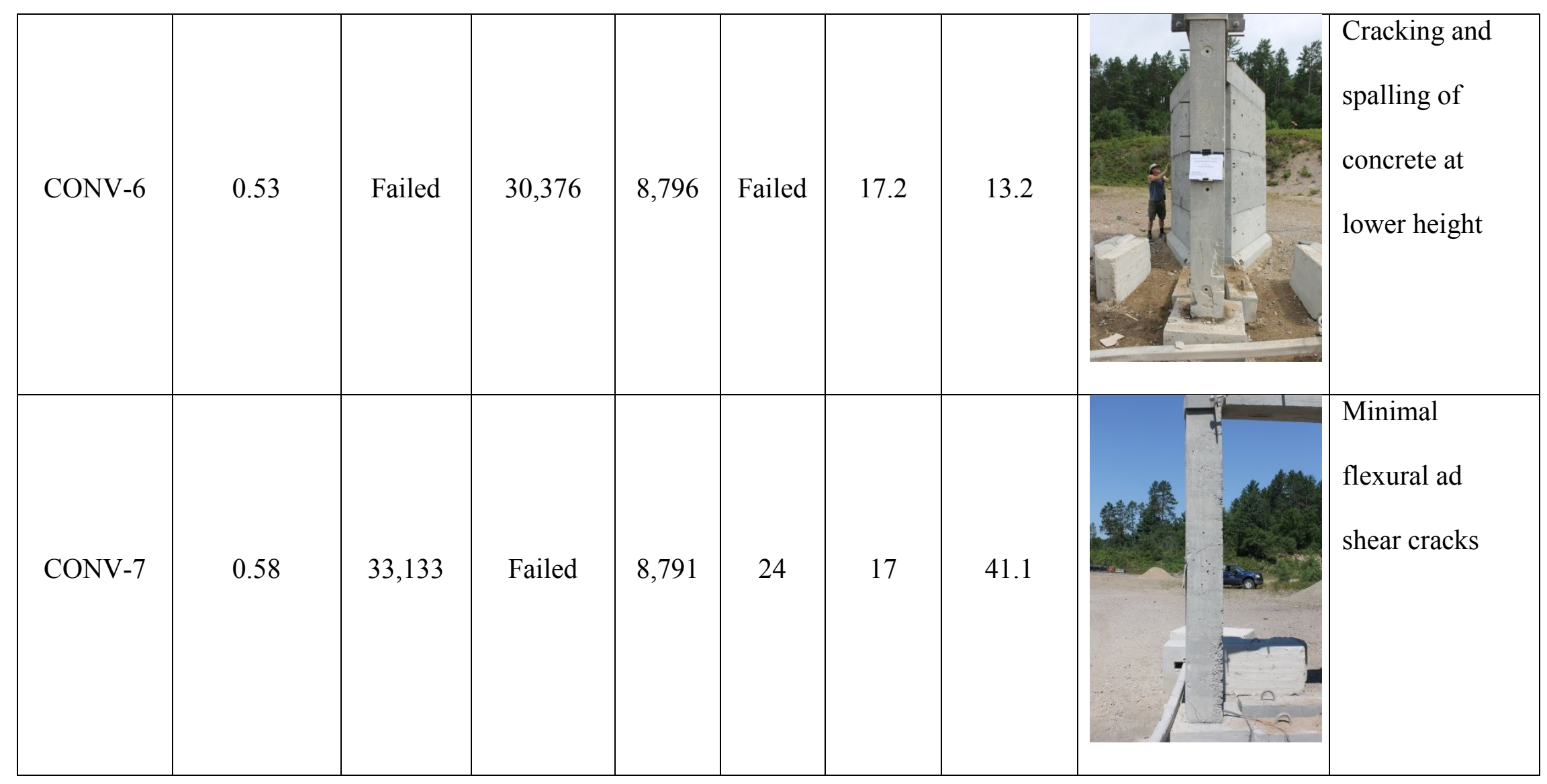




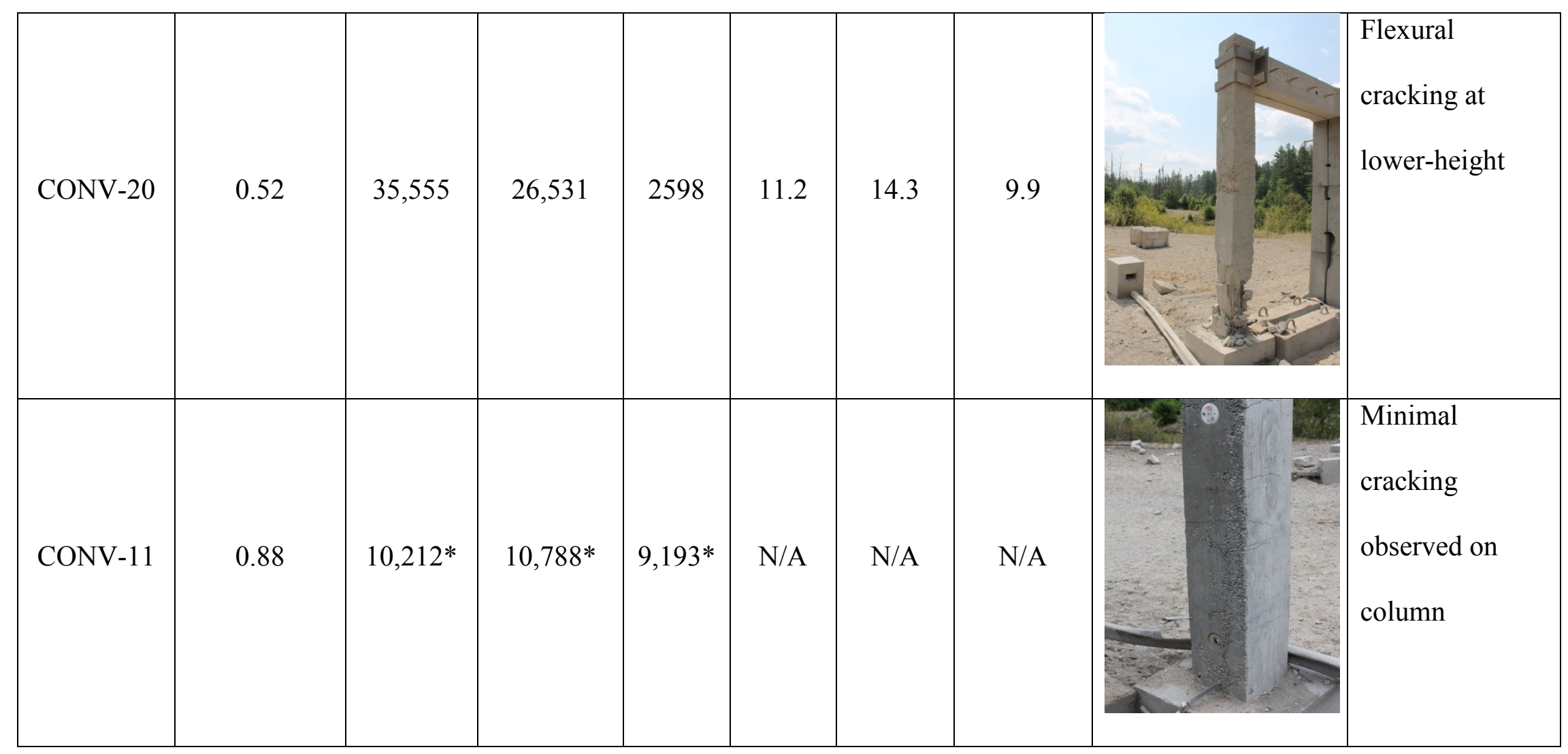




\begin{tabular}{|l|l|l|l|l|l|l|l|l|}
\hline CONV-12 & 0.82 & $11,944^{*}$ & $12,450^{*}$ & 10,614 & N/A & N/A & N/A & \\
\hline
\end{tabular}




\begin{tabular}{|c|c|c|c|c|c|c|c|c|c|}
\hline CONV-10 & 0.53 & Failed & 30,376 & 8,796 & 39.3 & 20 & 7.4 & 24 & $\begin{array}{l}\text { Substantial } \\
\text { cracking and } \\
\text { spalling of } \\
\text { concrete at } \\
\text { lower to mid- } \\
\text { height }\end{array}$ \\
\hline CONV-15 & 0.86 & $11,035^{*}$ & $11,532^{*}$ & $\begin{array}{l}10,022 \\
*\end{array}$ & N/A & N/A & N/A & 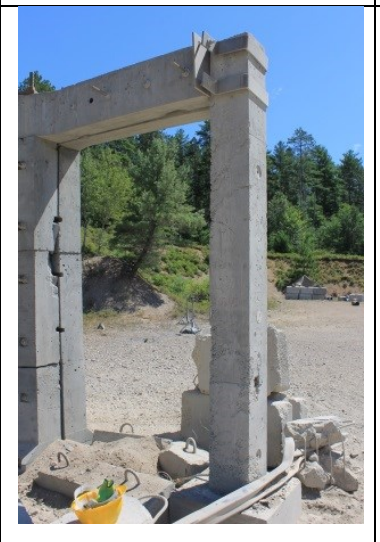 & $\begin{array}{l}\text { Minimal cracks } \\
\text { at the sides and } \\
\text { back }\end{array}$ \\
\hline
\end{tabular}




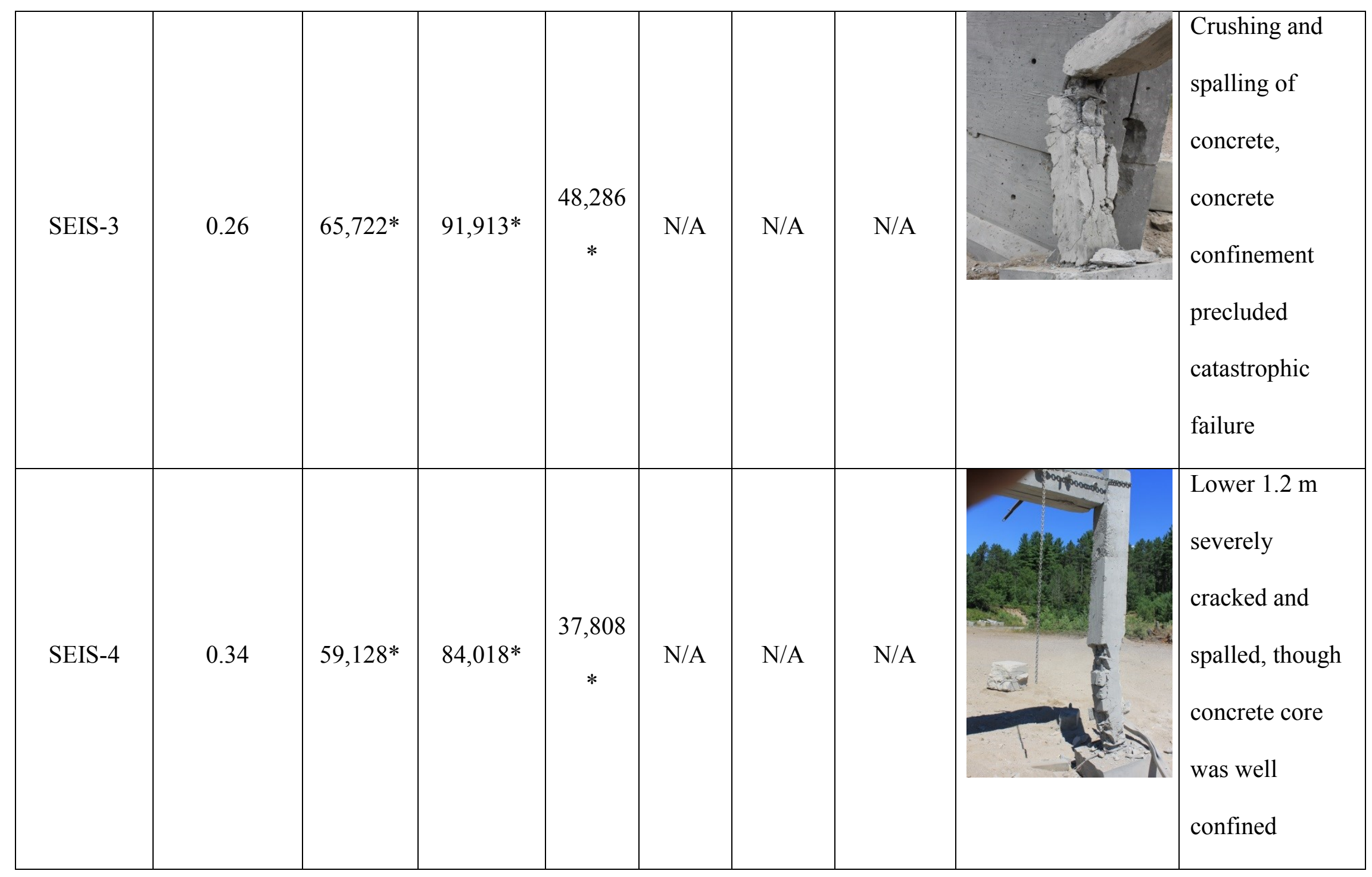




\begin{tabular}{|l|l|l|l|l|l|l|l|l|l|}
\hline \multirow{2}{*}{ SEIS-8 } & 0.58 & 33,133 & Failed & 8,791 & Failed & Failed & 24.9 & & \\
\hline
\end{tabular}




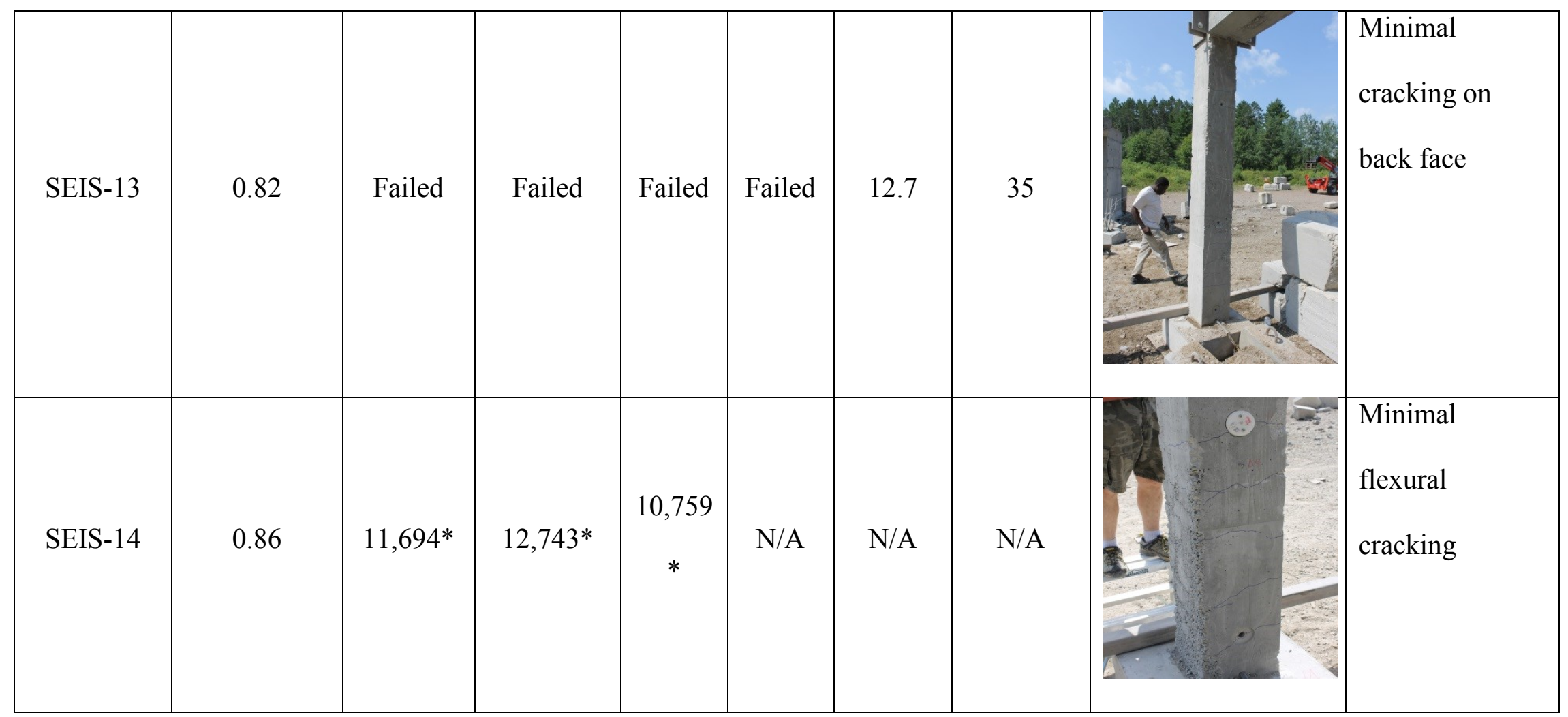

*Reflected pressure results using Kingery-Bulmash polynomials

${ }^{1}$ Instantenous displacements prior to column failure 


\section{Chapter: Conclusions}

\subsection{Summary}

The explosion effects on reinforced concrete columns in the near-field was investigated. Review of the literature revealed a dearth of information on the response of reinforced concrete columns to live explosion testing in close-in range of scaled distance, $\mathrm{z} \leq 1.0$ $\mathrm{m} / \mathrm{kg}^{1 / 3}$.

An experimental program was designed to study the effects of close-in blast loading on reinforced concrete columns. The experimental program involved reinforced concrete columns with different transverse reinforcement detailing and subjected to live explosion testing in an open field at the Canadian Forces Base (CFB) Petawawa. The columns were instrumented with pressure gauges, string potentiometers and strain gauges.

Columns' pressure-time histories and displacement-time histories were recorded and presented. The effect of transverse reinforcement detailing, effect of scaled distance as well as the effect of axial load ratio were analyzed by comparing the damage and failure modes and the displacement response of conventional columns, prestressed columns and columns designed as part of structures lateral load resisting system.

\subsection{Conclusions}

The results of the experimental investigation of this thesis support the following conclusions:

- The response of the concrete columns irrespective of the column type (Conventional, Seismic or Prestressed) failed at the scaled distance of 0.22 $\mathrm{m} / \mathrm{kg}^{1 / 3}$. As the scaled distance increases, the severity of damage is less. At the 
higher scaled distance of $0.86 \mathrm{~m} / \mathrm{kg}^{1 / 3}$, the response for all columns was relatively the same.

- The effects of transverse detailing and the location of the lap splice was very much pronounced in tests with scaled distance $\mathrm{z}=0.22 \mathrm{~m} / \mathrm{kg}^{1 / 3}$. The concrete in Conventional columns was stripped off reinforcement and the columns severed into two pieces. In the seismic column only concrete cover was crushed and spalled. The concrete core was well confined.

- At scaled distance of $\mathrm{z}=0.54 \mathrm{~m} / \mathrm{kg}^{1 / 3}$, columns with ALR of 0.32 suffered more damage relative to a comparable conventional columns.

- The closely spaced transverse reinforcement detailing increased the blast resistance of the columns, especially at the smaller scaled distances. Thus, seismically detailed columns have an inherently higher blast resistance in comparison with conventionally detailed columns.

\subsection{Recommendations}

From the results of this experimental investigations, the underlying recommendations are made for future research:

- Column footing must be buried so as to avoid the support rotation at the footing. This will also enable the permanent displacement of columns to be accurately measured

- While it is evident that the reaction structure worked to some degree, a fixed structure on the site would have worked to a better degree since the tendency of horizontal displacement will be eliminated 


\section{Bibliography}

ASTM standard C39/C39-12a, "Standard Test Method for Compressive Strength of Cylindrical Concrete Specimens", West Conshohocken, PA, ASTM International.

ASTM standard C143, "Standard Test Method for Slump of Hydraulic Cement Concrete" West Conshohocken, PA, ASTM International.

ASTM standard C192/C192M-07, "Standard Practice for Making and Curing Concrete Test Specimens in the Laboratory" West Conshohocken, PA, ASTM International.

ASTM standard E8/E8-09, "Standard Test Methods for Tension Testing of Metallic Materials" West Conshohocken, PA, ASTM International.

Armstrong, J. G. (2002). The Halifax Explosion and the Royal Canadian Navy: Inquiry and Intrigue. UBC Press.

Baker, W. E. (1973). Explosions in air (pp. 7-15). Austin: University of Texas Press.

Baker, W. E., Cox, P., Kulesz, J., Strehlow, R., and Westine, P. (1983). Explosion hazards and evaluation. Elsevier.

Bao, X., and Li, B. (2010). "Residual strength of blast damaged reinforced concrete columns." Int.J.Impact Eng., 37(3), 295-308.

Baylot, J. T., and Bevins, T. L. (2007). "Effect of responding and failing structural components on the airblast pressures and loads on and inside of the structure." Comput.Struct., 85(11), 891-910.

Beshara, F. (1994). "Modelling of blast loading on aboveground structures-I. General phenomenology and external blast." Comput.Struct., 51(5), 585-596

Birkland, T. A. (2004), “The World Changed Today”: Agenda-Setting and Policy Change in the Wake of the September 11 Terrorist Attacks. Review of Policy Research, 21: 179200. 
Blocker, V., and Blocker Jr., T. G. (1949). "The texas city disaster: A survey of 3,000 casualties." The American Journal of Surgery, 78(5), 756-771.

Braimah, A. (2012). "Blast Load on Structures". CIVE 5707/IPIS 5507 Blast Load Effects on Structures Lecture Notes, Carleton University, Ottawa, ON,".

Bodden, V. (2014). "Boston Marathon Bombings". ABDO Publishing Company, Minneapolis, MN, USA. ISBN 978-1-62403-054-3

Buchanan, B. J. (Ed.). (2006). Gunpowder, explosives and the state: a technological history. Ashgate Publishing, Ltd.

Campbell, B. (2013). "The Lac-Mégantic Disaster." Canadian Centre for Policy Alternatives. Ottawa, Ontario.

Carriere, M., Heffernan, P. J., Wight, R. G., and Braimah, a. (2009). "Behaviour of steel reinforced polymer (SRP) strengthened RC members under blast load." Canadian Journal of Civil Engineering, 36(8), 1356-1365.

Charles, A., and Darné, O. (2006). "Large shocks and the September 11th terrorist attacks on international stock markets." Econ.Model., 23(4), 683-698.

Comite Euro-International Du Beton (CEB). (1988). "Concrete Structures Under Impact and Impulsive Loading: Synthesis Report." CEB Bulletin No. 187, Lausanne, Switzerland.

Corley W. Gene, Mlakar Paul F. Sr., Mete A. Sozen, and Charles H. Thornton (1998). "The Oklahoma City Bombing: Summary and Recommendations for Multihazard Mitigation.” J. Perform. Constr. Facil., 12(3), 100-112.

CSA (2004). Design of concrete structures, CSA Standard A23.3-04. Canadian Standards Association, Mississauga, Ontario. 
Dechy, N., Bourdeaux, T., Ayrault, N., Kordek, M., and Le Coze, J. (2004). "First lessons of the Toulouse ammonium nitrate disaster, 21st September 2001, AZF plant, France." J.Hazard.Mater., 111(1-3), 131-138.

Dewey, J., and Sperrazza, J. (1950). The Effect of Atmospheric Pressure and Temperature on Air Shock. Ballistic Research Laboratories. Maryland, USA.

Elsanadedy, H. M., Almusallam, T. H., Abbas, H., Al-Salloum, Y. A., \& Alsayed, S. H. (2011). Effect of blast loading on CFRP-Retrofitted RC columns-a numerical study. Latin American Journal of Solids and Structures, 8(1), 55-81.

Elsanadedy, H., Almusallam, T., Abbas, H., Al-Salloum, Y., Alsayed, S., and Al-Haddad, M. (2010). "Effect of Blast Loading on CFRP Retrofitted RC Columnss.".

E Network (2013), "Lac-Mégantic: A Social and Ecological Tragedy| The Bullet No. 856." Available at http://www.socialistproject.ca/bullet/856.php (Search date: January 22, 2014).

Flathau, W. J., Krauthammer, T., Smith, J. L., and Betz, J. F. (1989). "Lessons from explosive tests on RC buried arches." J.Struct.Eng., 115(4), 809-825.

Furlong, R. W. (1967). "Strength of steel-encased concrete beam columns." Journal of the Structural Division, American Society of Civil Engineers, 93113.

Goodrich, J. N. (2002). "September 11, 2001 attack on America: a record of the immediate impacts and reactions in the USA travel and tourism industry." Tourism Management, 23(6), 573-580.

Gunaratna, R. (2008). "The Islamabad Marriott in Flames: The Attack on the World's Most Protected Hotel." Journal of Policing, Intelligence and Counter Terrorism, 3(2), 99116.

Ha, Kyoo-Man \& Ahn, Ji-Young. (2008). "Developing voluntary agencies in emergency management: The United States and Korea.” Journal of Emergency Management. 6(4): 39-50. 
Han Sungjoo (1978). "The growing security dilemma, South Korea." Asian Survey, Vol. 19, No. 1, A Survey of Asia in 1978: Part I (Jan., 1979), pp. 41-50.

Hinman, E. (2003). "Primer for Design of Commercial Buildings to Mitigate Terrorist Attacks. " Applied Technology Council (ATC), United States of America.

Hornung, H. (1986). "Regular and Mach reflection of shock waves. " Annual Review of Fluid Mechanics, 18, 33-58.

Hull, L. M. (1997). "Detonation propagation and Mach stem formation in PBXN-9 (No. LA-UR--97-3827; CONF-9709157). " Los Alamos National Lab., NM, USA.

Jébrak, Y. (2014) "Rebuilding Memories, Projecting Utopia in Lac-Megantic Reconstruction" XVIII ISA World Congress of Sociology (July 13-19, 2014).

Kellermann, A. L., and Peleg, K. (2013). "Lessons from Boston." N.Engl.J.Med., 368(21), 1956-1957.

Kinney, G. F., and Graham, K. J. (1985). "Explosive shocks in air." Berlin and New York, Springer-Verlag, 1985, 282 p., 1.

Klontz J.C., and Jain A.K. (2013). A Case Study on Unconstrained Facial Recognition Using the Boston Marathon Bombings Suspects. Michigan State University, Tech. Rep. MSU-CSE-13-4

Lang T., Schwoebel V., Diene E, Bauvin E., Garrigue E., Lapierre-Duval K., Guinard A., Cassadou S., (2007). "Scientific and Operational Committees. Assessing post-disaster consequences for health at the population level: experience from the AZF factory explosion in Toulouse. " J Epidemiol Community Health 2007;61:103-7.

Larson, S. L., Jones, R. P., Escalon, L. and Parker, D. (1999), Classification of explosives transformation products in plant tissue. Environmental Toxicology and Chemistry, 18: 1270-1276. doi: 10.1002/etc.5620180629. 
Li, B., Nair, A., and Kai, Q. (2012). "Residual Axial Capacity of Reinforced Concrete Columns with Simulated Blast Damage." J.Perform.Constr.Facil., 26(3), 287-299.

Luccioni, B., Ambrosini, R., and Danesi, R. (2003). "Analysis of building collapse under blast loads." Eng.Struct., 26(1), 63-71.

Mahadevan, E. G. (2013) Classification of Explosives, in Ammonium Nitrate Explosives for Civil Applications: Slurries, Emulsions and Ammonium Nitrate Fuel Oils, WileyVCH Verlag $\mathrm{GmbH} \&$ Co. KGaA, Weinheim, Germany. doi: $10.1002 / 9783527645688 . c h 1$

Malvar, L. J., \& Crawford, J. E. (1998). Dynamic increase factors for concrete. NAVAL FACILITIES ENGINEERING SERVICE CENTER PORT HUENEME. California, USA.

Marjanishvili, S., and Gallant, S. (2005). "Analysis of Reinforced Concrete Columns for Airblast Loads." 12th International Symposium on Interaction of the Effects of Munitions with Structures.

Marjanishvili, S., and Agnew, E. (2007). Comparison of various procedures for progressive collapse analysis. Journal of Performance of Constructed Facilities,20(4), 365-374.

McVay, M.K. (1998). Spall damage of concrete structures, U.S. Army Engineer Waterways Experiment Station, Vicksburg, Mississippi, Technical Report WES-TR-SL88-22.

Meyers, S., and Shanley, E. S. (1990). "Industrial explosives - a brief history of their development and use." J.Hazard.Mater., 23(2), 183-201.

Mlakar Paul F. Sr., Corley W. Gene, Mete A. Sozen, and Charles H. Thornton (1998). "The Oklahoma City Bombing: Analysis of Blast Damage to the Murrah Building.” J. Perform. Constr. Facil., 12(3), 113-119. 
Ngo, T., Mendis, P., and Krauthammer, T. (2007). "Behavior of Ultrahigh-Strength Prestressed Concrete Panels." Journal of Structural Engineering, 133, 1582-1590.

Norton, F. H. (1929). The creep of steel at high temperatures. McGraw-Hill Book Company, Incorporated.

Piotrowski, C., and Vodanovich, S. J. (2007). "Oklahoma City Bombing, Stress Effects of." Encyclopedia of Stress (Second Edition), G. Fink, ed., Academic Press, New York, $8-11$.

Remennikov, A. M. (2003). "A review of methods for predicting bomb blast effects on buildings." Journal of Battlefield Technology, 6(3), 5.

Rodoplu, Ü., Arnold, J. L., Tokyay, R., Ersoy, G., Cetiner, S., and Yücel, T. (2005). "Impact of the terrorist bombings of the Neve Shalom and Beth Israel Synagogues on a hospital in Istanbul, Turkey." Acad.Emerg.Med., 12(2), 135-141.

Ruby, C. L. (2002), The Definition of Terrorism. Analyses of Social Issues and Public Policy, 2: 9-14. doi: 10.1111/j.1530-2415.2002.00021.x

Rubin, G. J., Brewin, C. R., Greenberg, N., Simpson, J., and Wessely, S. (2005). "Psychological and behavioural reactions to the bombings in London on 7 July 2005: cross sectional survey of a representative sample of Londoners." Bmj, 331(7517), 606.

Seifert, J. W. (2002). "The effects of September 11, 2001, terrorist attacks on public and private information infrastructures: a preliminary assessment of lessons learned." Government Information Quarterly, 19(3), 225-242.

Shaplen R. (1958), "Annals of Science, Adventures of a Pacifist." The New Yorker.

Sharma, A. (1986). "Shear strength of steel fiber reinforced concrete beams." ACI Journal Proceedings (Vol. 83, No. 4).

Slutter, R. G., and Driscoll Jr, G. C. (1963). "Flexural strength of steel and concrete composite beams." preserve.lehigh.edu, Pennsylvania, USA. 
Smith, P. D., Hetherington, J. G., Smith, P., and Hetherington. (1994). Blast and ballistic loading of structures. Butterworth-Heinemann Oxford.

Sperrazza, J. (1963). "Modeling of air blast." Use of models and scaling in shock and vibration, ASME, New York, 65-70.

Stephens, H. (1997), The Texas City Disaster, 1947, University of Texas Press, Austin, TX.

Strehlow, R. A., and Baker, W. E. (1976). "The characterization and evaluation of accidental explosions." Progress in Energy and Combustion Science, 2(1), 27-60.

Thompson D, Brown S, Mallonee S, Sunshine D. (2004). "Fatal and non-fatal injuries among US Air Force personnel resulting from the terrorist bombing of the Khobar Towers." J Trauma-Inj Infect Crit Care; 57(2) 208-15.

TM 5-1300, "Structures to Resist Effects of Accidental Explosions," Technical Manual 5-1300, Department of the Army, Navy and Air Force, Washington DC, 1990.

Unified Facilities Code (UFC) 03-340-02 (2008). Structures to Resist the Effects of Accidental Explosions, United States of America Department of Defense, Washington, D.C.

U.S. Department of State, Country report on terrorism (2013). Available at http://www.state.gov/documents/organization/210288.pdf (Search date: December 20, 2013)

U.S. Department of State, Country report on terrorism (2014). Available at http://www.state.gov/documents/organization/225043.pdf (Search date: July 20, 2014)

Wernick, D. A. and Von Glinow, M. A. (2012), Reflections on the Evolving Terrorist Threat to Luxury Hotels: A Case Study on Marriott International. Thunderbird Int'l Bus Rev, 54: 729-746. doi: 10.1002/tie.21496. 
Wightman, J. M., and Gladish, S. L. (2001). "Explosions and blast injuries." Ann.Emerg.Med., 37(6), 664-678.

Yeres, C. (2014) "WED: MTA train service is suspended until further notice due to gas explosion in Manhattan". 


\section{Appendix A - Raw Data}

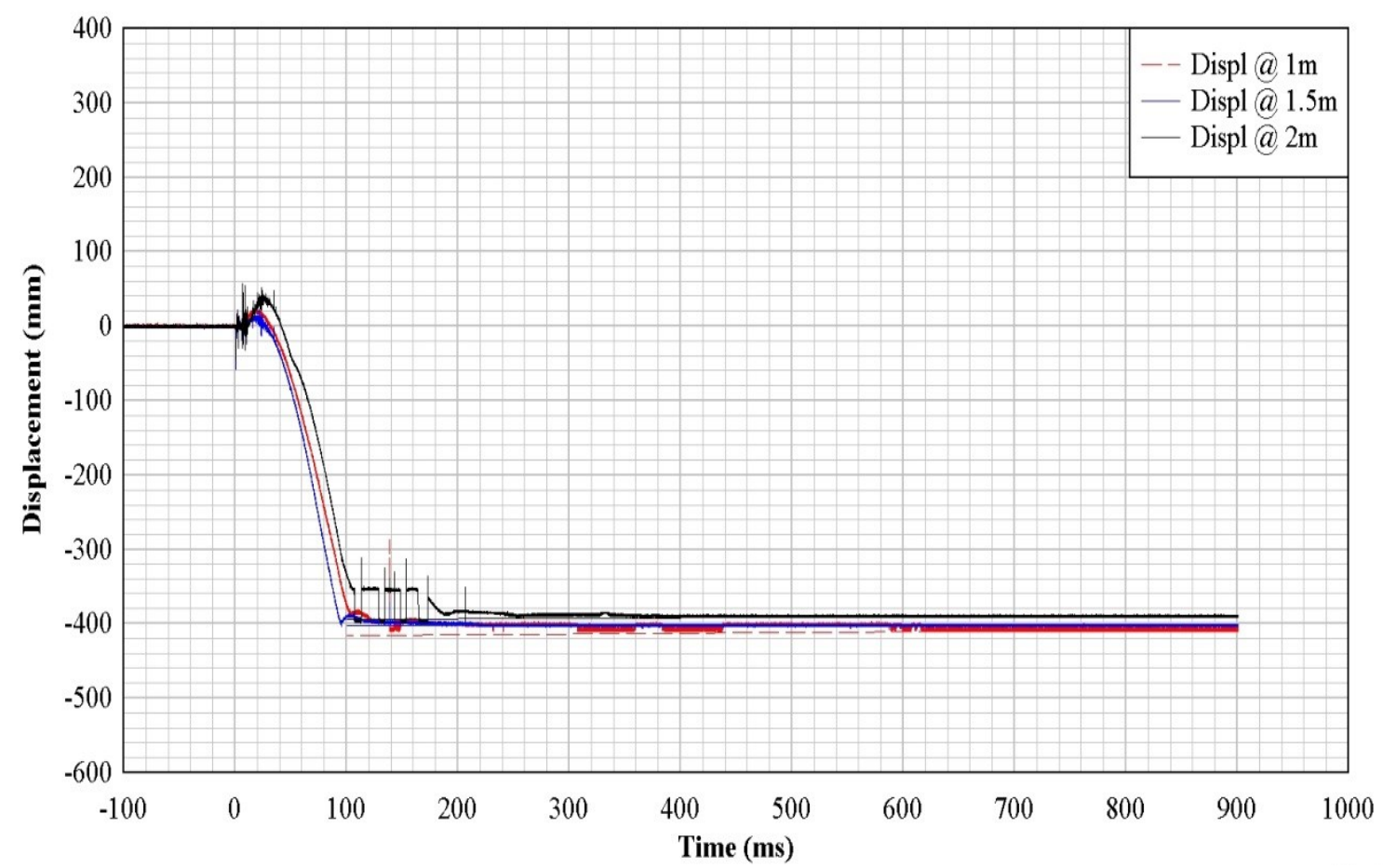

Figure 5-1: Displacement Time History CONV-7 (Raw Data)

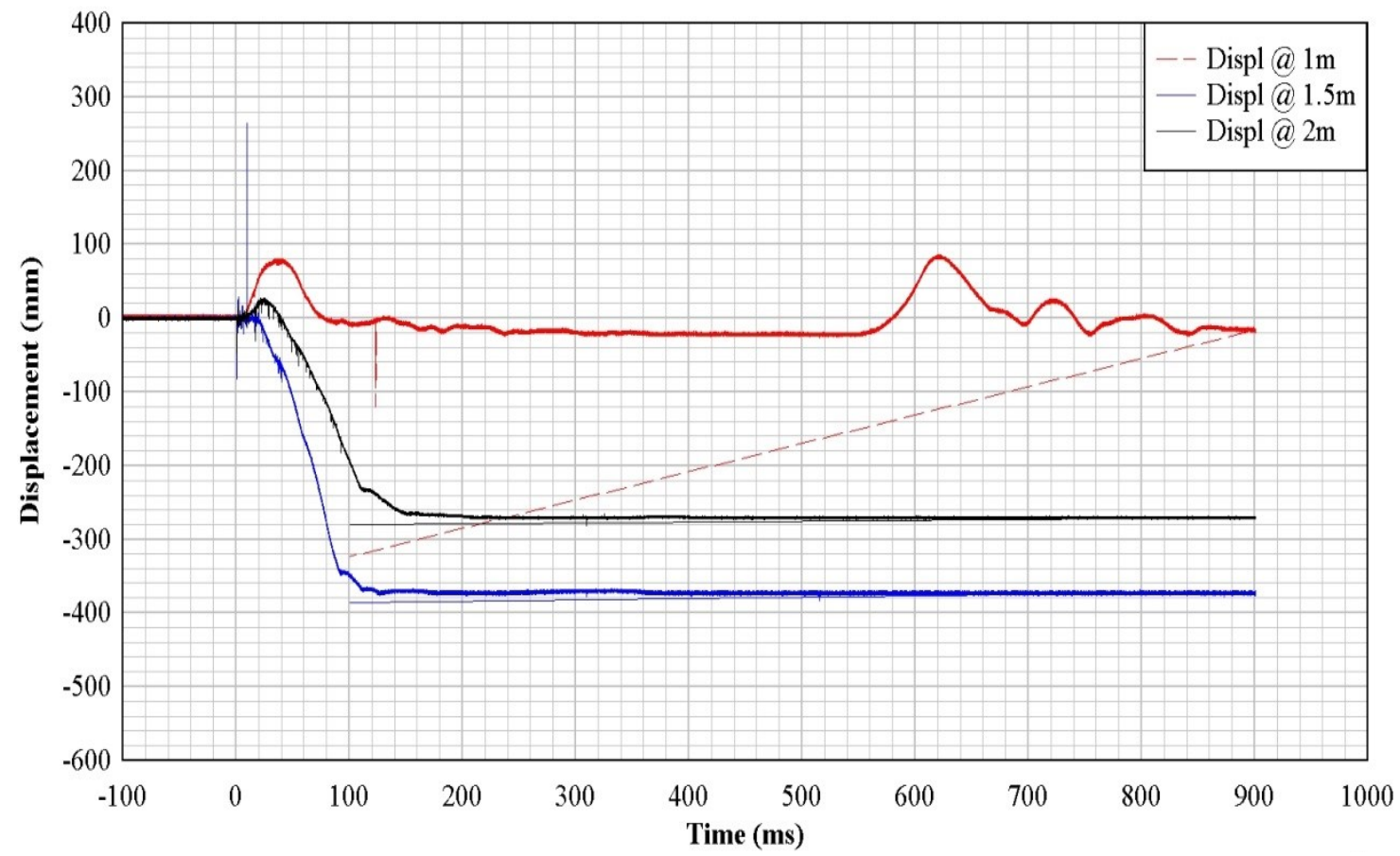

Figure 5-2: Displacement Time History SEIS-8 (Raw Data) 


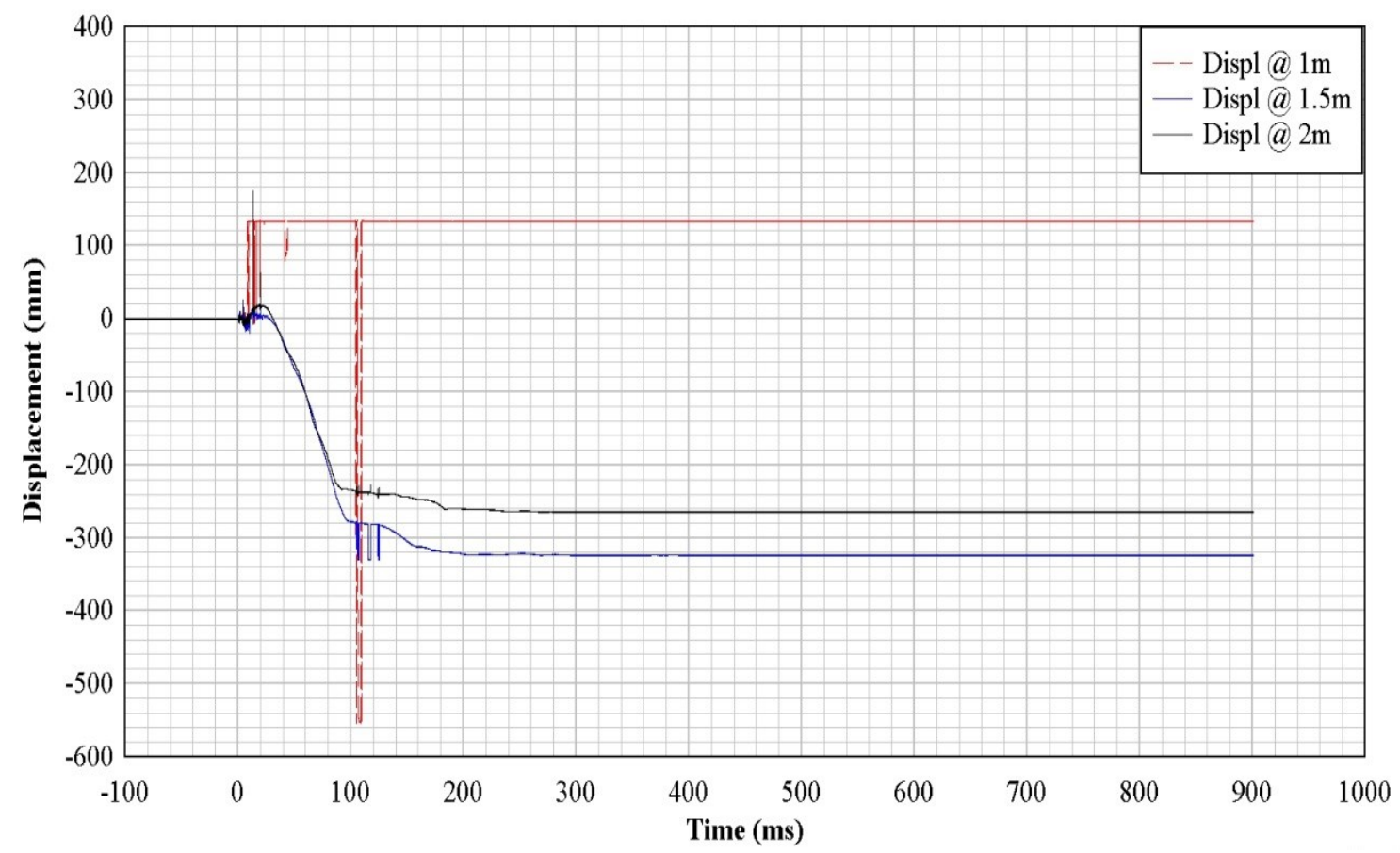

Figure 5-3: Displacement Time History SEIS-9 (Raw Data)

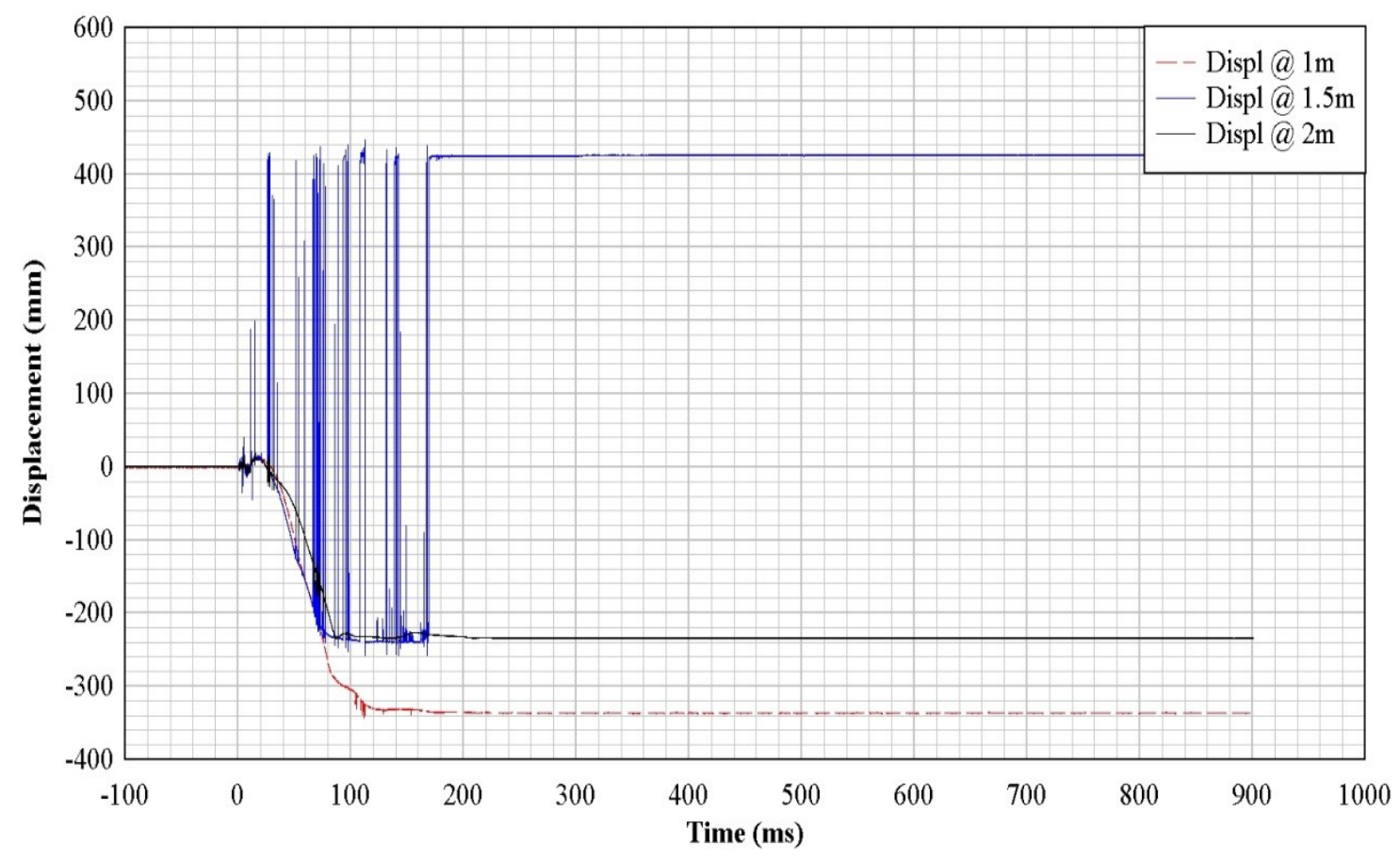

Figure 5-4: Displacement Time History CONV-20 (Raw Data) 


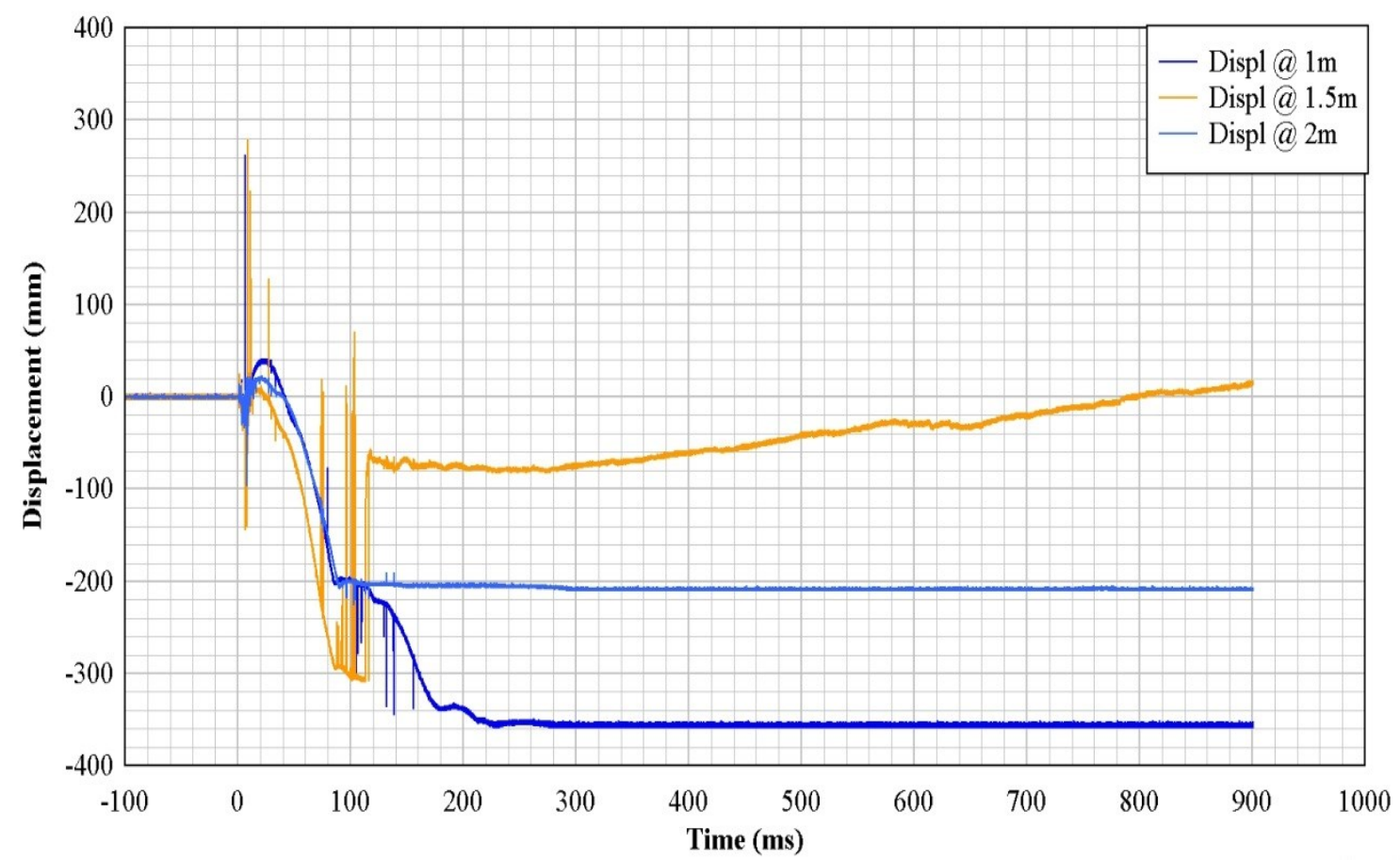

Figure 5-5: Displacement Time History CONV-10 (Raw Data)

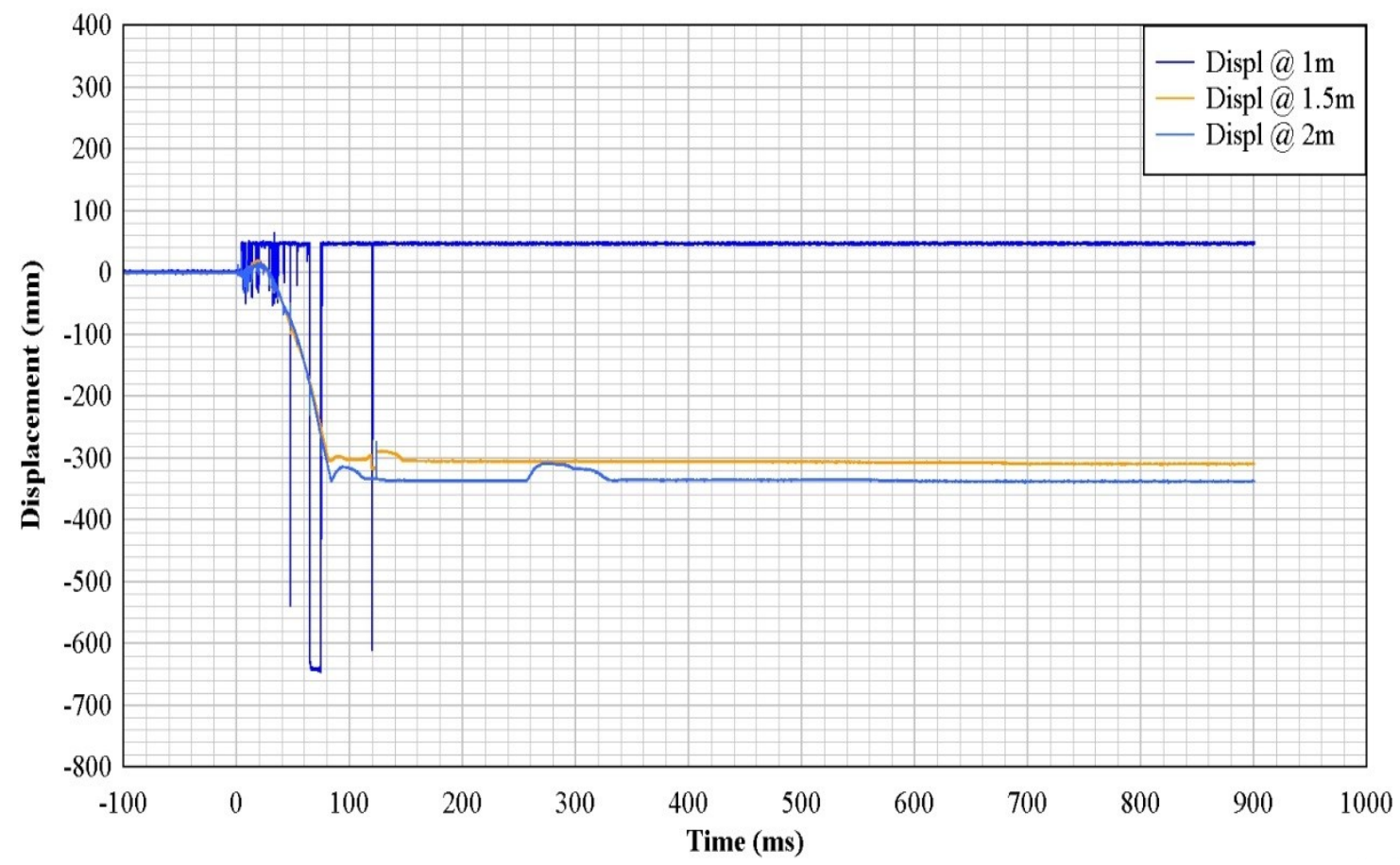

Figure 5-6: Displacement Time History CONV-6 (Raw Data) 


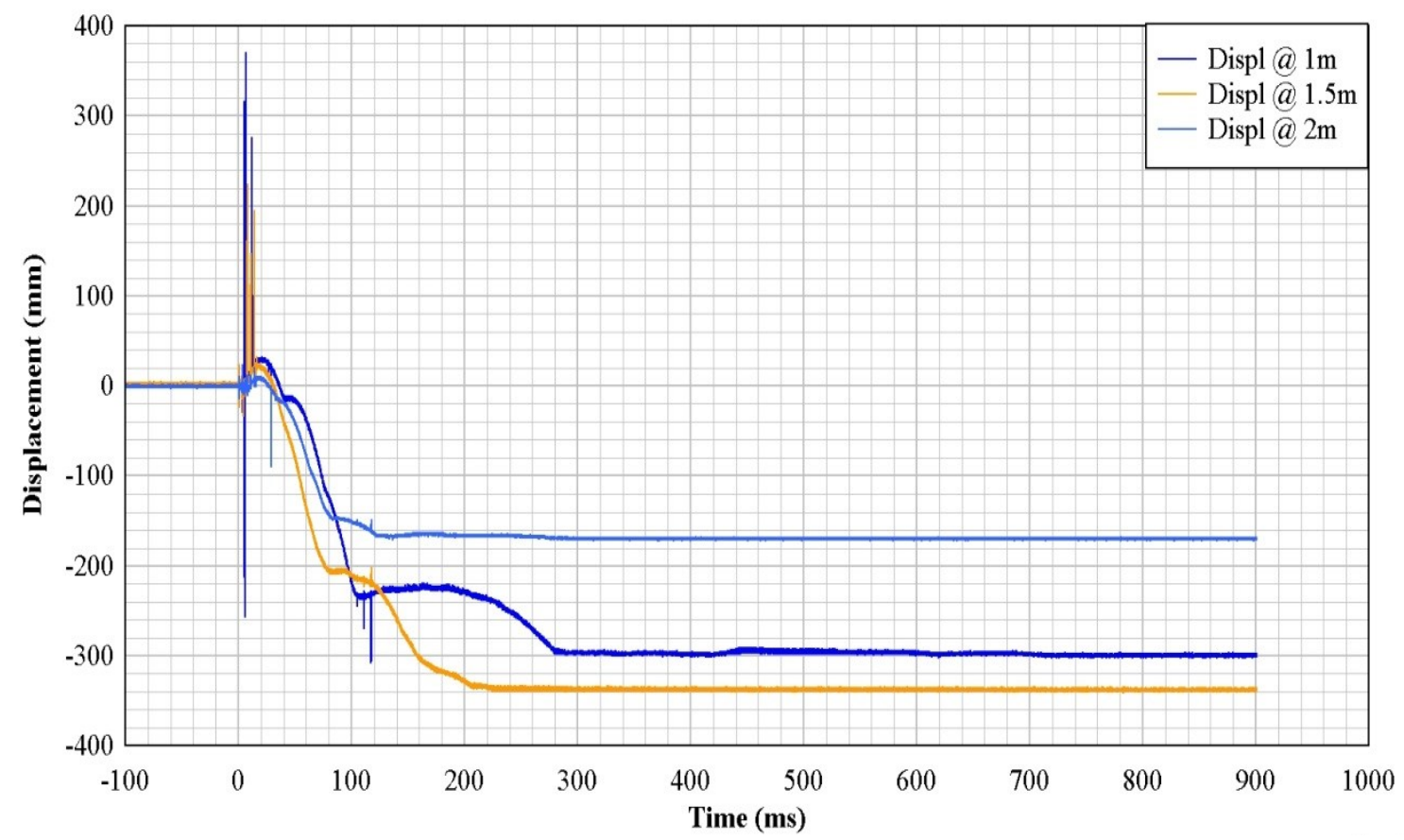

Figure 5-7: Displacement Time History CONV-1 (Raw Data)

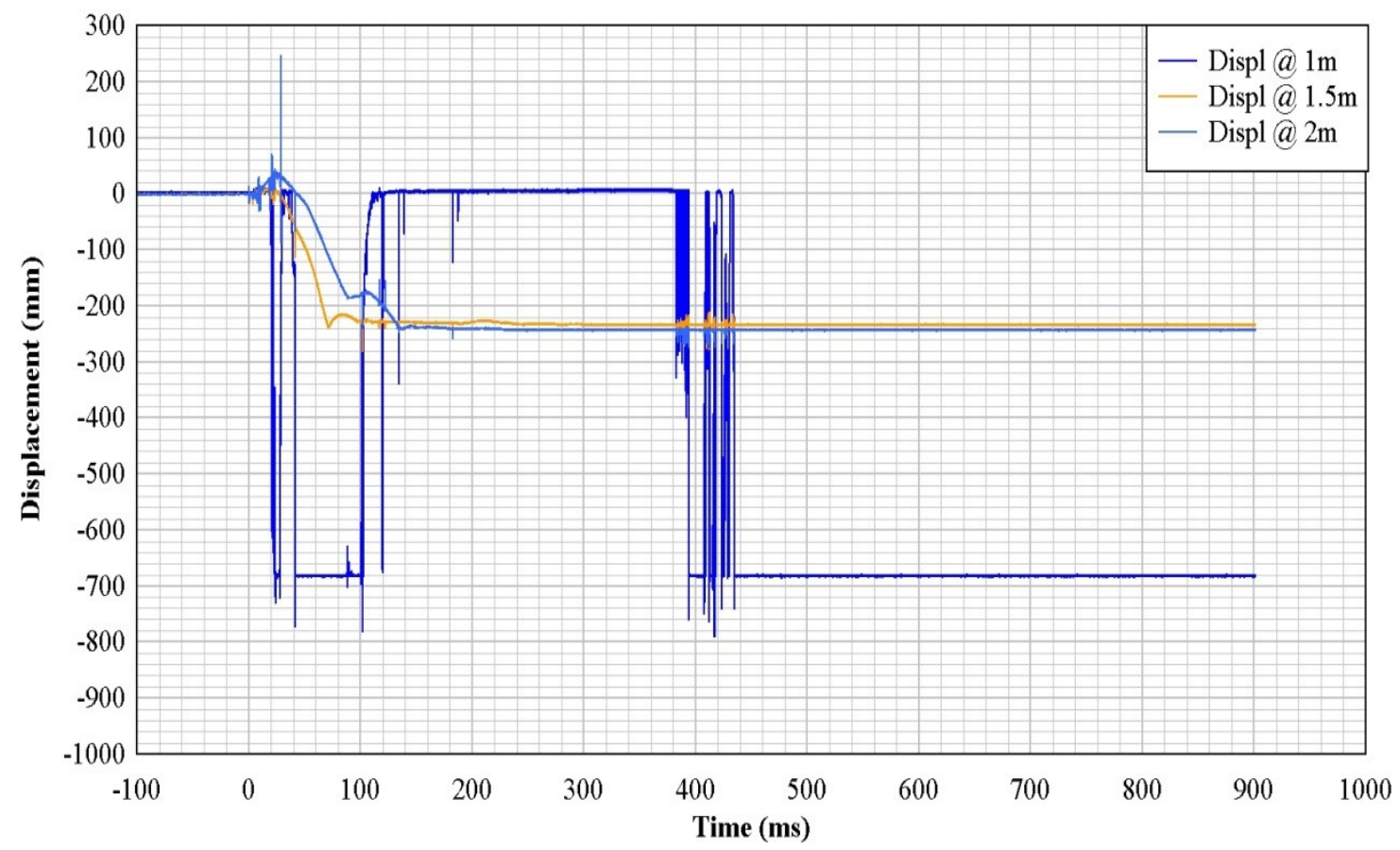

Figure 5-8: Displacement Time History SEIS-13 (Raw Data) 


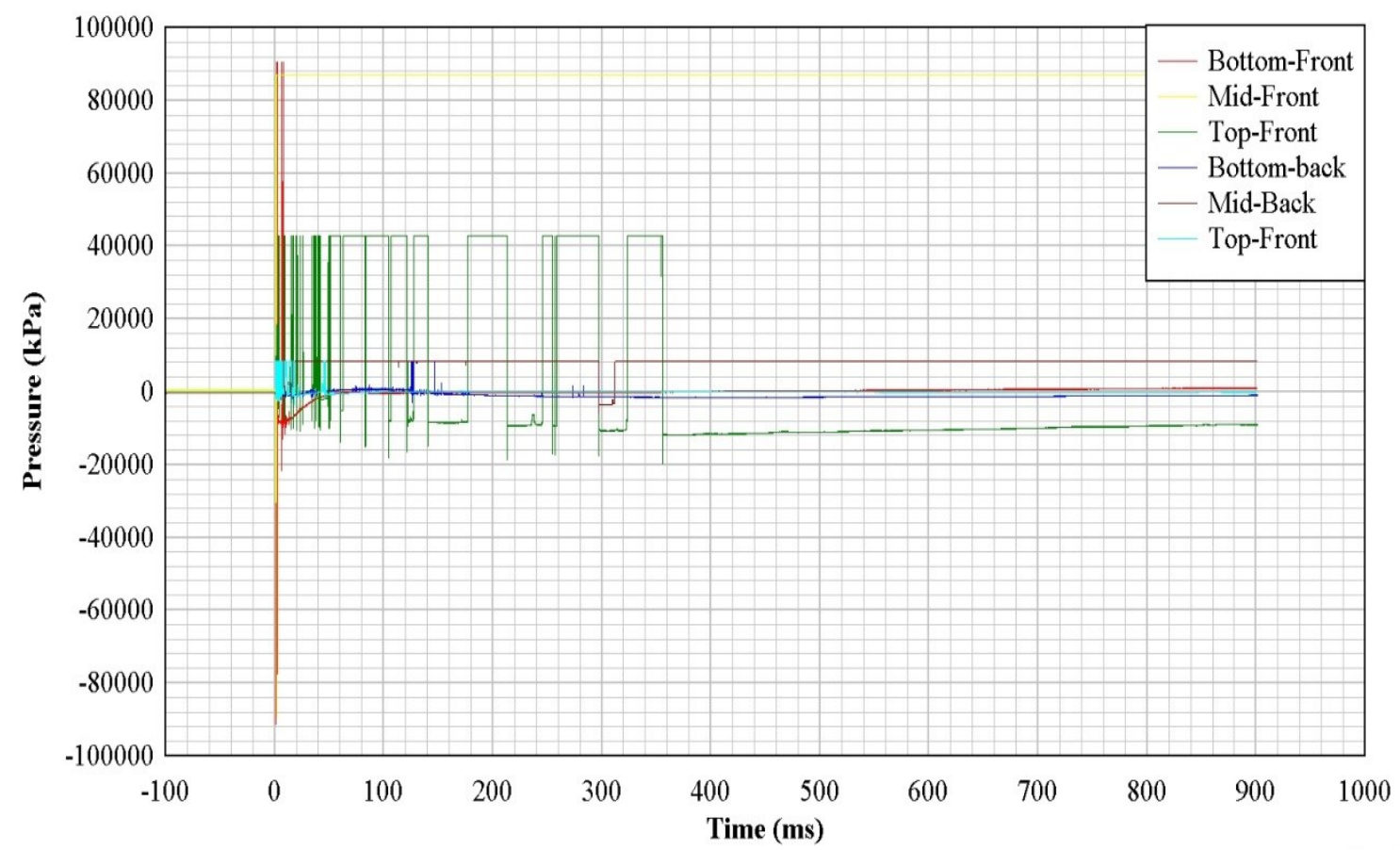

Figure 5-9: Blast pressure profile for Test 1 (CONV-7 and SEIS-8)

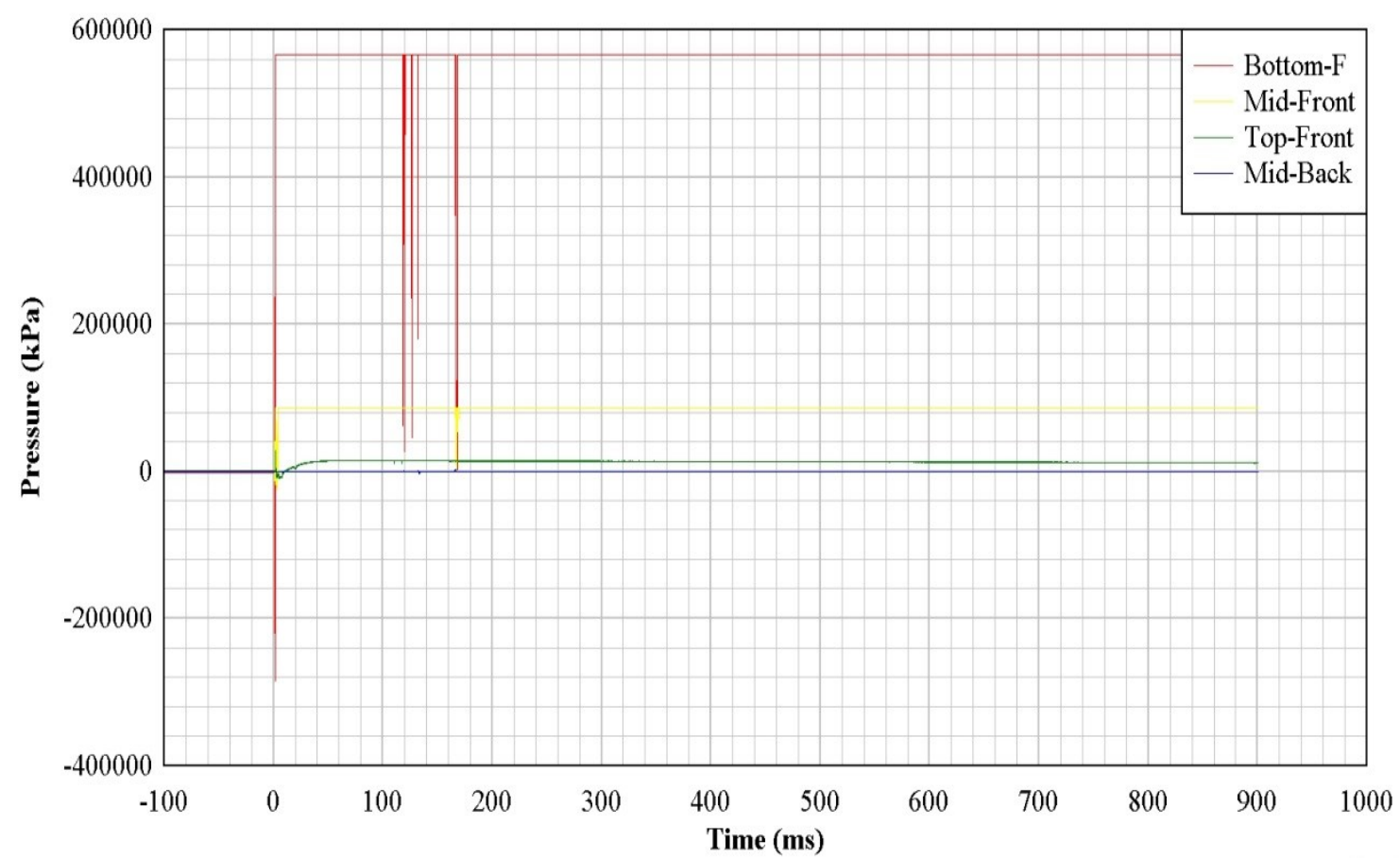

Figure 5-10: Blast pressure profile for Test 2 (CONV-20 and SEIS-9) 


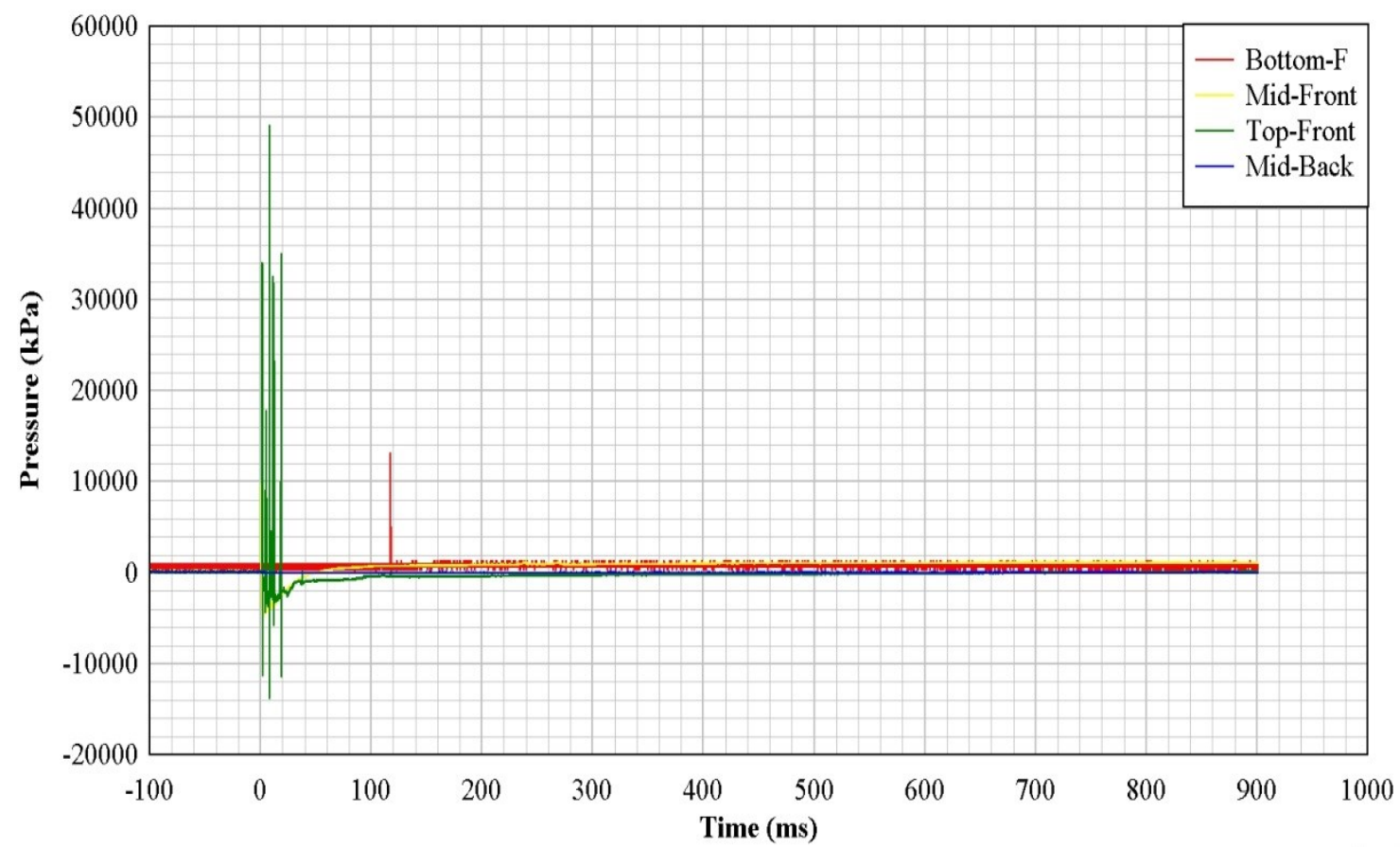

Figure 5-11: Blast pressure profile for Test 3 (CONV-6 and CONV-10)

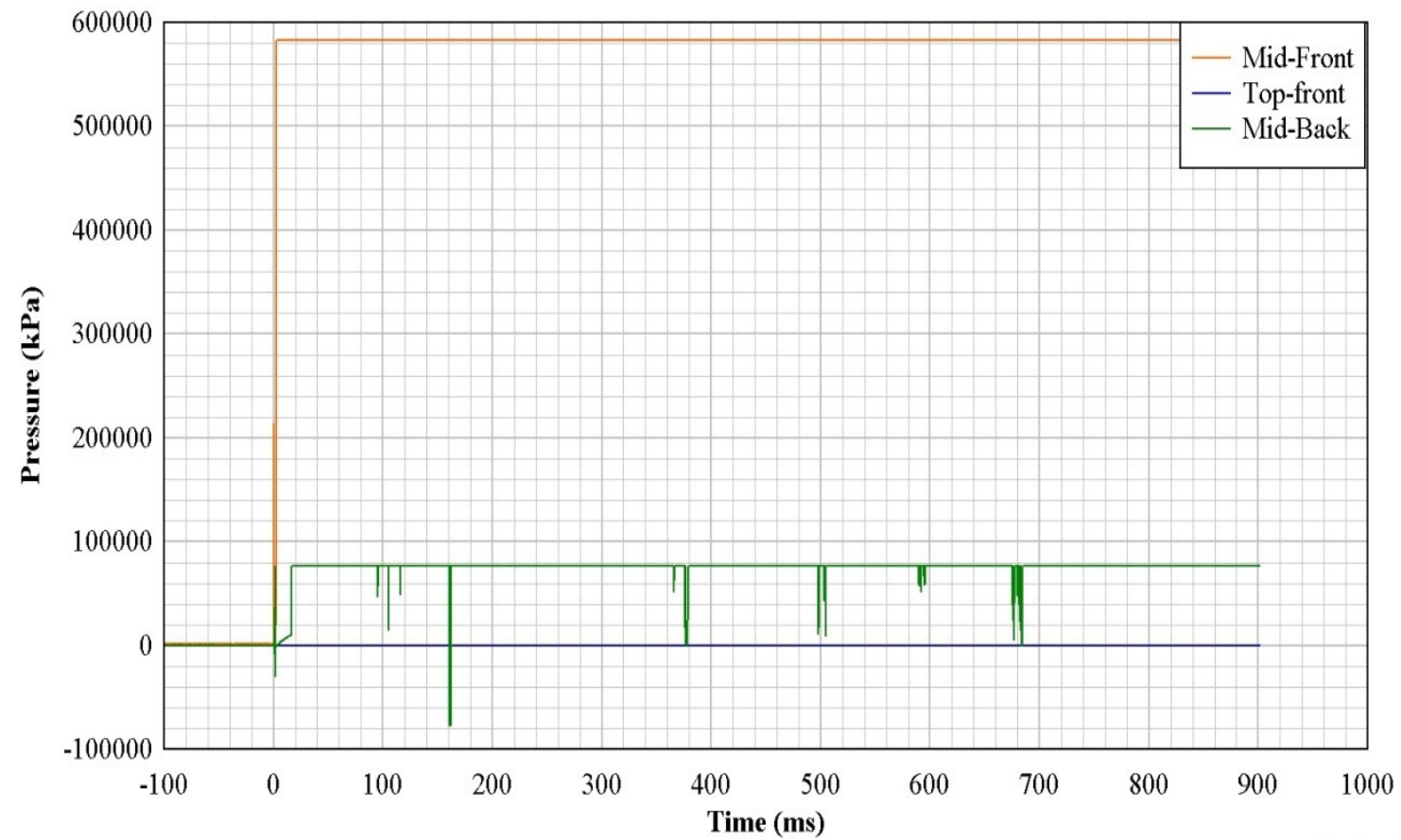

Figure 5-12: Blast pressure profile for Test 4 (CONV-1) 


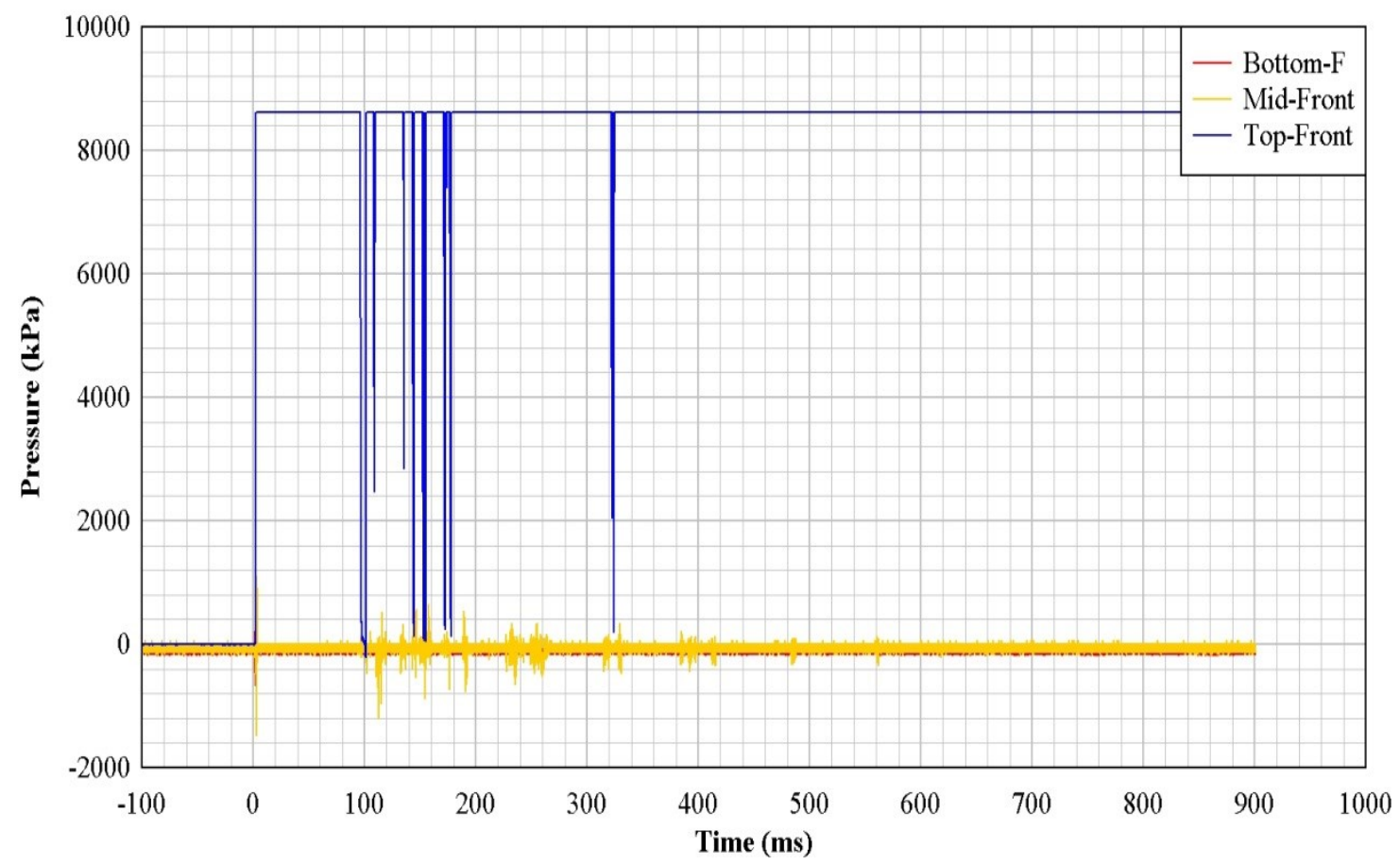

Figure 5-13: Blast pressure profile for Test 4 (SEIS-13) 